\title{
SUSTAINABLE ASSET AND PROJECT MANAGEMENT
}

by

\begin{abstract}
Abdollah Abdi
Master of Science in Industrial Engineering

Bu-Ali Sina University, 2011

Shomal University, 2008

\author{
A dissertation \\ presented to Ryerson University \\ in partial fulfillment of the \\ requirements for the degree of \\ Doctor of Philosophy \\ in the program of \\ Mechanical and Industrial Engineering.
}

Bachelor of Science in Industrial Engineering, Minor in Industrial Production

Toronto, Ontario, Canada, 2019.

(C) Abdollah Abdi, 2019 


\section{AUTHOR'S DECLARATION FOR ELECTRONIC SUBMISSION OF A DISSERTATION}

I hereby declare that I am the sole author of this dissertation. This is a true copy of the dissertation, including any required final revisions, as accepted by my examiners.

I authorize Ryerson University to lend this dissertation to other institutions or individuals for the purpose of scholarly research.

I further authorize Ryerson University to reproduce this dissertation by photocopying or by other means, in total or in part, at the request of other institutions or individuals for the purpose of scholarly research.

I understand that my thesis may be made electronically available to the public. 


\title{
Sustainable Asset and Project Management
}

\author{
Abdollah Abdi \\ Doctor of Philosophy \\ Department of Mechanical and Industrial Engineering \\ Ryerson University
}

2019

\begin{abstract}
There is a growing demand for companies to report and demonstrate their environmental credentials and corporate responsibility, which presents an opportunity for them to differentiate and gain a competitive advantage in the marketplace. They are now recognizing the limited capacity of the environment to endure the current level of development and economic growth, depletion of natural resources, increasing problem of waste, worrying carbon dioxide emissions, and other environmental impacts. In fact, for asset and project managers, financial criteria are no longer the sole considerations to achieve success and shareholder value. Therefore, environment is being considered as a future source of risk or opportunity. The present research proposes methodology and mathematical models for a sustainable asset and project management, with the focus on the environmental aspect of sustainable development and more specifically the issue of greenhouse gas $(\mathrm{GHG})$ emissions.

The following models have been presented in this dissertation. First, a mathematical fleet optimization model is developed, which incorporates the environmental impacts of a fleet of assets over a finite horizon, in addition to its total cost of ownership. As a unique feature of the model, it allows the assets to be kept in storage over any time period, in which such assets do not deteriorate as in-use assets do. The mathematical model optimizes the number of new, in-use, in-storage, and salvaged assets in each time period, so that the total economic costs and environmental impacts are minimized. The application of this work is illustrated in a fleet of excavators.
\end{abstract}


Second, a hybrid Bayesian network (BN) is proposed for fleet availability analysis, focusing on the uncertainty of assets failure and repair rates. We model the common causes to individual rates, as well as the common causes that affect both failure and repair rates at the same time. The proposed model explicitly quantifies uncertainty in repair and failure rates of a fleet of assets and provides an appropriate method for modeling complex dependencies and factors affecting reliability, maintainability, or both, by considering influencing factors, either technical (such as working temperature, environment, quality, stress, etc.) or organizational (such as staff quality, management policies, etc.). We will then extend the model to consider extremely rare and/or previously unobserved risks (e.g. heavy storms, droughts, floods, etc.) that can significantly weaken reliability or maintainability levels.

Third, a deterministic model for equipment repair-replacement $(\mathrm{R} / \mathrm{R})$ decision with both economic and environmental considerations is formulated. We converted the model into an algorithm and an automatic R/R Calculator. A probabilistic version of this model is then developed to factor in the quality of preventive maintenance, repair perfection, and risk events. We also model the causal relationship between equipment reliability and its GHG emissions during the operation phase. A plastic shredder case study was used to present the models' results.

Fourth, we aim to capture the uncertainty of carbon price in the Western Climate Initiative (WCI) market, by determining the causality between carbon price and its driving forces. A probabilistic model is developed using BNs to infer the possible ranges of each driving force that could have an escalation/depreciation effect on price as well as the magnitude of this effect. The model is developed and run based on a database of historical and projection on the selected driving factors in all the jurisdictions of the WCI market, providing the most probable price(s) over the next ten years.

Finally, we developed two models to estimate and control project GHG emissions. The first model is developed based the earned value management (EVM) technique, a common practice in project cost and schedule performance measurement. The proposed model provides project managers with metrics to measure project GHG performance at any point in time over the life of a project and forecast the final emissions. In addition, we proposed a probabilistic model to quantify the uncertainty of project GHG emissions using Monte Carlo Simulation and BN techniques. The model provides a quantitative risk analysis mechanism to estimate the total 
emissions of the project as well as prediction of final emissions during the implementation process. The proposed models are applied to a work package of a real construction project. 


\section{Acknowledgements}

I would like to thank my supervisor, Dr. Sharareh Taghipour, for her encouragement, support and assistance throughout my time as her student. While I was free to apply techniques and methodologies from my previous research background, I learned so much from her and benefited from her guidance and advice. It was a great pleasure to work with her.

I would also like to thank Dr. Mohamad Y. Jaber and Dr. Cory Searcy as the members of my Supervisory Committee members for their constructive feedbacks during my PhD study. Many thanks go to Marc Castel and Katie Allen from Fiix Software for their valuable comments and supports on parts of my research.

Thanks to Dr. Min Xie from Systems Engineering and Engineering Management Department of City University of Hong Kong, Dr. Hossein Zolfagharinia from Ted Rogers School of Management, Dr. Mohamad Y. Jaber, Dr. Cory Searcy and Dr. Ahmad Ghasempoor for serving on the examination committee.

My sincere thanks go out to my family_my best friend and devoted wife, Rana, for her support, encouragement, and patience. To my father, the wisest and most respectful man in my life, mother, brothers and friends-my thanks as well. 


\section{Table of Contents}

$\begin{array}{ll}\text { ABSTRACT } & \text { iii }\end{array}$

ACKNOWLEDGEMENTS vi vi

$\begin{array}{lc}\text { LIST OF TABLES } & \mathbf{x}\end{array}$

LIST OF FIGURES

LIST OF APPENDICES X xiii

1. INTRODUCTION 1

$\begin{array}{lr}\text { 1.1. STATEMENT OF AUThORShiP } & 8\end{array}$

2. FLEET OPTIMIZATION WITH ECONOMIC AND ENVIRONMENTAL CONSIDERATIONS

2.1. INTRODUCTION AND BACKGROUND $\quad 12$

2.1.1. CLASSICAL, ECONOMIC MODELS 12

2.1.2. COMBINED, SUSTAINABLE MODELS 13

2.1.3. CARBON FOOTPRINTING 14

2.2. OPTIMIZATION MODEL

2.3. NUMERICAL EXAMPLES

2.4. DISCUSSION

$\begin{array}{lr}\text { 2.5. CONCLUSION } & 27\end{array}$

3. IMPROVING FLEET AVAILABILITY ANALYSIS BY INCORPORATING COMPLEX CAUSAL FACTORS

3.1. INTRODUCTION

3.1.1. RELIABILITY, MAINTAINABILITY, AND AVAILABILITY 31

3.1.2. PREVIOUS STUDIES IN RELIABILITY, MAINTAINABILITY, AND AVAILABILITY MODELING 33

3.2. DEVELOPMENT OF THE MODEL $\quad 35$

3.2.1. BAYESIAN NETWORKS (BNS): A BRIEF INTRODUCTION

3.2.2. MODEL STRUCTURE $\quad 37$

3.2.3. RARE EVENT $\quad 40$

3.2.4. LEARNING $\quad 42$

3.3. APPLICATION

3.4. ANALYTICAL CAPABILITIES

3.5. FORECASTING ACCURACY $\quad 54$

$\begin{array}{ll}\text { 3.6. CONCLUSION } & 57\end{array}$ 
4.1. INTRODUCTION AND BACKGROUND

4.2. METHODOLOGY

4.2.1. DETERMINISTIC ECONOMIC R/R MODEL

4.3. COMBINED MODEL $\quad 69$

4.4. PROBABILISTIC MODEL $\quad 71$

4.4.1. INCORPORATING RISK EVENTS

4.4.2. INCORPORATING EMISSIONS

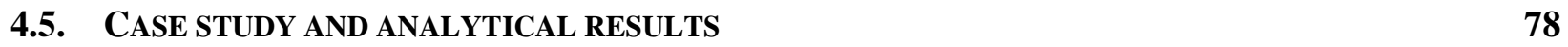

$\begin{array}{lr}\text { 4.6. DISCUSSION } & 84\end{array}$

\begin{tabular}{lr} 
4.7. & CONCLUSION \\
\hline
\end{tabular}

5. CARBON PRICE FORECASTING IN A CAP-AND-TRADE MARKET 91

$\begin{array}{ll}\text { 5.1. INTRODUCTION AND BACKGROUND } & 91\end{array}$

5.1.1. PREVIOUS WORKS 93

5.2. METHODOLOGY 94

5.3. DATA COLLECTION

5.4. BEST-WORST METHOD (BWM) $\quad 96$

5.5. PROPOSED BN MODEL $\quad 97$

5.6. RESULTS AND ANALYSIS $\quad 102$

$\begin{array}{lr}\text { 5.7. CONCLUSION } & 109\end{array}$

6. PROJECT GHG PERFORMANCE MEASUREMENT 111

6.1. INTRODUCTION AND BACKGROUND 112

6.1.1. PREVIOUS STUDIES 113

6.1.2. EVM, AN OVERVIEW 116

6.2. PROJECT GHG PERFORMANCE MEASUREMENT MODEL 118

6.2.1. GHG MEASURES OF A SINGLE TASK 119

6.2.2. GHG MEASURES OVER MULTIPLE TASKS 120

6.2.3. PERFORMANCE MEASUREMENTS AND FORECASTING FINAL EMISSION 121

6.2.4. PUTTING THE MODEL TO WORK 122

$\begin{array}{ll}\text { 6.3. UnCERTAinty AnAlysis OF Project EMissions } & 127\end{array}$

6.3.1. NUMERICAL EXAMPLE 129

6.4. DISCUSSION

$\begin{array}{ll}\text { 6.5. CONCLUSION } & 135\end{array}$

$\begin{array}{ll}\text { 7. CONCLUSIONS AND FUTURE RESEARCH } & 137\end{array}$

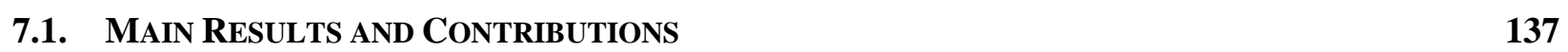

7.2. WEAKNESSES AND FUTURE WORK

$\begin{array}{ll}\text { APPENDICES } & 146\end{array}$ 
APPENDiX A. GLOBAL WARMING POTENTIALS AND SCOPE 1 AND SCOPE 2 EMISSION FACTORS 146 APPENDIX A-1. GLOBAL WARMING POTENTIALS (GWPS) BY IPCC FIFTH ASSESSMENT REPORT

$\begin{array}{ll}\text { APPENDIX A-2. SCOPE } 1 \text { EMISSION FACTORS } & 148\end{array}$

$\begin{array}{ll}\text { APPENDIX A-3. SCOPE } 2 \text { EMISSION FACTORS } & 153\end{array}$

APPENDIX A-4. CO2_EQ EMISSION FACTORS FOR MANUFACTURED MATERIALS 153

APPENDIX B. THE GHG CALCULATOR

APPENDIX C. A METHOD TO ESTIMATE PRIOR PROBABILITIES OF COMMON CAUSES 155

$\begin{array}{lr}\text { REFERENCES } & 157\end{array}$ 


\section{List of Tables}

Table 1: Number of excavators with age $\mathrm{j}$ and past utilization $\mathrm{k}$ in the beginning of the planning

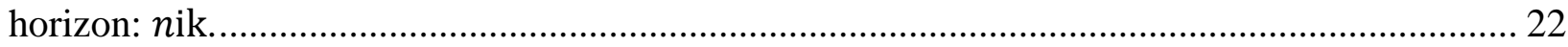

Table 2. Estimated economic and environmental parameters ............................................. 23

Table 3. Non-zero values of decision variables in the excavator fleet case ............................... 24

Table 4. Non-zero values of decision variables in the economic replacement model ................. 26

Table 5. Total number of in-use, in-storage, and salvaged equipment (X, Y, and S) with the

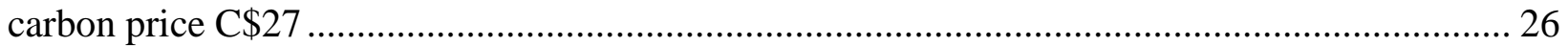

Table 6. The NPT for F in the BN model with rare event R .............................................. 42

Table 7. Elicited probabilities for ranked nodes assigned to common causes............................ 46

Table 8. Elicited distributions for repair activity durations ................................................... 46

Table 9. Prior failure times based on Staff Quality (S) and Environmental Harshness (E) ........ 46

Table 10. Final failure and repair rates adjusted by a coefficient corresponding to Asset

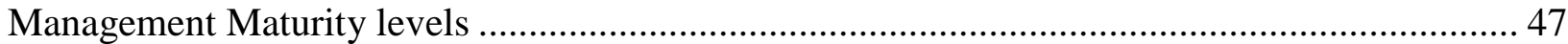

Table 11. History of power outages in Ontario..................................................................... 49

Table 12. Incomplete NPT of Repair Rate, with judgments on rate reduction in the case of a

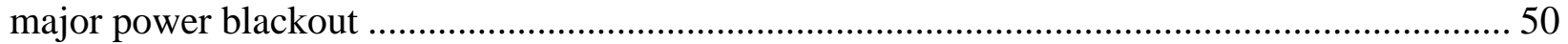

Table 13. Total expected utilities under scenario 3 and baseline scenario, and their difference as a measure of priority areas for availability improvement........................................................ 54

Table 14. RMSE values of three predictions ....................................................................... 57

Table 15. Repair cost breakdown structure over the equipment remaining life ........................ 64

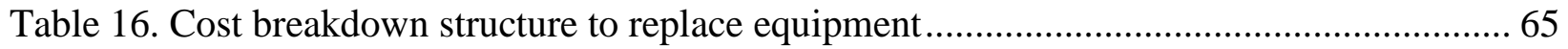

Table 17. Risk probability and impact scales ................................................................... 76

Table 18. Estimated parameters and probabilities for the Bayesian R/R calculation .................. 78

Table 19. Repair perfection prior and repair activity durations conditional on the level of

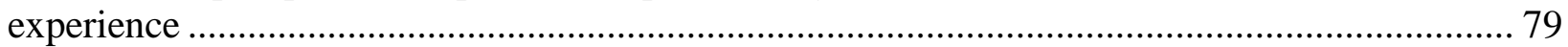

Table 20. NPT of the node f3 conditional on the level of PM Quality and Repair Perfection ..... 79

Table 21. Identified risks, related affected items, probability of occurrence, and impacts ......... 81

Table 22. Emissions costs of each lifecycle phase based on the carbon price in the WCI market82 Table 23. Probability distribution functions (PDFs) and parameters of the proposed model for the

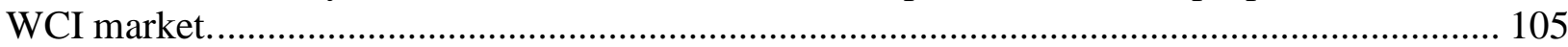

Table 24. Determination of GHG accounts of each activity and their related category in the GHG

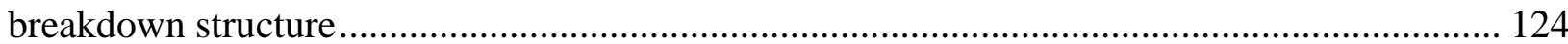

Table 25. Activity data, emission factors, and total $\mathrm{CO}_{2}$ eq associated with each $\mathrm{GHG}$ account

Table 26. Quantities of GHG control model for the case study............................................ 126 Table 27. The parameters for Triangular distribution of CO2_eq of values associated with GHG items, conditional on risks and common factors. 


\section{List of Figures}

Figure 1: The inputs and outputs of the fleet optimization model. 16 Figure 2: Depiction of the decision variables' network for a problem with $\mathrm{T}=4, \mathrm{M}=3$, and $\mathrm{N}=2$.

Figure 3: Number of brand new excavators purchased in each year

Figure 4: A Naïve Bayesian network to model correlated lifetime distributions of $\mathrm{n}$ components $(\mathrm{Fi})$, with a shared common cause $(\mathrm{C})$ 37

Figure 5: A schematic of proposed model to analyze reliability, maintainability, and availability of a single component 38

Figure 6: Expanded PDF of triangle distribution to handle the uncertainty of repair times; the10 percent of the probability in the tails of the distribution is not equally distributed. This skewness will be calculated based on the location of the most-likely value with respect to the initial upper

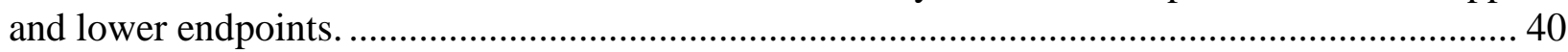
Figure 7: Adding a rare event variable $(\mathrm{R})$ into $\mathrm{BN}$ model in modelling of failure rate $(\mathrm{F})$........ 41 Figure 8: Parameter learning structure for failure rate based on $\mathrm{Z}$ real evidences ..................... 43 Figure 9: Graphical representation of the case model (dashed lines are created because there are intermediate nodes in the model to facilitate NPT assignments and to lower the calculation

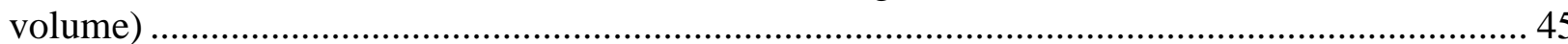

Figure 10: Primary results of fleet availability prediction .................................................. 47

Figure 11: Update of Failure and Repair rates in light of new observations ............................ 48

Figure 12: Update of fleet availability considering new evidences ........................................ 49

Figure 13: Fleet repair rate and availability distributions under power blackout ....................... 51

Figure 14: Availability distribution under Scenario 1 in comparison with the baseline availability

Figure 15: Inferring the level of experience, the duration of remaining repair tasks and the final

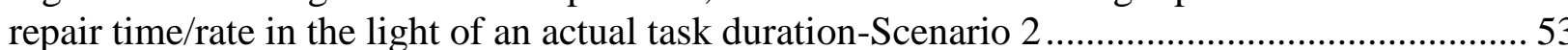
Figure 16: Inferring the required level of experience in maintenance people, quality of operation staff, and management maturity, to achieve a certain level of availability-Scenario 3 ............... 54 Figure 17: Comparison of three failure times' predictions (color lines) with actual failure times (black line)....

Figure 18: Comparison of three Repair times' predictions (color lines) with actual repair times

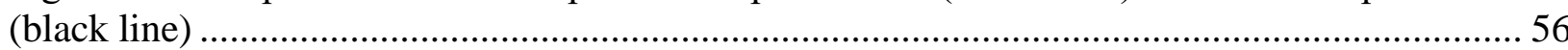

Figure 19: Different aspects of the proposed methodology ............................................... 64

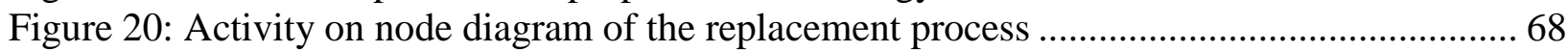

Figure 21: A condition for the mixed 'repair and replacement' decision..................................69

Figure 22: The R/R Calculator..................................................................................... 71

Figure 23: Economic Bayesian R/R model...................................................................... 73

Figure 24: A BN to model the dependency between repair tasks durations (Di) and the shared driving factor experience (E) (a) and its influence on the repair perfection (R)........................ 74

Figure 25: Learning structure for spare parts rate............................................................. 75

Figure 26: Integration of emission costs into the economic model ........................................ 77

Figure 27: Part of the BN model which includes the priors and posteriors of PM Quality, Repair Perfection, failure time parameters, the upcoming failure time, as well as the updated number of 
failures (Dashed lines are created due to the existence of intermediate nodes to ease the calculation).....

Figure 28: The probability distributions of total repair (TRC) and replacement (TRC') costs in economic model.

Figure 29: Posterior distribution of emission escalating threshold and update of O\&M emissions

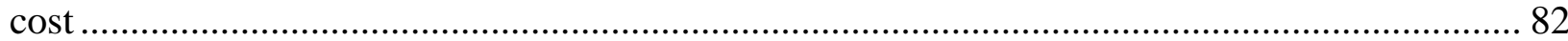

Figure 30: The probability distributions of combined total repair (TRC $\varepsilon$ ) and replacement $\left(\mathrm{TRC}^{\prime} \varepsilon\right)$ costs 83

Figure 31: The effect of scenario 1 on failure time, repair perfection, total repair duration, ....... 85 Figure 32: Comparison of total repair and replacement costs in baseline scenario and scenario 1

Figure 33: Probability-Impact matrix before (a) and after (b) responses implementation .......... 87 Figure 34: TRC $\varepsilon$ and $\mathrm{TRC}^{\prime} \varepsilon$ distributions before and after responding to the high-level risks .... 88 Figure 35: The PDF of combined total repair (TRC $\varepsilon$ ) and replacement (TRC' $\varepsilon$ ) costs with only

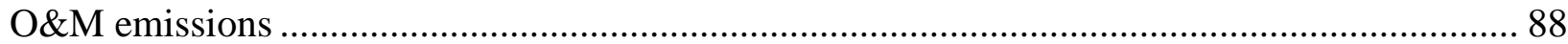

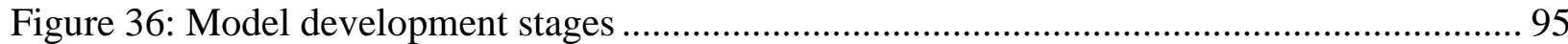

Figure 37: A naïve Bayesian network with two nodes: Carbon price $(\mathrm{P})$ and its cause $(\mathrm{C})$........ 98 Figure 38: A BN to model the causality between oil price $(\mathrm{O})$, carbon price $(\mathrm{P})$ and the impact

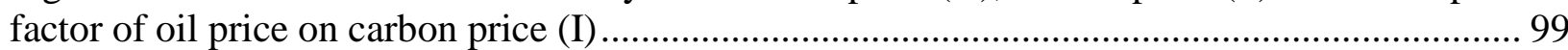
Figure 39: Graphical structure of the proposed BN model. The first layer indicates the nodes that are created to capture the uncertainty of driving forces. The second layer is the impact scale (IS) of the driving forces. The third layer of nodes shows the escalating and depreciating impact factors (EIF and DIF) (dashed lines are created because there are intermediate nodes in the model to facilitates NPT assignments and to lower the calculation volume)......................... 100 Figure 40: The probabilistic distribution of the driving force $\mathrm{X}$ and its threshold parameters $x 1$ and $x 2$, to define normal, depreciating and escalating regions.... 101 Figure 41: RMSE values associated with the eight tests conducted in two 4-fold cross-validations

Figure 42: Distribution of carbon price over the period 2018-2030 only dependent on a single category of driving forces, i.e. energy prices, GDP, and temperature .................................... 106 Figure 43: Probability distribution function of the predicted carbon price in the WCI market.. 107 Figure 44: PDF of carbon price in Scenario 1 compared to the baseline PDF ........................ 108 Figure 45: PDF of projected carbon price for the years 2019, 2022, and 2027 ...................... 109

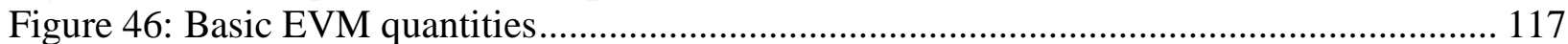

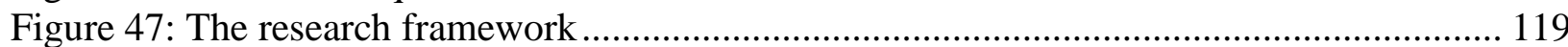

Figure 48: Project GHG performance measurement model ................................................ 122

Figure 49: Intersection of project GHG breakdown structure (GBS) and work breakdown

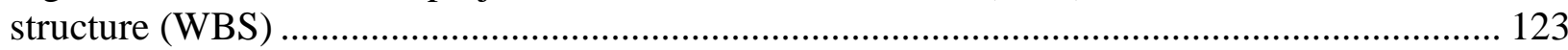

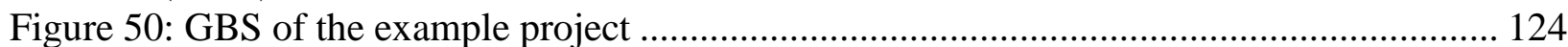

Figure 51: Components of the proposed model ................................................................... 128

Figure 52: Baseline total GHG emissions of the example project (in $\mathrm{kg} \mathrm{CO}_{2} \_$eq) .................. 132

Figure 53: Cumulative distribution of total emissions....................................................... 132

Figure 54: GHG emissions at completion....................................................................... 133 


\section{List of Appendices}

Appendix A. Global warming potentials and Scope 1 and Scope 2 emission factors ................. 146

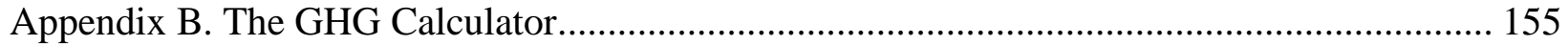

Appendix C. A method to estimate prior probabilities of common causes ................................. 155 


\section{Introduction}

In recent decades, sustainable development, with three interdependent pillars, has been the basis for emerging numerous systems and standards in various fields. The pillars are economy, society, and environment, also known as "the triple bottom line" (TBL), which are mutually reinforcing [1] $]^{1}$. Following this view, governments and organizations are increasingly seeking not just economic accomplishments but environmental and social success as well [2-4].

According to Searcy (2018) [5] to be truly sustainable, companies must perform within their specific TBL thresholds. To act sustainably, they even need to go beyond and consider their indirect influence on a broader sustainable environment [6]. In this journey, there is a growing demand for asset and project managers to report and demonstrate their environmental credentials and corporate responsibility, which presents an opportunity for them to differentiate and gain a competitive advantage in the marketplace. They are now recognizing the limited capacity of the environment to endure the current level of development and economic growth, depletion of natural resources, increasing problem of waste, worrying carbon dioxide emissions, and other environmental impacts. In fact, financial criteria are no longer the sole considerations to achieve success and shareholder value. One of the critical environmental impact categories is climate change and its most problematic effect, global warming, which is highly attributed to the greenhouse gas (GHG) emissions released from human activities [7], such as assets operation and development of mega infrastructure projects.

According to the Asset Management Council of Australia, asset management is defined as "The life cycle management of physical assets to achieve the stated outputs of the enterprise" [8]. Regardless of how sustainable assets have been designed at the very early stages of their lifecycle, they should be maintained effectively to address the triple bottom line of sustainability. However, there is a lack of methodology on sustainable asset management [9]. In view of environmental dimension of sustainability, the impact of industrial activities on environment needs to be incorporated into traditional economic based asset management practices. This impact includes

\footnotetext{
${ }^{1}$ John Elkington coined the term "The triple bottom line" (TBL) in 1994. He was the founder of SustainAbility, a British consultancy [232]. He argued that companies should think of three particular bottom lines. The first one is the "profit and loss account" bottom line, which existed traditionally as a basis to measure a corporate's profit. Company's "people account" is the second bottom line, which judges how socially responsible the company's operations are. Lastly, "planet account" is the third bottom line, and it measure the company's performance in terms of its environmental responsibility. The three Ps of TBL are therefore: profit, people and planet, which base an approach to control the financial, environmental and social performances integratively.
} 
several categories, such as global warming and climate change, ozone depletion, human toxicity, fossil fuel depletion, etc. [10]. Due to the regulatory schemes or carbon pricing policies in place (or scheduled to be implemented), organizations are currently under strict pressure to comply with environmental regulations. They should manage their engineering assets sustainably to ensure the reduction of energy use and GHG emissions.

Over the last decades, many models have been introduced for planning a fleet of assets. The objective of traditional fleet models has been to find the economic life of the fleet, neglecting its environmental impact. A comprehensive study on such models can be found in [11] and [12]. However, it is essential for fleet managers to incorporate environmental impacts into their asset management systems. To integrate and incorporate environmental burdens into fleet management, and to address national and international concerns on climate change, GHG emissions can be considered as a cost item for fleet decisions. A motivation behind this is carbon-pricing using a carbon-tax or cap-and-trade programs that encourage organizations to model their fleet's environmental impacts in their strategic planning. Moreover, most countries have set emission mitigation targets for the future decades, which implies that the issue of GHG control will be of much more importance to various industries and sectors. According to the Greenhouse Gas Emissions Reference Case [13], Canada's annual emission target is 523 megatons of carbon dioxide equivalent in 2030, which is 239 megatons less than the historical emissions recorded for year 2014. Motivated by this target, regulations including carbon pricing scheme are already in place or under implementation in some Canadian provinces.

Likewise, sustainable organizations need to have a control on the carbon footprint of their projects and any business change they intend to create in the form of a project. We believe that the project management community as a whole has the responsibility for supporting sustainable strategies, specifically for energy hungry construction and infrastructure projects. As such we need to incorporate GHG emissions monitoring and control as part of the project planning process. Incorporating a GHG module like the one we aim to present in this research could be a step in the right direction. In their book, Maltzman and Shirley (2010) [14] coin their own word to define and possibly measure how environmentally efficient project managers are; greenality, and define it as "the degree to which an organization has considered environmental (green) factors that affect its projects during the entire project life cycle and beyond." This is associated with two project management processes: (1) developing a plan for the project in order to minimize its product's environmental impacts (which involves efforts that make the project implementation more efficient 
and effective); and (2) the tracking and controlling these impacts during the execution phase. A project with greater greenality score has a positive impact on the bottom line, as it will be an efficient and effective project which saves resources [14].

Therefore, there is a need for today's organizations to move forward on a sustainable project management discipline. Projects, with a significant role in global economy as much as one third [15], have a serious contribution to global climate change and GHGs. This is the case specifically in construction projects which are the primary contributor of global GHG emissions [16]. Moreover, because of the growing competitive pressure and tendency to apply modern management techniques, organizations are being more and more projectized or project oriented [17]. Despite this fact, common practices in project performance measurement use project conventional triple constraints (i.e. quality, time and cost), neglecting its investment effectiveness and organizational benefits [18]. To integrate and incorporate the impact of GHG emissions in project execution and control, and to address national and international concern on the climate change, sustainability and reducing environmental impacts, GHG emissions can be considered as a cost for almost any types of project.

Following the Paris accord [19] and to fight climate change, governments have already implemented (or plan to implement) carbon pricing schemes such as a carbon tax and emission trading scheme (ETS), also known as cap-and-trade. The former puts a price on carbon emissions, with the objective of reducing emissions. In this approach, the outcome of emission reduction is uncertain. In contrast, an ETS provides an emission trading market with a pre-defined emission cap for the whole market, where the price of carbon is decided by the market [20]. According to Scholtens \& Van Der Goot (2014), an ETS can influence the participating firms' value due to two circumstances. First, there is a direct complying cost which requires the firms to adjust their business processes towards low carbon technologies and/or purchase more emission allowances, thereby impacting their cash flows. Second, unlike carbon tax, ETS's price of carbon is uncertain in that it is changing and volatile.

Affected organizations in this market, therefore, need to be able to predict carbon price so that they can vigilantly adjust their business plans. Many studies have been conducted to forecast and analyse the price of carbon in, for example, European Union ETS (EUETS) [21-30], China's ETSs [31,32], and Korea ETS [33]. However, similarly exhaustive forecasting studies have been seldom (if not never) performed in the Western Climate Initiative (WCI)' market. Sousa and Aguiar-Conraria [34] evaluated the dynamics of this market and the connection between energy and carbon prices. They reported contrasting market dynamics in WCI compared to EUETS. Hence, the results of research on other markets may not be applicable to forecast the carbon price in this market. Of course, 
regardless of the market, there is a continuous challenge about modelling the causality between driving forces (including energy prices, economic growth, weather, etc.) and carbon price.

Forecasting and monitoring availability is a key aspect of asset management. In fact, availability assessment provides a direct measure for production capacity, as well as a criterion to decide on required corrective actions [35]. However, assessment and optimization of a fleet's unavailability accounting for real world uncertainties is a challenging task and without a rigorous risk analysis on failure and repair rates (as the two main indicators of availability), the decisions on acceptability of availability may not be reliable [36]. For decades, researchers have been developing methods for assessment of failure and repair times, including fault trees (FTs) and dynamic fault trees (DFTs) [37], artificial neural networks (ANNs) [38], Bayesian networks (BNs) [39], Monte-Carlo simulation (MCS) [40], fuzzy MCS [41], renewal processes [42], Markov chains [43], and geometric processes [44].

A debate, however, continues over the estimation of actual failure and repair rates and therefore the assets availability. In addition to internal characteristics of a tangible asset, there are external, sometimes intangible common causes, such as quality of operating staff, which can affect failure rate. Further, the duration of repair tasks (such as diagnosis, procurement, remove and install, etc.) may not be independent, meaning the high duration of one task may affect the time of another because of the existence of a common cause, such as shared staff or technology. Such dependency, if it exists, must be modelled, or the uncertainty of repair time will not be precisely represented in the final distribution [45]. Modelling these dependencies- which without conditioning arrangements would be much more problematic for human subjects [46] has not been considered in analysing a system/fleet availability, especially with regard to complex organizational factors. Likewise, failure and repair distributions may be correlated due to complex common causal factors, such as shared physical environment, personnel qualifications, and management policy and attitudes. These factors can affect both reliability and maintainability of assets. This type of dependency has not been modelled in previous work on the availability analysis of a fleet of assets.

The decision to repair or replace a physical asset is another practical aspect of asset management. It involves many contradictory, conflicting, and uncertain factors related to the old and new assets, known as the defender and the challenger, respectively. Many models have been introduced for asset repair/replacement $(\mathrm{R} / \mathrm{R})$ decision-making. Traditionally, $\mathrm{R} / \mathrm{R}$ models rely on life cycle costing (LCC) concepts [47]. Recently, more advanced techniques have been also proposed in this domain to account for technological improvements [48], uncertainty of demand and market parameters [49], 
technical failure characteristics of assets [50], the effect of unknown parameters on time-to-failure distribution [51], and so forth.

Despite all these attempts, however, there are complexities associated with this problem that have not been modelled yet. To make an $\mathrm{R} / \mathrm{R}$ decision, we need to know whether the ongoing preventive or corrective maintenance is truly making a positive difference, and hence, it is better to keep the defender. A major factor is the quality of preventive maintenance (PM) and its impact on the defender's failure rate and health. In other words, whether or not a PM program, with certain costs, would be actually effective in delaying equipment degradation, remains uncertain. Likewise, the perfection of repairs can inform $\mathrm{R} / \mathrm{R}$ decision making. Theoretically, the so called minimal and perfect repairs recover a failed system to as bad as what it was just before failure and as good as new, respectively. Practically, however, the real outcome of these repairs, except in some special cases, may not be deterministic and therefore, every repair work could be regarded as an imperfect repair with the effectiveness between minimal (worst-case) and perfect (best-case) repairs. Although complex, these factors, i.e. quality and perfection of preventive and corrective maintenance, have not been examined in the previous works. They can be broken down to the quality/ perfection of smaller activities including lubrication, storage, cleaning, parts selection and installation, so forth. Other complex causal factors, such as organizational factors (e.g. repair staff experience), the risk of unanticipated loads, and variations in material quality are also missing in the asset replacement literature. If the uncertainty of such factors is not modelled, the results of LCC may not also be accurate.

On the other side, to control the increasing, worrying greenhouse gas (GHG) emissions, an environmental dimension is being added to asset replacement decisions (e.g. Afrinaldi, Taufik, Tasman, Zhang, \& Hasan, 2017; Ahani, Arantes, \& Melo, 2016; Ansaripoor, Oliveira, \& Liret, 2014). However, the combined replacement models (with both economic and environmental objectives) fail to model the impact of maintenance and equipment health on the amount of released GHG emissions. According to [55], equipment reliability can significantly improve energy efficiency and thus the amount of direct and indirect emissions.

Based on the above-stated problems, the focus of the present research can be defined in five major lines:

\section{Asset planning with both economic and environmental considerations}

A fleet optimization mathematical model will be developed, which incorporates the environmental 
impacts of assets over a finite horizon, in addition to the total cost of ownership. More specifically, we consider a fleet of systems over T operating periods. The model allows the assets to be kept in storage over any time period, in which such assets do not deteriorate as in-use assets do. The mathematical model optimizes the number of new, in-use, in-storage, and salvaged assets in each time period, so that the total economic costs and environmental impacts are minimized. To make a more realistic difference between assets, we consider asset capacity as well as its environmental impact. Therefore, the assets, which are purchased in the future, are considered more technologically improved, so they have a higher capacity and are more energy-efficient. It is to be noted that by "asset" in this thesis refers to physical assets such as construction and military equipment, aircrafts, industrial machineries, computers and electronic devises, turbines, etc.

This work is covered by chapter 2 which is based on the paper entitled "An optimization model for fleet management with economic and environmental considerations, under a cap-and-trade market", published in the Journal of Cleaner Production, as well as the paper entitled "Optimal Replacement of a Fleet of Assets with Economic and Environmental Considerations", presented at the Annual Reliability and Maintainability Symposium (RAMS) 2018 and published in the Proceedings of the Annual Reliability and Maintainability Symposium 2018.

\section{Improving fleet availability analysis by modelling causal factors and risk}

We develop a hybrid Bayesian network (BN) (with both discrete and continuous variables) to formulate a fully probabilistic availability analysis, focusing on the uncertainty of failure and repair rates. We model the common causes to individual rates, as well as the common causes that affect both failure and repair rates at the same time. The proposed model explicitly quantifies uncertainty in repair and failure rates of a fleet of assets and provides an appropriate method for modelling complex dependencies and factors affecting reliability, maintainability, or both, by considering influencing factors, either technical (such as working temperature, environment, quality, stress, etc.) or organizational (such as staff quality, management policies, etc.). Starting with incomplete or subjective information, the model can be updated in the light of new evidences. To further improve availability risk analysis, we will then extend the model to take into account extremely rare and/or previously unobserved risks (e.g. heavy storms, droughts, floods, etc.) that can significantly weaken reliability or maintainability levels. 
This work is covered by chapter 3 which is based on the paper entitled "A Bayesian network approach to fleet availability analysis", submitted to the journal of International Journal of Operations \& Production Management.

3. Improving repair-replacement decision analysis by incorporating GHG emissions, quality of maintenance, and risk

Firstly, we formulate a model for equipment repair-replace decision with both economic and environmental considerations, so that the quality of preventive maintenance (PM) and the level of repair perfection are taken into account in the equipment life cycle cost. A probabilistic reasoning mechanism is designed to formulate the effect of PM quality (and/or any other driving force) on equipment health and infer the effectiveness of maintenance. How perfect or imperfect the repair work is, is also modelled to more accurately predict the failure rate of the existing equipment during its remaining useful life. Secondly, we will model the causal relationship between maintenance, equipment reliability and equipment GHG emissions. To achieve the above objectives, we will develop a probabilistic $\mathrm{R} / \mathrm{R}$ model using $\mathrm{BNs}$, which also allows us to account for the uncertainty of effectual parameters. Equipped with expert knowledge and data-driven inference, the proposed model provides asset managers with a smart, explanatory mechanism that not only makes more accurate $R / R$ decisions, through capturing more effectual uncertainties and causal factors, but also identifies risk and opportunities that should be focused on to further reduce lifecycle economic and environmental costs.

This work is covered by chapter 4 which is based on the paper entitled "Incorporating maintenance quality, carbon emissions, and risk into asset repair-replacement decision", submitted to the journal of Computers \& Industrial Engineering.

\section{Forecasting carbon price in a cap-and-trade market}

We aim to capture the uncertainty of carbon price in the WCI market, by determining the causality between carbon price and its driving forces. A probabilistic model is developed using BNs to infer the possible ranges of each driving force that could have an escalation/depreciation effect on price as well as the magnitude of the impact. The model is developed based on retrospective and prospective information on the selected driving factors in all the jurisdictions of the WCI market, providing the most probable price(s) over the next ten years. 
This work is covered by chapter 5 which is based on the paper entitled "Forecasting carbon price in the Western Climate Initiative market using Bayesian networks", submitted to the journal of Carbon Management.

\section{Incorporating GHG emissions into project management practices}

We develop a model for estimation and control of a project GHGs during its implementation process. A set of metrics are designed to measure GHG performance at any point in time over the life of a project. The performance indices and forecasting formula are developed based upon the logic behind (earned value management) EVM methodology. In addition, we propose a probabilistic model to quantify the uncertainty of project GHG emissions using Monte Carlo Simulation and BNs techniques. The model provides a quantitative risk analysis mechanism to estimate the total emissions of a project as well as prediction of final emissions associated with the implementation process. The proposed models are applied to a work package of a real construction project.

This work is covered by chapter 6 which is based on the paper entitled "A model to control environmental performance of project execution process based on greenhouse gas emissions using earned value management", published in the International Journal of Project Management, as well as the paper entitled "Uncertainty Analysis of Project Emissions: A Bayesian Network Model to Estimate and Monitor Greenhous Gas Emissions", presented at the 18th annual IEEE Canada Electrical Power and Energy Conference (EPEC 2018).

Chapter 7 provides a summary of major conclusions and a direction for future research. References section compiles a list of bibliographical references used throughout this dissertation. Appendices contain supplementary materials and data that were not included in the main body of the present dissertation.

\subsection{Statement of Authorship}

This dissertation is developed with a manuscript-based format. Most of the chapters presented in this dissertation are the extensions of the following journal and conference papers, which are published, accepted or submitted for publication:

\section{$\underline{\text { Peer-Reviewed Journal Articles }}$}

1. Abdi, A., \& Taghipour, S. (2018). An optimization model for fleet management with economic and environmental considerations, under a cap-and-trade market. Journal of Cleaner Production, 204, 130-143 [Used in Chapter 2].

Published online at: $\underline{\text { https://doi.org/10.1016/j.jclepro.2018.08.345 }}$ 
Principal author's contribution: developing the mathematical model, programming the model, running the numerical examples, discussion of the results, and drafting the paper.

Second author's contribution: verification of the mathematical model and results and proofreading the draft paper.

2. Abdi, A., Taghipour, S., \& Khamooshi, H. (2018). A model to control environmental performance of project execution process based on greenhouse gas emissions using earned value management. International Journal of Project Management, 36(3), 397-413 [Used in Chapter 6].

Published online at: https://doi.org/10.1016/j.ijproman.2017.12.003

Principal author's contribution: developing the proposed technique, case study, discussion of the results, and drafting the paper.

Second author's contribution: verification of the results and proofreading the draft paper.

Third author's contribution: verification of the discussions and proofreading the draft paper.

3. Abdi, A., Taghipour, S. (2018). A Bayesian network approach to fleet availability analysis. International Journal of Operations \& Production Management. Under Review [Used in Chapter 3].

Principal author's contribution: developing the proposed technique, constructing the computer model, running the numerical examples, discussion of the results, and drafting the paper. Second author's contribution: verification of the results and proofreading the draft paper.

4. Abdi, A., Taghipour, S. (2018). Incorporating maintenance quality, carbon emissions, and risk into asset repair-replacement decision. Computers \& Industrial Engineering. Under Review [Used in Chapter 4].

Principal author's contribution: developing the proposed technique, constructing the computer model, running the numerical examples, discussion of the results, and drafting the paper. Second author's contribution: verification of the results and proofreading the draft paper.

5. Abdi, A., Taghipour, S. (2018). Forecasting carbon price in the Western Climate Initiative market using Bayesian networks. Carbon Management. In Revision [Used in Chapter 5]. Principal author's contribution: developing the proposed technique, constructing the computer model, running the numerical examples, discussion of the results, and drafting the paper. Second author's contribution: verification of the results and proofreading the draft paper.

\section{$\underline{\text { Peer-Reviewed Conference Articles }}$}


6. Abdi, A., Taghipour, S. (2018). Optimal Replacement of a Fleet of Assets with Economic and Environmental Considerations. Proceedings of the Annual Reliability and Maintainability Symposium 2018 [Used in Chapter 2].

Published online at: https://doi-org.ezproxy.lib.ryerson.ca/10.1109/RAM.2018.8462994

Principal author's contribution: developing the mathematical model, programming the model, running the numerical examples, discussion of the results, and drafting the paper.

Second author's contribution: verification of the mathematical model and results and proofreading the draft paper.

7. Abdi, A., Taghipour, S. (2018). Uncertainty Analysis of Project Emissions: A Bayesian Network Model to Estimate and Monitor Greenhous Gas Emissions. The 18th annual IEEE Canada Electrical Power and Energy Conference (EPEC 2018) [Used in Chapter 6].

Principal author's contribution: developing the proposed technique, case study, discussion of the results, drafting the paper, and presenting the paper.

Second author's contribution: verification of the results and proofreading the draft paper. 


\section{Fleet Optimization with Economic and Environmental Considerations}

The present chapter is based on the following papers:

Abdi, A., Taghipour, S. (2018). Optimal Replacement of a Fleet of Assets with Economic and Environmental Considerations. Proceedings of the Annual Reliability and Maintainability Symposium 2018 [56]. Published online at:

https://doi-org.ezproxy.lib.ryerson.ca/10.1109/RAM.2018.8462994

Abdi, A., \& Taghipour, S. (2018). An optimization model for fleet management with economic and environmental considerations, under a cap-and-trade market. Journal of Cleaner Production, 204, 130-143 [57]. Published online at: https://doi.org/10.1016/i.jclepro.2018.08.345

The objective of traditional fleet optimization models has been to find the economic life of the assets, neglecting their environmental impacts. However, due to the effect of carbon pricing schemes, in addition to the international concerns about global warming and carbon emissions, it is essential for affected fleet owners to incorporate environmental burdens into their asset management systems. The contribution of this research is a fleet optimization model which factors in the environmental impacts of a fleet of assets over a finite horizon, in addition to its total cost of ownership. As an indicator of environmental impacts, the greenhouse gas (GHG) emissions associated with the fleet ownership are considered. GHG emissions are converted into a monetary value, using the expected price of carbon in the Western Climate Initiative (WCI) market. To support implementing this model, a GHG calculator tool is built to calculate total carbon emissions associated with any segment of an asset life cycle, i.e. manufacturing, shipping to the fleet location, operation, maintenance, holding, and decommissioning. It has been built using a database of emissions factors associated with various fuels, energies, materials, and transportation activities. The optimization model is then applied to a fleet of excavators located in Ontario, Canada.

Keywords: Fleet, Asset replacement, Optimization, Greenhouse gas (GHG) emissions, Carbon price 


\subsection{Introduction and Background}

In this section, we review the published literature in two areas: economic replacement models, and models with both economic and environmental factors.

\subsubsection{Classical, economic models}

The classic decision of when to replace an operating asset was first modelled in 1949, when this problem was studied by Terborgh (1949). Later, increasing maintenance costs, the main reason for replacing old assets, were taken into account [59,60]. More considerations were modelled in published works thereafter. For instance, Vander Veen and Jordan (1989) [61] considered interdependencies between investment and machine utilization in a parallel machine replacement problem. Many studies aimed to model the technological changes of new equipment (e.g. [62-64]). Ouda et al. (2010) [65] integrated Fault Tree Analysis (FTA) and a set of technical, financial, and safety factors to model the replacement decision of medical equipment. These factors were hazard and alerts, cost, useful life, and vendor performance. Ben Abdallah and Lasserre (2016) [66] studied the tree harvesting decision as a version of the asset replacement problem. They modelled the replacement decision of two species with stochastic values (as a timber) and deterministic growth functions.

With regard to fleet replacement models, Büyüktahtakın and Hartman (2015) [67] developed a mixed-integer programming (MIP) formulation to optimize the replacement policy of a fleet of assets that operate in parallel. They model the technological change by considering capacity gains such that newer, technologically improved assets have higher capacity than assets purchased earlier. A key contribution of their model is that the assets that can be in inventory in each period are formulated. An issue with this model, however, is that in-storage assets are allowed to age as those in-use do. A real option model was proposed by Zheng and Chen (2018) [49] to decide on the replacement timing of a fleet of ships, when the owner deals with uncertain demand on different routes and uncertain prices of the fuel Marine gas oil (MGO) and liquefied natural gas (LNG). They compared the results, taking into account two affecting government policies, i.e. vessel subsidy and fuel subsidy ${ }^{2}$. In order to find the replacement probabilities in future periods and the expected net present values (NPVs) of

\footnotetext{
${ }^{2}$ Fossil fuel subsidies are government regulations that reduce the cost of fossil fuel energy generation, increase the price received by energy producers, or reduce the price paid by the consumers. Generally, these subsidies rig the energy markets in support of fossil fuel production against other sources such as renewable and cleaner energies.
} 
after replacement cost savings, they used a multi-option least squares Monte Carlo simulation algorithm, using the data from a chemical tanker shipping company.

More recently, He et al. (2017) [68] developed a decision model for replacement of fuel-powered vehicles with hybrid electric vehicles (HEVs), considering trade-in and subsidy for vehicle owners and fuel uncertainty. Wang and Nguyen (2017) [69] developed a stochastic dynamic programming model for technology replacement, so that the expected net present profit is maximized over a finite time horizon. They employed a pattern search-genetic algorithm to solve the modelled problem. Using real data from railroad tracks and Markov chain Monte Carlo methods, Merrick and Soyer (2017) [50] proposed a Bayesian decision support system for optimal replacement. By specifying a nonparametric form with a gamma process prior for modelling wear and considering the effect of covariates using a parametric function, they conducted a semiparametric analysis to model the failure characteristics of rail tracks. Nguyen et al. (2017) [70] developed a new decision support system for the optimal maintenance, replacement, and new technology adoption timing of a repairable asset. They considered the information acquisition option on the profitability of a new technology, which is not yet available on the market.

\subsubsection{Combined, sustainable models}

Researchers are adding another dimension to the replacement problem, by accounting for the environmental burden of equipment as well as its financial costs. This view implies that a replacement decision must be made based on all pillars of sustainability, i.e. economic, environmental and social [71]. There are various studies in the published literature, which have attempted to address aspects of this issue. Sloan (2011) [72] developed a combined economic-environmental replacement model based on the method presented by NAIR (1995) [73], which allowed uncertain introduction time of improved technologies. Afrinaldi et al. (2017) [54] developed a mathematical model to calculate the optimal schedule of preventive replacement of a single asset, aiming to minimize the economic and environmental impacts of the asset. The economic side of this model is formulated regarding operation, failure and replacement cost items. The environmental part consists of GHG emissions associated with the operation and replacement processes. A genetic algorithm (GA) was used in this study to find the optimal solutions for tire replacement of a bus fleet. To find the most sustainable asset management strategy, Matthews et al. (2016) [74] examined three pipe management strategies, namely: a reactive run-to-failure and then replace; a pre-emptive replacement prior to failure based on assumed condition; and a balanced approach of active condition assessment and taking actions 
relevant to the known conditions. They compared the strategies considering 144 criteria in five categories: quality of life; leadership; resource allocation; natural world; and climate and risk. Their results showed that the most sustainable strategy is the balanced approach.

An approximate dynamic programming model was proposed by Stasko and Oliver Gao (2012) [75] to make decisions on salvages, upgrades, and new purchases in a fleet of vehicles, taking into account stochastic breakdowns and impact of emissions regulations on the value of the fleet vehicles. Feng and Figliozzi (2013) [76] proposed a replacement model for a fleet of electric commercial vehicles (ECVs), with an objective function that minimizes both financial costs and GHG costs. This work, however, does not allow a vehicle to be kept in inventory when it is not needed. In addition, some of the relevant GHG accounts are missing; such as those associated with manufacturing new assets and salvaging old ones. Based on this study, Ahani et al. (2016) [53] presented an optimization method to find the best combination of electric vehicles (EVs) vs. internal combustion engine vehicles (ICEVs). In particular, they addressed the risk associated with energy costs and EVs purchase costs in their model. In one of the very few attempts to model the risk of environmental factors (such as carbon price), Ansaripoor et al. (2014) [52] developed a general-purpose fleet replacement model using stochastic programming and conditional value at risk $(\mathrm{CVaR})$. To take into account the uncertainty of such factors, they used discrete scenarios or states. For example, they modelled the carbon price uncertainty by a 3-point Likert scale (low price, medium price, and high price), which may not be a reliable risk quantification.

The review of the literature makes it evident that modelling the full environmental impacts of the assets, including the impacts associated with the production of a brand-new asset, operation and maintenance (O\&M), holding, and salvage is restricted in published research aiming to determine the optimal fleet replacement decisions. There are also some unrealistic assumptions in the existing relevant mathematical models. The most noticeable is that they allow the assets in inventory to age, while these assets are not used in the related periods.

\subsubsection{Carbon footprinting}

According to the IPCC's (2014) [7] latest report, the growth of carbon emissions has surged over the last decade, despite the many mitigation programs that have been introduced so far. This might be in connection with rapidly rising consumption of fossil fuels, which is the largest contributor to carbon emissions [77]. The main GHGs included in the Kyoto Protocol [78] are carbon dioxide $\left(\mathrm{CO}_{2}\right)$, methane $\left(\mathrm{CH}_{4}\right)$, nitrous oxide $\left(\mathrm{N}_{2} \mathrm{O}\right)$, hydrofluorocarbons (HFCs), perfluorocarbons (PFCs), and 
sulphur hexafluoride (SF6). These GHGs can be translated into a carbon equivalent measure $\left(\mathrm{CO}_{2} \_\right.$eq) by use of a global warming potentials (GWP) factor (an updated list of GWPs is provided in Appendix A). In global warming terms, $\mathrm{CO}_{2}, \mathrm{CH}_{4}$, and $\mathrm{N}_{2} \mathrm{O}$ are considered as the main GHGs, with GWPs equal to 1,28 , and 265 , respectively.

The GHG Protocol Corporate Standard [79] categorizes an organization's carbon emissions into three 'scopes'. Scope 1 GHGs are emitted directly from the sources which are owned or controlled by the reporting organization. Scope 2 refers to indirect emissions released from the production process of purchased energies. Scope 3 emissions are not controlled or owned by the reporting agency and are associated with its value chain. The carbon footprint of fleets' ownership, therefore, consists of the $\mathrm{CO}_{2}$ eq of stationary and/or mobile combustions for operating and decommissioning of the fleet's assets (Scope 1), $\mathrm{CO}_{2}$ eq from electricity/heat/steam consumption in operation period (Scope 2), as well as tons of $\mathrm{CO}_{2} \_$eq associated with all materials that directly contribute to the manufacturing of an asset.

The total carbon dioxide equivalent $\left(\mathrm{CO}_{2}\right.$ eq) footprint of an activity can be calculated as the product of the activity data (AD) and its emission factor (EF) [80]:

$$
\mathrm{CO}_{2 \_} \mathrm{eq}=\mathrm{AD} * \mathrm{EF}
$$

Activity data is the value of the significance of a human activity that releases GHG emissions over a period of time [81]. An activity data may include information about more than one type of greenhouse gas. In such cases, the equivalent carbon emission of each type of gas will be accounted for, using a relevant EF. We conducted a study to collect the latest EFs, including Scope 1, Scope 2, and manufactured material, reported by well-known environmental organizations, such as Environmental Protection Agency (EPA), International Energy Agency (IEA), World Bank, Canada Environment, and different governments' energy related departments. Scope 1 emission factors includes EFs related to stationary and mobile combustion sources. Scope 2 EFs are mostly associated with electricity usage, and hence, vary by the location of the fleet because countries and jurisdictions have their specific mix of energy generation [82]. Therefore, for different countries and regions, Scope 2 EFs are collected separately (if reported). In addition, emission factors of important manufactured materials are extracted (EFs database is provided in Appendix A).

Using our EFs database, we developed a GHG calculator to calculate the carbon footprint of an activity with the modules: Scope 1, Scope 2, and Manufactured Materials, using Visual Basic for Applications (VBA) of Microsoft Excel. This calculator allows the users to enter detailed evidences 
about the activity data (such as location, type of vehicle, distance travelled, fuel, material, amount of electricity/heat/fuel, etc.), and provides the total carbon emissions and its cost in the corresponding carbon market, if in place. The interface of the GHG calculator is shown in Appendix B.

\subsection{Optimization model}

This section provides a description of our methodology. As presented in Figure 1, the core of this chapter is a mixed-integer programming (MIP) optimization model for the fleet replacement problem, with both environmental and economic parameters. Other stages that are fed into the optimization model include the GHG calculator tool and the carbon price forecast (which is presented in chapter 5). Using information from an excavator fleet case study, the model is run, outputs of which allow fleet managers to decide on new equipment purchases as well as the existing equipment that should be in-use, in-storage, and salvaged in each period of planning horizon.

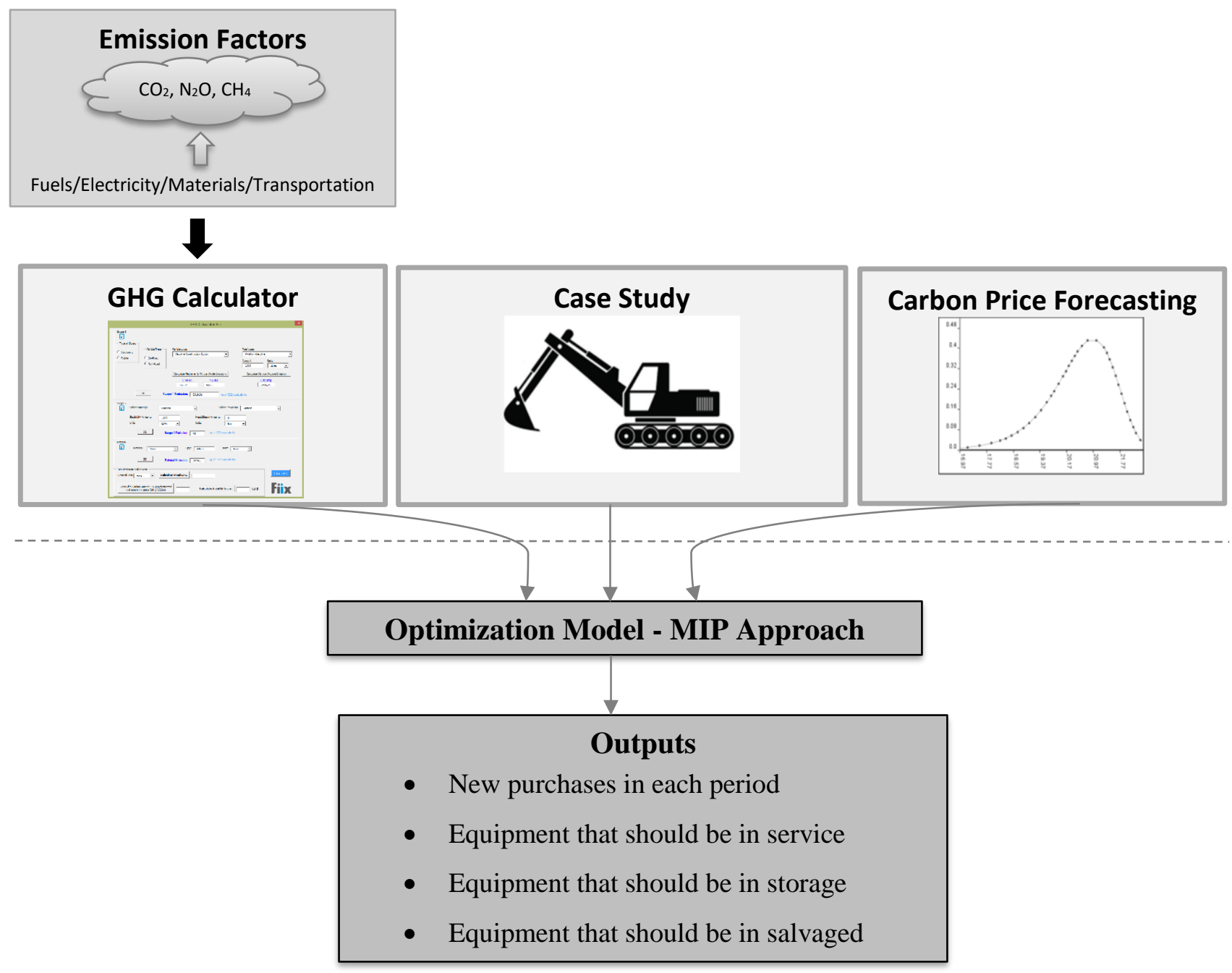

Figure 1: The inputs and outputs of the fleet optimization model. 
The objective is to develop a mathematical model for a fleet planning, which simultaneously minimizes the total ownership cost and the total greenhouse gas (GHG) emissions caused by the fleet. The model allows the assets to be kept in storage in any period, over which such assets do not age. We have modelled previous utilization ${ }^{3}$ to make a more realistic difference between assets. It is assumed that an asset in a given period is either in service with full capacity or it is in storage. Thus, there is no intermediate capacity considered for the asset. To take into account the economic and environmental factors, we include purchasing new assets, operation and maintenance (O\&M) of inuse assets, holding in-storage assets, and salvaging assets. GHG cap and budget limit of the fleet owner is also formulated. The outputs of the model include the optimal decision on the mix of assets that should be in-use, in-storage, and salvaged in each period. Additionally, the model determines how many new assets should be purchased and added to the fleet in each period. We optimize the replacement decisions over a planning horizon with T periods. Each equipment is specified by its age $\mathrm{j}=0, \ldots, \mathrm{M}$, and the number of periods that it has been previously in service $\mathrm{k}=0, \ldots, \mathrm{N}$, where $\mathrm{M}$ and $\mathrm{N}$ represents the maximum age and utilization periods of an asset, respectively, and $\mathrm{N} \leq \mathrm{M}$. As the number of previous utilization periods cannot exceed the age of equipment, $\mathrm{k} \leq \mathrm{j}$. Purchase and salvation actions are taken at the beginning of each period $i=1, \ldots, \mathrm{T}$. At the end of the last period, all the assets will be salvaged. Depreciation is assumed to be already reflected in salvage value, as a component of the depreciation calculation. Decision variables and parameters of the model are as follows:

\section{- Decision variables:}

$-\mathrm{X}_{i j k}$ number of $\mathrm{j}$-period-old and previously in operation for $\mathrm{k}$ period assets, used in period $\mathrm{i}$

$-\mathrm{S}_{i j k}$ number of $\mathrm{j}$-period-old and previously in operation for $\mathrm{k}$ period assets, salvaged at the beginning of period $\mathrm{i}$

$-\mathrm{Y}_{i j k}$ number of $\mathrm{j}$-period-old and previously in operation for $\mathrm{k}$ period assets, in inventory in period i

$-A_{i} \quad$ number of new assets purchased at the beginning of period $i$

$-\mathrm{Z}_{\mathrm{i}} \quad 1$, if there is a purchase in period $\mathrm{i}$, else $\mathrm{Z}_{\mathrm{i}}=0$.

\section{- Economic and technical parameters:}

$-c_{i j k}$ capacity (technological change) parameter for a j-period-old and previously in operation for $\mathrm{k}$ period asset in period $\mathrm{i}$

$-p_{i} \quad$ purchase cost of a new asset at the beginning of period $\mathrm{i}$

\footnotetext{
${ }^{3}$ The term utilization was chosen to express the exact number of previous periods in which an asset has been used and hence it is not meant to refer to the conventional definition of capacity utilization, which is the proportion of time that a piece of equipment is operating.
} 
$-u_{i} \quad$ fixed cost for purchasing an asset at the beginning of period $\mathrm{i}$

$-m_{i j k} \mathrm{O} \& \mathrm{M}$ costs for operating a j-period-old and previously in operation for $\mathrm{k}$ period asset in period i

$-h_{i j k}$ holding cost for keeping in inventory a j-period-old and previously in operation for $\mathrm{k}$ period asset, in period $\mathrm{i}$

$-r_{i j k}$ revenue from salvaging a j-period-old and previously in operation for $\mathrm{k}$ period asset at the beginning of period $\mathrm{i}$

$-n_{j k}$ number of $\mathrm{j}$-period-old and previously in operation for $\mathrm{k}$ period assets available at the beginning of the time horizon

$-d_{i} \quad$ demand (with the same unit of capacity) in period $\mathrm{i}$

$-b_{i} \quad$ budget available for new investment in period $\mathrm{i}$

\section{- Environmental parameters:}

$-q_{i} \quad$ environmental impact of manufacturing a new asset at the beginning of period $\mathrm{i}$

$-l_{i} \quad$ fixed environmental impact for purchasing an asset at the beginning of period $\mathrm{i}$

$-g_{i j k}$ environmental impact for operating a j-period-old and previously in operation for $\mathrm{k}$ period asset in period $\mathrm{i}$

$-w_{i j k}$ environmental impact of keeping a j-period-old and previously in operation for k period asset in inventory in period $\mathrm{i}$

$-v_{i j k}$ environmental impact of salvaging a $\mathrm{j}$-period-old and previously in operation for $\mathrm{k}$ period asset at the beginning of period $\mathrm{i}$

$-f_{i} \quad$ environmental impact limit (or cap) in period $\mathrm{i}$

The objective function is the minimization of the discounted sum of the economic and environmental costs associated with purchasing new assets, O\&M of in-use assets, holding in-storage assets, and salvaging the assets over the period of analysis, i.e. from year one (present) to the end of year T:

Minimize:

$\sum_{i=1}^{T}\left[\left(p_{i}+q_{i}\right) A_{i}+\left(l_{i}+u_{i}\right) Z_{i}\right]+\sum_{i=1}^{T} \sum_{j=0}^{M-1} \sum_{k=0}^{\min (j, N-1)}\left[\left(m_{i j k}+g_{i j k}\right) X_{i j k}+\left(h_{i j k}+w_{i j k}\right) Y_{i j k}\right]-\sum_{i=1}^{T} \sum_{j=1}^{M-1} \sum_{k=1}^{\min (j, N-1)}\left[\left(r_{i j k}-v_{i j k}\right) S_{i j k}\right]$

This objective function is subject to the following constraints:

$$
\begin{aligned}
& \mathrm{A}_{\mathrm{i}} \mathrm{p}_{\mathrm{i}}+\mathrm{Z}_{\mathrm{i}} \mathrm{u}_{\mathrm{i}} \leq \mathrm{b}_{\mathrm{i}}, \quad \forall \mathrm{i}=1, \ldots, \mathrm{T} \\
& \sum_{\mathrm{j}=1}^{\mathrm{T}} \sum_{\mathrm{k}=0}^{\min (\mathrm{j}, \mathrm{N}-1)} \mathrm{c}_{\mathrm{ijk}} \mathrm{X}_{\mathrm{ijk}} \geq \mathrm{d}_{\mathrm{i}}, \quad \forall \mathrm{i}=1, \ldots, \mathrm{T} \\
& \mathrm{A}_{1}+\mathrm{n}_{00}=\mathrm{X}_{100}+\mathrm{Y}_{100}
\end{aligned}
$$




$$
\begin{aligned}
& \mathrm{A}_{\mathrm{i}}=\mathrm{X}_{\mathrm{i} 00}+\mathrm{Y}_{\mathrm{i} 00}, \quad \forall \mathrm{i}=2, \ldots, \mathrm{T} \\
& \mathrm{n}_{\mathrm{jk}}=\mathrm{X}_{1 \mathrm{jk}}+\mathrm{Y}_{1 \mathrm{jk}}+\mathrm{S}_{1 \mathrm{jk}}, \quad \forall \mathrm{j}=1, \ldots, \mathrm{M} ; \forall \mathrm{k}=1, \ldots, \min (\mathrm{j}, \mathrm{N}) \\
& \mathrm{X}_{(\mathrm{i}-1)(\mathrm{j}-1)(\mathrm{k}-1)}+\mathrm{Y}_{(\mathrm{i}-1)(\mathrm{j}-1) \mathrm{k}}=\mathrm{X}_{\mathrm{ijk}}+\mathrm{Y}_{\mathrm{ijk}}+\mathrm{S}_{\mathrm{ijk}}, \forall \mathrm{i}=2, \ldots, \mathrm{T} ; \forall \mathrm{j}=2, \ldots, \mathrm{M} ; \quad \forall \mathrm{k}=1, \ldots, \mathrm{j}-1 \\
& \mathrm{Y}_{(\mathrm{i}-1)(\mathrm{j}-1)(0)}=\mathrm{X}_{\mathrm{ij0}}+\mathrm{Y}_{\mathrm{ij} 0}+\mathrm{S}_{\mathrm{ij} 0}, \forall \mathrm{i}=2, \ldots, \mathrm{T} ; \forall \mathrm{j}=1, \ldots, \mathrm{M} \\
& \mathrm{X}_{(\mathrm{i}-1)(\mathrm{j}-1)(\mathrm{k}-1)}=\mathrm{X}_{\mathrm{ijk}}+\mathrm{Y}_{\mathrm{ijk}}+\mathrm{S}_{\mathrm{ijk}}, \forall \mathrm{i}=2, \ldots, \mathrm{T} ; \forall \mathrm{j}=1, \ldots, \mathrm{M} ; \quad \forall \mathrm{k}=\mathrm{j} \\
& \mathrm{X}_{\mathrm{iMk}}=0, \quad \forall \mathrm{i}=1, \ldots, \mathrm{T} ; \forall \mathrm{k}=1, \ldots, \mathrm{N} \\
& \mathrm{Y}_{\mathrm{iMk}}=0, \quad \forall \mathrm{i}=1, \ldots, \mathrm{T} ; \forall \mathrm{k}=1, \ldots, \mathrm{N} \\
& \mathrm{X}_{\mathrm{ijN}}=0, \quad \forall \mathrm{i}=1, \ldots, \mathrm{T} ; \forall \mathrm{j}=1, \ldots, \mathrm{M} \\
& \mathrm{Y}_{\mathrm{ijN}}=0, \quad \forall \mathrm{i}=1, \ldots, \mathrm{T} ; \forall \mathrm{j}=1, \ldots, \mathrm{M} \\
& \mathrm{S}_{\mathrm{i} 00}=0, \quad \forall \mathrm{i}=1, \ldots, \mathrm{T} \\
& \sum_{\mathrm{j}=0}^{\mathrm{M}} \sum_{\mathrm{k}=0}^{\mathrm{min}(\mathrm{j}, \mathrm{N})}\left(\mathrm{g}_{\mathrm{ijk}} \mathrm{X}_{\mathrm{ijk}}+\mathrm{q}_{\mathrm{i}} \mathrm{A}_{\mathrm{i}}+\mathrm{l}_{\mathrm{i}} \mathrm{Z}_{\mathrm{i}}+\mathrm{W} \mathrm{w}_{\mathrm{ijk}} \mathrm{Y}_{\mathrm{ijk}}+\mathrm{v}_{\mathrm{ijk}} \mathrm{S}_{\mathrm{ijk}}\right) \leq \mathrm{f}_{\mathrm{i}}, \quad \forall \mathrm{i}=1, \ldots, \mathrm{T} \\
& \mathrm{Z}_{\mathrm{i}}=\left\lceil\mathrm{A}_{\mathrm{i}} /\left(\mathrm{A}_{\mathrm{i}}+1\right) 1, \quad \forall \mathrm{i}=1, \ldots, \mathrm{T}\right. \\
& \mathrm{X}_{\mathrm{ijk}}, \mathrm{Y}_{\mathrm{ijk}}, \mathrm{A}_{\mathrm{i}}, \mathrm{S}_{\mathrm{ijk}} \in\{0,1,2, \ldots\}
\end{aligned}
$$

Purchase costs cannot exceed the annual budget available for new investments (Eq.3). This item includes variable costs affected by the number of new equipment and its price, and a fixed cost which happens whenever there is at least one new equipment to order. We have assumed that financing sources provide cash ready for purchasing the assets. The annual demand should be met by the total capacity gained by in-service assets (Eq.4). That is to say, the total capacity met by operational assets should be equal or greater than the required capacity in the corresponding period. It should be noted that deterioration in capacity occurs by utilization and new technology in the market, therefore; $\mathrm{c}_{\mathrm{ij}(\mathrm{k}+1)} \leq \mathrm{c}_{\mathrm{ijk}}$ and $\mathrm{c}_{(\mathrm{i}+1) \mathrm{jk}} \leq \mathrm{c}_{\mathrm{ijk}}$. Because of the harsh conditions of the holding environment, there might be some cases in which the capacity of in-storage assets deteriorates on a smaller scale, comparing with the deterioration caused by utilization. For such cases, we consider $c_{i(j+1)(k+1)} \leq$ $\mathrm{c}_{\mathrm{i}(\mathrm{j}+1) \mathrm{k}} \leq \mathrm{c}_{\mathrm{ijk}}$. Example of this case includes machines that face "forced deterioration" during the operation times, due to defects and abnormalities, exposure of machine to abnormal stresses, abnormal wear and tear as a result of mal operation or improper maintenance. The same machine kept 
in inventory, however, would only deteriorate as a result of "natural deterioration", mainly because of proper environmental conditions.

As mentioned earlier, the purchases occur at the beginning of each period including the first period. Therefore, at the beginning of the first year, i.e. period 1, the number of initial age-0 (new) assets plus the number of purchased age- 0 assets should be equal to the number of in-use, in-storage assets within year 1 (Eq.5). The purchased new assets in all the other periods should be either used or kept in storage in each of those periods (Eq.6). This makes sure again that new assets are not salvaged. At the beginning of the planning horizon, initial assets with any ages and utilization (other than age 0) should be either used, stored or salvaged (Eq.7). The used or in-storage assets in one period should be either used, kept in storage or salvaged in the next period (Eq.8-10). These equations can be further explained by the graph shown in Figure 2, where the flow of the problem network is illustrated. It is assumed that any asset that reaches its maximum age $\mathrm{M}$ will not be used anymore (Eq.11 and Eq.12). Moreover, any asset that reaches its maximum utilization $\mathrm{N}$ will be salvaged (Eq.13 and Eq.14). New assets cannot be sold immediately (Eq.15). The sum of all environmental costs should not exceed a specific environmental limit or cap (Eq.16). The left-hand side of this equation captures every carbon emission item of the fleet. In each period, decision variable $\mathrm{Z}$ is restricted to be binary, so that it must be zero, if there is no new purchase $(A=0)$, and be one, if there is at least one new purchase $(A \geq 1)$ (Eq.17). All decision variables must be non-negative integers (Eq.18).

Fig.2 is a graphical representation of the constraints (4) to (14) for an example in which planning horizon, maximum age, and maximum utilization are equal to 4, 3, and 2, respectively. Take, for example, the assets with age 2 and utilization 1 in period 2 . These assets are either salvaged at the beginning of this period $\left(\mathrm{S}_{221}\right)$, used $\left(\mathrm{X}_{221}\right)$ and/or stored $\left(\mathrm{Y}_{221}\right)$ during the period. They are coming from two inputs: 1) the 1-year old assets, which have not been used before, and have been in service over the first year $\left(\mathrm{X}_{110}\right)$, and 2 ) the 1-year old assets, which have been previously used for one year and stored over the first year $\left(\mathrm{Y}_{111}\right)$. At the beginning of the next year (i.e. period 3), all these in-use and in-storage assets will be salvaged, as they reach their maximum age $\left(S_{331}\right.$ and $\left.S_{332}\right)$. However, in-service, in-storage, and salvaged assets that are older than a brand new and have not been utilized previously (zero-utilization) must come only from in-storage assets in the previous period (Eq.8). Similarly, those that have been always in service (full-utilization), must come from the assets that have been in-service in the previous period (Eq.9). 


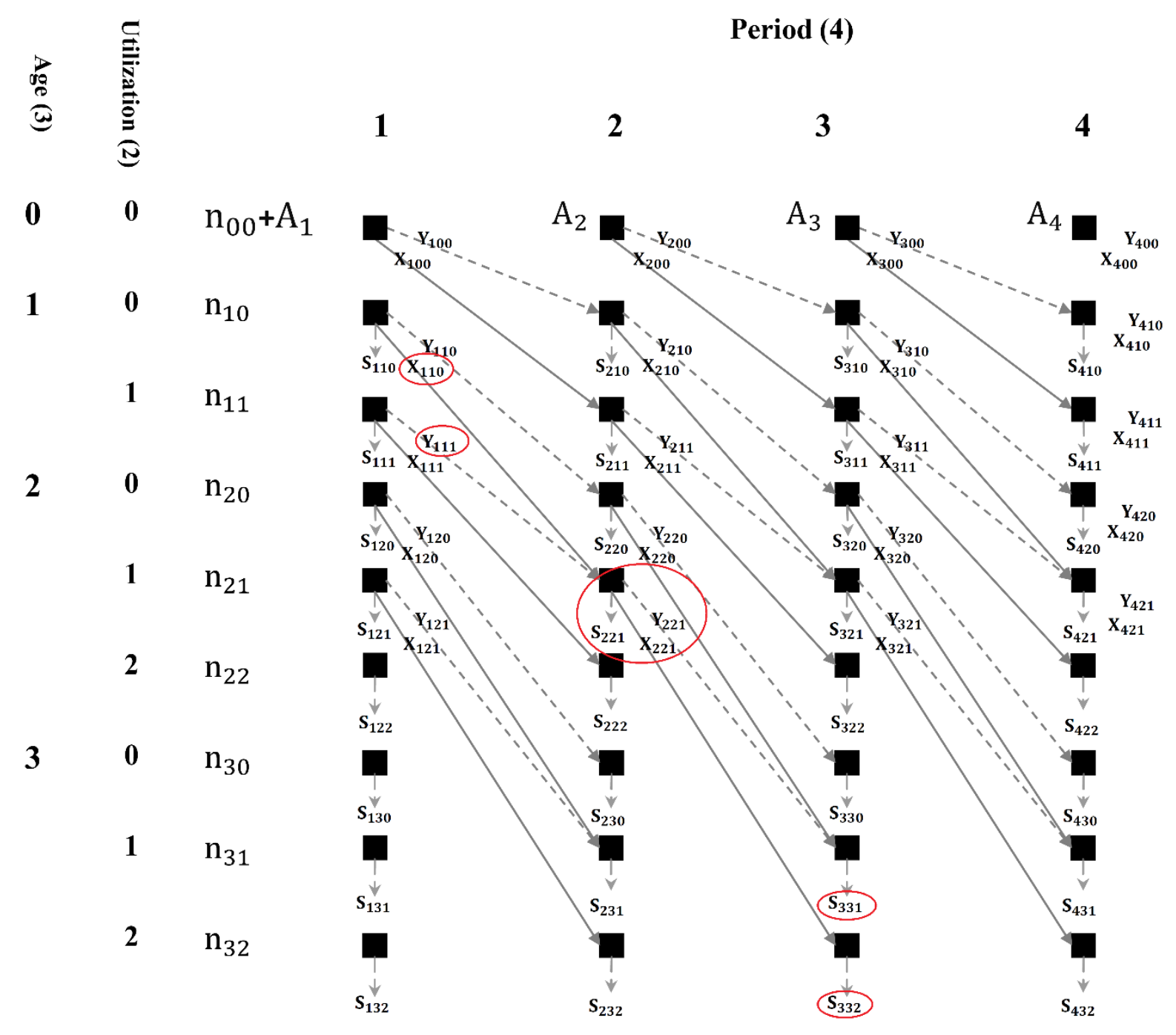

Figure 2: Depiction of the decision variables' network for a problem with $\mathrm{T}=4, \mathrm{M}=3$, and $\mathrm{N}=2$.

\subsection{Numerical Examples}

This section contains a numerical example for the model previously discussed. The proposed model of this study is designed to be generic, and hence applicable to any type of industry and assets. We applied the proposed model to a fleet of excavators using hypothetical data. We chose this example because we had access to relatively realistic data on the parameters, including the price of excavators, operation costs, emissions of manufacturing and operating the vehicle, etc. The planning horizon is 10 years $(\mathrm{T}=10)$. We use this as the useful life and the maximum age of the excavators as well $(\mathrm{M}=$ 9). The maximum utilization period is considered to be the economic lifetime of an excavator, which is 5 years $(\mathrm{N}=4)$ [83]. Currently, the fleet owner has 21 excavators. Table 1 shows the number of excavators with different ages and utilization history. As mentioned earlier, the case study of this chapter is designed using hypothetical data and it does not mach an existing real-world company. 
However, the parameters were estimated by the author's experience and exploring several websites and equipment catalogs to provide reasonable values. After the estimation of relevant activity data (such as the type and amount of fuel consumption, materal usage to manufacture the excavators, etc.), we applied our GHG Calculator to obtain the carbon footprint associated with them.

Table 1: Number of excavators with age $\mathrm{j}$ and past utilization $\mathrm{k}$ in the beginning of the planning horizon: $n_{\mathrm{ik}}$.

\begin{tabular}{|c|c|c|c|c|c|}
\hline j $k$ & 0 & 1 & 2 & 3 & 4 \\
\hline $\mathbf{0}$ & 3 & & & & \\
\hline 1 & 1 & 2 & & & \\
\hline 2 & 0 & 3 & 3 & & \\
\hline 3 & 0 & 0 & 1 & 1 & \\
\hline 4 & 2 & 0 & 2 & 1 & 0 \\
\hline 5 & 0 & 0 & 0 & 0 & 0 \\
\hline 6 & 0 & 1 & 0 & 1 & 0 \\
\hline 7 & 0 & 0 & 0 & 0 & 0 \\
\hline 8 & 0 & 0 & 0 & 0 & 0 \\
\hline 9 & 0 & 0 & 0 & 0 & 0 \\
\hline
\end{tabular}

Let us assume that using historical records of the company, economic and technical parameters are estimated for the upcoming year and the escalation of parameters are elicited from the company's experts. The GHG calculator was used to estimate the carbon emissions associated with the environmental parameters. We used the results of the carbon price modelling (covered by chapter 5) to convert the emissions into a dollar value over the planning horizon. The input environmental and economic parameters are presented in Table 2, as functions of the asset age and utilization, as well as the related period in the planning horizon. As it can be seen, a function contains a constant representing the estimation of the related parameter for the next year and a changing value that is dependent on one or more of age, utilization, and period indices and their corresponding coefficient. It has been assumed that emission cap is decremental for five years and after that there will be a fixed cap.

We used CPLEX [84] to solve the model, on a PC running Windows 10 with a $2.5 \mathrm{GHz} \mathrm{CPU}$ and 12 GB memory. Objective value is C $\$ 24,010,000$, representing the sum of the economic and environmental costs. The number of new equipment that should be purchased in each period is provided by Figure 3. The decision variables in different periods are obtained as Table 3. As shown, the model decides to salvage six from 21 excavators that were available at the beginning. Looking 
more closely at the other periods, it can be seen that the model mostly chooses rather new excavators with low utilization history and hence salvages those that have been utilized for four or more years (note that a $\mathrm{k}=3$ means four years of utilization). Based on the input parameters, the model tends not to put excavators in inventory, except in the first, seventh, eighth, and ninth period.

Table 2. Estimated economic and environmental parameters

\begin{tabular}{|c|c|c|}
\hline Parameter & Function & Unit \\
\hline \multicolumn{3}{|l|}{ Economic } \\
\hline $\mathrm{p}_{\mathrm{i}}$ & $300,000+10,000 i$ & CAD\$ \\
\hline$l_{i}$ & $10,000+1,000 \mathrm{i}$ & CAD\$ \\
\hline $\mathrm{d}_{\mathrm{i}}$ & $700,000+60,000 \mathrm{i}$ & CUM (cubic meter) \\
\hline $\mathrm{m}_{\mathrm{ijk}}$ & $80,000+5000(-0.5 i+0.2 j+k)$ & CAD\$ \\
\hline $\mathrm{h}_{\mathrm{ijk}}$ & $7000+500(\mathrm{k})$ & CAD\$ \\
\hline $\mathrm{C}_{\mathrm{ijk}}$ & $63,000+5000(0.5 i-0.2 j-k)$ & CUM (cubic meter) \\
\hline $\mathrm{b}_{\mathrm{j}}$ & $10,000,000+1000,000 i$ & CAD\$ \\
\hline$r_{i j k}$ & $180,000-10,000(0.5 j+2 k-i)$ & $\$$ \\
\hline \multicolumn{3}{|c|}{ Environmental } \\
\hline $\mathrm{q}_{\mathrm{i}}$ & $1100-50 \mathrm{i}$ & tons of $\mathrm{CO}_{2}$ eq \\
\hline $\mathrm{u}_{\mathrm{i}}$ & $110-5 i$ & tons of $\mathrm{CO}_{2}$ eq \\
\hline$g_{i j k}$ & $500+100(-\mathrm{i}+\mathrm{k}+0.2 \mathrm{j})$ & tons of $\mathrm{CO}_{2} \_$eq \\
\hline $\mathrm{w}_{\mathrm{ijk}}$ & $85+5(0.2 j+k)$ & tons of $\mathrm{CO}_{2}$ eq \\
\hline $\mathrm{v}_{\mathrm{ijk}}$ & $120+5(0.2 j+k)$ & tons of $\mathrm{CO}_{2} \_$eq \\
\hline $\mathrm{f}_{\mathrm{i}}$ & $\begin{array}{ll}350,000-50,000 \mathrm{i}, & i=1, \ldots, 5 \\
150000 & i=6, \ldots, 10\end{array}$ & tons of $\mathrm{CO}_{2} \_$eq \\
\hline
\end{tabular}

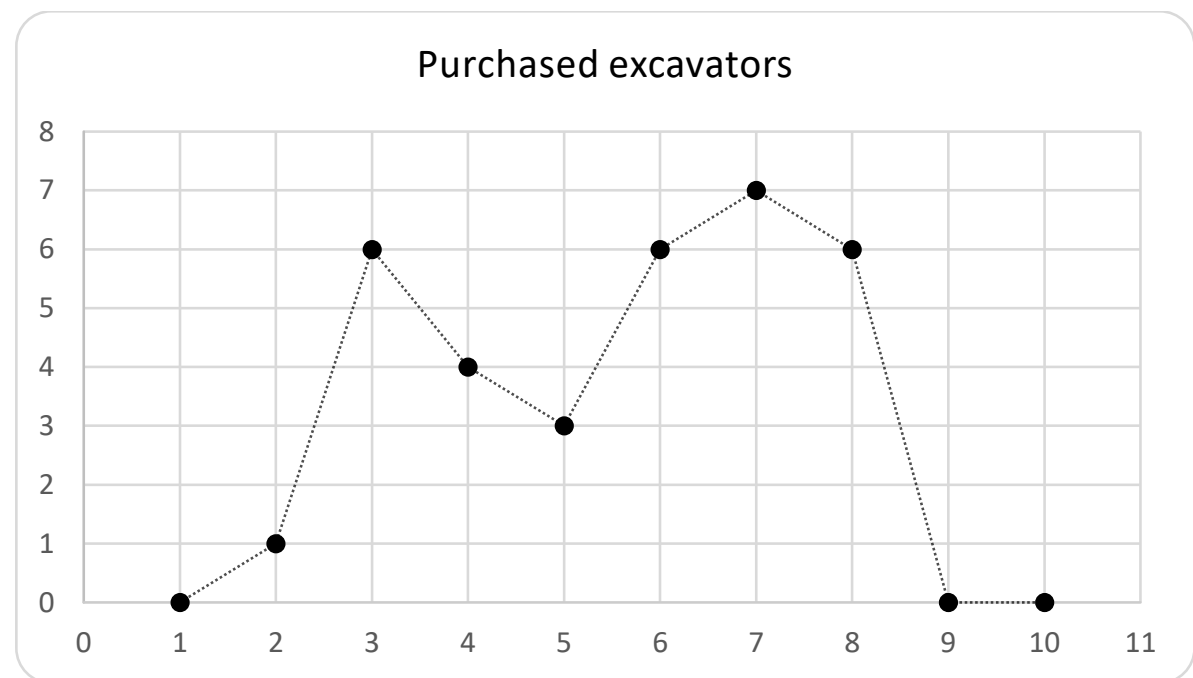

Figure 3: Number of brand new excavators purchased in each year 
Table 3. Non-zero values of decision variables in the excavator fleet case

\begin{tabular}{|c|c|c|c|c|}
\hline Period & $\begin{array}{c}\text { New purchase } \\
\text { (A) }\end{array}$ & $\begin{array}{c}\text { In service excavators } \\
(\mathrm{X})\end{array}$ & $\begin{array}{c}\text { In storage excavators } \\
(\mathbf{Y})\end{array}$ & $\begin{array}{l}\text { Salvaged excavators } \\
\text { (S) }\end{array}$ \\
\hline \multirow[t]{2}{*}{1} & \multirow[t]{2}{*}{$A_{1}=0$} & $\begin{array}{l}X_{100}=2, X_{110}=1 \\
X_{111}=1, X_{121}=1 \\
X_{122}=3, X_{132}=1 \\
X_{140}=2\end{array}$ & $\begin{array}{l}Y_{100}=1, Y_{111}=1 \\
Y_{121}=2\end{array}$ & $\begin{array}{l}\mathrm{S}_{142}=2, \mathrm{~S}_{163}=1 \\
\mathrm{~S}_{161}=1, \mathrm{~S}_{143}=1 \\
\mathrm{~S}_{133}=1\end{array}$ \\
\hline & & Total: 11 & Total: 4 & Total: 6 \\
\hline \multirow[t]{2}{*}{2} & \multirow[t]{2}{*}{$A_{2}=1$} & $\begin{array}{l}X_{200}=1, X_{210}=1 \\
X_{211}=2, X_{221}=2 \\
X_{222}=1, X_{231}=2 \\
X_{232}=1, X_{251}=2\end{array}$ & & $S_{233}=3, S_{243}=1$ \\
\hline & & Total: 12 & Total: 0 & Total: 4 \\
\hline \multirow[t]{2}{*}{3} & \multirow[t]{2}{*}{$A_{3}=6$} & $\begin{array}{l}X_{300}=6, X_{311}=1 \\
X_{321}=1, X_{322}=2 \\
X_{332}=1, X_{342}=1\end{array}$ & & $\begin{array}{l}S_{362}=2, S_{343}=1 \\
S_{342}=1, S_{333}=1 \\
S_{332}=1\end{array}$ \\
\hline & & Total: 12 & Total: 0 & Total: 6 \\
\hline \multirow[t]{2}{*}{4} & \multirow[t]{2}{*}{$\mathrm{A}_{4}=4$} & $\begin{array}{l}X_{400}=4, X_{411}=6 \\
X_{422}=1, X_{433}=2\end{array}$ & & $\begin{array}{l}S_{453}=1, S_{443}=1 \\
S_{432}=1\end{array}$ \\
\hline & & Total: 13 & Total: 0 & Total: 3 \\
\hline \multirow[t]{2}{*}{5} & \multirow[t]{2}{*}{$A_{5}=3$} & $\begin{array}{l}X_{500}=3, X_{511}=4 \\
X_{522}=6, X_{533}=1\end{array}$ & & $\mathrm{~S}_{544}=2$ \\
\hline & & Total: 14 & Total: 0 & Total: 2 \\
\hline \multirow[t]{2}{*}{6} & \multirow[t]{2}{*}{$A_{6}=6$} & $\begin{array}{l}X_{600}=6, X_{611}=3 \\
X_{622}=4, X_{633}=1\end{array}$ & & $S_{633}=5, S_{644}=1$ \\
\hline & & Total: 14 & Total: 0 & Total: 6 \\
\hline \multirow[t]{2}{*}{7} & \multirow[t]{2}{*}{$A_{7}=7$} & $\begin{array}{l}X_{700}=7, X_{711}=6 \\
X_{722}=1\end{array}$ & $Y_{722}=1$ & $\begin{array}{l}S_{733}=4, S_{744}=1 \\
S_{722}=1\end{array}$ \\
\hline & & Total: 14 & Total: 1 & Total: 6 \\
\hline \multirow[t]{2}{*}{8} & \multirow[t]{2}{*}{$A_{8}=6$} & $\begin{array}{l}X_{800}=6, X_{811}=6 \\
X_{822}=3\end{array}$ & $\begin{array}{l}Y_{811}=1, Y_{822}=3 \\
Y_{832}=1\end{array}$ & $S_{833}=1$ \\
\hline & & Total: 15 & Total: 5 & Total: 1 \\
\hline \multirow[t]{2}{*}{9} & \multirow[t]{2}{*}{$A_{9}=0$} & $\begin{array}{l}X_{911}=6, X_{921}=1 \\
X_{922}=6, X_{932}=3 \\
X_{942}=1\end{array}$ & $Y_{933}=3$ & \\
\hline & & Total: 17 & Total: 3 & Total: 0 \\
\hline \multirow[t]{2}{*}{10} & \multirow[t]{2}{*}{$\mathrm{A}_{10}=0$} & $\begin{array}{l}X_{1022}=6, X_{1032}=1 \\
X_{1033}=6, X_{1043}=6 \\
X_{1053}=1\end{array}$ & & \\
\hline & & Total: 20 & Total: 0 & Total: 4 \\
\hline
\end{tabular}




\subsection{Discussion}

Around $13.6 \%$ of the total optimum cost (i.e. $C \$ 3,265,360$ ) is the cost of environmental burden of the fleet, in terms of a trading carbon price. For this reason, we should not expect that the solutions are greatly influenced by the environmental parameters. We run the model with mere economic parameters, results of which are shown in Table. 4. The optimum objective value, representing the minimum total cost of the fleet, decreases to $C \$ 20,744,000$. It can be seen that in this scenario, minor changes have happened to the decision variables, mainly the mix of in-use, in-storage, and salvaged equipment (X, Y, and $\mathrm{S})$. Overall, the number of new purchases over the entire planning horizon has slightly increased, despite the general expectation that taking into account environmental impacts should suggest purchasing more new assets in comparison to the economic model. This is not surprising, because we have formulated GHG items other than O\&M emissions, like emissions associated with manufacturing a new equipment. Although the operating organization does not always pay for the carbon footprint of this stage of the equipment life cycle, when it comes to climate change and global warming, it is important to design a sustainable asset management that considers emissions from manufacturing and even the supply chain of the materials being converted into the final equipment. In fact, extraction and processing materials used for manufacturing many of the so called "low carbon" technologies (such as windmills, batteries of electric vehicles, solar panels, and biofuels), release a significant amount of carbon emissions.

Minor changes in the mix of in-use, in-storage, and salvaged equipment (X, Y, and S) variables obtained from the economic model is attributed to the fact that in a cap-and-trade market, emissions cost of a fleet is dwarf, comparing to its economic costs. Therefore, we expect that bigger carbon prices make a more significant adjustment in the decision variables. For example, a carbon price of $\mathrm{C} \$ 27$ leads to a total cost of $\mathrm{C} \$ 27,564,000$. Total values of $\mathrm{X}, \mathrm{Y}$, and $\mathrm{S}$ corresponding to this scenario are presented in Table. 5. As indicated, this price requires less salvaged assets (due to bigger decommissioning carbon footprints) and instead more in storage assets. 
Table 4. Non-zero values of decision variables in the economic replacement model

\begin{tabular}{|c|c|c|c|c|}
\hline Period & $\begin{array}{c}\text { New purchase } \\
\text { (A) }\end{array}$ & $\begin{array}{l}\text { In service excavators } \\
\qquad(\mathrm{X})\end{array}$ & $\begin{array}{c}\text { In storage excavators } \\
(\mathbf{Y})\end{array}$ & $\begin{array}{l}\text { Salvaged excavators } \\
\text { (S) }\end{array}$ \\
\hline 1 & $A_{1}=0$ & $\begin{array}{l}X_{100}=2, X_{110}=1 \\
X_{111}=1, X_{121}=1 \\
X_{122}=3, X_{132}=1 \\
X_{140}=2\end{array}$ & $\begin{array}{l}Y_{100}=1, Y_{111}=1 \\
Y_{121}=2\end{array}$ & $\begin{array}{l}\mathrm{S}_{163}=1, \mathrm{~S}_{161}=1 \\
\mathrm{~S}_{143}=1, \mathrm{~S}_{142}=2 \\
\mathrm{~S}_{133}=1\end{array}$ \\
\hline 2 & $A_{2}=1$ & $\begin{array}{l}X_{200}=1, X_{210}=1 \\
X_{211}=2, X_{221}=2 \\
X_{222}=1, X_{231}=2 \\
X_{232}=1, X_{251}=2\end{array}$ & & $S_{233}=3, S_{243}=1$ \\
\hline 3 & $A_{3}=6$ & $\begin{array}{l}X_{300}=6, X_{311}=1 \\
X_{321}=1, X_{322}=2 \\
X_{332}=2\end{array}$ & & $\begin{array}{l}S_{362}=2, S_{343}=1 \\
S_{342}=2, S_{333}=1\end{array}$ \\
\hline 4 & $\mathrm{~A}_{4}=4$ & $\begin{array}{l}X_{400}=4, X_{411}=6 \\
X_{422}=1, X_{432}=1 \\
X_{433}=1\end{array}$ & & $S_{443}=2, S_{433}=1$ \\
\hline 5 & $A_{5}=3$ & $\begin{array}{l}X_{500}=3, X_{511}=4 \\
X_{522}=6, X_{533}=1\end{array}$ & & $S_{544}=1, S_{543}=1$ \\
\hline 6 & $A_{6}=4$ & $\begin{array}{l}X_{600}=4, X_{611}=3 \\
X_{622}=4, X_{633}=4\end{array}$ & & $S_{633}=2, S_{644}=1$ \\
\hline 7 & $A_{7}=8$ & $\begin{array}{l}X_{700}=8, X_{711}=3 \\
X_{722}=3\end{array}$ & $Y_{711}=1$ & $S_{733}=4, S_{744}=4$ \\
\hline 8 & $A_{8}=6$ & $\begin{array}{l}X_{800}=6, X_{811}=8 \\
X_{822}=1\end{array}$ & $\begin{array}{l}Y_{821}=1, Y_{822}=2 \\
Y_{833}=2\end{array}$ & $S_{833}=1$ \\
\hline 9 & $A_{9}=0$ & $\begin{array}{l}X_{911}=6, X_{922}=8 \\
X_{931}=1, X_{932}=2\end{array}$ & $Y_{933}=1, Y_{943}=2$ & \\
\hline 10 & $A_{10}=0$ & $\begin{array}{l}X_{1022}=6, X_{1033}=8 \\
X_{1042}=1, X_{1043}=3 \\
X_{1053}=2\end{array}$ & & \\
\hline
\end{tabular}

Table 5. Total number of in-use, in-storage, and salvaged equipment (X, Y, and $\mathrm{S})$ with the carbon price $\mathrm{C} \$ 27$

\begin{tabular}{ccccc}
\hline Period & $(\mathbf{A})$ & $(\mathbf{X})$ & $(\mathbf{Y})$ & $(\mathbf{S})$ \\
\hline 1 & 1 & 12 & 1 & 9 \\
\hline 2 & 4 & 14 & 2 & 1 \\
\hline 3 & 5 & 16 & 1 & 4 \\
\hline 4 & 5 & 16 & 2 & 4 \\
\hline 5 & 5 & 16 & 3 & 4 \\
\hline 6 & 5 & 17 & 2 & 5 \\
\hline 7 & 5 & 18 & 2 & 4 \\
\hline 8 & 3 & 19 & 2 & 1 \\
\hline 9 & 2 & 20 & 2 & 1 \\
\hline 10 & 0 & 21 & 0 & 1 \\
\hline & & & &
\end{tabular}




\subsection{Conclusion}

This present chapter proposes a fleet replacement optimization model with both economic and environmental considerations. The optimization model, unlike previous asset planning models, allows assets to be in storage without deteriorating as in-use assets do. Other decision variables include the mix of in-use assets, the assets that should be salvaged, as well as the number of new assets, which should be added to the fleet. This model formulates the capacity of assets by which the technological improvement of new assets is considered. Both economic and environmental costs of the fleet are taken into consideration. Environmental burdens of the fleet are modelled by capturing the GHG emissions of manufacturing new assets, shipping them to the fleet location, O\&M process of inservice assets, holding in inventory assets, and decommission assets, under a cap to limit the total carbon footprint of the fleet. We also developed an automatic GHG calculator built on a timely database of Scope 1 (direct) and Scope 2 (indirect) emission factors. Possessing an integrated platform, the calculator allows asset managers to measure the total carbon footprint of their fleets, involving various activities such as manufacturing, stationary combustion, transportation, material usage, and electricity/heat consumption.

The optimization model was applied to a fleet of excavators. GHG emissions of the fleet were converted into a monetary value by use of carbon price in the Western Climate Initiative (WCI) market. To estimate the price of carbon in this market, an uncertainty analysis study was conducted, which predicts the most probable prices over the intended planning horizon of the optimization model. This prediction study is important in that it provides emitting organizations with a long-term and short-term forecast of price in a carbon market (covered by Chapter 5).

This monetary value of fleet's emissions, however, may not reflect the exact concern of environmental impacts, in a global warming point of view. From the result of the case study, we found out that considering the P10 carbon price in the WCI market (i.e. the price associated with $90 \%$ probability in the cumulative distribution function of carbon price) cannot change the fleet decisions, and so mitigate its emissions significantly, comparing to a mere economic decision model. This would become even more discouraging if we exclude GHG emissions for which, the fleet owner does not yet pay in a carbon market (e.g. emissions from manufacturing new equipment or outsourced decommissioning projects). As indicated, much greater prices (with very small probabilities based on the WCI market dynamics), would alter the decision variable and hence reduce the total emissions more considerably. 


\section{Acknowledgements}

This work was partially supported by Fiix Software and Ontario Centres of Excellence (OCE)'s Voucher for Innovation and Productivity (VIP) (No. 26114). 


\section{Improving Fleet Availability Analysis by Incorporating Complex Causal Factors}

The present chapter is based on the following paper:

Abdi, A., Taghipour, S. (2018). A Bayesian network approach to fleet availability analysis. International Journal of Operations \& Production Management. Under Review.

As an important aspect of fleet management, availability analysis requires modelling uncertainties associated with the two main elements; reliability and maintainability. This paper aims to improve prediction and uncertainty analysis of reliability (or failure rate), maintainability (or repair rate), and hence the availability of a fleet of assets, by focusing on common causal factors and rare events which might impact one or both failure and repair rates. To this aim, we propose a Bayesian network approach with learning and analytical features which allows fleet managers to not just predict the most likely availability of their fleet but analyse the impact of any observed shift in the influential factors, update prior beliefs about the predictions, and discover the root causes of troubling failure and repair rates as well. We applied the proposed model to a fleet of excavators.

Keywords: Fleet, Availability, Failure rate, Repair rate, Common causes, Bayesian networks.

\subsection{Introduction}

Forecasting and monitoring availability is a key aspect of maintenance and fleet management. In fact, availability assessment provides a direct measure for production capacity, as well as a criterion to decide on the required corrective actions [35]. However, assessment and optimization of a fleet unavailability accounting for real world uncertainties is a challenging task and without a rigorous risk analysis on failure and repair rates (as the two main indicators of availability), the decisions on acceptability of availability may not be reliable [36]. For decades, researchers have been developing methods for assessment of failure and repair times, including fault trees (FTs) and dynamic fault trees (DFTs) [37], artificial neural networks (ANNs) [38], Bayesian networks (BNs) [39], Monte-Carlo simulation (MCS) [40], fuzzy MCS [41], renewal processes [42], Markov chains [43], and geometric processes [44].

A common assumption behind these techniques is the consideration of constant failure and repair rate (CFRR) of the fleet assets. In reality, however, CFRR does not apply to industrial systems and 
assets, with the main failure mode of deterioration (Wilkins, 2002; and Saranga and Kumar, 2006). CFRR does not reflect the effect of preventive maintenance and managerial interventions on both the failure behaviour and repair time of assets. These interventions are often reflected in a number of complex causal factors that dynamically affect fleet's failure rate, repair rate, or both. We categorize these causal factors into three groups. First, there are external, often intangible factors such as organizational and human factors that can increase the failure rate of an operating asset/fleet [85]. For example, quality of operating staff ${ }^{4}$ may contribute to system failure. Second, there are such organizational factors, such as the quality of repair instruments and materials, that influence repair rate. They act as a common cause and impact two or more tasks of the repair process (such as diagnosis, procurement, remove and install, etc.), making them correlated. Third, there exist common causal factors that affect equipment failure rate and repair rate simultaneously. For instance, a harsh environmental condition not only increases the chance of failure in a fleet of assets, it also can delay the process of returning a failed asset to the working condition.

Moreover, fleet availability can be significantly negatively affected by extremely rare or previously unobserved risks. Examples of such events include an extreme cyber-attack, a major power outage, etc., that if occurred, can escalate failure rates and diminish repair rates.

Capturing these causal factors is incredibly important as they allow us to dynamically assess the reliability and maintainability of fleets by considering time-dependent failure and repair rates. These factors have not been examined in reliability, maintainability and availability analysis models. In this paper, we develop a hybrid Bayesian network $(\mathrm{BN})$ (with both discrete and continuous variables) to formulate a fully probabilistic availability analysis, focusing on the uncertainty of failure and repair rates. We model the causal factors that influence failure or repair rate as well as those that affect both failure and repair rates at the same time. The proposed model explicitly quantifies uncertainty in repair and failure rates of a fleet of assets and provides an appropriate method for modelling complex dependencies and factors affecting reliability, maintainability, or both, by considering influencing factors, either technical (such as working temperature, environment, quality, stress, etc.) or organizational (such as staff quality, management policies, etc.). To improve availability risk analysis, we will then extend the model to consider extremely rare and/or previously unobserved events, adopting an approach proposed by Constantinou et al. [86]. The aim of this research is to improve the analysis of operational availability, which is in fact the actual level of availability that a fleet's

\footnotetext{
${ }^{4}$ As an evidence example, Walia et al. (2010) reported that users of ophthalmic equipment, for example, cause almost one-third of failures.
} 
customers experience. It accounts for every downtime items, such as logistical delays, administrative downtime, etc.

Application of the model and its analytical features are evaluated using an excavator fleet example. Using this case study, in addition to the fundamental objective of the proposed model, i.e. prediction of fleet availability, we have demonstrated other features of the model including learning, scenario analysis, and diagnosis. The prediction accuracy of the proposed model is evaluated using a measure of prediction error.

\subsubsection{Reliability, maintainability, and availability}

This section presents an overview of three dependability attributes [87], i.e. reliability, maintainability, and availability, and discusses the published literature in each of these attributes.

\subsubsection{Reliability and failure rate}

As an aspect of availability estimation, reliability is a crucial step in equipment design and is defined as the degree to which the equipment is expected to perform its promised task with required accuracy [88]. Reliability at time $\mathrm{t}, \mathrm{R}(\mathrm{t})$, is calculated as the probability that the equipment survives until time t:

$$
R(t)=\int_{t}^{\infty} f(t) d t=1-F(t)
$$

where $F(t)$ is the distribution function of the system lifetime. Reliability analysis is closely connected with distribution of failure times (or life distribution), $\mathrm{f}(\mathrm{t})$, and failure rate (or hazard distribution), $\mathrm{h}(\mathrm{t})$ :

$$
R(t)=\frac{f(t)}{h(t)}
$$

The higher the failure rate, the larger the probability that the system will fail in a short time, whereas a low failure rate means that there is a small probability that the system will fail soon [89]. Many distributions have been used as life distribution of a system or component. One of the most common distributions is exponential distribution, with the density $f(t)=\lambda e^{-\lambda t}$. In this case, failure rate is constant: $\mathrm{h}(\mathrm{t})=\lambda$, and the mean time to failure (MTTF) is $1 / \lambda$. Other lifetime distributions that can be used to model reliability, include Weibull, Normal, Lognormal, Mixed Weibull, Gamma, Generalized Gamma, Logistic, Loglogistic, and Gumbel. An overview of many applicable lifetime distributions can be found in [90]. 
There are several factors that can affect the failure rate and time. These include component quality and poor selection of materials, overloading or stress, temperature, environment conditions, design deficiencies, inadequate maintenance, etc. [91].

\subsubsection{Maintainability and Repair rate}

Via a maintenance action such as replacement or part adjustment, a repairable system can be restored to operating condition after a failure [92]. There are three types of repair models, depending on the performance level to which the system can be restored: 1) perfect repair, under which the system is restored to an "as good as new" condition, 2) minimal repair, under which the system is recovered to an "as bad as old" condition (the same as it was immediately before its failure), and 3) imperfect repair, under which the system is restored to somewhere between as good as new and as bad as old.

Maintainability can be defined as the chance that a repairable system/component can be repaired in a specific environment within a defined schedule through normal maintenance [93]. The time to restore a system/component is the sum of the duration of some stages in the renewal chain, such as diagnosis, procurement, repair, inspection, and return. This can be affected by administrative delays (such as holidays). Often these sub-processes require some time to be completed, which is not zero. The existing queuing effects makes these stages dependent and adds to the complexity of maintainability estimation. This dependency should be modelled to assess the likelihood distribution of repair time or total down time.

For renewal processes with several parallel and interlinked stages, the total repair duration (TRD) can be calculated using techniques of schedule network analysis [94] from the project management discipline, notably program evaluation and review technique (PERT) [95] and critical path method (CPM) [96]. In fairly simple networks, critical path would be the longest path through the renewal process. If there are no parallel activities in the renewal process, TRD can be expressed as follows:

$$
\mathrm{TRD}=\sum \mathrm{D}_{\mathrm{i}}, \mathrm{D}_{\mathrm{i}} \geq 0
$$

where $D_{i}$ is the duration of the individual activity $i$ in the repair/renewal process.

\subsubsection{Availability}

Availability is calculated as the probability of the system being working properly at a given time [97]. Availability is a function of reliability and maintainability-that is, the system is unavailable if it is failed and waiting for repair (or renewal) or undergoing a repair action. Three different availability terms have therefore been defined to calculate availability [98]: Inherent Availability (IA); Achieved 
Availability (AA); and Operational Availability (OA). IA, used by maintenance personnel, does not consider preventive maintenance, and administrative and supply times, and is calculated as follows:

$$
\mathrm{IA}=\frac{\mathrm{MTBF}}{\mathrm{MTBF}+\mathrm{MTTR}},
$$

where MTBF is the mean time between failures and MTTR represents the mean time to repair. This gets simplified for a system as IA = MTTF/(MTTF + MTTR), where MTTF is mean time to failure. AA, used by the maintenance department, considers both corrective and preventive maintenance, but still excludes supply and administrative delays, and can be calculated as follows:

$$
\mathrm{AA}=\frac{\mathrm{MTBM}}{\mathrm{MTBM}+\mathrm{MMDT}},
$$

where MTBM is the mean time between corrective and preventive maintenance, and MMDT is the mean maintenance downtime. OA, used by the user, is computed as follows:

$$
\mathrm{OA}=\frac{\mathrm{MTBF}}{\mathrm{MTBF}+\mathrm{MTTR}+\mathrm{MLDT}},
$$

where MLDT is the mean logistical delay time. The quantities MTBF, MTTR, MTBM, and MMDT can be defined as follows (the main concepts, theory, and models of availability can be found in [99]):

MTBF Uptime / number of system failures

MTBM Uptime / (number of system failures + number of system downing preventive maintenance $\left.(\mathrm{PM})^{*}\right)$

MTTR Corrective maintenance (CM) downtime / number of system failures

MMDT (CM downtime + PM downtime) / (number of system failures + number of system downing PMs)

\footnotetext{
*System Downing PMs are PMs that cause the system to go down or require a shutdown of the system
}

\subsection{2. $\quad$ Previous studies in reliability, maintainability, and availability modeling}

Classic reliability analysis models mostly rely on parametric and non-parametric statistical techniques of time to failure data and their related metrics [100]. Such techniques assume lifetime distributions follow a coherent and statistical model, which are expected to precisely analyse the behaviour of a system over its lifetime. These statistical models, however, may not be rigorous for assessment of today's complex circumstances. Therefore, more flexible methods have been developed for reliability modelling over the past decade. Among the most distinguished techniques are fault trees (FTs) and dynamic fault trees (DFTs), artificial neural networks (ANNs), Bayesian networks (BNs), Monte- 
Carlo simulation (MCS), fuzzy MCS, renewal processes, Markov chains, and geometric processes. Kutyłowska [38] proposed an ANN model to predict failure rates of distribution pipes and house connections in Poland. This model is intended to be used by a water utility to determine the frequency of failure and therefore schedule the renewal of deteriorated pipe. A BN algorithm was proposed by [39] to model lifetime distributions and analyse reliability of complex systems. The algorithm extends FTs by considering failure times of the FTs' constructs, as specific functions of the related failure times of input components. Using their method, different configuration of static and dynamic gates with general lifetime distributions can be solved. Sriramdas et al. [101] proposed a reliability allocation approach using fuzzy numbers. They assigned fuzzy linguistic terms to the allocation factors, such as complexity, criticality, and cost. Khalafi et al. [41] proposed a fuzzy MCS method to analyse reliability of observability and loss of data expectation in lines of a power system considering data uncertainty in failure and repair times. Alam et al. [102] used point estimate method (PEM) to capture data uncertainty in modelling failure rate, repair time, and load. In this study, they have considered only normal distributions. Brissaud [103] proposed a failure rate estimation model for safety systems using field feedback with confidence intervals. They used data from two categories of failures: (1) detected failures (or online failures diagnosed by automatic tests); and (2) undetected failures (revealed by proof tests).

Regarding previous research on maintainability analysis, Jian et al. [93] presented a theory and connotation for maintainability of a product. Taking into account both internal and external attributes, they have developed evaluation indicators for maintainability of the product, based on its life cycle. A weight factor was also calculated for each indicator using fuzzy AHP and expert judgment. Considering backup mechanism of repairable systems with random repair times, Levitin et al. [104] presented an algorithm to model mission reliability of single-component system. They also examined the impact of repair efficiency on mission indices of reliability. Kumar and Rath [105] developed a maintainability prediction models using functional link artificial neural network, genetic algorithm, particle swarm optimization, and clonal selection algorithm. They showed that the combination of functional link artificial neural network and genetic algorithm yields the most effective results. Barabadi et al. [106] used software (Relex) and statistical models to model renewal time. In this model environmental and operational factors have been taken into consideration to improve maintainability analysis.

Different tools and techniques have been employed to assess the availability of a system. Using a Markov approach, Angus [107] developed a closed form solution to analyse MTBF and steady state 
availability of a k-out-of-n with independent and identically distributed components, assuming a constant rate for failure and repair. Monte Carlo Simulation (MCS) was used by Sadaghiani et al. [108] to analyse the availability of a system consisting of identical components, with exponential time to failure and repair. Fault trees and a Markov based method were applied in an algorithm to calculate steady state availability of the system. To analyse the availability of a repairable system, Neil and Marquez [36] presented a BN in which distributions of corrective maintenance, preventive maintenance, and logistics delay times have been modelled and integrated with the distribution of failure time. In most of the previous studies, however, failure time and repair time are assumed to be independent.

More recently, Penttinen et al. (2019) introduced an open modelling approach for reliability and availability analysis. It allows the analyst to integrate several risks assessment methods to provide flexibility and relax more simplification assumptions that individual methods make. In their case study, the showed the feasibility of this approach by combining the Fault Tree, Markov and Petri Net models. Smit et al. (2019) addressed the long-term availability of water treatment plants (WTPs), using a two-level approach: a component level using a conditioned-based or failure-based technique; and a system level using the block diagram of the system's components and the results of the component level availability assessment.

\subsection{Development of the model}

This section explains a new BN model for fleet reliability, maintainability and availability analysis. First, a brief introduction of $\mathrm{BN}$ and its application to modelling common causal factors is presented. The framework of the proposed model is then described.

\subsubsection{Bayesian networks (BNs): A brief introduction}

As an inference technique, BNs are models for explicit uncertainty analysis, parameter and structural learning, combining different knowledge domains, and quick responses [111]. With a logical and mathematical structure, they are applied to the situations with prior experience/information and resultant data, and can be developed on small-scale or incomplete datasets [112]. BNs have been recently applied to construct promising models in forecasting stock market indices and prices [113115], urban rail passenger flows [116], solar radiation [117], electricity demand [118], project cost [119], and so forth. 
BNs contain several nodes, as the uncertain variables, and arrows, indicating the cause-and-effect relationship between the variables. The nodes might represent initial variables without an inward arrow (called parent nodes), or a dependent variable with arrows directed towards them (called child nodes). To quantify a node, a node probability table (NPT) is assigned to it which determines its possible states and probabilities. A BN containing the nodes $\mathrm{X}_{1}, \ldots, \mathrm{X}_{\mathrm{n}}$ must be structured in such a way that their connecting arrows create a directed acyclic graph (DAG). A DAG cannot have the path $X_{1} \rightarrow \cdots \rightarrow X_{n}$ so that $X_{1}=X_{n}$. If the node $\mathrm{X}$ is dependent on its parent nodes, $Y_{1}, \ldots, Y_{n}$, its conditional NPT would be $\mathrm{P}\left(\mathrm{X} \mid \mathrm{Y}_{1}, \ldots, \mathrm{Y}_{\mathrm{n}}\right)$. This NPT would be curtailed to the prior probability $\mathrm{P}(\mathrm{X})$, if the node $\mathrm{X}$ has no parents. Equipped with chain rule, BNs can describe the joint distribution, $\mathrm{P}\left(\mathrm{X}_{1}, \ldots, \mathrm{X}_{\mathrm{n}}\right)$, in a compact configuration as follows [120]: $\mathrm{P}\left(\mathrm{X}_{1}, \ldots, \mathrm{X}_{\mathrm{n}}\right)=$ $\prod_{i} P\left(X_{i} \mid X_{1}, \ldots, X_{n}\right)$.

Figure 4 is a naïve Bayes model that can be used to describe Bayes rule in a reliability analysis context. Variables $\mathrm{F}_{1}, \mathrm{~F}_{2} \ldots, \mathrm{F}_{\mathrm{n}}$ are failure times of $\mathrm{n}$ components, and variable $\mathrm{C}$ represents a 'common cause', such as shared 'quality', that affects $F_{i}$. Starting with a prior probability for the cause, $\mathrm{P}(\mathrm{C})$, the likelihood for failure times conditional on the cause, $\mathrm{P}(\mathrm{P} \mid \mathrm{C})$, is calculated from a cause-to-effect inference or forward propagation:

$$
P(F \mid C)=\frac{P(C \mid F) P(F)}{P(C)}
$$

This rule provides an effect-to-cause or backward propagation, which allows the causation from failure times to its cause to be captured. Thus, evidence on reliability can be used to revise our belief about the actual level of quality, that is $\mathrm{P}(\mathrm{C} \mid \mathrm{F})$, which can be calculated by multiplying the prior probability of the cause, $\mathrm{P}(\mathrm{C})$, by the likelihood $\mathrm{P}(\mathrm{F} \mid \mathrm{C})$, and normalizing the results by dividing by the constant $\mathrm{P}(\mathrm{F})$ :

$$
\mathrm{P}(\mathrm{C} / \mathrm{F})=\frac{\mathrm{P}(\mathrm{F} / \mathrm{C}) \mathrm{P}(\mathrm{C})}{\mathrm{P}(\mathrm{F})} .
$$

Thus, this updated prediction for quality can be used to predict the failure times of other components, $\mathrm{F}_{\mathrm{j}}$ by employing Eq. (26). 


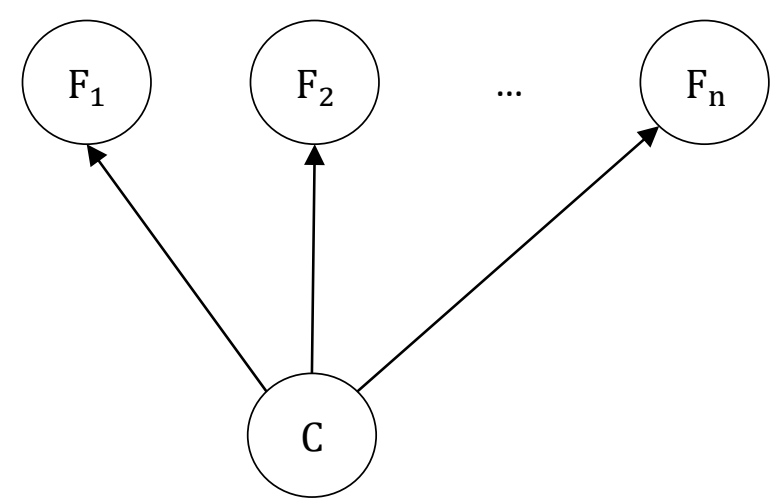

Figure 4: A Naïve Bayesian network to model correlated lifetime distributions of $\mathrm{n}$ components $\left(\mathrm{F}_{\mathrm{i}}\right)$, with a shared common cause $(\mathrm{C})$

The purpose of modelling common causes is to consider following risks: (1) organizational issues, e.g. people quality, which can affect failure and repair time uncertainty. Expert elicitation can be employed to come up with prior estimation on these complex or poorly understood factors; and (2) Other influential factors like available technology, materials, environmental conditions, etc., which if occur in a non-normal situation, can lead to higher failure rates (or lower repair rates). This mechanism allows us to model dependencies in system/component reliability and maintainability.

Several computer tools have been developed to build and run BN models with numerous variables. We have used AgenaRisk software [121] to run the designed BN models in this dissertation. A comprehensive list and review of BN tools can be found in [122].

\subsubsection{Model structure}

Figure 5 represents the conceptual framework of the proposed model. We develop a probabilistic model in which uncertainty sources of failure/repair rate are captured. To begin with, common causes to failure rate $\left(C_{f_{i}}, i=1, \ldots, l\right)$, repair activities $\left(C_{r_{j}}, j=1, \ldots, n\right)$, and that of both failure and repair rates $\left(\mathrm{C}_{\mathrm{f}_{\mathrm{k}}}, \mathrm{k}=1, \ldots, \mathrm{m}\right)$ are identified. As mentioned earlier, among examples of these common causes are temperature, environment, component quality, staff quality, etc., which can be either a quantitative variable (e.g. temperature) or a qualitative factor (e.g. staff quality). The common causes can be identified from published literature, brainstorming sessions and conducting interviews with experts. A "ranked" variable with linguistic terms- such as Low, Medium, and High- is assigned to the qualitative causes to represent their uncertainty. In this paper, the systematic approach in determining the probabilities of Bayesian network, proposed by Chin et al. [123] is used to generate prior probabilities of common causes (see Appendix C). To capture the uncertainty of quantitative 
causes, a relevant probabilistic distribution can be calculated based on the technical characteristics of the related variable.

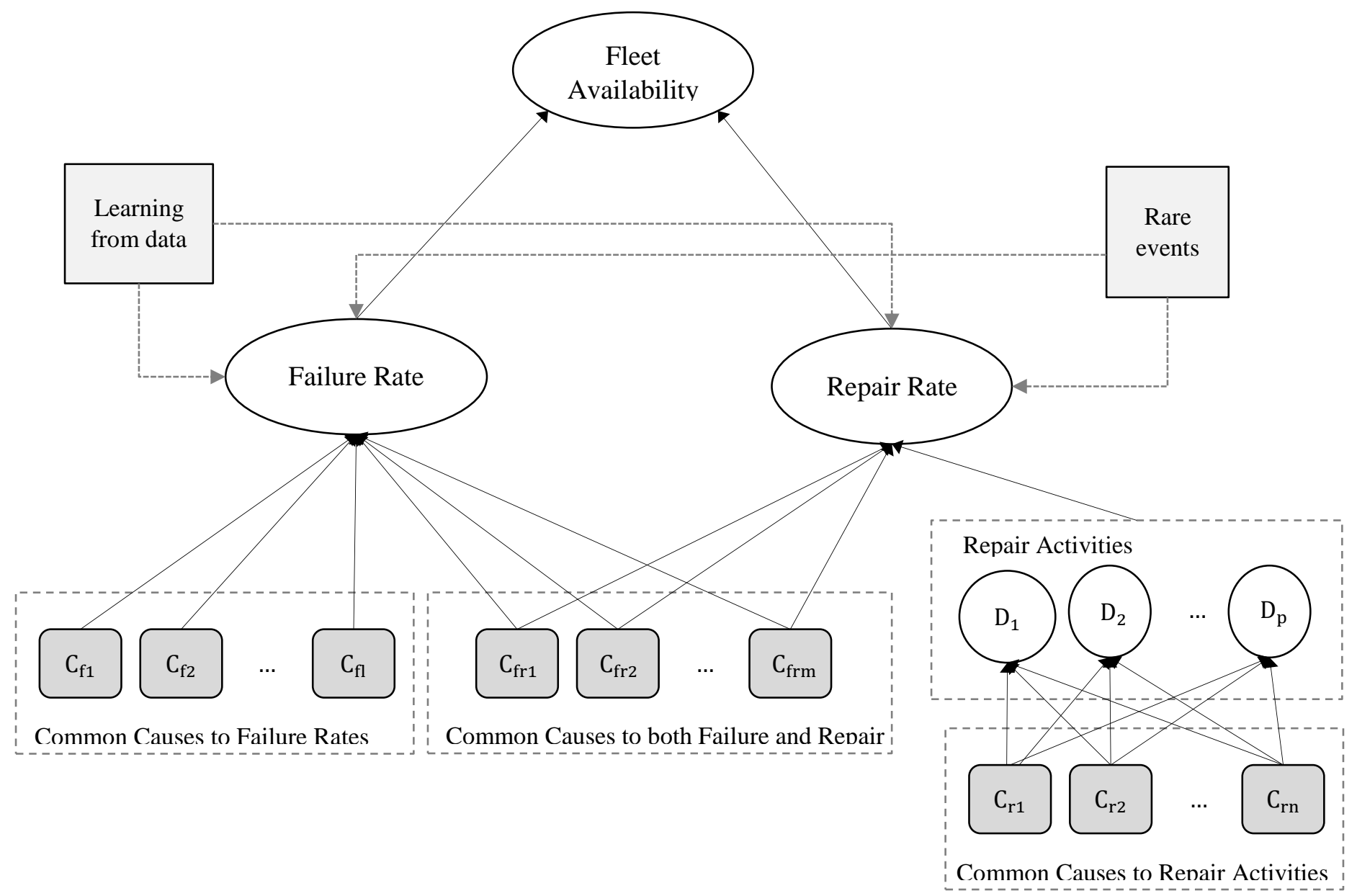

Figure 5: A schematic of proposed model to analyze reliability, maintainability, and availability of a single component

A prior distribution will be assigned to the node Failure Rate conditional on different states of its common causes. A prior can be estimated using data or subjective judgment if there is no historical information on failure records of the system. A prior distribution will also be assigned to the duration of each repair task $\left(D_{1}, D_{2}, \ldots, D_{p}\right)$. If data from previous repair projects is available, the first option would be fitting a theoretical probability distribution to the data and verify its statistical goodness of fit [124]. Contrary to classical frequentist methods which heavily rely on the distribution type and specific practice to elicit these distributions, Bayesian networks are agnostic with regard to the input data and prior distributions. This allows to handle the situations where there is no historical data but a plenty of expert judgment. 
Triangular, Normal, Lognormal, Uniform, Weibull, Pearson, and Beta, are common distributions that are usually assigned to duration and cost items in order to perform a quantitative risk analysis [125]. When there is no data to fit to the desired distribution, he common practice is to apply a threepoint estimate [126] and elicit minimum, most likely, and maximum values to calculate time/cost distributions. We use a continuous triangle distribution throughout this dissertation to capture the uncertainty of the quantitative variables, if we aim to conduct a probabilistic risk analysis. Triangle distribution is easy to derive from expert judgment, can model asymmetrical situations and is bounded within determined limits $[127,128]$. The probability density function (PDF) of this distribution is as follows:

$$
f(x, a, b, c)=\left\{\begin{array}{ll}
\frac{2(x-a)}{(b-a)(c-a)} & \text { for } a \leq x \leq c \\
\frac{2(b-x)}{(b-a)(c-a)} & \text { for } c \leq x \leq b
\end{array} \quad a \leq x \leq c, a<b<c .\right.
$$

Triangle distribution has three parameters: a, b, and c, which represent lower, most-likely, and upper values of the variable $\mathrm{x}$, respectively. Thus, the probability of any values outside the lower and upper bounds is zero and the density increases linearly from a to b and then falls linearly from $\mathrm{b}$ to $\mathrm{c}$. The mean and variance of this distribution are formulated as follows [119]:

$$
\begin{aligned}
& \mu=\frac{a+b+c}{3} \\
& \sigma^{2}=\frac{a^{2}+b^{2}+c^{2}-a b-a c-b c}{18}
\end{aligned}
$$

One could create an "expanded" triangle [129] to eliminate over optimism as well as known biases. The procedure is to use the elicited values of a and $\mathrm{c}$ to constrain 90 percent of the distribution and then calculate the new endpoints based upon the location of most-likely value (see Figure 6). The elicited numbers should be set as 0.05, 0.50, and 0.95-quantiles and the following approximate mean and variance need to be computed by use of Pearson-Tukey procedure proposed by [130].

$$
\begin{aligned}
& \hat{\mu}=0.63 \mathrm{q}_{0.5}+0.185\left(\mathrm{q}_{0.05}+\mathrm{q}_{0.95}\right) . \\
& \widehat{\sigma}^{2}=0.63\left(\mathrm{q}_{0.5}-\hat{\mu}\right)^{2}+0.185\left[\left(\mathrm{q}_{0.05}-\hat{\mu}\right)^{2}+\left(\mathrm{q}_{0.95}-\hat{\mu}\right)^{2}\right],
\end{aligned}
$$

where $\mathrm{q}_{0.05}, \mathrm{q}_{0.5}$, and $\mathrm{q}_{0.95}$ represent $0.05,0.50$, and 0.95-quantiles, respectively. Now a system including Eqs. (28), (29) and any one of the following nonlinear integral equations should be solved: 


$$
\begin{aligned}
& \int_{a}^{q_{0.05}} f(x, a, b, c) d x=0.05 . \\
& \int_{a}^{q_{0.50}} f(x, a, b, c) d x=0.5 . \\
& \int_{a}^{q_{0.95}} f(x, a, b, c) d x=0.95 .
\end{aligned}
$$

Due to the lack of a closed form solution, numerical root-finding methods, e.g. the LevenbergMarquardt algorithm [131], can be used to solve the system.

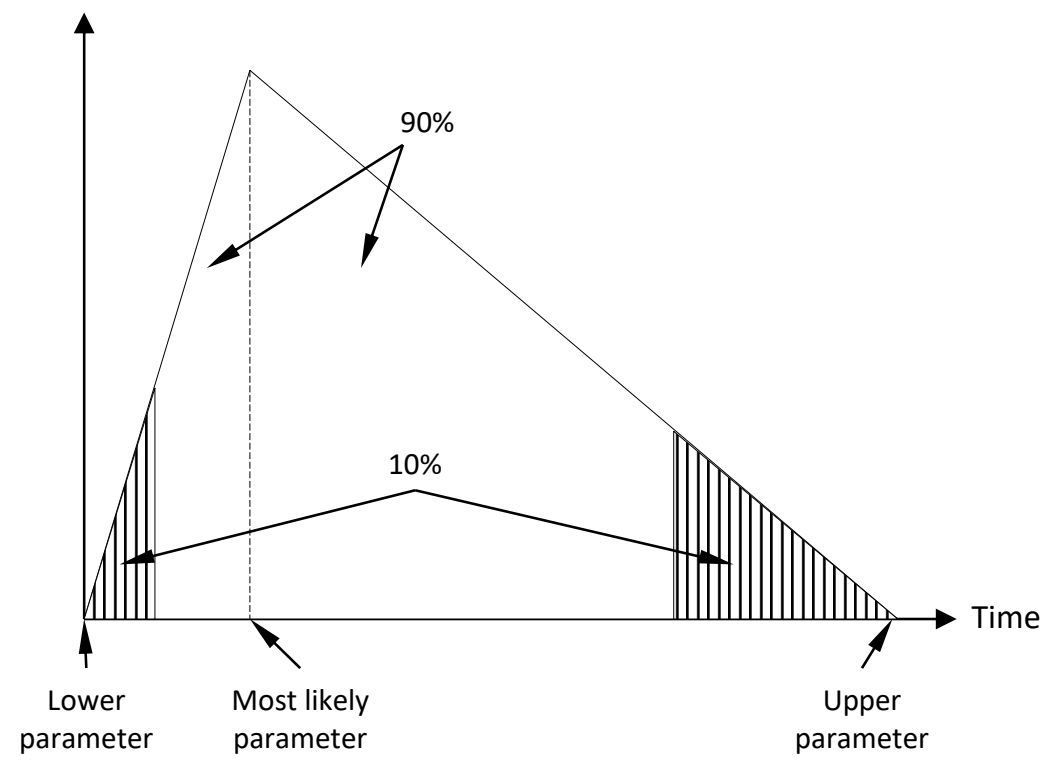

Figure 6: Expanded PDF of triangle distribution to handle the uncertainty of repair times; the 10 percent of the probability in the tails of the distribution is not equally distributed. This skewness will be calculated based on the location of the most-likely value with respect to the initial upper and lower endpoints. Adopted from [129].

We can now simulate repair rate of the equipment by integrating duration distribution of repair tasks, using the fact that Repair rate $=1 /$ (total MTTR). Assuming that the repair tasks happen in a serial order, this can be simplified as follows:

$$
\text { Repair Rate }=\frac{1}{\text { total MTTR }}=\frac{1}{\mathrm{MTTR}_{1}+\cdots+\mathrm{MTTR}_{\mathrm{p}}} \text {. }
$$

\subsubsection{Rare event}

To predict average failure and repair rates of a fleet more accurately, we incorporate the negative impact of extremely rare or previously unobserved risks. Failure and repair rates can be dramatically affected by rare events, such as a major power outage. So far in the modelling process, the statistical outcomes to capture uncertainty of failure and repair rates are already influenced by the common causes. In order to incorporate the effect of highly rare events, a variable associated with this event should be added to the model in such a way that the initial distributions of failure/repair rates are 
preserved, as long as this rare event remains unobserved [86]. In this regard, an expert elicitation method has recently been proposed by Constantinou et al. (2016). As depicted in the very simple BN model illustrated in Figure 7, we have already assigned a distribution-either from data or expert- to a failure rate $(\mathrm{F})$ given a known common cause $(\mathrm{C})$. In this model, the failure rate is expressed as a function of various states of $C$. This is to say $P\left(C_{s}\right)=c_{s}$ is known for each $s=1, \ldots, S$ and $f\left(F \mid C_{s}\right)$ is a known distribution for each $\mathrm{s}=1, \ldots, \mathrm{S}$.

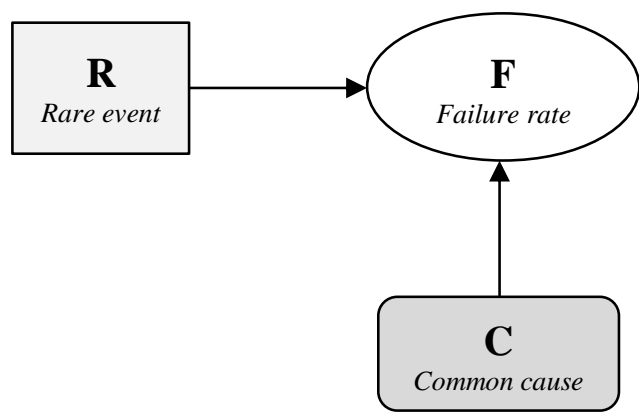

Figure 7: Adding a rare event variable $(\mathrm{R})$ into $\mathrm{BN}$ model in modelling of failure rate $(\mathrm{F})$

Let the expected value $\mathrm{E}\left(\mathrm{F} \mid \mathrm{C}_{\mathrm{s}}\right)=\varphi_{\mathrm{s}}$ for each $\mathrm{s}=1, \ldots, \mathrm{S}$. Before adding the rare event variable $(\mathrm{R})$, the expected value of $\mathrm{F}$ is:

$$
\mathrm{E}(\mathrm{F})=\sum_{\mathrm{s}=1}^{\mathrm{S}} \mathrm{E}\left(\mathrm{F} \mid \mathrm{C}_{\mathrm{s}}\right) \mathrm{P}\left(\mathrm{C}_{\mathrm{s}}\right)=\sum_{\mathrm{s}=1}^{\mathrm{n}} \varphi_{\mathrm{s}} \mathrm{c}_{\mathrm{s}}
$$

Now, consider the new variable, $\mathrm{R}$, with $\mathrm{Q}$ states $\mathrm{R}_{1}, \ldots, \mathrm{R}_{\mathrm{Q}}$. We assume the expert provides the prior probabilities for $R$, i.e. $P\left(R_{q} \mid C_{s}\right)=p_{s q}$ for each $s=1, \ldots, S$ and for each $q=1, \ldots, Q$. If $C$ and $\mathrm{R}$ are not linked, then instead of $\mathrm{S} \times \mathrm{Q}$ priors, only $\mathrm{Q}$ priors is needed: $\mathrm{P}\left(\mathrm{R}_{\mathrm{q}}\right)=\mathrm{p}_{\mathrm{q}}$ for each $\mathrm{q}=$ $1, \ldots, \mathrm{Q}$. The expert' challenge is to complete the node probability table for $\mathrm{F}$, so that all conditional expected values of $\mathrm{F}$ given $\mathrm{C}$ in the original model as well as the marginal expectation remain unchanged. More precisely, we desire:

$$
\widehat{\mathrm{E}}\left(\mathrm{F} \mid \mathrm{C}_{\mathrm{s}}\right)=\mathrm{E}\left(\mathrm{F} \mid \mathrm{C}_{\mathrm{s}}\right)=\varphi_{\mathrm{s}} \text { for each } \mathrm{s}=1, \ldots, \mathrm{S},
$$

where $\widehat{\mathrm{E}}\left(F \mid C_{S}\right)$ shows expected value of $f\left(F \mid C_{S}\right)$ in the $\mathrm{BN}$ model with a rare event node. That is to say, this new variable, when it is at its prior state (i.e. as long as it is unobserved), should not affect the predicted outcome of $\mathrm{F}$. This is because this outcome has already been influenced by the rare event; that is, just because our dataset or expert elicitation does not capture this rare event, it does not imply that the outcome of F should not be dependent on it. Of course, when you observe a state for the rare event, it should change $\mathrm{F}$ depending on how we have defined the conditional probabilities. If one can formulate Eq. (35), it can be concluded from Eq. (34) that: 


$$
\widehat{\mathrm{E}}(\mathrm{F})=\mathrm{E}(\mathrm{F}) .
$$

Eq. (35) is ample to prove that the unconditional expected value of $\mathrm{F}$ is remained unchanged in the BN model containing the rare event. In this model, the general form of the NPT for F can be written as a function $\left(\mathrm{f}_{\mathrm{sq}}\right)$, with expected value $\varphi_{\mathrm{sq}}, \mathrm{s}=1, \ldots, \mathrm{S} ; \mathrm{q}=1, \ldots, \mathrm{Q}$, as expressed in the following equation, and also shown in Table 6:

$$
\mathrm{E}\left(\mathrm{f}_{\mathrm{sq}}\right)=\widehat{\mathrm{E}}\left(\mathrm{F} \mid \mathrm{C}_{\mathrm{s}}, \mathrm{R}_{\mathrm{q}}\right)=\varphi_{\mathrm{sq}}, \mathrm{s}=1, \ldots, \mathrm{S} ; \mathrm{q}=1, \ldots, \mathrm{Q} .
$$

Table 6. The NPT for F in the BN model with rare event $\mathrm{R}$

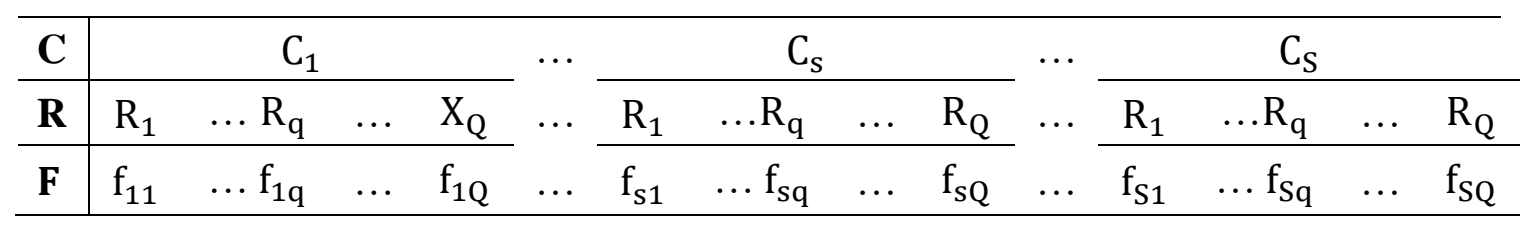

Because $\mathrm{R}_{\mathrm{q}}$ is dependent on $\mathrm{C}_{\mathrm{s}}$, marginalization can be used to calculate:

$$
\widehat{\mathrm{E}}\left(\mathrm{F} \mid \mathrm{C}_{\mathrm{s}}\right)=\sum_{\mathrm{q}=1}^{\mathrm{Q}} \mathrm{E}\left(\mathrm{F} \mid \mathrm{C}_{\mathrm{s}}, \mathrm{R}_{\mathrm{q}}\right) \mathrm{P}\left(\mathrm{R}_{\mathrm{q}} \mid \mathrm{C}_{\mathrm{s}}\right)=\sum_{\mathrm{q}=1}^{\mathrm{Q}} \varphi_{\mathrm{sq}} \mathrm{p}_{\mathrm{sq}} \cdot
$$

Thus, from equations (35) and (38) we desire:

$$
\sum_{\mathrm{q}=1}^{\mathrm{Q}} \varphi_{\mathrm{sq}} \mathrm{p}_{\mathrm{sq}}=\varphi_{\mathrm{s}}, \mathrm{s}=1, \ldots, \mathrm{S} .
$$

Therefore, Eq. (39) includes the required constraints related to the expert judgments for $\varphi_{\text {sq. }}$. There would be a specific solution, if the user can only provide $Q-1$ of the required $Q$ values $\varphi_{11}, \varphi_{12}, \ldots, \varphi_{1 \mathrm{Q}-1}, \varphi_{1 \mathrm{Q}}$. Applying Eq. (39), we can find the missing values. Assuming $\varphi_{\mathrm{SQ}}$ is the missing value, it can be seen from Eq. (39) that $\varphi_{\mathrm{s}}=\sum_{\mathrm{q}=1}^{\mathrm{Q}} \varphi_{\mathrm{sq}} \mathrm{p}_{\mathrm{sq}}$, therefore, $\varphi_{\mathrm{s}}=\left(\sum_{\mathrm{q}=1}^{\mathrm{Q}-1} \varphi_{\mathrm{sq}} \mathrm{p}_{\mathrm{sq}}\right)+$ $\varphi_{\mathrm{sQ}} \mathrm{p}_{\mathrm{sQ}}$. As a result:

$$
\varphi_{\mathrm{sQ}}=\frac{\varphi_{\mathrm{s}}-\left(\sum_{\mathrm{q}=1}^{\mathrm{Q}-1} \varphi_{\mathrm{sq}} \mathrm{p}_{\mathrm{sq}}\right)}{\mathrm{p}_{\mathrm{sQ}}}, \mathrm{s}=1, \ldots, \mathrm{S} .
$$

Thus, Eq. (40) can be employed to calculate the missing NPT values needed to keep the expected values of $\mathrm{F}$ conditional on $\mathrm{C}$ in the initial model [86].

\subsubsection{Learning}

This section covers the learning feature of our Bayesian model. This specific feature is important in cases where sufficient historical information on the desired failure and repair rates is not available, or where we would like to continuously update the estimations whenever a new evidence on 
failure/repair time is available. For instance, consider the failure rate $(\mathrm{F})$ of a component/asset which has been newly designed and manufactured, and hence historical data is not captured. However, it is known that failure times follow an exponential distribution with rate $\mathrm{F}$ (and mean $\mathrm{F}^{-1}$ ). The objective is to use inter-failure times to estimate the posterior distribution of failure rate. Thus, if $\mathrm{Z}$ independent failures were observed with an underlying exponential distribution (see Figure 8):

$$
\{\text { Evidence } \zeta\}_{\zeta=1}^{Z} \sim \exp (\mathrm{F})
$$

Using backward propagation (or effect to cause inference) in this structure, the model infers $\mathrm{F}$ and updates the prior estimation of failure rate (and therefore lifetime distribution) upon the observance of a failure:

$$
\mathrm{f}(\mathrm{F} \mid \text { Evidence } \zeta)=\frac{\mathrm{P}(\mathrm{F}) \cdot \mathrm{P}(\text { Evidence } \zeta \mid \mathrm{F})}{\int \mathrm{P}(\mathrm{F}) \cdot \mathrm{P}(\text { Evidence } \zeta \mid \mathrm{F}) \mathrm{dF}}, \zeta=1, \ldots, \mathrm{Z} \text {. }
$$

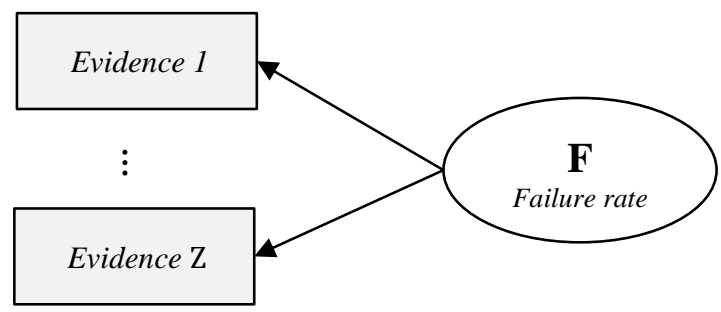

Figure 8: Parameter learning structure for failure rate based on $\mathrm{Z}$ real evidences

Having modelled the failure and repair rates, we can now formulate any of availability types (IA, AA, and OA), presented in Section 3.1.1.3, in the "Fleet Availability" variable of Figure 5, as a result node. This node will also represent the uncertainty of the fleet availability.

\subsection{Application}

In this section, we illustrate the applicability of the proposed model for availability analysis of a fleet of excavators. We use hypothetical data to illustrate the model features and demonstrate how the prediction performance of the model can be measured. We specifically develop the model to assess the availability of a proportion of the fleet that are less than two years old, which includes 7 excavators. This would remove the effect of age variable on the availability analysis. However, the same methodology can be applied to estimate the availability of assets with other range of age, and therefore, the fleet manager could have an estimation of the availability of the whole fleet in average.

The graphical representation of the model and its nodes is provided by Figure 9. To begin with, 'Environmental Harshness' is a causal factor affecting the failure rate of assets. Comparing with the medium levels of physical environment, high or low level of environmental conditions, including 
temperature, humidity and moisture, dust, etc., would obviously impact assets' reliability and their failure times [132]. 'Staff Quality' is the other cause attributed to failure times, as inappropriate use of asset, and operators' performance/characteristics are effectual in systems reliability. It has been now decades since researchers started modelling such complex factors [133,134], and yet, it is an imperative criterion to model reliability and maintainability [135]. On the other hand, 'Experience' is considered as a common cause to repair activities. We assign a Likert scale with three states 'Low', 'Medium', and 'High' to these common causes. We decide 'Asset Management Maturity' is the common cause that affects both failure and repair rates. This factor refers to the extent to which the company has well defined, documented, and used availability management procedures as standards of operations and maintenance. This reflects the maturity of the company in management practices related to service availability, including risk management. We define three levels for asset management maturity which signify the following characteristics:

- Level 1; Ad-hoc: this level reflects a reactive company that has operations with almost chaotic manners. In the case of crisis, it is hard to anticipate how the management would react, as there is limited control on the processes.

- Level 2; Managed: well-defined operation and maintenance procedures are documented, implemented, and understood and assisted by management. Maintenance actions are mostly preventive and there is little reactive maintenance.

- Level 3; Optimized: Asset management strategies are aligned with risk-informed operation and maintenance. The focus of management is on continuous improvement. Comprehensive training exists at all layers of the company. The company is acting proactively, rather than reactively.

Table 7 represents discrete probabilities of identified common causes. 


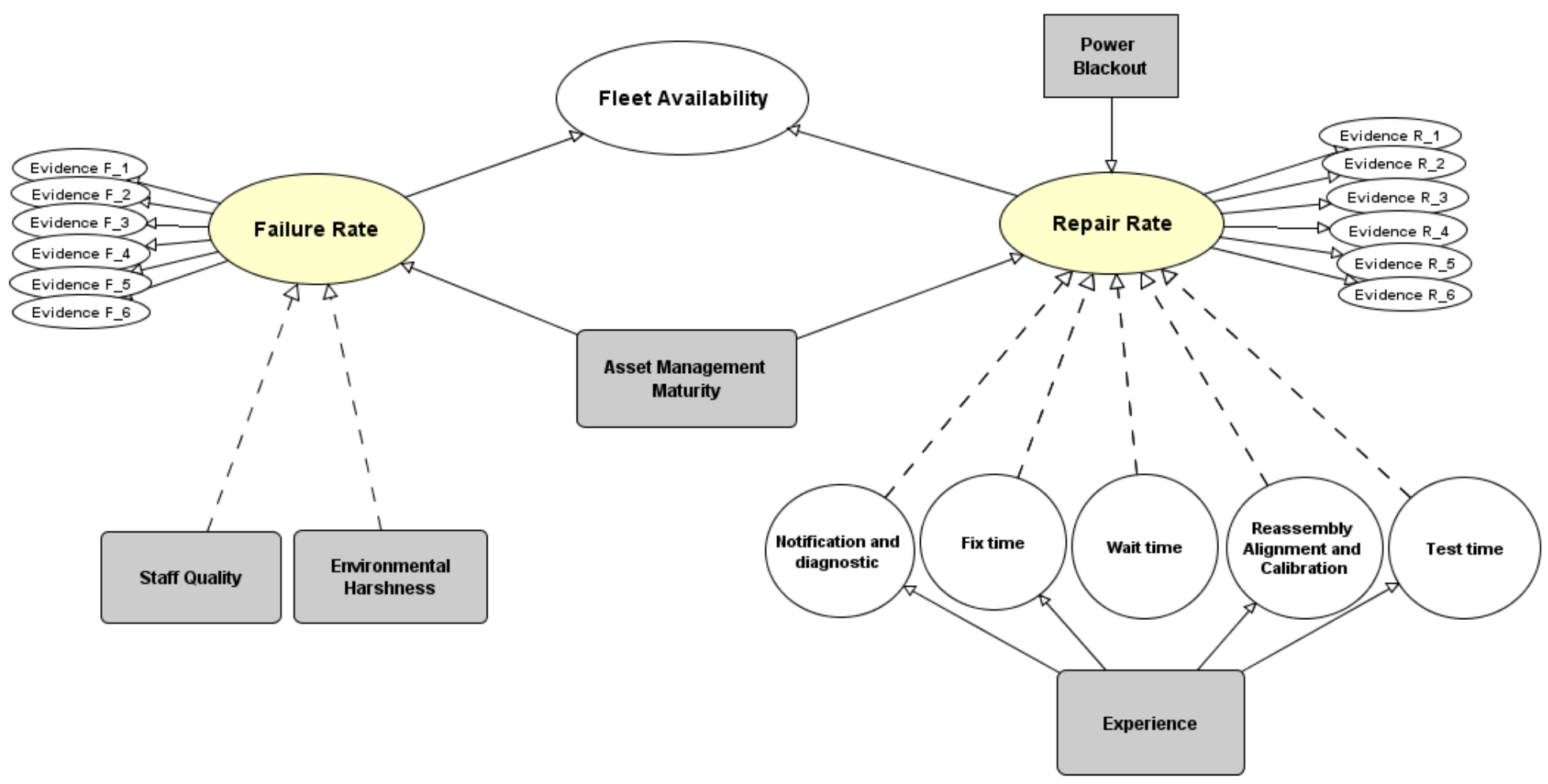

Figure 9: Graphical representation of the case model (dashed lines are created because there are intermediate nodes in the model to facilitate NPT assignments and to lower the calculation volume)

Five tasks are assigned to the repair job: notification and diagnosis, fix time, wait time, reassembly alignment and calibration, and test time. As noted earlier, the common cause 'Experience' impacts the duration of most of the above tasks. A triangular distribution is fit to the duration of a task, conditional on the state of their common cause, i.e. Experience (Table. 8). Because the tasks are sequencing in series, total repair duration (TRD) is formulated as the summation of all the above task durations. The prior distribution for repair rate can be now generated using TRD distribution and a coefficient associated with each state of the common cause 'Asset Management Maturity' (see last column of Table 10). This coefficient also eases conditional probabilities elicitation in generating prior failure rate, where we first elicited failure times by conditioning them on the two causes Staff Quality and Environmental Harshness, i.e. Failure Time|SE (FTSE) as shown in Table 9, and then we formulated the failure rate and amended it using the aforementioned coefficients, as presented by Table 10. As there was not a historical record for failure times, we set a non-informative uniform prior, known as Bayes-Laplace prior to estimate failure times, which is a satisfactory method to begin uncertainty modelling when there is no significant past data [136]. However, when there is past information, either from the same assets or from similar assets, these uniform distributions should be 
regarded as pre-priors which will be then updated to informative priors using historical information [137].

Table 7. Elicited probabilities for ranked nodes assigned to common causes

\begin{tabular}{ll}
\hline Node & Probabilities, Parameters and Coefficients \\
\hline Environmental Harshness & (low, medium, high $)=(0.132,0.477,0.391)$ \\
Staff Quality & (low, medium, high $)=(0.263,0.582,0.155)$ \\
Asset Management & (ad-hoc, managed, optimized $)=(0.254,0.629,0.117)$ \\
Maturity & (low, medium, high $)=(0.375,0.404,0.221)$ \\
Experience &
\end{tabular}

Table 8. Elicited distributions for repair activity durations

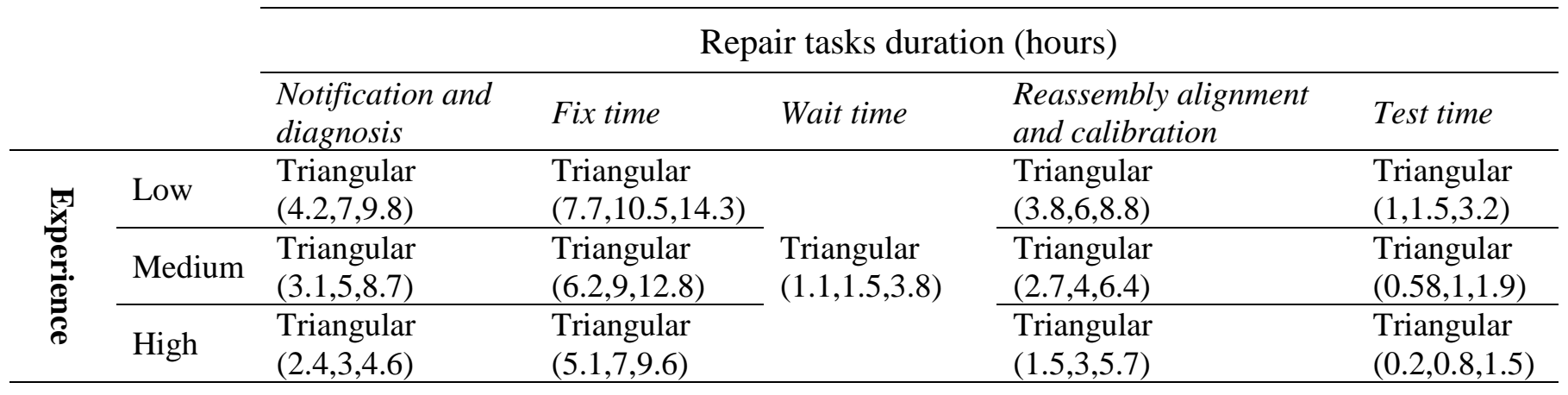

Table 9. Prior failure times based on Staff Quality (S) and Environmental Harshness (E)

\begin{tabular}{|c|c|c|c|}
\hline & & Environmental Harshness & Failure Time|SE (FTSE) \\
\hline \multirow{9}{*}{ 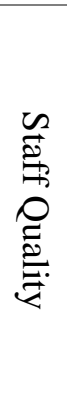 } & \multirow{3}{*}{ Low } & Low & $\mathrm{U}(35,55)$ \\
\hline & & Medium & $\mathrm{U}(30,50)$ \\
\hline & & High & $\mathrm{U}(25,45)$ \\
\hline & \multirow{3}{*}{ Medium } & Low & $\mathrm{U}(45,65)$ \\
\hline & & Medium & $\mathrm{U}(40,60)$ \\
\hline & & High & $\mathrm{U}(35,55)$ \\
\hline & \multirow{3}{*}{ High } & Low & $\mathrm{U}(55,75)$ \\
\hline & & Medium & $\mathrm{U}(50,70)$ \\
\hline & & High & $\mathrm{U}(45,65)$ \\
\hline
\end{tabular}


Table 10. Final failure and repair rates adjusted by a coefficient corresponding to Asset Management Maturity levels

\begin{tabular}{lll}
\hline $\begin{array}{l}\text { Asset Management } \\
\text { Maturity }\end{array}$ & Failure Rate & Repair Rate \\
\hline Ad-hoc & $\mathrm{FTSE}^{-1} * 1.25$ & $\mathrm{TRD}^{-1} * 0.7$ \\
\hline Managed & $\mathrm{FTSE}^{-1} * 1$ & $\mathrm{TRD}^{-1} * 1$ \\
\hline Optimized & $\mathrm{FTSE}^{-1} * 0.8$ & $\mathrm{TRD}^{-1} * 1.2$
\end{tabular}

Assuming that failure and repair times follow an exponential distribution, we simulate the node 'Fleet Availability' using the following formula:

Fleet Availability $=\frac{\text { Repair Rate }}{\text { Repair Rate+Failure Rate }}$.

Having entered the above information and formulation into the BN model, we obtained the preliminary result of availability prediction and modelling its uncertainty, as illustrated in Figure 10. The results show that the average availability of the under-study fleet is 66 percent and with a $75 \%$ of confidence the fleet will be available in at least 58 percent of the time. Moreover, the nodes Failure Rate and Repair Rate represent the uncertainty about MTBF and MTTR, with mean values equal to 0.0229 and 0.0478 , respectively.

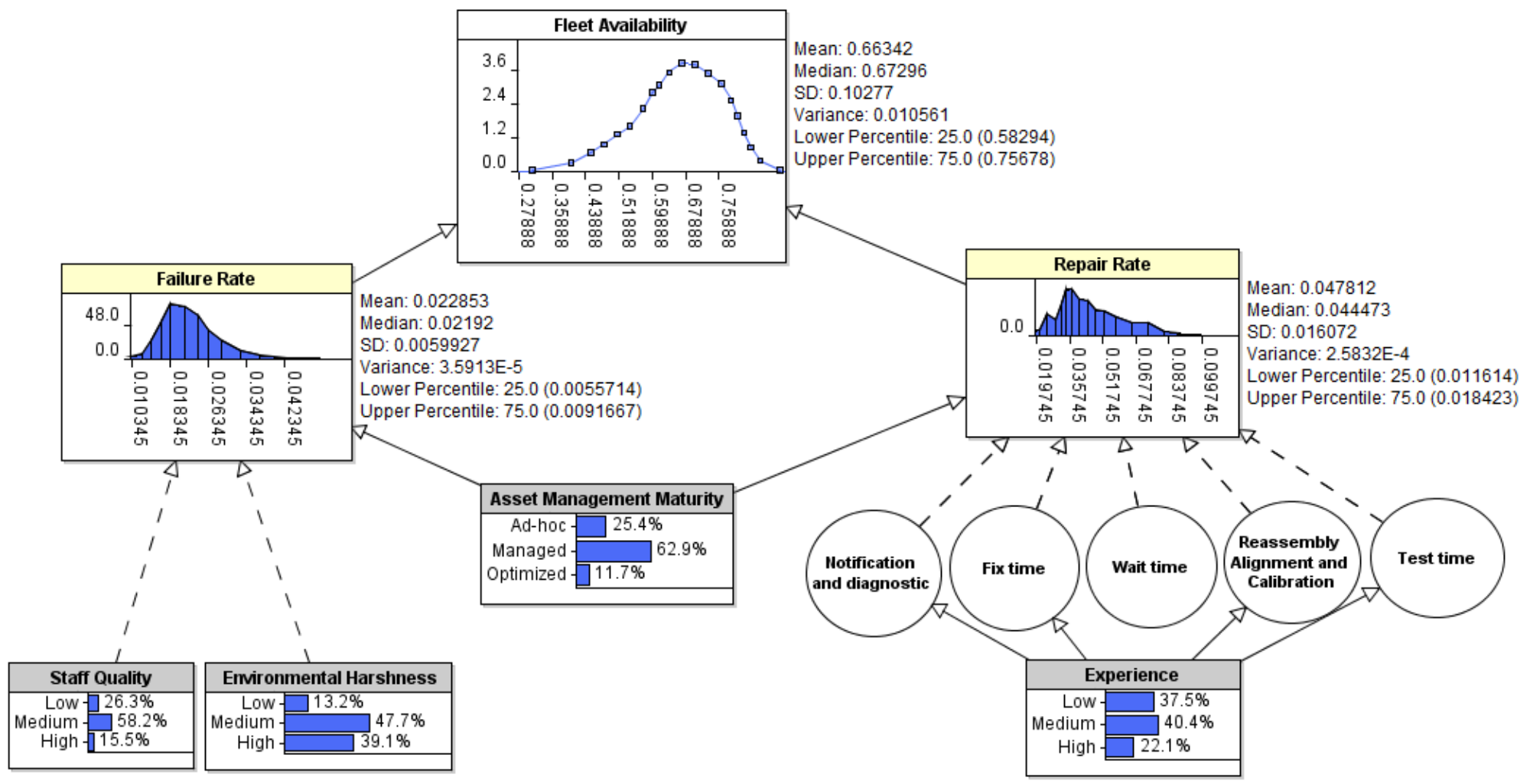

Figure 10: Primary results of fleet availability prediction 
To raise accuracy, we can update the availability distribution, as well as the distribution of Failure and Repair rates, in response to new observations from the fleet. The following failure and repair times (in hours) were gathered from the excavators after 35 operational weeks:

\begin{tabular}{lllllll}
\hline Failure Time & 34 & 41 & 55 & 18 & 48 & 39 \\
Repair Time & 53 & 15 & 33 & 28 & 36 & 21 \\
\hline
\end{tabular}

We created exponential distribution nodes with parameter 'Failure Rate' and 'Repair Rate' and entered the above observations as data into these nodes. Figure 11 shows the posterior distributions of Failure Rate, Repair Rate, and their common cause Asset Management Maturity. Rate distributions have been revised through evidence propagation in multiple rounds. When a failure/repair time is introduced, a backward propagation develops which will first updates the failure/repair rate probability distribution, based on which the level of Asset Management Maturity is then inferred. This revised information will again update repair/failure rate on the other side. Therefore, any new information on actual reliability (or maintainability) will modify our belief about management policy and from there maintainability (or reliability) will be revised through a forward propagation.

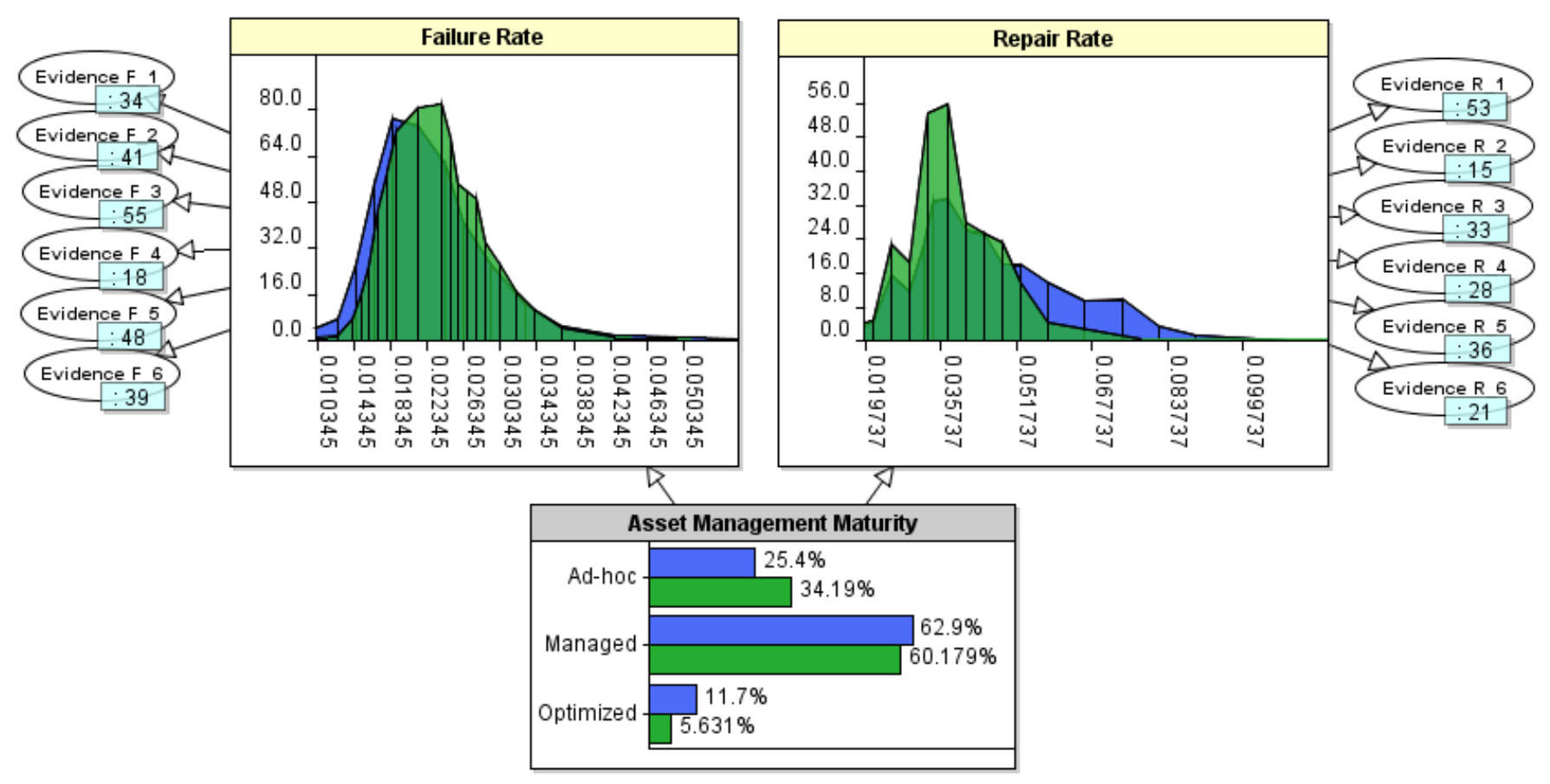

Figure 11: Update of Failure and Repair rates in light of new observations

Accordingly, the updated distribution of fleet availability is calculated, as depicted by Figure 12. The new distribution is skewed toward left which means we had been optimistic about the real level of fleet availability. The updated average availability is now 62\%. Outputs of Figures 11 and 12 show 
that new evidence and the mechanism of backward propagation has reduced the uncertainty of estimations in failure/repair rates, and therefore, in availability, as the variance of these distributions has declined.
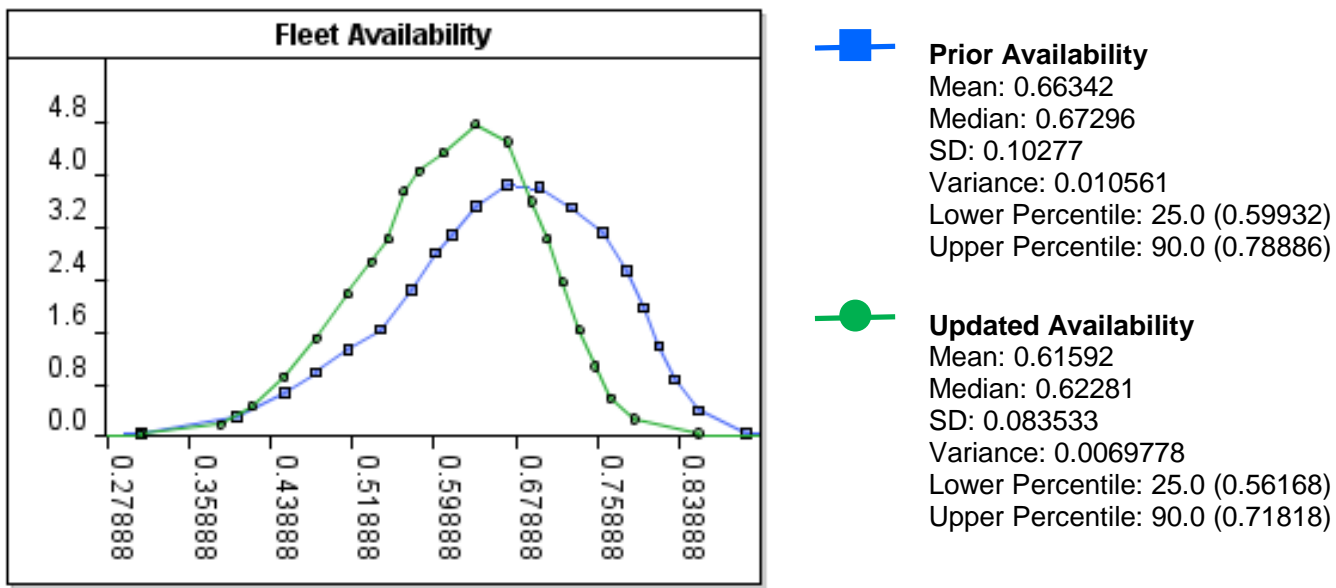

Figure 12: Update of fleet availability considering new evidences

The fleet manager wants to assimilate the impact of the rare event 'Power Blackout', like Northeast Blackout of 2003, which occurred throughout Ontario Province as well as parts of the Midwestern and Northeastern US, on the repair rate of the fleet. On August 14, 2003, a massive power outage happened which lasted for two days and affected about 55 million people, including 10 million Ontarians [138]. We assign a Bernoulli variable to this event with the states Yes and No. A history of such major blackouts over the past few decades across Ontario can be found in Table 11. This information can be accordingly used to estimate the prior for the rare event Power Blackout expected to happen in the current year, i.e. $\mathrm{P}(\mathrm{Yes})=\frac{5}{52}=0.096$ and $\mathrm{P}(\mathrm{No})=0.904$.

Table 11. History of power outages in Ontario

\begin{tabular}{|c|c|}
\hline Year & Event \\
\hline 1965 & $\begin{array}{l}\text { A Northeast blackout happened on November } 9 \text { and impacted parts of seven northeastern } \\
\text { states in the US and the Canadian province of Ontario. }\end{array}$ \\
\hline 1991 & $\begin{array}{l}\text { A large portion of central North America was affected by a powerful wind storm which } \\
\text { caused power outages on July } 7 \text { for about one million customers in Iowa to Ontario. }\end{array}$ \\
\hline 2003 & $\begin{array}{l}\text { Hurricane Isabel disrupted electricity for } 4.3 \text { million people across nine states in the US } \\
\text { and portions of Ontario, On September } 19 .\end{array}$ \\
\hline 2006 & $\begin{array}{l}\text { About a quarter million customers of Hydro One experienced a power outage On August } \\
2 \text {, after powerful thunderstorms with tornadoes ripped through southern and eastern } \\
\text { Ontario. }\end{array}$ \\
\hline 2013 & $\begin{array}{l}\text { The December } 2013 \text { North American ice storm, caused a power outage on December } 22 . \\
\text { Between 300,000 to 600,000 customers in Toronto were affected. The storm also caused } \\
\text { widespread power outages in mid-Michigan. }\end{array}$ \\
\hline
\end{tabular}


Repair experts know from their background that when there is no power, repair rate dramatically reduces, as presented in Table 12. We would like to complete missing parts of Repair Rate NPT in Table. 7 , i.e. $R_{A N}, R_{M N}$, and $R_{O N}$, so that the expectations of the previous elicited repair rates are preserved while power blackout remains unobserved.

Table 12. Incomplete NPT of Repair Rate, with judgments on rate reduction in the case of a major power blackout

\begin{tabular}{l|l|l|l|l|l|l}
\hline Asset Management Maturity & \multicolumn{2}{|l|}{ Ad-hoc } & \multicolumn{2}{l}{ Managed } & \multicolumn{2}{l}{ Optimized } \\
\hline Power Blackout & Yes & No & Yes & No & Yes & No \\
\hline Repair Rate & $0.1 * \mathrm{TRD}^{-1}$ & $\mathrm{R}_{\mathrm{AN}}=?$ & $0.4 * \mathrm{TRD}^{-1}$ & $\mathrm{R}_{\mathrm{MN}}=?$ & $0.5 * \mathrm{TRD}^{-1}$ & $\mathrm{R}_{\mathrm{ON}}=?$ \\
\hline
\end{tabular}

Using Eq. 40, repair rates associated with negative outcome of Power Blackout are calculated as follows:

$$
\begin{aligned}
& \mathrm{R}_{\mathrm{AN}}=\frac{0.7 \mathrm{TRD}^{-1}-\left(0.1 \mathrm{TRD}^{-1} * 0.096\right)}{0.904}=0.76 \mathrm{TRD}^{-1} . \\
& \mathrm{R}_{\mathrm{MN}}=\frac{1 \mathrm{TRD}^{-1}-\left(0.4 \mathrm{TRD}^{-1} * 0.096\right)}{0.904}=1.06 \mathrm{TRD}^{-1} \\
& \mathrm{R}_{\mathrm{ON}}=\frac{1.2 \mathrm{TRD}^{-1}-\left(0.5 \mathrm{TRD}^{-1} * 0.096\right)}{0.904}=1.27 \mathrm{TRD}^{-1}
\end{aligned}
$$

We then incorporated the node 'Power Blackout' as a rare event into the model and revised the NPT of the node 'Repair Rate' using the information in Table 12. As long as this event is unobserved, the mean value of Repair Rate is unchanged (0.040). What would be the repair rate and the availability if this happens in Toronto? Once the fleet manager observes the blackout happening, he/she can conclude that the fleet repair rate and availability will decline as shown in Figure 13. The average repair rate drops to 0.023 and this decreases the average availability to $51 \%$, with a much greater certainty. 


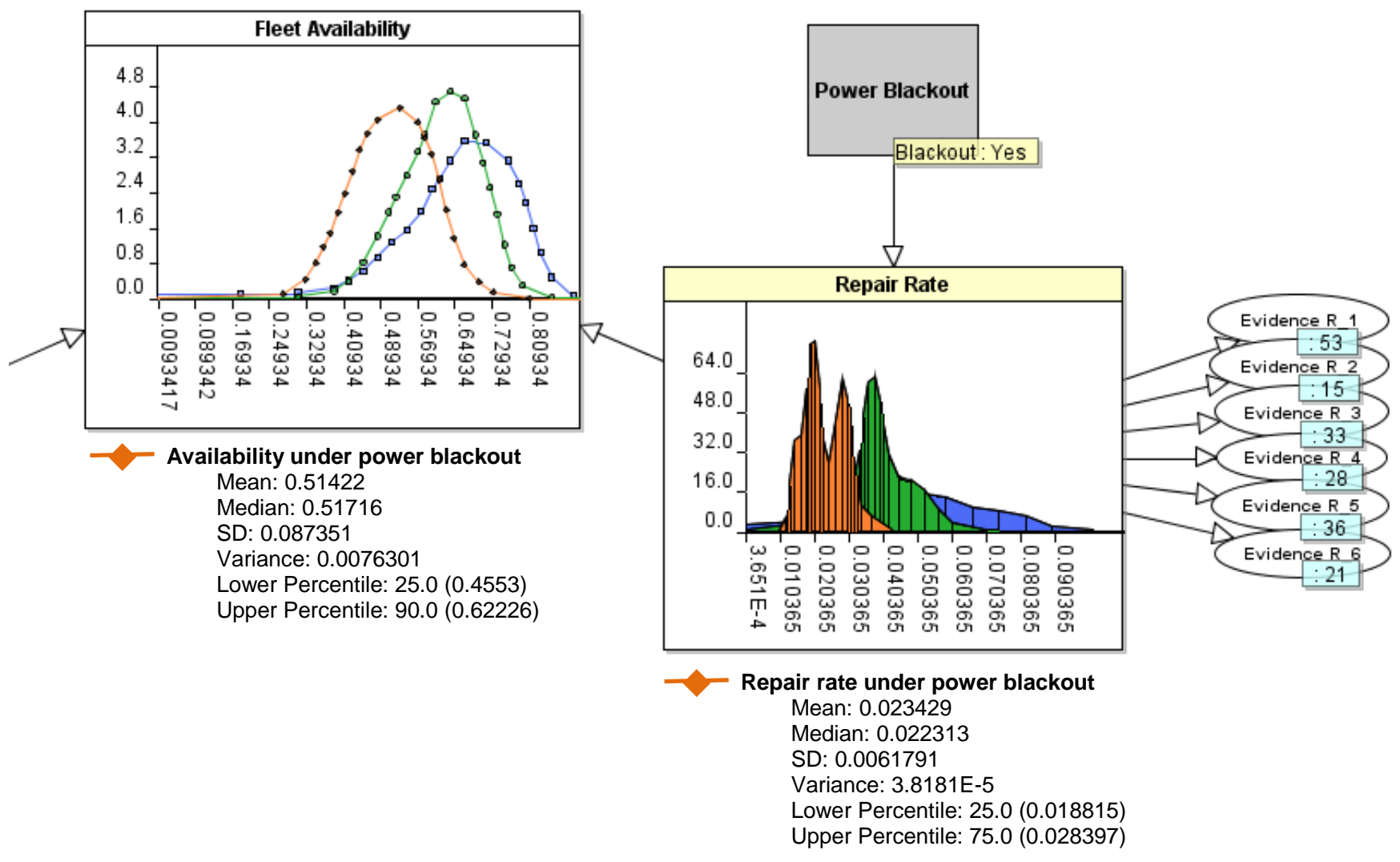

Figure 13: Fleet repair rate and availability distributions under power blackout

\subsection{Analytical capabilities}

In addition to the above predictions on fleet availability, the model possesses analytical features, including what-if and scenario analyses. The following scenarios are designed to illustrate these features:

Scenario 1; The company is running a construction project in a site with highly harsh conditions. Excavators' operators enjoy medium skills, but repair mans are highly experienced. The manager would like to know the average availability of equipment.

Scenario 2; It took repair personal 7.5 hours to diagnose the problem with a failed equipment. The manager would like to update her/his estimation on the remaining repair tasks and also the final repair time.

We take the availability distribution updated by real data (presented in Figures 12 and 13 in green colours) as a baseline for our scenario analysis. Running the model under the scenario 1, the fleet availability is calculated, as illustrated in Figure 14. This output shows that although there is a high level of harsh conditions, this can be not just negated, but also outweighed by the high level of repair experience. As it can be seen, there would be an average increase of $3 \%$ in fleet availability. 

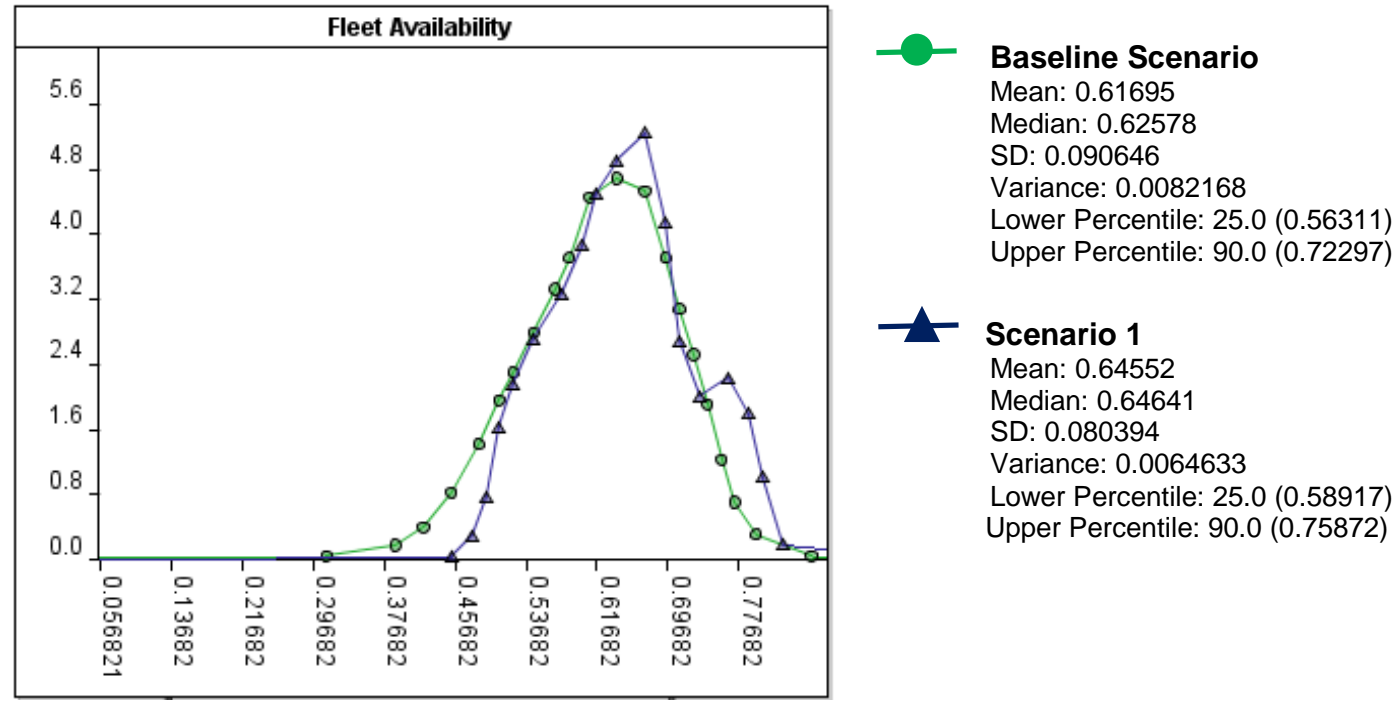

Figure 14: Availability distribution under Scenario 1 in comparison with the baseline availability

Having entered the actual duration of the task 'Notification and Diagnosis', the model will revise the expert belief about the actual level of Experience (skewed more toward Low), and consequently, will update the duration of incomplete repair tasks. As a result, repair rate is slightly skewed toward left, predicting an average rate of 0.036, and therefore, a final repair time of 28 hours (Figure 15). This result can be regarded as a diagnostic mechanism to find obstacles to timely repair the equipment or complete bigger maintenance projects. 


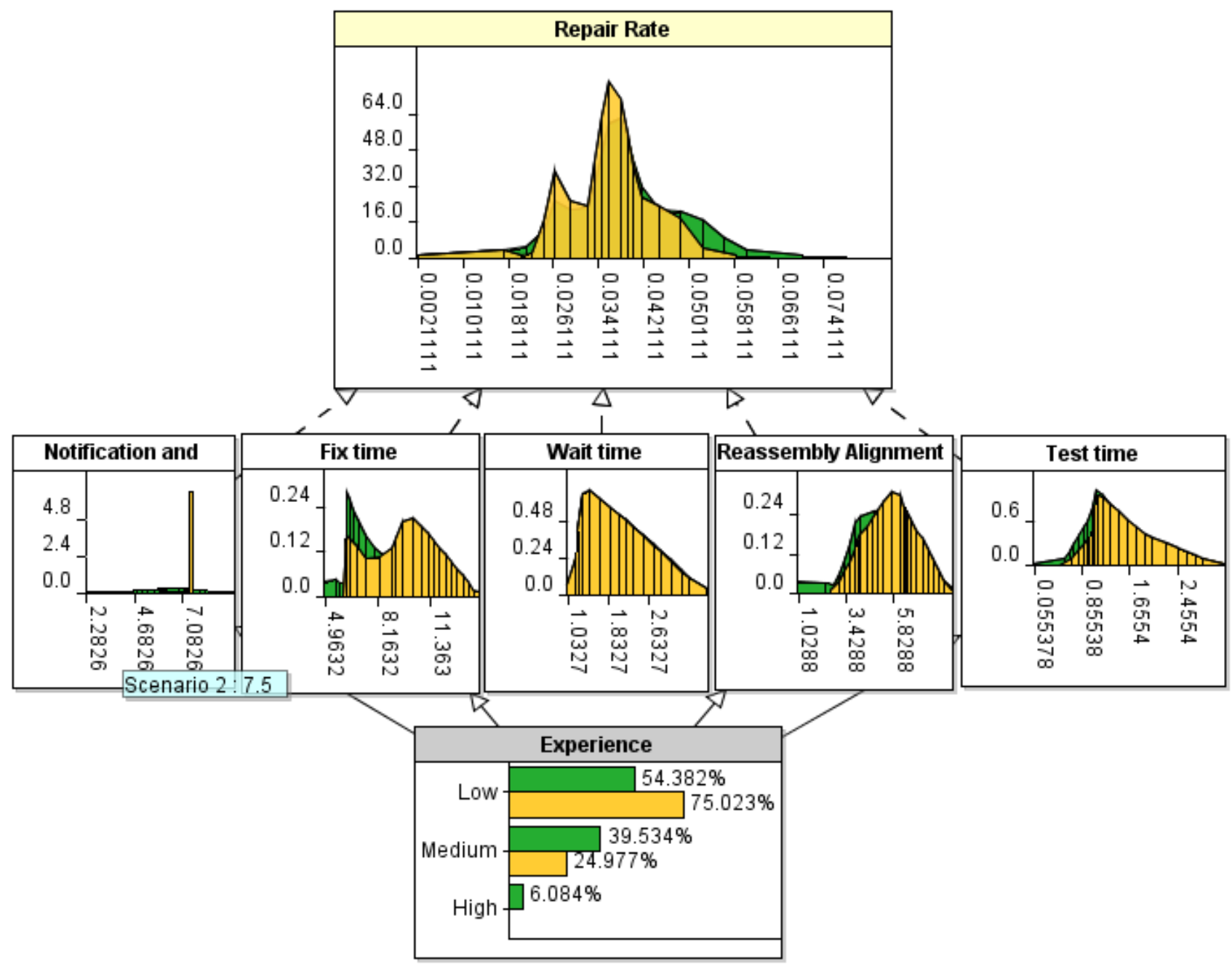

Baseline Scenario

Scenario 2

Figure 15: Inferring the level of experience, the duration of remaining repair tasks and the final repair time/rate in the light of an actual task duration-Scenario 2

The next scenario will demonstrate the applicability of the model in calculating the required level of common causal factors when there is a desired floor availability. Suppose that the fleet manager wants to know the needed level of experience and skill in maintenance and operation personals, and the maturity of asset management processes, to achieve a minimum availability of $90 \%$, while the environmental harshness is moderate. Figure 16 presents the results of running the model under these conditions (Scenario 3) in terms of the three unobserved common causes; Asset Management Maturity, Staff Quality, and Experience. Clearly, staff quality distribution on the reliability side has showed less necessary improvement, compared to the two other factors. To prioritize the factor(s) that should be focused on, we use the concept of total expected utility [139] and calculate the difference between the factor's total expected utilities ( $\triangle \mathrm{TEU})$ under the both scenarios: 


$$
\Delta \text { TEU }=\sum_{\mathrm{i}} \mathrm{Utility}(\text { State i }) * \mathrm{P}_{S 2}(\text { State } \mathrm{i})-\sum_{\mathrm{i}} \mathrm{Utility}(\text { State } \mathrm{i}) * \mathrm{P}_{B S}(\text { State } \mathrm{i}) \text {, }
$$

where $\quad \mathrm{P}_{\mathrm{S} 2}$ (State i) and $\mathrm{P}_{\mathrm{BS}}($ State i) represent the probability of state i under the Scenario 3 and Baseline Scenario, respectively. Using state utilities such as: Utility (low) $=0$, Utility (medium) $=0.5$, and Utility (high) $=1$, the $\Delta$ TEUs are obtained as provided in Table 13 . Therefore, it is Asset Management Maturity that should be enhanced primarily in order to achieve the desired availability defined in Scenario 3.
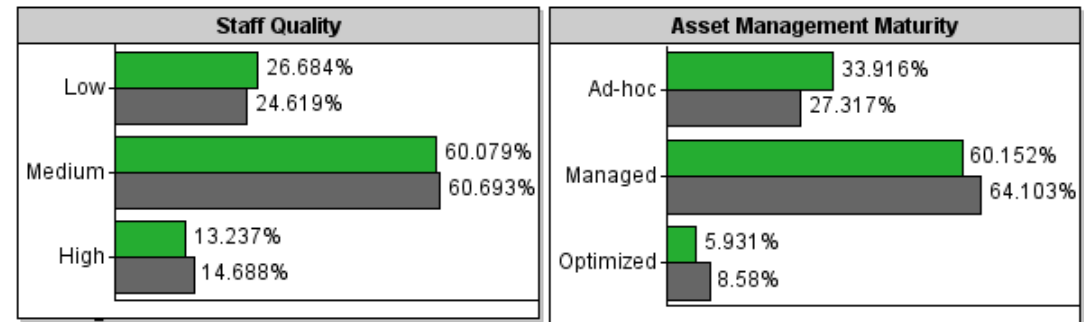

Baseline Scenario

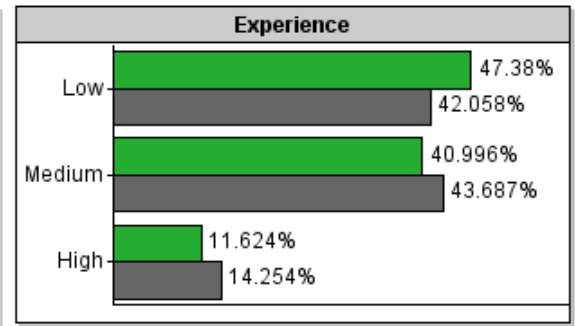

Scenario 3

Figure 16: Inferring the required level of experience in maintenance people, quality of operation staff, and management maturity, to achieve a certain level of availability-Scenario 3

Table 13. Total expected utilities under scenario 3 and baseline scenario, and their difference as a measure of priority areas for availability improvement

\begin{tabular}{|c|c|c|c|c|c|c|}
\hline Node & \multicolumn{2}{|c|}{ Asset Management Maturity } & \multicolumn{2}{|c|}{ Staff Quality } & \multicolumn{2}{|c|}{ Experience } \\
\hline Scenario & Scenario 3 & Baseline & Scenario 3 & Baseline & Scenario 3 & Baseline \\
\hline TEU & 40.632 & 36.007 & 45.035 & 43.277 & 36.098 & 32.140 \\
\hline$\triangle \mathrm{TEU}$ & \multicolumn{2}{|c|}{4.625} & \multicolumn{2}{|c|}{1.758} & \multicolumn{2}{|c|}{3.958} \\
\hline
\end{tabular}

\subsection{Forecasting accuracy}

In this section, we propose a procedure to evaluate the forecasting accuracy of the model, based on the information from a hypothetical completed project (what was discussed in the case study) and an under-construction project. We compared three types of failure and repair time predictions. These predictions are:

1. A measure of central tendency of the historical repair and failure times from the past project.

2. Mean values of the failure and repair distributions from the proposed model-built for the past project- after being updated by the final failure and repair times.

3. Mean values of the failure and repair distributions from the proposed model-built for the current project- after being updated by the newest failure and repair times. 
Each of the above predictions were compared to the actual failure/repair times from the current project. We applied the root mean squared error (RMSE), to measure the accuracy of each prediction. Obviously, more accurate predictions should show lower RMSE. RMSE is a widely acceptable criterion, which can be calculated as follows:

$$
\operatorname{RMSE}=\sqrt{\frac{1}{\mathrm{n}} \sum_{\mathrm{k}=1}^{\mathrm{n}}\left(\mathrm{Y}_{\mathrm{k}}-\mathrm{P}_{\mathrm{k}}\right)^{2}}
$$

where $Y_{k}$ is the predicted value of the real number $P_{k}$, and $n$ represents the number of forecasted events or periods [140].

As the historical data recorded for the past project did not follow a symmetric distribution, we employed Trimean as the measure of tendency [141], so that the best forecast is derived from the historical data and hence the comparison will be as fair as possible. This measure can robustly reflect the most likely value from a sample of data, and also to represent a more reliable most likely value when the sample shows a significant skew in one side of the median value. If the historical failure/repair rates have $4 n+3$ samples $(n>0)$ which are sorted ascendingly; the Trimean of this group of data is defined as follows:

$$
\mathrm{T}=\frac{\mathrm{H}_{\mathrm{L}}+2 \mathrm{M}+\mathrm{H}_{\mathrm{R}}}{4}
$$

where $M$ represents the median value, which is actually the sample [2n+2], and $H_{L}, H_{R}$ are so-called the hinges, computed as follows:

$$
\begin{aligned}
& \mathrm{H}_{\mathrm{L}}=\frac{\text { sample }[\mathrm{n}+1]+\text { sample }[\mathrm{n}+2]}{2} \\
& \mathrm{H}_{\mathrm{R}}=\frac{\text { sample }[3 n+2]+\text { sample }[3 n+3]}{2}
\end{aligned}
$$

Under-study excavators were working for 20 weeks, and 23 failures happened in this period. Trimean value of the related failure and repair times were calculated as 33.50 and 26.25 hours, respectively. The mean value of the failure and repair distributions predicted by the proposed model (after being refined by the 23 data) are 41.47 and 25.57, respectively. For the current project, the BN model was reconstructed (based on new beliefs on common causes). Therefore, this new model was suggesting renewed predictions for the new project, which are being again updated by actual failure/repair times. Nine failures and repairs have been recorded so far in the current project, times of which will be the basis to compare the accuracy of different predictions. The above central 
tendency and data sets are depicted in Figure 17 and Figure 18, for failure times and repair times, respectively.

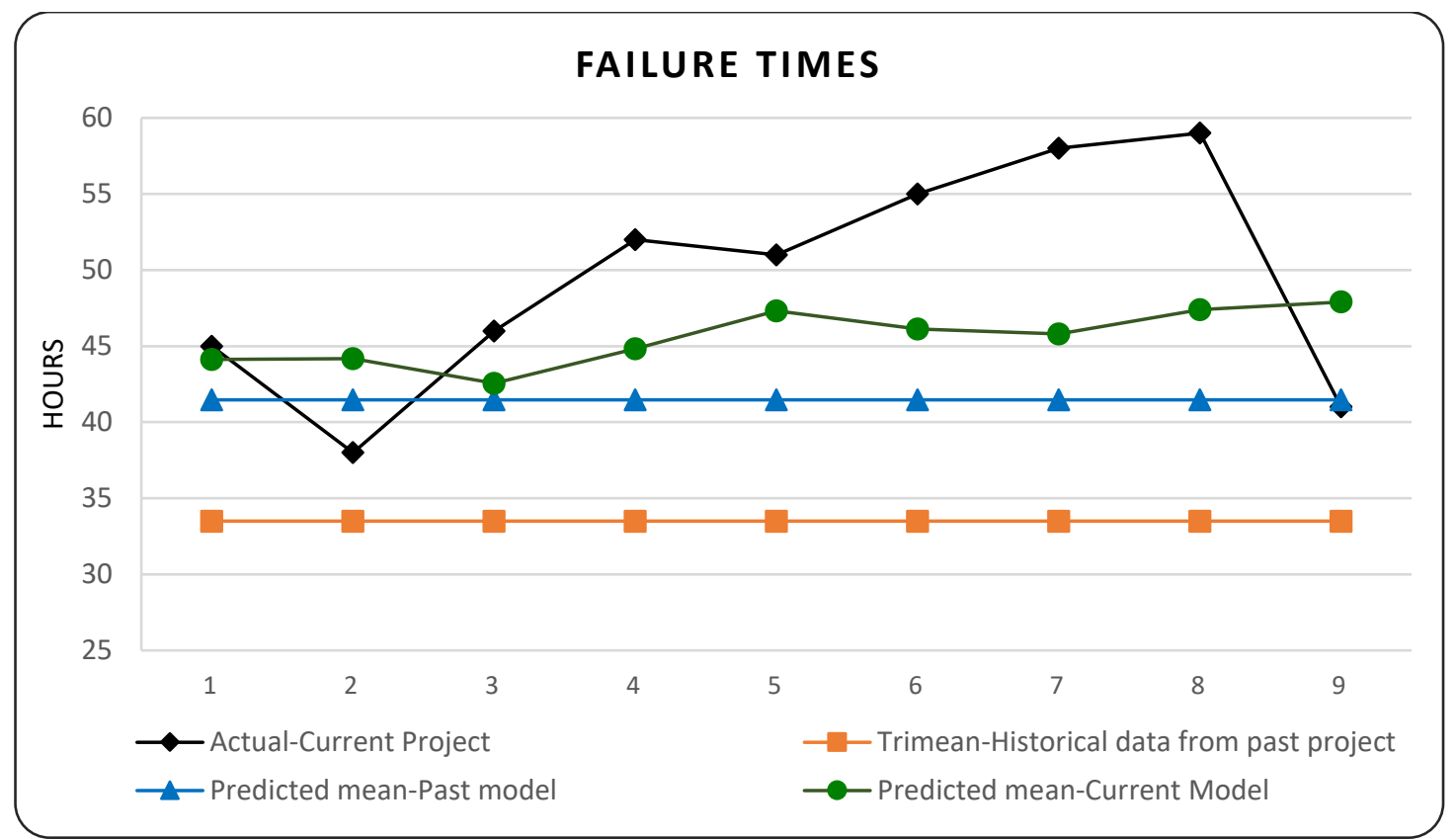

Figure 17: Comparison of three failure times' predictions (color lines) with actual failure times (black line)

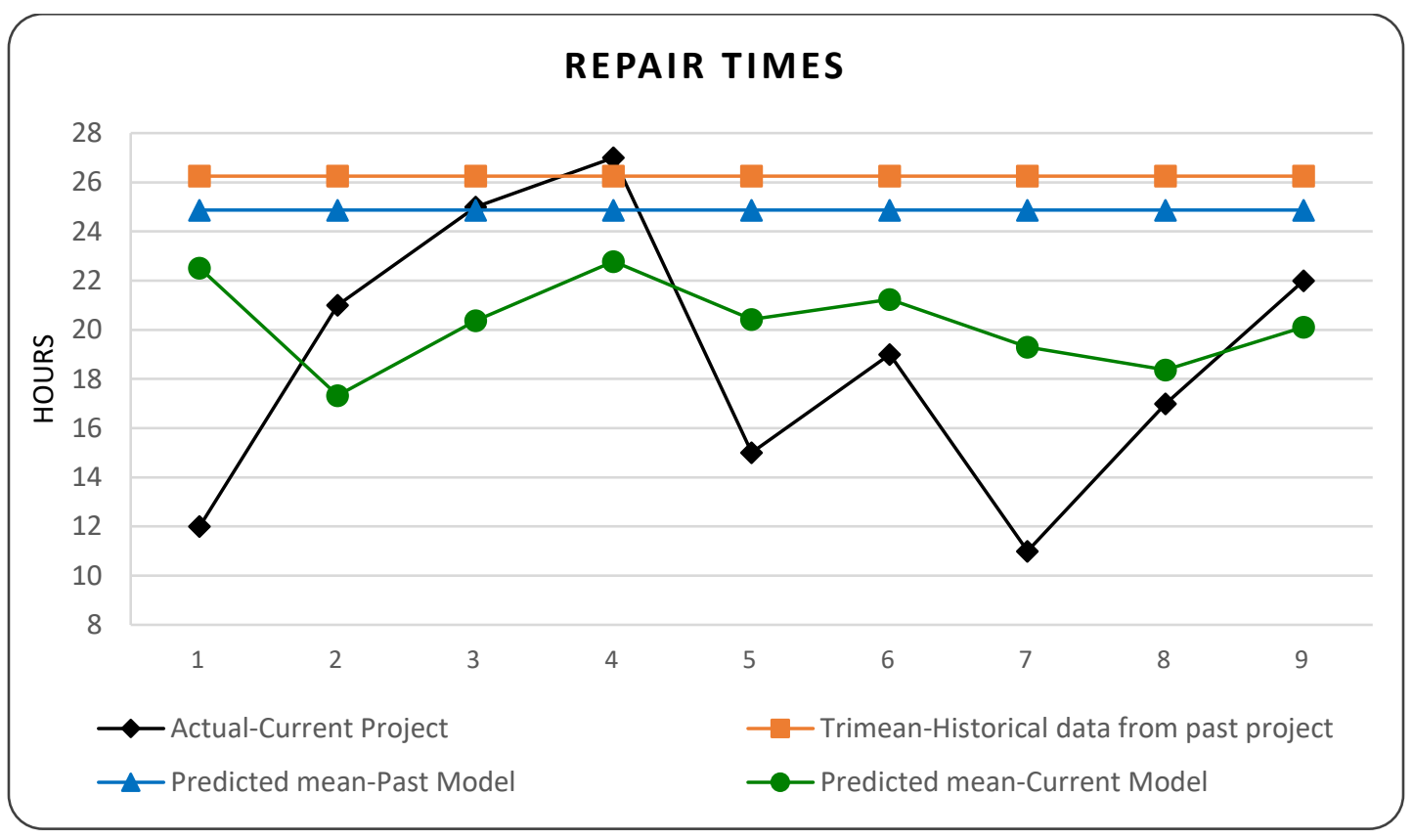

Figure 18: Comparison of three Repair times' predictions (color lines) with actual repair times (black line)

Looking more closely at the failure time's graph, it can be observed that the Trimean measure calculated based on the historical data from the past project underestimates failure times in the current 
project. This is not surprising, as the affecting common causes became more favourable in this project (mainly the operating staff quality). That is presumably the reason why the final predicted failure time from the previous model is also pessimistic about failure times in the current project. As illustrated, predictions from the rebuilt model, powered by learning from occurring failures, starts from a relatively improved prediction and tends to adopt to the real failure times.

The same interpretation applies to the repair times' graph. This is proven by the result of RMSE calculations, provided in Table 14. As shown, the current model for the current project gives more accurate forecasts, with the lowest RMSEs in both failure and repair cases.

Table 14. RMSE values of three predictions

\begin{tabular}{lcc}
\hline \multicolumn{1}{c}{ Predictions } & \multicolumn{2}{c}{ RMSEs } \\
\hline \multirow{2}{*}{ Trimean-Historical data from past project } & Failure & 17.405 \\
\cline { 2 - 3 } & Repair & 9.117 \\
\hline \multirow{2}{*}{ Predicted mean-Past model } & Failure & 10.596 \\
\cline { 2 - 3 } Predicted mean-Current model & Repair & 8.025 \\
\cline { 2 - 3 } & Failure & 7.644 \\
\cline { 2 - 3 }
\end{tabular}

\subsection{Conclusion}

This chapter presented an intelligent model to estimate fleet availability, based on a Bayesian network, equipped with several uncertainty and causality modelling techniques. Primarily, it factors in the complex organizational factors, e.g. Asset Management Maturity, which allows us to model the performance of intangible assets (also known as organizational capabilities including business processes), simultaneously with that of tangible assets (or physical organizational resources including machines). This mechanism, if it comprises all effectual factors, could be employed by fleet owners to control processes and equipment to manage the fleet availability.

Other features of the model include modelling common causal factors to tackle the problem of dependency between failure and repair distributions, as well as the dependency between distinct stages in the repair process; formal elicitation of expert's judgments, and learning from new evidences that allow the model to improve itself as more actual data become available; and modelling rare or previously unseen events (of low probability but high impacts). For the later, we combined the model of Constantinou et al. [86] into our proposed approach to availability analysis. For the sake of simplicity, however, we incorporated as fewer causal factors and rare events as possible from the case 
study. A more realistic application of the proposed method could take more variables into account, in the same structure.

The proposed approach allows fleet managers to not just predict the uncertainty of their fleet availability, but also conduct enlightening analyses under various circumstances (Scenario 1). It is possible to monitor and control the performance of operation (in terms of reliability) and maintenance through actual failure and repair times and inference on causal factors (Scenario 2). Moreover, having the advantage of backward information propagation, the fleet owner would be able to find root causes and improvement points (Scenario 3).

\section{Acknowledgment}

The author would also like to thank Dr. William Vesely and Dr. Miroslav Sýkora for their guidance and constructive comments. 


\section{Equipment repair-replacement decision analysis with economic and environmental considerations}

The present chapter is based on the following paper:

Abdi, A., Taghipour, S. (2018). Incorporating maintenance quality, carbon emissions, and risk into asset repair-replacement decision. Computers \& Industrial Engineering. Under Review.

Equipment repair/replacement decision is an important aspect of asset management, which aims to find the best time to retire an in-use system based on its lifecycle costs. Previously, lifecycle analysis techniques have assumed that the distribution of equipment's failure and repair time remain unaltered during the usage phase. In reality, however, the actual parameters that represent equipment's reliability and maintainability could change by several causal factors including the quality of preventive and corrective maintenance, which can be dynamically adjusted through management intervention. Another dimension of repair/replacement problem is the environmental impact of equipment, which is important to be taken into account due to the effect of carbon pricing programs in addition to the international concerns about global warming and carbon emissions. Not every aspect of this issue has been addressed in the published replacement decision models. Most importantly, the causality between equipment failure behaviour and its greenhouse gas (GHG) emissions has not been examined.

The contribution of this paper is twofold. First, an economic repair/replacement model is developed in two phases: 1) deterministic phase, in which the mathematical structure of the total repair and replacement costs are defined, and 2) probabilistic phase, which factors in the uncertainty of parameters in the deterministic model, preventive maintenance quality, and repair perfection. The probabilistic phase provides also a mechanism to learn from the observations to modify the predictions on the equipment failure rate and thus, updates the repair or replacement decision. Second, the economic model is extended to a combined model, in which the emissions associated with different phases of equipment lifecycle are considered. To predict the emissions of usage phase of inuse equipment accurately, using Bayesian inference and historical data on failure times and consumed energy, the probable thresholds of failure rate are computed, above which the equipment begins to consume more energy/fuel. 
Keywords: Equipment replacement, Bayesian networks (BN), Greenhouse gas (GHG) emissions.

\subsection{Introduction and Background}

The decision to repair or replace a physical asset is a key aspect of asset management. It involves many contradictory, conflicting, and uncertain factors related to the old and new assets, known as the defender and the challenger, respectively. Many models have been introduced for asset repair/replacement $(\mathrm{R} / \mathrm{R})$ decision-making. Traditionally, $\mathrm{R} / \mathrm{R}$ models rely on life cycle costing (LCC) concepts [47]. Recently, more advanced techniques have been also proposed in this domain to account for technological improvements [64], uncertainty of demand and market parameters [49], technical failure characteristics of assets [50], the effect of unknown parameters on time-to-failure distribution [51], and so forth.

Despite all these attempts, however, there are complexities associated with this problem that have not been modelled yet. To make an R/R decision, we need to know whether the ongoing preventive or corrective maintenance is truly making a positive difference, and hence, it is better to keep the defender. A major factor is the quality of preventive maintenance (PM) and its impact on the defender's failure rate and health. In other words, whether or not a PM program, with certain costs, would be actually effective in delaying equipment degradation, remains uncertain. Likewise, the perfection of repairs can inform $\mathrm{R} / \mathrm{R}$ decision making. Theoretically, the so called minimal and perfect repairs recover a failed system to as bad as what it was just before failure and as good as new, respectively. Practically, however, the real outcome of these repairs, except in some special cases, may not be deterministic and therefore, every repair work could be regarded as an imperfect repair with the effectiveness between minimal (worst-case) and perfect (best-case) repairs. Although complex, these factors, i.e. quality and perfection of preventive and corrective maintenance, have not been quantified in the previous works. They can be broken down to the quality/ perfection of smaller activities including lubrication, storage, cleaning, parts selection and installation, so forth. Other complex causal factors, such as organizational factors (e.g. repair staff experience), the risk of unanticipated loads, and variations in material quality are also missing in the asset replacement literature. If the uncertainty of such factors is not modelled, the results of LCC may not also be accurate.

On the other side, environmental burdens of equipment are being considered in repair/replacement decisions (e.g. [52-54]. However, the new combined replacement models (with both economic and environmental factors) fail to model the impact of maintenance and equipment health on the amount 
of released GHG emissions. According to [55], equipment reliability can significantly improve energy efficiency and thus the amount of direct and indirect emissions.

The objective of this chapter is twofold. Firstly, we aim to formulate a model for equipment repairreplace decision with both economic and environmental considerations, so that PM quality and repair perfection are taken into account in the equipment life cycle cost. A probabilistic reasoning mechanism is designed to formulate the effect of PM quality (and/or any other driving force) on equipment health and infer the effectiveness of maintenance. How perfect or imperfect the repair work is, is also modelled to more accurately predict the failure rate of the existing equipment during its remaining useful life. Secondly, we will model the causal relationship between maintenance, equipment reliability and equipment GHG emissions. To achieve the above objectives, we will develop a probabilistic R/R model using Bayesian networks (BNs), which also allows us to account for the uncertainty of effectual parameters. Equipped with expert knowledge and data-driven inference, the proposed model provides asset managers with a smart, explanatory mechanism that not only makes more accurate $\mathrm{R} / \mathrm{R}$ decisions, through capturing more effectual uncertainties and causal factors, but also identifies risk and opportunities that should be focused on to further reduce lifecycle economic and environmental costs.

The classic $\mathrm{R} / \mathrm{R}$ problem refers to the decision of whether to replace or maintain an operating asset. Traditionally, the motivation behind replacing an old system is its deterioration and increasing operating and maintenance (O\&M) costs. Yeh (1988) [142] used a geometric process technique that analysed the deterioration behaviour of a repairable system, where he considered separate replacement policies based on operation time or the number of failures. These models were later generalized by [143] using a bivariate replacement policy with both time of operation and the number of failures, either of which was enough to decide for the system replacement. Thereafter, more factors were taken into account in addition to O\&M costs. A large number of studies incorporated the technological improvement of new system into the R/R problem (e.g. $[48,62-64,73])$. Reindorp and Fu [144] and Stutzman et al. [145] considered the application of real options in asset rejuvenation instead of complete replacement. Fouladirad et al. [51] measured the sensitivity of three different time-based replacement policies to the uncertainty of unknown lifetime distribution parameters. Wang and Zhang [146] analysed the optimal replacement decision for equipment with two failure types: repairable failure and unrepairable failure. Limiting availability and long-run costs were the objectives to find the optimal decision, which is either the $\mathrm{n}^{\text {th }}$ repairable failure or the unrepairable 
failure (if it happens first). The application of the R/R problem has been also addressed in nonengineering assets, such as medical equipment [65] and tree harvesting [66].

The mere environmental evaluation of physical asset has been traditionally addressed by use of life cycle assessment (LCA), which is defined by International Standard Organization's ISO 14040 [147] as "the compilation and evaluation of the inputs, outputs and potential environmental impacts of a product system throughout its life cycle". There is ongoing research to combine LCC and LCA techniques to evaluate both economic and environmental impacts of physical assets in an integrated approach. For instance, Afrinaldi et al. [54] proposed an optimization model for preventive replacement schedule of a single system, which considers both cost and emission minimization objectives. The cost objective consists of O\&M, breakdowns, replacement items, and the emission objective covers the GHGs related to the operating phase and replacement action. Alba-Rodríguez et al. [148] compared the economic and environmental impacts of rehabilitation scenario of a building versus its demolition and total replacement with a new construction. They used project bill of quantities and ecological footprint as economic and environmental criteria, respectively. Using a multi-family building case study in Spain, they concluded that regardless of the building damage level, retrofit and repair is a more effective option. Ahani et al. [53] optimized the combination of electric vehicles (EVs) and internal combustion engine vehicles (ICEVs), taking into account the uncertainty of energy costs and EVs purchase costs. Feng and Figliozzi (2013) [76] proposed a replacement model for a fleet of electric commercial vehicles (ECVs), with an objective function that minimizes both financial costs and GHG costs. Some GHG accounts such as the emissions related to the manufacturing process of new equipment and salvaging old equipment are missing in this work. Giordano et al. (2017) [149] conducted a comprehensive study to compare the environmental, social and economic impacts of battery electric versus diesel vans. The result of this study proves the importance of indirect GHG emissions. They showed that in cities with a clean mix of electricity generation, replacing diesel vans with battery electric vehicles would significantly reduce carbon emissions (by 93 to 98 percent). In regions with coal-fired electricity generation, however, mitigation is only 12 to 13 percent.

In the literature, the models make simplified assumptions about the degradation and failure behaviour of equipment. For example, the models use static probabilistic failure distributions, which remain unchanged until the end of the equipment useful life. This is diametrically opposed to the intended dynamic failure distribution of this study that can be continuously modified through maintenance quality in specific and asset management performance in general. In addition, despite 
the fact that maintenance is a major part of the usage phase of a product life cycle, the environmental impact of maintenance itself has not been considered. Equipment complexity probably makes the maintenance steps more resource intensive, which consequently creates more environmental impact [150].

\subsection{Methodology}

In this section, we will elaborate on the details of different stages and aspects of the proposed model. Figure 19 graphically illustrates the modelling process. It begins with a deterministic repairreplacement model, with economic considerations. We were provided with an initial version of the deterministic model by our industry partner, Fiix Software, which was revised and improved in a few aspects (e.g. the blended decision which will be explained later in this chapter). This model will be then extended to incorporate the environmental burdens, specifically GHG emissions, of each decision scenario. At this stage, we converted the model into an algorithm and an automatic $R / R$ Calculator. The GHG calculator is used to support this part of the research. The next step is to map the model into a Bayesian network, which allows modelling the uncertainty of input parameters, PM quality and the extent to which the repair is perfect, risk events and other causal factors, which affect two or more parameters, and the casual relationship between equipment failure time and GHG emissions. In addition to the formulation of $\mathrm{R} / \mathrm{R}$ decision model, a learning feature is included in the model to improve the precision of this decision, considering new evidence from the system. Details of the above steps are described in the following subsections. 


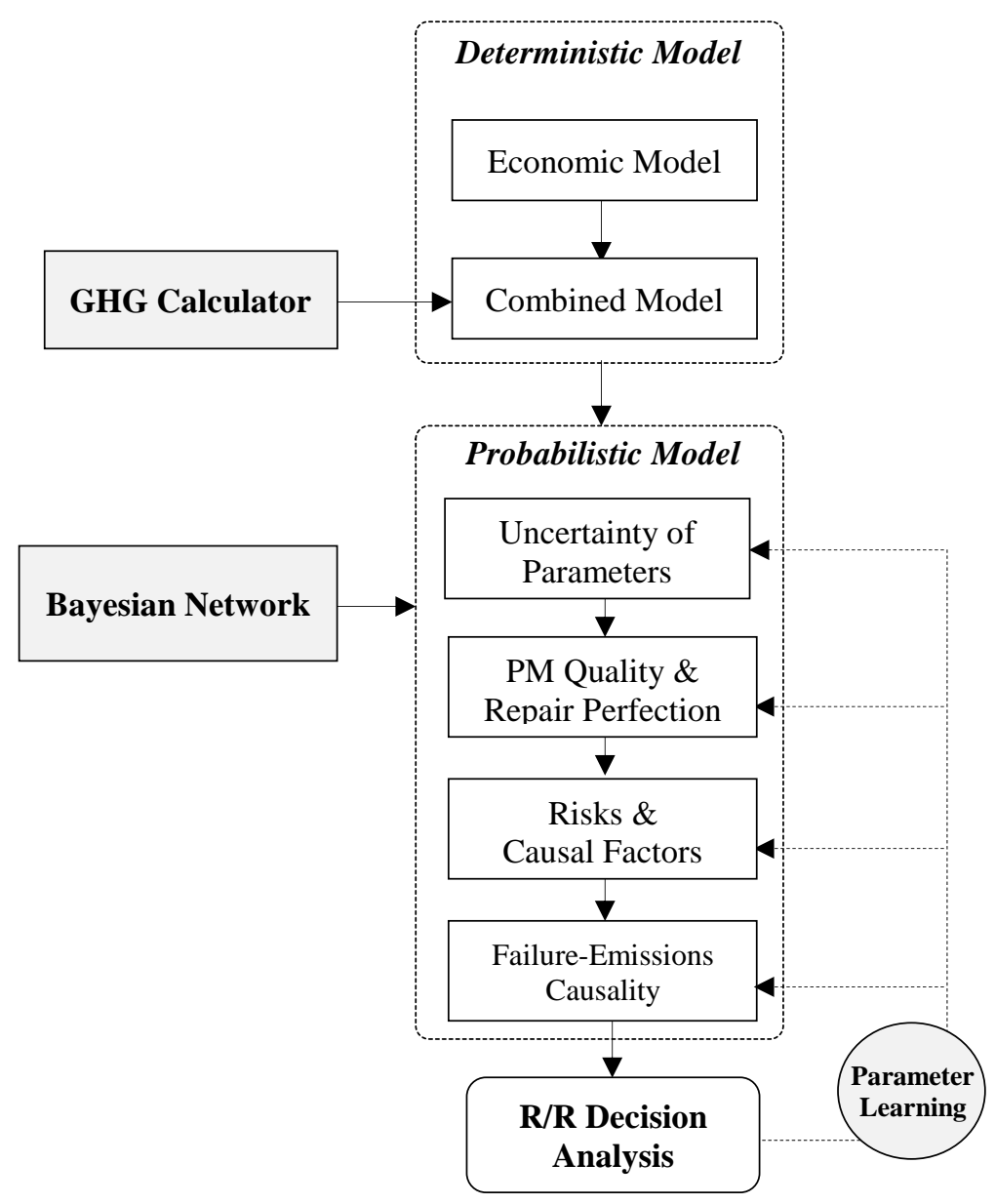

Figure 19: Different aspects of the proposed methodology

\subsubsection{Deterministic economic $R / R$ model}

The primary deterministic $\mathrm{R} / \mathrm{R}$ decision model calculates the total life cycle cost of equipment, based on cost breakdown structures of repair and replacement scenarios. The cost breakdown structures of the repair and replace scenarios are provided in Tables 15 and 16, respectively. The following sections describe their mathematical relations.

Table 15. Repair cost breakdown structure over the equipment remaining life

\begin{tabular}{lll}
\hline Level $\mathbf{0}$ & Level 1 & Level 3 \\
\hline Cost of repair (COR) & Labour costs & Direct labour cost \\
\cline { 2 - 3 } & & Indirect labour cost \\
\hline & $\begin{array}{l}\text { Cost of disposing component } \\
\text { Supplies }\end{array}$ & \\
\hline Cost of lost production (COL) & Cost of equipment downtime & Direct cost of lost profit from lost production \\
\cline { 2 - 3 } & & Cost of scrap per breakdown \\
\hline $\begin{array}{l}\text { Collateral costs per incident } \\
\text { (COC) }\end{array}$ & $\begin{array}{l}\text { Occupational health and safety } \\
\text { fines and penalties }\end{array}$ & \\
\hline
\end{tabular}




\begin{tabular}{ll}
\hline & $\begin{array}{l}\text { Miscellaneous legal liability } \\
\text { costs }\end{array}$ \\
\hline Cost of Inventory (COI) & $\begin{array}{l}\text { Capital cost of additional } \\
\text { rotating spares to compensate } \\
\text { for lost production (CCR) }\end{array}$ \\
\cline { 2 - 2 } & Capital carrying cost (CCC) \\
\hline $\begin{array}{l}\text { Impact on product quality and } \\
\text { production capacity (IPQ) }\end{array}$ & \\
\hline
\end{tabular}

Table 16. Cost breakdown structure to replace equipment

\begin{tabular}{|c|c|c|}
\hline Level 0 & Level 1 & Level 3 \\
\hline \multirow{5}{*}{$\begin{array}{l}\text { Disposal and salvage cost } \\
\text { (DSC) }\end{array}$} & \multirow[t]{3}{*}{ Cost of decommissioning } & Direct labour cost \\
\hline & & Indirect labour cost \\
\hline & & Cost of disposing equipment \\
\hline & Realized salvage value & \\
\hline & Write off cost (non-cash) & \\
\hline \multirow[t]{11}{*}{$\begin{array}{l}\text { Equipment replacement cost } \\
\text { (ERC) }\end{array}$} & $\begin{array}{l}\text { Cost of researching replacement } \\
\text { unit }\end{array}$ & \\
\hline & Direct cost of new equipment & \\
\hline & Cost of spare parts inventory & \\
\hline & Inbound shipping & \\
\hline & Monthly financing cost & \\
\hline & \multirow{6}{*}{$\begin{array}{l}\text { Cost of installing replacement } \\
\text { equipment }\end{array}$} & Direct labour Cost \\
\hline & & Indirect labour cost \\
\hline & & Parts and supplies \\
\hline & & Safety inspection and certifications \\
\hline & & Training \\
\hline & & Safety meetings \\
\hline Lost production cost (LPC) & $\begin{array}{l}\text { Direct cost of lost profit from lost } \\
\text { production }\end{array}$ & \\
\hline \multirow{6}{*}{$\begin{array}{l}\text { During warranty cost/saving } \\
\text { (DWC/S) }\end{array}$} & \multirow{5}{*}{$\begin{array}{l}\text { Impact on product quality and } \\
\text { production capacity }\end{array}$} & Improved production capacity \\
\hline & & $\begin{array}{l}\text { Miscellaneous impact on improved quality } \\
\text { (returns, reworks, etc.) }\end{array}$ \\
\hline & & $\begin{array}{l}\text { Reduced operating costs (energy, utilities, } \\
\text { services, etc.) }\end{array}$ \\
\hline & & Labour (reduction if negative) \\
\hline & & Indirect labour cost (overhead) \\
\hline & Cost of scrap & \\
\hline \multirow{12}{*}{$\begin{array}{l}\text { Out of warranty cost } \\
\text { (OWC/S) }\end{array}$} & \multirow[t]{3}{*}{ Cost of removing component } & Direct labour cost \\
\hline & & Indirect labour cost (overhead) \\
\hline & & Cost of disposing component \\
\hline & \multirow{3}{*}{$\begin{array}{l}\text { Cost of installing replacement } \\
\text { components }\end{array}$} & Direct labour cost \\
\hline & & Indirect labour cost (overhead) \\
\hline & & Cost of replacement parts and supplies \\
\hline & \multirow[t]{3}{*}{ Cost of equipment downtime } & $\begin{array}{l}\text { Direct Cost of lost profit from lost } \\
\text { production per day }\end{array}$ \\
\hline & & Cost of Scrap per breakdown \\
\hline & & Miscellaneous Costs \\
\hline & \multirow[t]{3}{*}{ Collateral costs } & Environmental clean-up, fines, etc. \\
\hline & & $\begin{array}{l}\text { Occupational health and safety fines and } \\
\text { penalties }\end{array}$ \\
\hline & & Miscellaneous legal liability costs \\
\hline
\end{tabular}




\begin{tabular}{ll} 
Cost of spares inventory & $\begin{array}{l}\text { Capital cost of additional rotating spares to } \\
\text { compensate for lost production }\end{array}$ \\
\hline Capital carrying cost
\end{tabular}

Impact on product quality and

production capacity (IPQ)

\subsubsection{Repair scenario}

Total repair cost (TRC) of the old equipment accounts for five categories of cost items: cost of repair $(\mathrm{COR})$ if a failure occurs; cost of lost production (COL) due to corrective maintenance; collateral costs (COC); cost of inventory (COI); and impact on product quality and production capacity (IPQ):

$$
\mathrm{TRC}=\mathrm{COR}+\mathrm{COL}+\mathrm{COC}+\mathrm{COI}+\mathrm{IPQ}
$$

Cost of repair, COR, is calculated from the expected number of failures, $n$, over the remaining equipment service lifetime in months, $l$, and the sum of labour costs (LAC), cost of disposing component (CDC), and cost of replacement parts and supplies (CRP):

$$
\mathrm{COR}=n *(\mathrm{LAC}+\mathrm{CDC}+\mathrm{CRP})
$$

Labour costs consist of direct cost of labour to complete total repair duration (TRD) in hours (including notification and diagnostic, fix time, reassembly alignment and calibration, and test time) and indirect labour costs as an overhead percentage for fully loaded labour rate (a), based on a standard labour rate per hour $(r)$ :

$$
\mathrm{LAC}=\mathrm{TRD} *(1+\mathrm{a}) * r
$$

Cost of lost production, COL, is calculated from the amount of downtime (practically TRD) in days multiplied by the cost of lost profit from lost production per day $(c)$, plus cost of scrap per breakdown (CSB). The total COL is obviously the product of $n$ and the above costs per incident:

$$
\mathrm{COL}=n *\left(\frac{\mathrm{TRD}}{8} * c+\mathrm{CSB}\right)
$$

Collateral costs, COC, includes occupational health and safety fines and penalties (OHS) and miscellaneous legal liability costs (LLC):

$$
\mathrm{COC}=n *(\mathrm{OHS}+\mathrm{LLC})
$$

Cost of inventory, COI, accounts for capital cost of additional rotating spares to compensate for lost production (CAR) and capital carrying cost (CCC):

$$
\mathrm{COI}=\mathrm{CAR}+\mathrm{CCC}
$$


CAR and CCC are calculated as follows:

$$
\begin{aligned}
& \mathrm{CAR}=s * \mathrm{CRP} \\
& \mathrm{CCC}=\mathrm{CAR} *\left(\frac{i}{12}\right) * l
\end{aligned}
$$

where $s$ is the number of scraps and $i$ is the annual cost of money. Finally, in this category of cost items, the impact on product quality and production capacity (IPQ) is formulated as IPQ $=-c * 30 *$ $\rho * l$, where $\rho$ denotes the percentage of production capacity gain or loss (if negative) following breakdown and repair. The value of IPQ is a measure of lost production cost, capacity gain/loss, and remaining lifetime in months.

Deterministically, the expected number of failures, $n$, is obtained by rounding up the ratio of the remaining useful life, $l$, to the mean time between failures (MTBF), that is, the sum of mean time to failure (MTTF) in months and the total repair duration, TRD:

$$
n=\left[l /\left(\mathrm{MTTF}+\frac{\mathrm{TRD}}{8 * 30}\right)\right]+1
$$

\subsubsection{Replacement scenario}

Total replacement cost $\left(\mathrm{TCR}^{\prime}\right)$ of the old equipment with a brand-new, takes into account the five categories of cost items: disposal and salvage costs (DSC); equipment replacement costs (ERC); lost production costs during replacement period (LPC); during warranty costs/savings (DWC/S); and out of warranty costs/savings (OWC/S):

$$
\mathrm{TCR}^{\prime}=\mathrm{DSC}+\mathrm{ERC}+\mathrm{LPC}+\mathrm{DWC} / \mathrm{S}+\mathrm{OWC} / \mathrm{S}
$$

Disposal and salvage costs, DSC, is calculated by considering the cost of decommissioning (COD), realized salvage value (RSV) of the retired equipment, and non-cash write off costs (WOC). COD is calculated from the hours required to complete the decommissioning process (TDD), indirect costs coefficient, and the standard labour rate per hour:

$$
\begin{aligned}
& \mathrm{DSC}=\mathrm{COD}-\mathrm{RSV}+\mathrm{WOC} \\
& \mathrm{COD}=\mathrm{TDD} *(1+\mathrm{a}) * \mathrm{r}
\end{aligned}
$$

Equipment replacement costs, ERC, factors in the cost of researching replacement unit (CRU), direct cost of new equipment (DCN), cost of spare parts inventory, as a percentage of equipment purchase price $(j)$, inbound shipping costs (ISC), monthly financing costs (MFC) to tie up working capital, and cost of installing replacement equipment (CIR): 


$$
\mathrm{ERC}=\mathrm{CRU}+\mathrm{DCN} *(1+j)+\mathrm{ISC}+\mathrm{MFC}+\mathrm{CIR}
$$

where cost of researching the replacement unit is calculated by multiplying the total selection duration (TSD) and the standard labour rate, and adding the related indirect costs: CRU $=\mathrm{TSD} *(1+\mathrm{a}) * r$. Monthly financing costs (as the cost to tie up working capital) includes the cost of invested money in replacement scenario, which is modelled as follows:

$$
\mathrm{MFC}=l *\left(\frac{i}{12}\right) *(\mathrm{DCN} *(1+j)+\mathrm{ISC}-\mathrm{RSV})
$$

Cost of installing replacement equipment, CIR, is computed using the following equation in which the direct and indirect labour costs associated with the total installation duration (TID), as well as the cost of parts and supplies (CPS), safety inspection and certification (SIC), training (TRN), and safety meetings (SMS) are factored in:

$$
\mathrm{CIR}=\mathrm{TID} *(1+\mathrm{a})+\mathrm{CPS}+\mathrm{SIC}+\mathrm{TRN}+\mathrm{SMS}
$$

Lost production cost during replacement period, LPC, is obtained from the total downtime until the replacement equipment is production ready and the corresponding lost profit. The total downtime would be the critical path (CP) over the activities of the replacement process, as depicted in Figure 20 , where LT is the lead time for receiving the equipment after placing the purchase order. Therefore, $\mathrm{LPC}=\left(\frac{\mathrm{CP}}{8}\right) * c$.

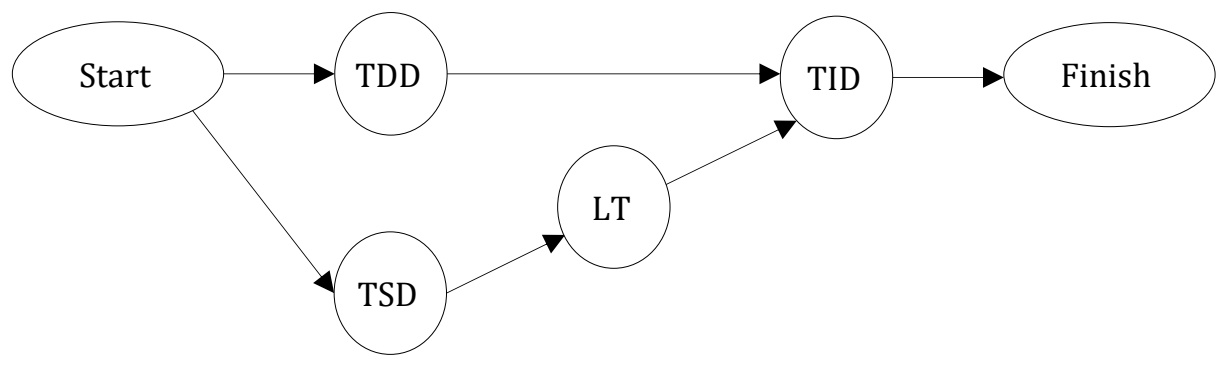

Figure 20: Activity on node diagram of the replacement process

During warranty costs/savings (DWC/S) is computed by taking into account the monthly impact of replacement on productivity (MIP), cost of scrap per breakdown, CSB, the expected number of failures during warranty period $\left(n^{\prime}\right)$, and the mean time to failure during warranty $\left(\mathrm{MTTF}^{\prime}\right)$ :

$$
\mathrm{DWC} / \mathrm{S}=\mathrm{CSB} * n^{\prime}-\mathrm{MIP} * \mathrm{MTTF}^{\prime}
$$

It is assumed that the reliability of new equipment will be improved by $\theta$ as a proxy for new mean time to failure: $\mathrm{MTTF}^{\prime}=\operatorname{MTTF} *(1+\theta)$. Clearly, $n^{\prime}=\left[\frac{\omega}{\operatorname{MTTF} *(1+\theta)+\frac{\mathrm{TRD}}{8 * 30}}\right]$. Monthly impact on 
productivity during the warranty period, MIP, measures the productivity increase of replacement unit during warranty, in terms of costs. It is calculated using the following formula, where $\sigma$ and $\tau$ denote improved production capacity of new equipment during warranty, and miscellaneous impact on improved quality (returns, reworks, etc.), respectively. ROC is the reduced operating costs (energy, utilities, services, etc.), FTE is the full time equivalent increase (or reduction if negative), $r^{\prime}$ is the related standard labour rate per hour, and $\omega$ is the warranty period:

$$
\mathrm{MIP}=(\sigma+\tau) * c * 30+\mathrm{ROC}+\mathrm{FTE} * 40 * 4 *(1+\mathrm{a}) * r^{\prime}
$$

Out of warranty costs/savings (OWC/S) is formulated as follows:

$$
\mathrm{OWC} / \mathrm{S}=n^{\prime \prime}(\mathrm{COR}+\mathrm{COC}+\mathrm{COL})+\mathrm{COI}^{\prime}-c * 30 * \rho *(l-\omega)
$$

where $n^{\prime \prime}$ is the expected number of failures after the warranty period; $n^{\prime \prime}=\left[\frac{l}{M T T F \prime}\right]-n^{\prime}$. COI' represents the cost of inventory after the warranty period which is calculated as COI $=s *$ $\operatorname{CRP}\left(1+\left(\frac{i}{12}\right) *(l-\omega)\right)$. Other cost items in this equation were defined earlier in the repair scenario.

\subsubsection{Blended repair and replace scenario}

It may take less time to repair an equipment than replacing it. Consider a case where the total cost of replacement decision is less than that of the repair decision. In this case, if the equipment can be repaired in a shorter time than the lead time, in essence TRD $<$ LT, and the cost of lost production during this lead time (CLT) is more than that of a one-time repair (CLT > COR + COC), then it is less costly to start repairing the old equipment in addition to placing the order for the new unit at the same time. Figure 21 graphically represents the above discussion.

Total replacement down time

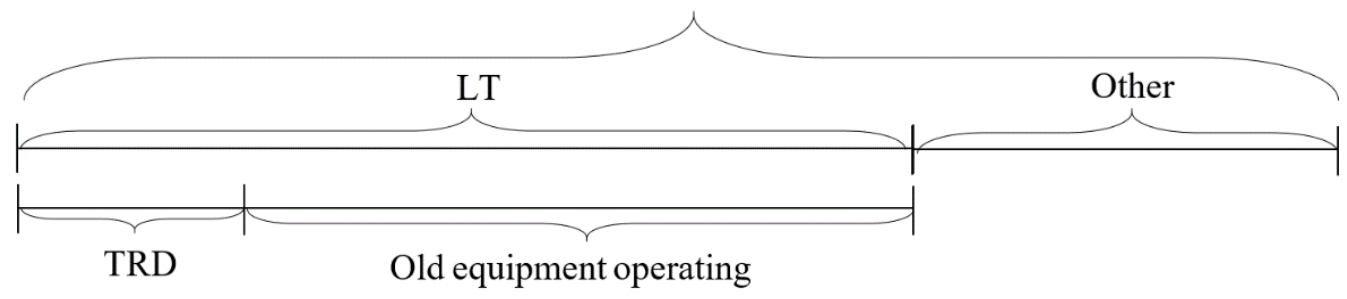

Figure 21: A condition for the mixed 'repair and replacement' decision

\subsection{Combined model}

We extend the deterministic $\mathrm{R} / \mathrm{R}$ model to a combined model with both environmental and economic 
considerations. For the environmental dimension of the decision model, we incorporate the impact of different life cycle stages of both defender and challenger, where applicable. The stages are: manufacturing; shipping; O\&M; and decommissioning. One or a group of impact category [151] such as Acidification Potential, Eutrophication Potential, Global Warming Potential, Ozone Depletion Potential, Photochemical Ozone Creation Potential, and Primary Energy Use can be used to construct the environmental dimension of the model. In this study, we use GHG emissions as an indicator for Global Warming Potential category to account for the environmental impacts of an equipment, when it comes to make an $\mathrm{R} / \mathrm{R}$ decision.

To have a single cost-based measure, emissions will be then converted into a monetary value, using the price of carbon in the related carbon market. To account for the cost of emissions corresponding to each decision scenario, total costs to repair and replacement of the equipment is revised as follows:

$$
\begin{aligned}
& \mathrm{TCR}_{\varepsilon}=\mathrm{TCR}+l * \mathrm{E}_{\mathrm{O} \& \mathrm{M}} \\
& \mathrm{TCR}_{\varepsilon}^{\prime}=\mathrm{TCR}^{\prime}+\mathrm{E}_{\mathrm{dec}}+\mathrm{E}_{\text {man }}+\mathrm{E}_{\text {ship }}+l * \mathrm{E}_{\text {O\&M }}^{\prime}
\end{aligned}
$$

where $\mathrm{TCR}_{\varepsilon}$ and $\mathrm{TCR}_{\varepsilon}^{\prime}$ represent the total cost of repair and replacement with both economic and environmental impacts. $E_{\text {man }}, E_{\text {ship }}$, and $E_{\text {dec }}$ denote the cost of emissions associated with manufacturing the challenger, shipping the challenger to the operation site, and decommissioning the defender, respectively. $\mathrm{E}_{O \& M}$ and $\mathrm{E}_{\mathrm{O} \& \mathrm{M}}^{\prime}$ represent the monthly emission cost of O\&M activities associated with the old and new equipment, respectively. Therefore, as long as $\mathrm{TCR}_{\varepsilon}>\mathrm{TCR}_{\varepsilon}^{\prime}$, the decision would be to maintain the defender.

We have converted the above model into an automatic repair/replacement (R/R) Calculator. The interface of this tool is shown in Figure 22. The tool is connected with the GHG Calculator (Appendix B) which allows the user to enter the activity data associated with each LCA phases and send their final carbon emissions to the R/R tool. We have also included a database of the carbon price in the carbon markets or carbon tax systems that are currently in place all over the world. Hence, the R/R tool is able to calculate the emission costs and add them to the economic cost items. 


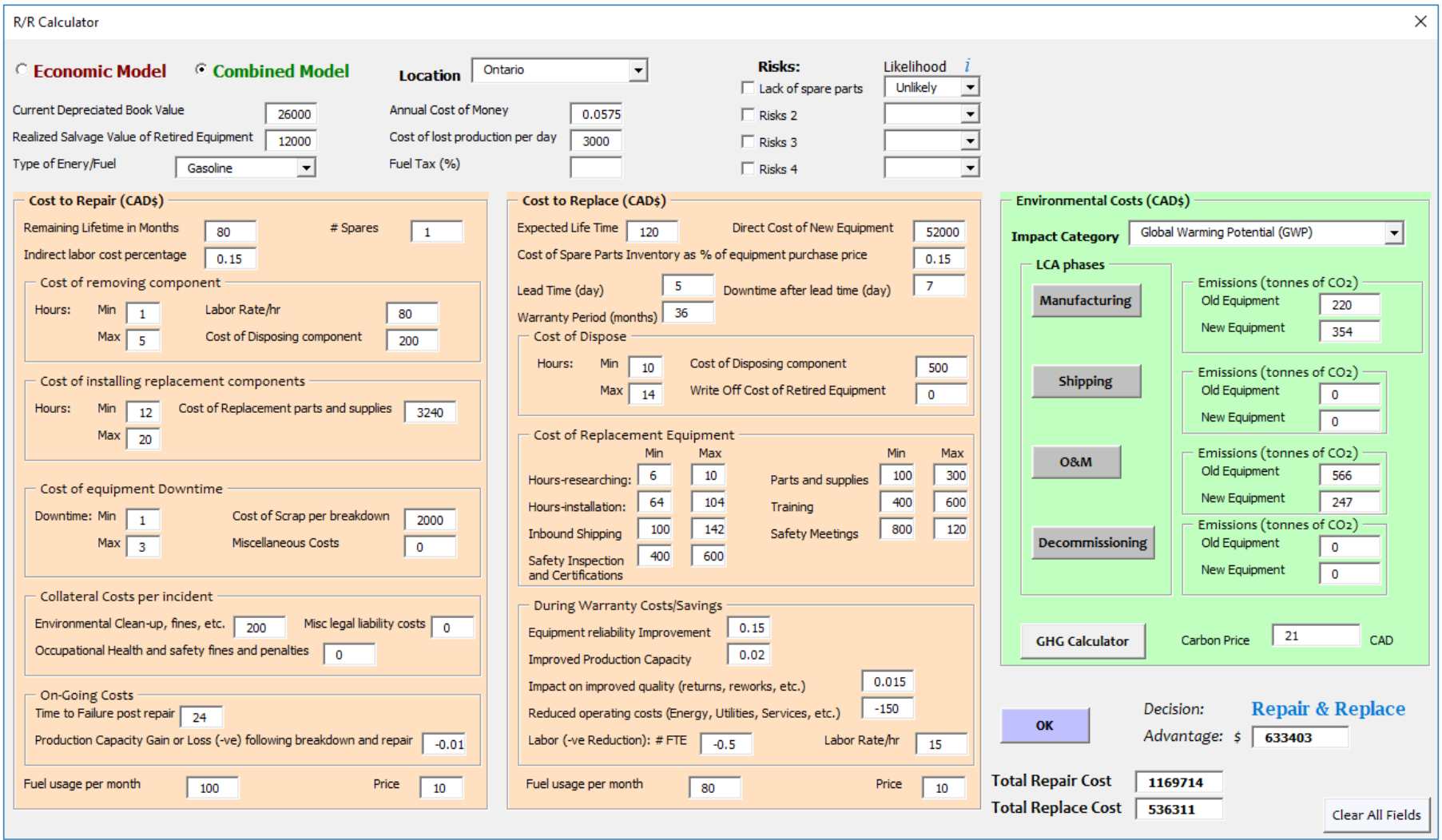

Figure 22: The R/R Calculator

\subsection{Probabilistic model}

In this section, we map the deterministic R/R model into a fully probabilistic model, using Bayesian networks. Then, we will include supplementary variables to incorporate the effect of PM quality, repair perfection, risks and common causal factors.

We first describe the economic Bayesian $R / R$ model and then the emissions modelling part will be incorporated. The schematic of the economic Bayesian $R / R$ is presented in Figure 23. A node is created in the $\mathrm{BN}$ model for the density function of the $i$ th failure time. If the equipment is new, the first failure density function is a baseline distribution, $\mathrm{f}_{0}$, with one or more parameters, depending on the type of the distribution. Failure density of the equipment is influenced by PM Quality and Repair Perfection nodes. Therefore, depending on the quality of PM and the perfection of repair, the next failure time will be reformed. This reformation is also advised by the actual failure times (occurred $i$ 1 times), through parameter learning feature of the model, which will be elaborated on later in this chapter. Accordingly, the expected number of failures during the useful lifetime of the equipment (n) is revised. A ranked probabilistic variable, with a 5-point Likert scale (Very poor, Poor, Fair, Good, Excellent) is assigned to PM Quality. Repair Perfection is modelled 
using a Bernoulli variable with two states: "Yes" and "No", such that $\operatorname{Pr}(\mathrm{Yes})=p$, and $\operatorname{Pr}(\mathrm{No})=q$, where $q=1-p$. This is compatible with the $(p, q)$ rule, which was first introduced by Nakagawa (1979) [152] for treating imperfect maintenance. We assign a prior distribution, $\mathrm{f}(\mathrm{y}), 0<\mathrm{y}<1$, to the node $p$, where the mean value of which will flow to the Repair Perfection node. PM Quality and $\mathrm{f}(\mathrm{y})$ can be estimated either from an expert judgment or by conditioning them on technical causes, such as repairing the wrong part, damaging adjacent parts, etc., and then use corresponding historical data, if available. There are several possible causes that contribute to an imperfect repair and/or a poor maintenance: repairing the part incompletely; repairing amiss part; damaging adjacent part(s); inaccurately determining the condition of the inspected unit; tardy maintenance; and invisible faults and breakdowns that are not noticeable during maintenance $[152,153]$.

The NPT of the node $\mathrm{f}_{i}$ is dependent on the status of the nodes Repair Perfection and PM Quality, as well as the updated baseline density function, $\mathrm{f}_{0}^{i-1}$, which its parameters have been now learnt from the observed times of the previous failures $\left(\mathrm{f}_{1}^{a}, \mathrm{f}_{2}^{a}, \ldots, \mathrm{f}_{i-1}^{a}\right)$. This updated density function will be intensified or diminished, depending on the PM quality and repair perfection status. If "Repair Perfection" = No, and "PM Quality" = Fair, then $\mathrm{f}_{i}=\mathrm{f}_{i-1}$, which means the equipment will have the same failure behaviour as what it had before the latest breakdown. If "Repair Perfection" = Yes, and "PM Quality" = Fair, then $\mathrm{f}_{i}=\mathrm{f}_{0}$, which means the equipment will have the failure behavior of a brand new one.

Applying backward propagation and effect to cause inference, the model infers the actual levels of PM quality and repair perfection, and updates the prior estimation of failure distribution parameters, using actual inter-failure times $\left(\mathrm{f}_{1}^{a}, \mathrm{f}_{2}^{a}, \ldots, \mathrm{f}_{i-1}^{a}\right)$. Posterior probabilities of PM Quality, for example, are updated using the following Bayes rule:

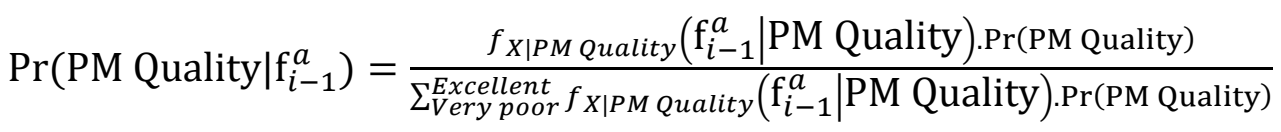

Consequently, the next time-to-failure, the number of failures during the remaining useful life (that is $l-\sum_{k=1}^{i-1} \mathrm{f}_{k}^{a}$ ), and therefore a considerable part of total repair cost will be predicted. 


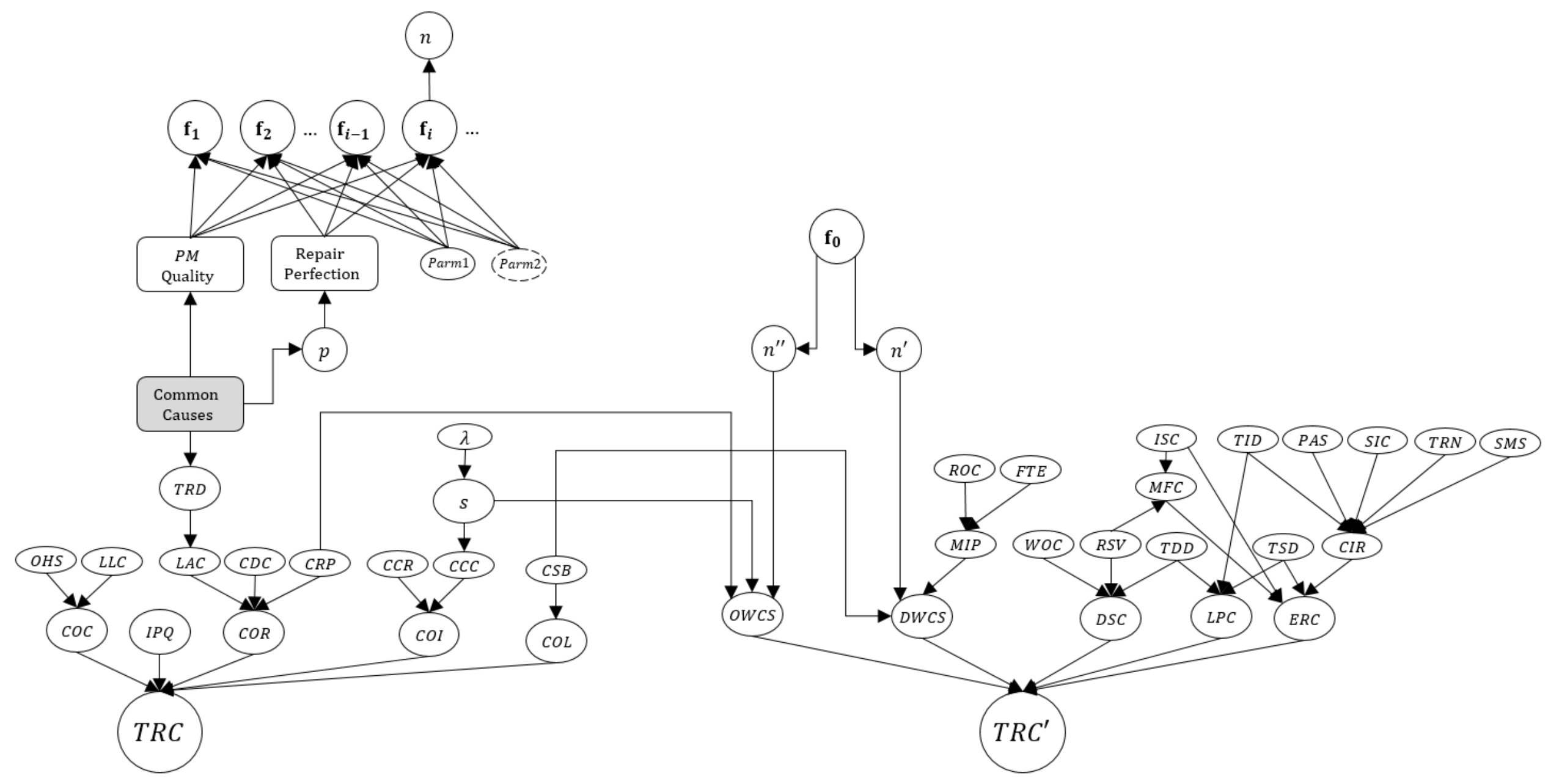

Figure 23: Economic Bayesian R/R model 
Together with PM Quality, the prior for the level of repair perfection ( $f(y))$ can be informed by common causal factors, such as staff experience, the maturity of (asset) management system, material quality, and so forth. These common causes might also affect the equipment maintainability and total repair duration (TRD). Like PM Quality, a ranked variable is assigned to the common causes related to repair durations. The simple BN in Figure 24 describes this dependency. Variables $D_{1}, D_{2} \ldots, D_{n}$ represent $n$ repair task durations (e.g. notification and diagnosis, fix time, wait time, reassembly alignment and calibration, and test time), and variable E represents a cause to $D_{i}$, such as shared experience, which influences repair perfection (R). The dependency connection between $R, E$, and $D$ is $\operatorname{Pr}(R, E, D)=\operatorname{Pr}(E \mid R) \operatorname{Pr}(E \mid D) \operatorname{Pr}(E)$, which means evidence on repair durations will influence experience and this subsequently influences the repair perfection. In this example, as discussed above, an observation on repair duration $D_{i}$ will infer the level of experience which in turn updates the duration of remaining tasks, $D_{j}$, as well as the level of repair perfection.

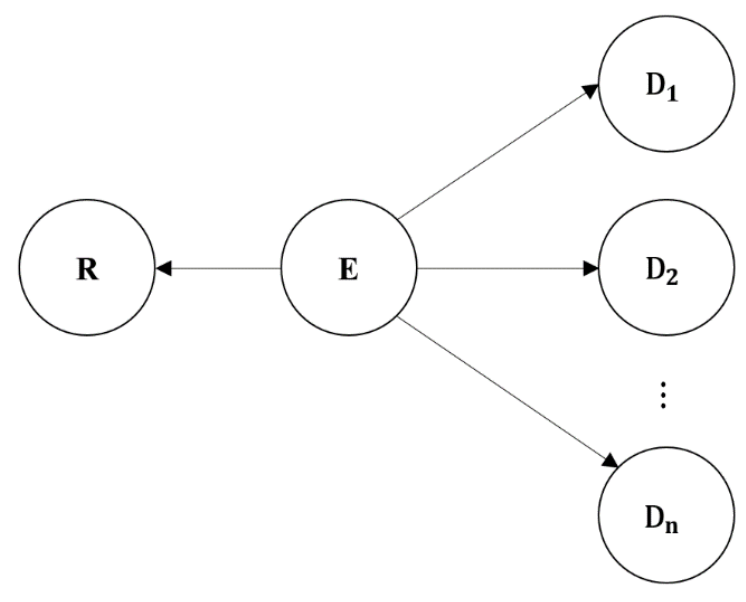

Figure 24: A BN to model the dependency between repair tasks durations $\left(D_{i}\right)$ and the shared driving factor experience (E) (a) and its influence on the repair perfection (R)

As depicted in the graph of Figure 23, a node is created for other time and cost items of the deterministic model, e.g. total selection duration (TSD), total installation duration (TID), realized salvage value (RSV), inbound shipping costs (ISC), etc. The distribution of these variables can be generated from historical data if data from similar cases is available. If we have insufficient or no historical data, the probability distribution can be elicited from expert-but subjective- judgment. 
A Poisson distribution with the parameter $\lambda$ is assigned to the node " $s$," corresponding to the number of spare parts per breakdown. Considering the previous failures as independent tests (Figure 25), the observations on the number of spare parts result in $i-1$ independent Poisson distributions: $\left\{s_{\zeta}\right\}_{\zeta=1}^{\mathrm{i}-1} \sim$ Poisson $(\lambda)$. The conjugate prior distribution for Poisson's parameter is Gamma with unknown hyperparameters $\alpha$ and $\beta$ [154]: $\lambda \sim \operatorname{Gamma}(\alpha, \beta) ; \mathrm{f}(\lambda)=$ $\frac{\beta^{\alpha}}{\Gamma(\alpha)} \lambda^{\alpha-1} e^{-\beta \lambda}, \lambda>0$, where $\alpha$ is the shape parameter, $\beta$ is an inverse scale parameter, and $\mathrm{f}(\lambda)$ is the Gamma density to distribute $\lambda$.

A prior probability distribution should be now assigned to the hyperparameters $\alpha$ and $\beta$. Because $\alpha$ and $\beta$ are unknown, there is no joint conjugate prior for them and hence their priors need to be specified independently. Although vague priors can be assigned to them, we can feed the model with priors containing additional information from experts. We assign Triangular priors for the shape and inverse scale, where its parameters are decided by experts: $\alpha \sim$ Triangular $\left(\mathrm{a}_{\alpha}, \mathrm{b}_{\alpha}, \mathrm{c}_{\alpha}\right) ; \log _{10} \beta \sim$ Triangular $\left(\mathrm{a}_{\beta}, \mathrm{b}_{\beta}, \mathrm{c}_{\beta}\right)$. Based on a sample of $i-1$ observations of the number of spare parts, the posterior distribution of the rate of spare parts per failure is: $\lambda \sim \operatorname{Gamma}\left(\alpha+\sum_{k=1}^{i-1} s_{k}, \beta+i-1\right)$. If there is only one observed number of spare part, the posterior becomes a negative binomial distribution [155] called the Gamma-Poisson distribution.

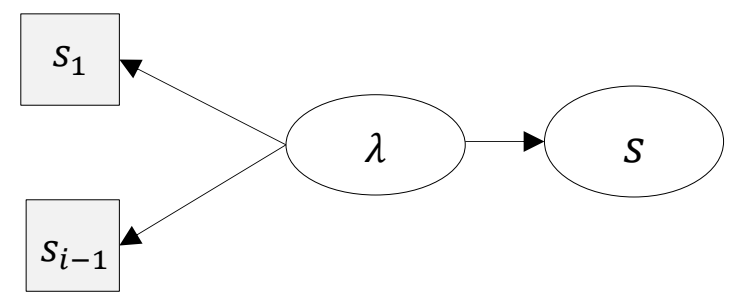

Figure 25: Learning structure for the rate of spare parts per failure

\subsubsection{Incorporating risk events}

It is assumed that the purpose of the probability distributions derived for the model quantities is to capture the quantities' inherent uncertainty. Therefore, these distributions do not account for event risks which, if they occurred, might escalate some of the quantities on both repair and replacement scenarios. For instance, rapid pace in technological change is an uncertain event that leads to unexpected obsolescence and consequently a lower realized salvaged value (RSV) 
of the equipment. To incorporate such risks into the $\mathrm{R} / \mathrm{R}$ model, we propose using a qualitative risk analysis with the following steps:

1 Risk identification: relevant risks can be identified through brainstorming sessions, historical records, or conducting special interviews with experts considering one or more quantity.

2 Risk analysis: the probability of occurrence and the impact of each identified risk will be estimated. Following the same structure in many risk management practices and standards $[94,156,157]$, the scales presented in Table 17 will be used to perform this step.

3 Risk connection: a node will be created for each risk and will be connected to the related quantity. The estimated probability acts as the prior probability of this node and the estimated impact will be used to revise the NPT of the affected quantity.

4 Risk mitigation: regardless of the optimal decision (repair or replacement), responses to the highest risks will be designed such that they will be possibly transmitted to lower levels and the total cost associated with the optimal decision will be further lowered. A Probability-Impact matrix can be used to classify the risks into ranked levels and identify the highest risks in need of a response.

Table 17. Risk probability and impact scales

\begin{tabular}{ll|ll}
\hline \multicolumn{2}{c|}{ Probability } & \multicolumn{1}{c}{ Impact } \\
\hline Improbable, not expected to occur & 0.10 & Very low & $\begin{array}{l}\text { Insignificant } \\
\text { impact }\end{array}$ \\
\hline Seldom, likely than not to occur & 0.30 & Low & $<10 \%$ impact \\
\hline Occasional, may or may not occur & 0.50 & Moderate & $10-20 \%$ impact \\
\hline Likely, more likely than not to occur & 0.70 & High & $20-40 \%$ impact \\
\hline Frequent, expected to occur & 0.90 & Very high & $>40 \%$ impact \\
\hline
\end{tabular}

\subsubsection{Incorporating emissions}

Similar to the cost and time items of the R/R model, a triangular distribution will be fit to the cost of $\mathrm{GHG}$ emissions related to keeping the old equipment $\left(\mathrm{E}_{\mathrm{O} \& \mathrm{M}}\right)$ and replacing it with new equipment $\left(E_{\mathrm{dec}}+\mathrm{E}_{\text {man }}+\mathrm{E}_{\text {ship }}+\mathrm{E}_{\mathrm{O} \text { \&M}}^{\prime}\right)$. Based on the assumption of a positive correlation between equipment reliability and the amount of consumed energy [55], we aim to find the causal relationship between the equipment failure distribution and its O\&M emissions. As illustrated in Figure 26, an emission impact scale (EIS) is defined for the latest predicted $\mathrm{f}_{i}$ as 
follows:

$$
\left\{\begin{array}{c}
\operatorname{Pr}\left(E S_{\mathrm{i}}=\text { Normal }\right)=\operatorname{Pr}(\mathrm{X} \geq \text { EET })=\int_{\text {EET }}^{\infty} \mathrm{f}_{\mathrm{i}}(\mathrm{X}) \mathrm{dx} \\
\operatorname{Pr}\left(\mathrm{EIS}_{\mathrm{i}}=\text { Scalating }\right)=\operatorname{Pr}(\mathrm{X}<\mathrm{EET})=\int_{0}^{\text {EET }} \mathrm{f}_{\mathrm{i}}(\mathrm{X}) \mathrm{dx}
\end{array} .\right.
$$

where $\mathrm{X}$ represents the possible values of the failure density function and EET is an unknown emission escalating threshold. That is to say, a shorter MTTF contributes to a larger energy consumption and GHG emission if it is less than a normal range [EET, $\infty$ ). The parameter EET can be modeled with an expert prior and be trained through experiments or historical records on both failure time and consumed energy, as a measure of emitted GHGs. It will be further trained after $(i-1)$ failures during the use phase of the current equipment as well. Let the probability distribution of O\&M emissions of new equipment be denoted as $f_{N}(e)$ and that of a retired equipment (which has reached to the end of its useful life) be denoted as $f_{R}(e)$. The cost of emissions associated with the equipment before its $(i-1)$ th failure is calculated as follows:

$$
\mathrm{E}_{\mathrm{O} \& \mathrm{M}}=\left[\operatorname{Pr}\left(\mathrm{IS}_{i}=\text { Normal }\right) \cdot \mathrm{f}_{\mathrm{N}}(\mathrm{e})+\operatorname{Pr}\left(\mathrm{IS}_{i}=\text { Scalating }\right) \cdot \mathrm{f}_{\mathrm{R}}(\mathrm{e})\right] * \mathrm{CP}
$$

where $\mathrm{CP}$ is the price of carbon emissions in a carbon market. As illustrated in Figure 26, the cost distribution of other emission items in each scenario is integrated into the economic impact to simulate the total combined economic and environmental impacts of the defender $\left(\mathrm{TRC}_{\varepsilon}\right)$ and the challenger $\left(\mathrm{TRC}_{\varepsilon}^{\prime}\right)$.

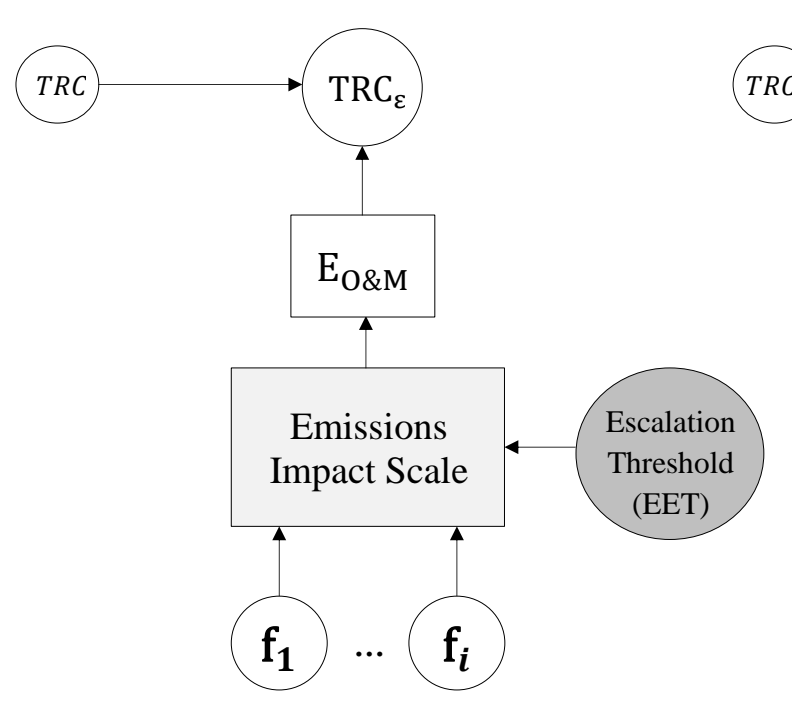

Figure 26: Integration of emission costs into the economic model 


\subsection{Case study and analytical results}

In this section, we demonstrate the application and analytical capabilities of the proposed model, using a plastic shredder case. The defender is Noma 44 XLR Plastic Shredder and the challenger is Noma XJ57 Grinder. The information on the model parameters and prior probabilities were estimated as presented in Tables 18-22. Table 18 includes the information on constants and most of the nodes that do not have a parent. The failure probability density functions are assumed to follow a Weibull distribution with the scale and shape parameters $\eta$ and $\gamma$, respectively. The useful life of a plastic shredder is considered 120 months. The old equipment has been operating for 41 months, and that two breakdowns have occurred thus far, with failure times 22 and 14 months, respectively. The number of spare parts associated with the failures were 2 and 3 . The common cause "Experience" affects both Repair Perfection and total repair duration consisting of the repair tasks: diagnosis time, fix time, reassembly alignment and calibration (RAC) time, and test time. This experience factor refers to the experience of the repair staff. The prior probability of repair perfection $(\mathrm{f}(\mathrm{y}))$ and the distribution of the above repair tasks conditional on this common cause are presented in Table 19. We have assumed that PM Quality is not influenced by Experience in this case study.

Table 18. Estimated parameters and probabilities for the Bayesian $\mathrm{R} / \mathrm{R}$ calculation

\begin{tabular}{|c|c|c|c|}
\hline$l$ & 84 months & $\mathrm{DCN}$ & $\mathrm{C} \$ 52000$ \\
\hline$c$ & $\mathrm{C} \$ 3000 /$ day & $\mathrm{CDC}$ & Triangular $(184,200,228) \mathrm{C} \$$ \\
\hline$\rho$ & $-1 \%$ & CRP & Triangular $(2950,3200,3550) \mathrm{C} \$$ \\
\hline $\mathrm{a}$ & $15 \%$ & $\mathrm{CSB}$ & Triangular $(1740,2000,2280) \mathrm{C} \$$ \\
\hline j & $15 \%$ & $\mathrm{OHS}$ & $0 \mathrm{C} \$$ \\
\hline$i$ & $5.75 \%$ & LLC & $0 \mathrm{C} \$$ \\
\hline$\omega$ & 36 months & TDD & Triangular $(9.5,12,14.8) \mathrm{hrs}$ \\
\hline$\sigma$ & $2 \%$ per month & TSD & Triangular $(6.5,8,9.9) \mathrm{hrs}$ \\
\hline$\tau$ & $1.5 \%$ per month & TID & Triangular $(79.5,84,91.2) \mathrm{hrs}$ \\
\hline$r$ & $\mathrm{C} \$ 80 / \mathrm{hr}$ & ISC & Triangular $(1040,1200,1495) \mathrm{C} \$$ \\
\hline$r^{\prime}$ & $\mathrm{C} \$ 15 / \mathrm{hr}$ & CPS & Triangular $(96,200,334) \mathrm{C} \$$ \\
\hline LT & 2 days & & Triangular $(388,400,528) \mathrm{C} \$$ \\
\hline ROC & $-150 \mathrm{C} \$$ & TRN & Triangular $(4450,5000,5611) \mathrm{C} \$$ \\
\hline FTE & -0.5 & SMS & Triangular $(779,1000,1243) \mathrm{C} \$$ \\
\hline WOC & $0 \mathrm{C} \$$ & RSV & Triangular $(9500,12000,13500) \mathrm{C} \$$ \\
\hline $\mathrm{f}_{0}$ & \multicolumn{3}{|c|}{ Weibull $(\eta, \gamma), \eta \sim \operatorname{Triangular}(19.14,24,29.63), \gamma \sim \operatorname{Triangular}(1,2,5)$} \\
\hline PM Qu & \multicolumn{3}{|c|}{$($ Very poor, Poor, Fair, Good, Excellent $)=(9.37,18.55,31.11,24.84,16.13)$} \\
\hline Experi & \multicolumn{3}{|c|}{$($ Low, Medium, High $)=(24.59,42,33.41)$} \\
\hline
\end{tabular}




\begin{tabular}{ll}
\hline \multirow{3}{*}{$\begin{array}{l}\text { Piosson }(\lambda), \lambda \sim \operatorname{Gamma}(\alpha, \beta), \alpha \sim \operatorname{Trian}(0.2,0.5,0.8), \\
\log _{10} \beta \sim \operatorname{Trian}(-6,-3,-1)\end{array}$}
\end{tabular}

Table 19. Repair perfection prior and repair activity durations conditional on the level of experience

\begin{tabular}{llllll}
\hline Experience & $\mathrm{f}(\mathrm{y})$ & Diagnostic & Fix & RAC & Test \\
\hline Low & Uniform $(0.2,0.5)$ & $(2,3,4.1)$ & $(13.1,15,17.6)$ & $(2.0,3,4.4)$ & $(1.1,1.5,2.7)$ \\
Medium & Uniform $(0.4,0.7)$ & $(1.3,2,3.5)$ & $(12.4,14,16.5)$ & $(1.2,2,3.5)$ & $(0.4,1,1.6)$ \\
High & Uniform $(0.6,0.9)$ & $(0.1,0.5,1.2)$ & $(10.7 .1,13,15.7)$ & $(0.6,1,1.4)$ & $(0.2,0.5,1.3)$ \\
\hline
\end{tabular}

The NPT of the upcoming failure distribution $\left(\mathrm{f}_{3}\right)$ conditional on the level of PM Quality and repair perfection state is provided in Table 20, in which $\eta^{\prime}$ and $\gamma^{\prime}$ are the latest updated parameters of the Weibull failure time. Having constructed and run the economic BN model using the estimated parameters and probabilities, Figure 27 illustrates part of the network, which includes the distribution of the node $\mathrm{f}_{3}$, and its parent and child nodes. As indicated, the PM Quality, Repair Perfection, and the Weibull parameters have been updated based on the observed failure times. It can be seen from the posterior probabilities that while the Repair Perfection posterior has slightly increased, PM Quality has skewed towards Very poor, revealing the root cause for the short time between failures. The distribution of the next failure $\left(f_{3}\right)$ has accordingly been revised, showing a decline in MTTF from 22.453 months (prior) to 20.994 months (posterior). Thus, the distribution for the number of failures during the remaining useful life of the equipment has skewed towards the right, raising the mean value of the distribution from 3.91 to 4.13 .

Table 20. NPT of the node $f_{3}$ conditional on the level of PM Quality and Repair Perfection

\begin{tabular}{|c|c|c|}
\hline \multirow{2}{*}{ PM Quality } & \multicolumn{2}{|c|}{ Repair Perfection } \\
\hline & Yes & No \\
\hline Very poor & $0.8 * \mathrm{f}_{0}$ & $0.8^{*}$ Weibull $\left(\eta^{\prime}, \gamma^{\prime}\right)$ \\
\hline Poor & $0.9 * \mathrm{f}_{0}$ & $0.9 *$ Weibull $\left(\eta^{\prime}, \gamma^{\prime}\right)$ \\
\hline Fair & $1.0 * \mathrm{f}_{0}$ & 1.0*Weibull $\left(\eta^{\prime}, \gamma^{\prime}\right)$ \\
\hline Good & $1.2 * \mathrm{f}_{0}$ & 1.2*Weibull $\left(\eta^{\prime}, \gamma^{\prime}\right)$ \\
\hline Excellent & $1.4 * \mathrm{f}_{0}$ & $1.4 *$ Weibull $\left(\eta^{\prime}, \gamma^{\prime}\right)$ \\
\hline
\end{tabular}




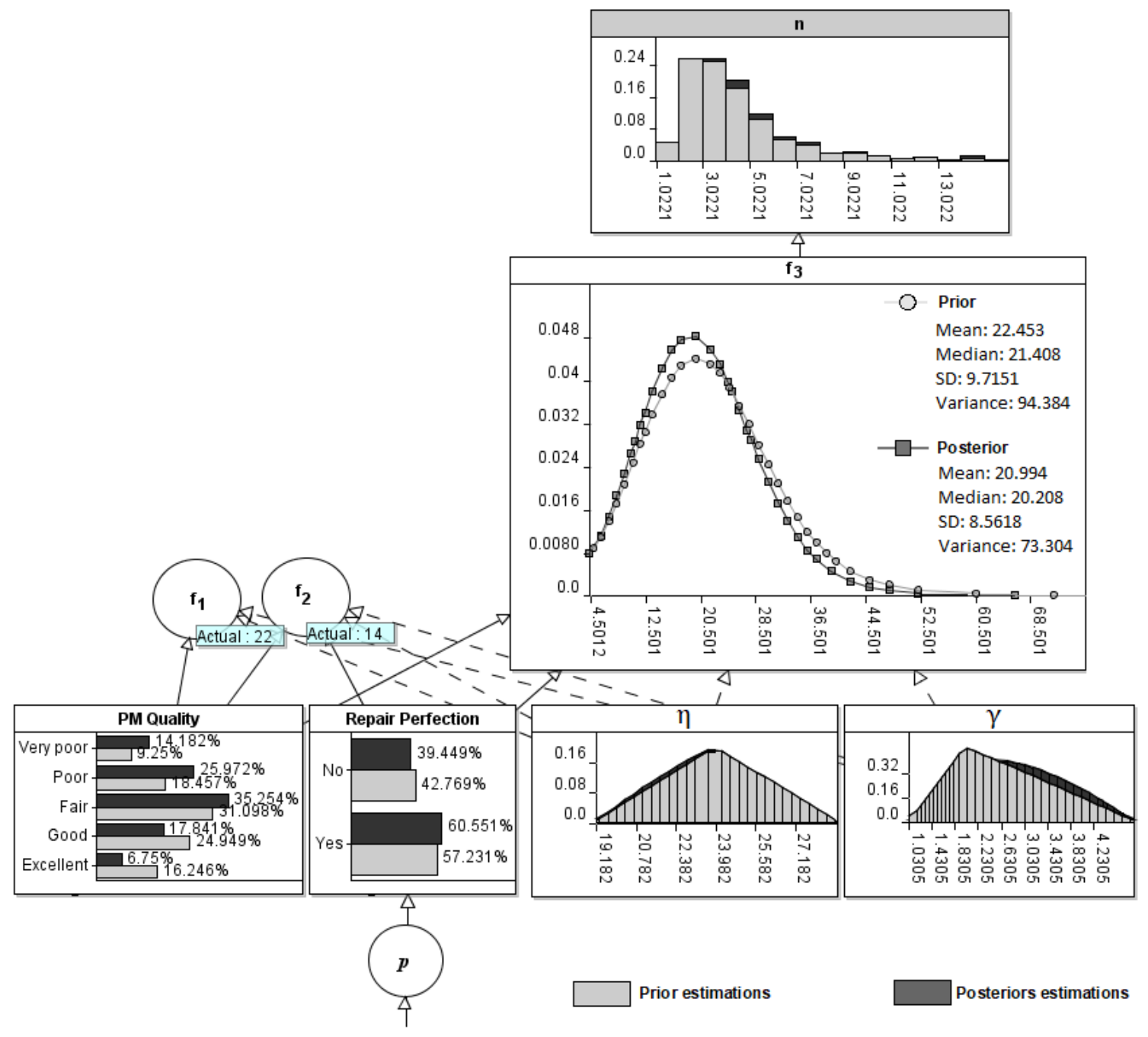

Figure 27: Part of the BN model which includes the priors and posteriors of PM Quality, Repair Perfection, failure time parameters, the upcoming failure time, as well as the updated number of failures (Dashed lines are created due to the existence of intermediate, hiden nodes to ease the calculation)

Four risks have been identified at this stage of the $\mathrm{R} / \mathrm{R}$ decision process. Table 21 indicates the risks, their probability and impact, and the affected quantities. By adding a node for each risk and revising the affected NPTs, we ran the entire economic network to calculate the total costs associated with the repair (TRC) and replace (TRC') scenarios. Figure 28 illustrates the probabilistic distributions of TRC and $\mathrm{TRC}^{\prime}$. As indicated, the most likely value of replacement costs $(\mathrm{C} \$ 89,264)$ is less than that of repair costs $(\mathrm{C} \$ 163,230)$ and hence, it is less costly to replace the old equipment. The chance of replacement costs being less than repair costs is $78.97 \%\left(\operatorname{Pr}\left(\mathrm{TRC}^{\prime}<\mathrm{TRC}\right)=0.7422\right)$, which shows our confidence about this decision. The most probable advantage of replacing the equipment over maintaining it would be $\mathrm{C} \$ 72,144$. 
Table 21. Identified risks, related affected items, probability of occurrence, and impacts

\begin{tabular}{lllll}
\hline ID & Risks & Item(s) affected & Probability & Impact \\
\hline 1 & $\begin{array}{l}\text { Faster technology change and obsolescence } \\
\text { of the old equipment }\end{array}$ & RSV & $34.28 \%$ & $-40 \%$ \\
\hline & $\begin{array}{l}\text { Safety incidents during the delivery and } \\
\text { locating process of new equipment and } \\
\text { decommissioning process of old equipment }\end{array}$ & DCN & $87.12 \%$ & $10 \%$ \\
\hline 3 & Lack of spare parts & TRD & $20.79 \%$ & $40 \%$ \\
\hline 4 & $\begin{array}{l}\text { Lack of knowledge on how to repair the } \\
\text { new equipment, due to unlikeness }\end{array}$ & $\begin{array}{l}\text { COR (as a component } \\
\text { in OWC/S), TRD }\end{array}$ & $67.33 \%$ & $20 \%$ (COR) \\
\end{tabular}

As provided in Table 22, cost of emissions, $E_{\text {man }}, E_{\text {ship }}$, and $E_{d e c}$, were estimated based on the related activity data in tons of $\mathrm{CO}_{2}$ eq and the carbon price in the Western Climate Initiative (WCI) cap-and-trade market. We used the price of $\mathrm{C} \$ 18.77 /$ ton estimated by our model presented in the next chapter.

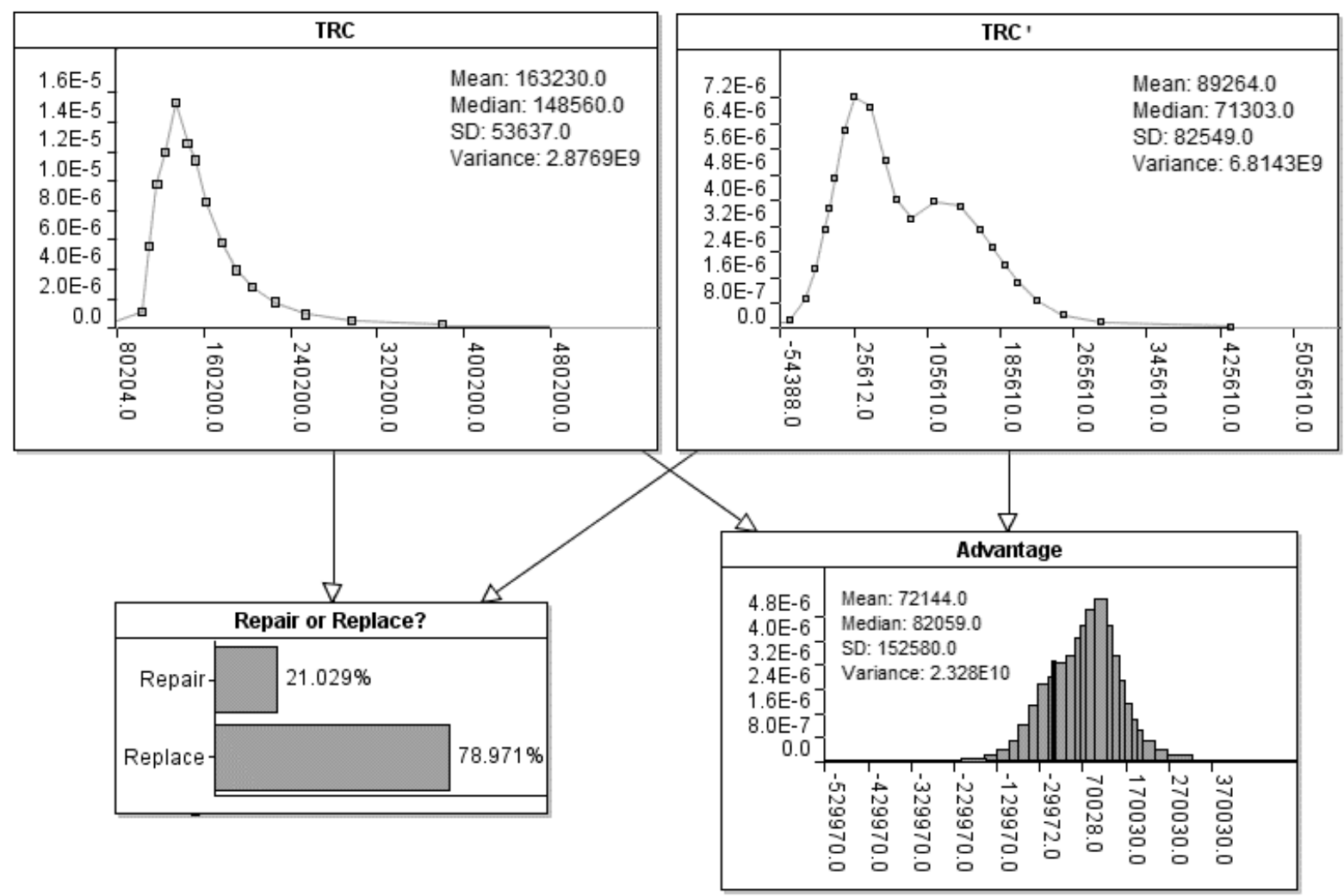

Figure 28: The probability distributions of total repair (TRC) and replacement (TRC') costs in economic model 
Table 22. Emissions costs of each lifecycle phase based on the carbon price in the WCI market

\begin{tabular}{ll|ll}
\hline $\mathrm{E}_{\text {man }}$ & $1035 \mathrm{C} \$$ & $\mathrm{f}_{\mathrm{N}}(\mathrm{e})$ & Normal $(800,100) \mathrm{kg} \mathrm{CO} \mathrm{CO}_{2}$ eq \\
\hline $\mathrm{E}_{\text {ship }}$ & $(11.3,16,24.8) \mathrm{C} \$$ & $\mathrm{f}_{\mathrm{R}}(\mathrm{e})$ & Normal $(1800,300) \mathrm{kg} \mathrm{CO}_{2}$ eq \\
\hline $\mathrm{E}_{\text {dec }}$ & $(27.9,32,41.5) \mathrm{C} \$$ & $\mathrm{CP}$ & $\mathrm{C} \$ 18.44 /$ ton \\
\hline
\end{tabular}

We assigned a Normal $(10,5)$ prior to the Emission Escalation Threshold (EET) and trained it by using 55 records of similar equipment on time between failures and monthly average cost of GHG emissions relevant to these times. The trained threshold is shown in Figure 29. Based on the records, the EET posterior shifts to the higher failure times, with a mean value of 14.23 months, having a smaller standard deviation (1.11 months), which represents a higher certainty than the starting prior (with a standard deviation of 5 months). The predicted amount of O\&M emissions is also updated, revealing that greater emissions are expected to be released over the remaining life time of the old equipment. Based on the prior EET, the probability of $f_{3}$ being escalating was about $12 \%$ and the estimated monthly emissions was initially calculated as 921 . The posterior EET rises this probability to $21 \%$ and the monthly emissions to $1010 \mathrm{~kg} \mathrm{CO}$ _eq. To calculate the cost of O\&M emissions $\left(\mathrm{E}_{\mathrm{O} \& \mathrm{M}}\right)$, this distribution was converted to a monetary based distribution using the carbon price.

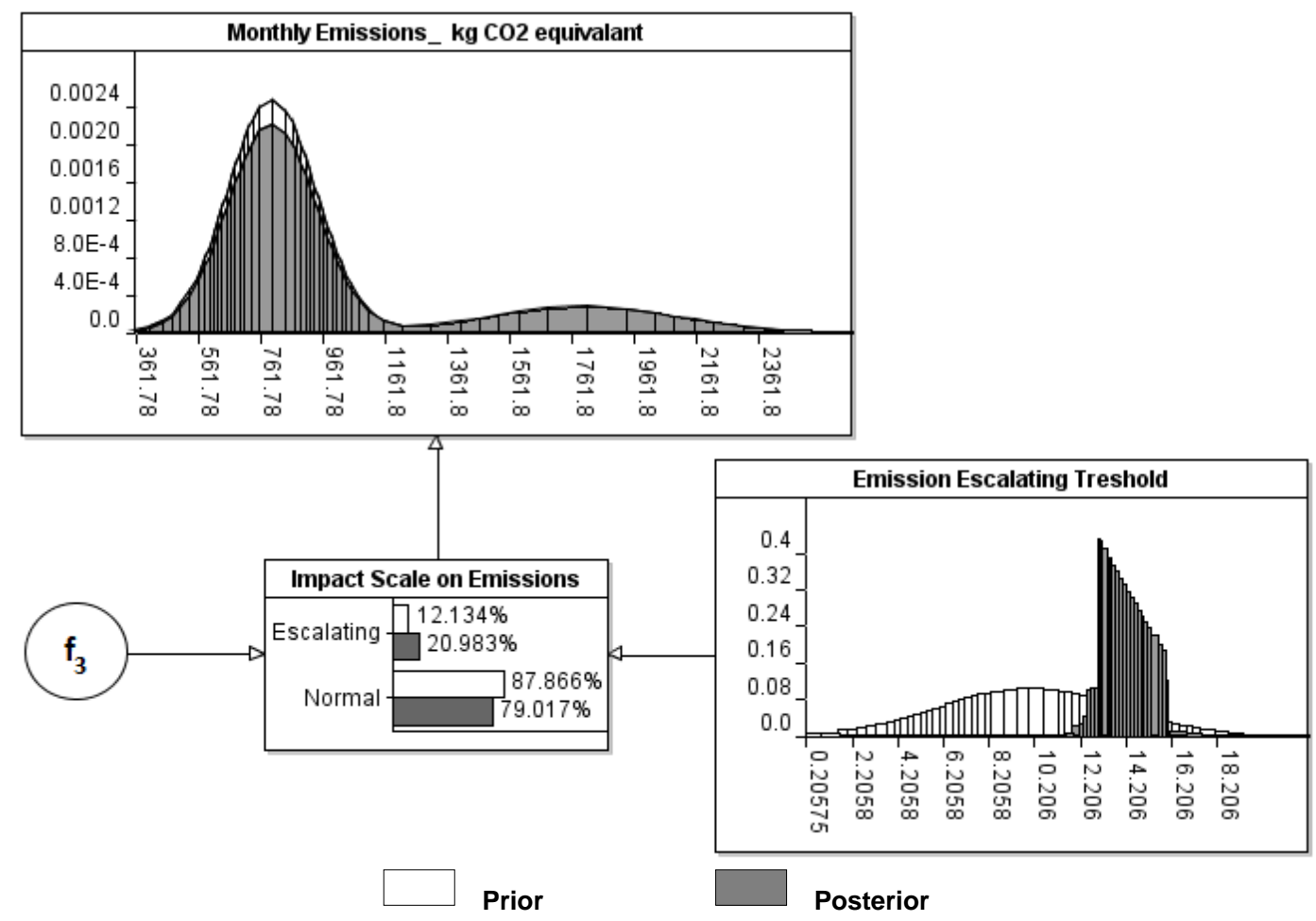

Figure 29: Posterior distribution of emission escalating threshold and update of O\&M emissions cost 
Having integrated the emissions cost items into the economic Bayesian model, the combined total cost of repair and replacement scenarios are calculated, as shown in Figure 30. The average total costs associated with the repair and replacement scenarios are $\mathrm{C} \$ 165,210$ and $\mathrm{C} \$ 91,465$. The best decision is still to replace the equipment, and the confidence has increased only slightly (79.29\%). The mean value of the advantage corresponding to this decision in the combined model is however $\mathrm{C} \$ 71,701$, which is marginally lower than the advantage in the economic model. This is not surprising because we have accounted for the carbon footprints of manufacturing new equipment, shipping it to the operation site, as well as that of decommissioning the old equipment. Although the operating organization does not always pay for the carbon emissions of these stages of the equipment life cycle, when it comes to climate change and global warming, it is imperative to design a sustainable asset management that considers emissions from manufacturing and even the supply chain of the materials being converted into the final equipment. In fact, extraction and processing the materials used for manufacturing many of the so called "low carbon" technologies (such as windmills, batteries of electric vehicles, solar panels, and biofuels), release a significant amount of carbon emissions.

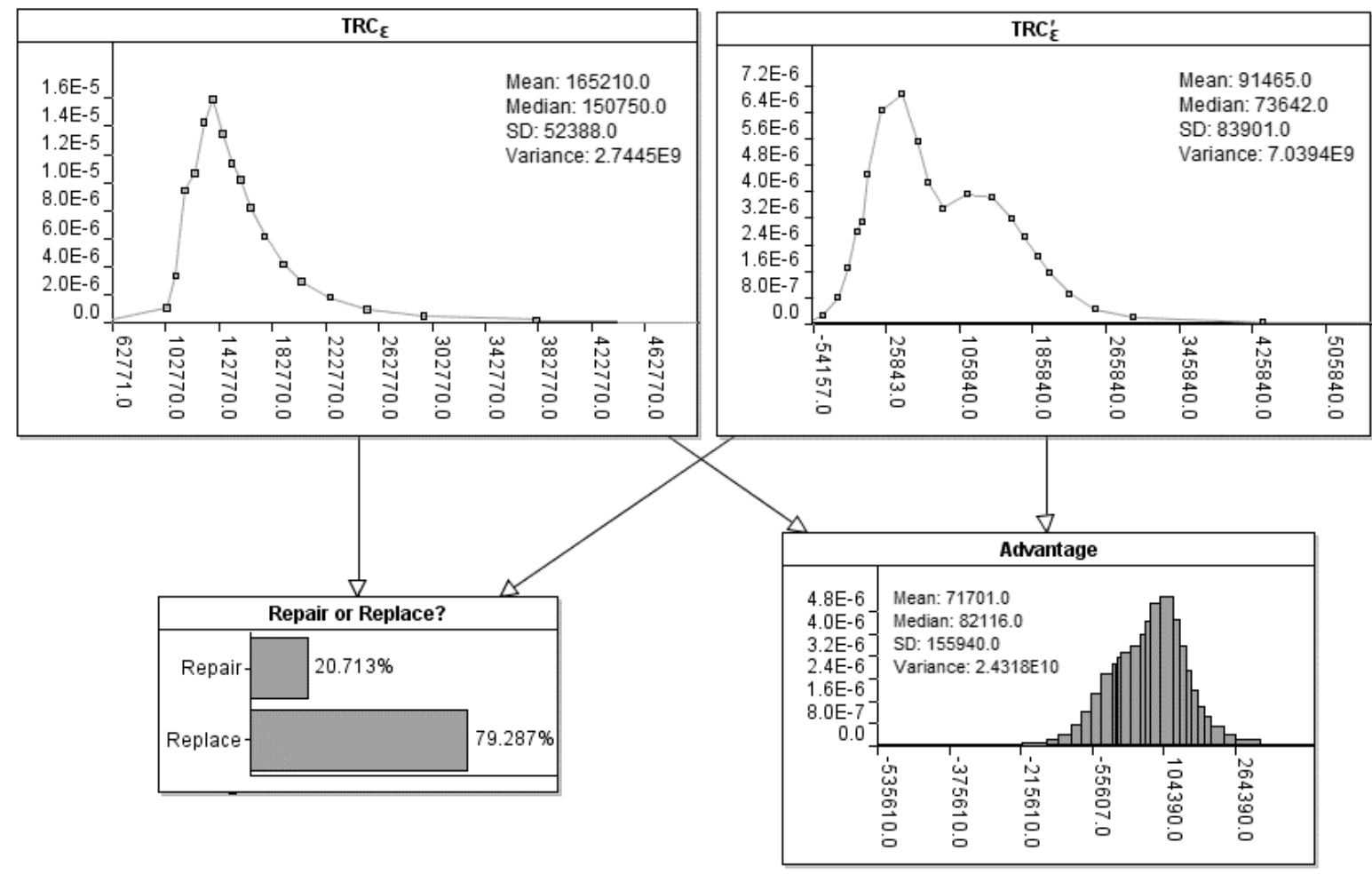

Figure 30: The probability distributions of combined total repair $\left(\mathrm{TRC}_{\varepsilon}\right)$ and replacement $\left(\mathrm{TRC}_{\varepsilon}^{\prime}\right)$ costs 


\subsection{Discussion}

In addition to primary comparative application, the proposed model has analytical and explanatory features, some of which are explored in this section. The decision maker can enter new evidence and information anywhere in the network to perform predictions, trade-off, and what-if analyses. Take, for instance, the following scenario. Scenario 1:

- The level of experience among maintenance staff is low,

- PM Quality is poor, and

- Technology change is undoubtable (Risk \#1=True), and the defender is no longer valuable as it was in the normal depreciation trend.

Figures 31 and 32 show how the failure time, repair perfection, total repair duration (TRD), and total repair and replacement costs have changed. From the model output, mean time to failure decreases to 19.45 months, and total repair duration (TRD) increases to almost 31 hours on average. Thus, the model has captured the dependency between the equipment reliability and its maintainability through a common cause that affects both. As illustrated in Figure 32, this scenario will escalate the total repair and replacement costs to $\mathrm{C} \$ 180,910$ and $\mathrm{C} \$ 101,640$, respectively. 


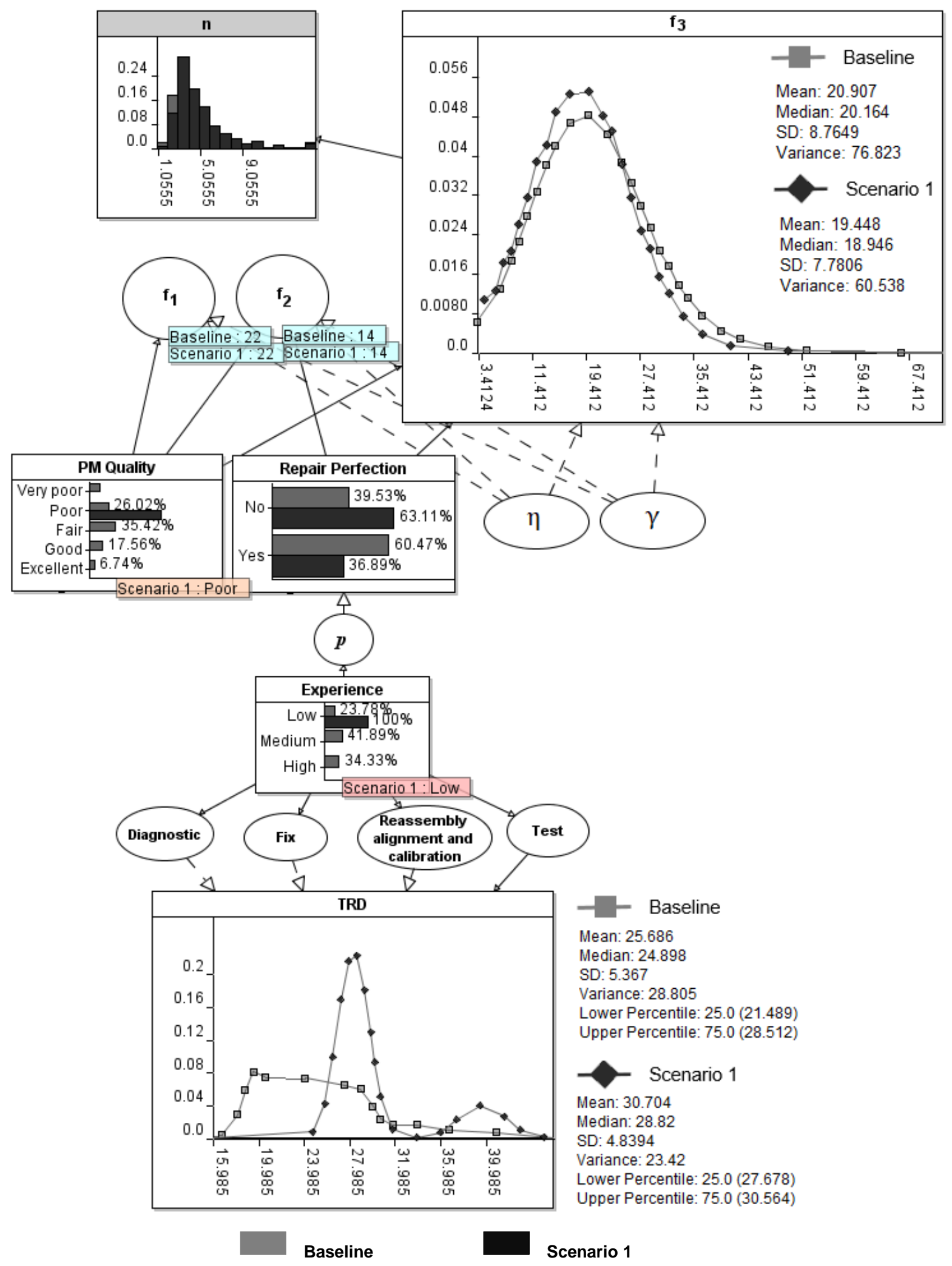

Figure 31: The effect of scenario 1 on failure time, repair perfection, and total repair duration 


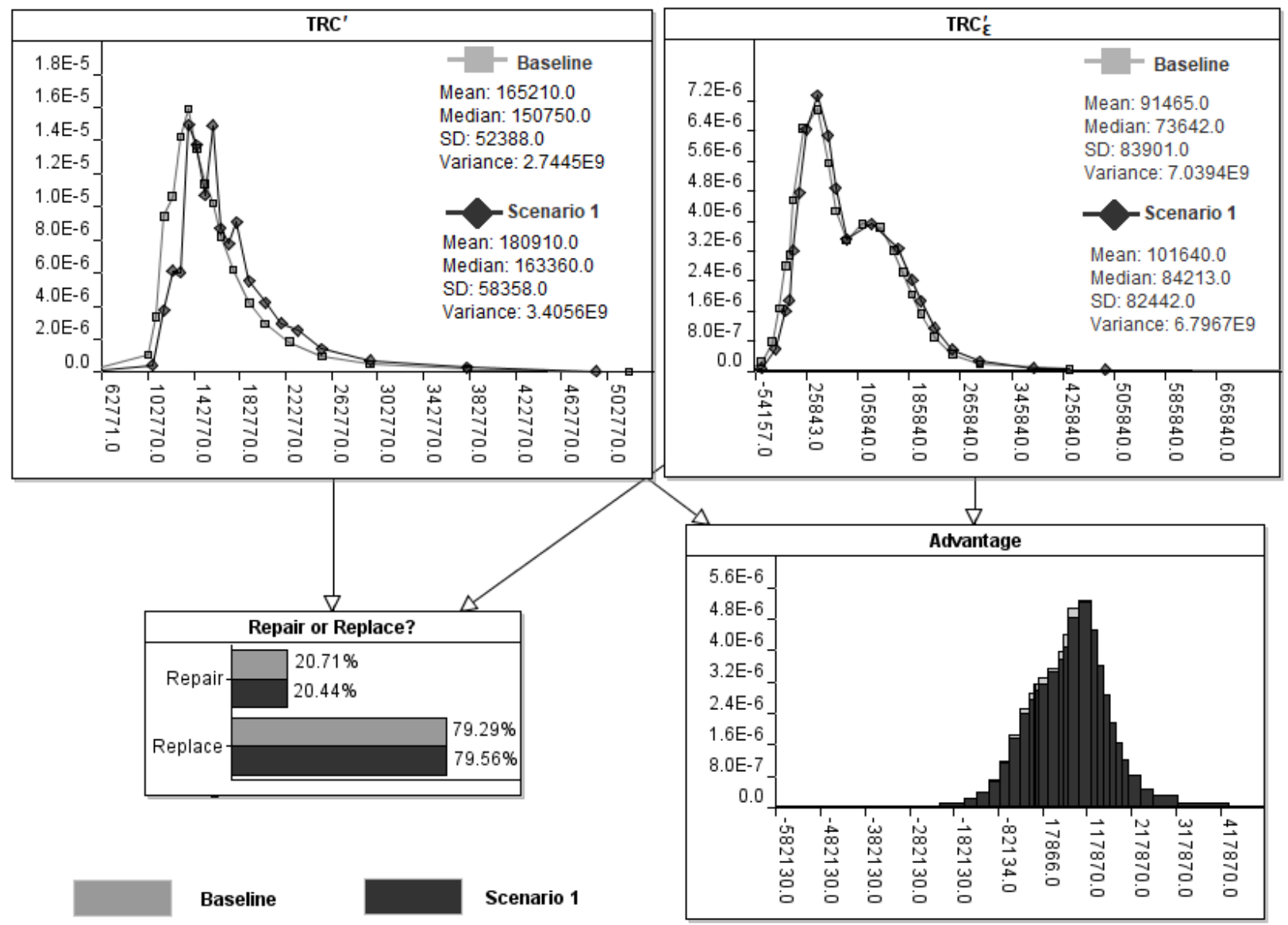

Figure 32: Comparison of total repair and replacement costs in baseline scenario and scenario 1

The risk analysis part of the project can proceed in order to mitigate the lifecycle costs. The common practice in risk management is to:

- rank the risks using qualitative analysis,

- design risk responses for top risks in the ranking (a risk response is driven from four strategies: avoidance, mitigation, transference, and acceptance), and

- re-rank the risks to monitor and control the overall risk level.

We used the probability-Impact (PI) matrix to classify the risks into three levels; minor, moderate, and major. Using the estimated probabilities of occurrence and impacts, the four identified risks are mapped on the PI matrix of Figure 33-a. Therefore, risks with the ID 2 and 4 are major risks, for which a response action is in priority. Let us suppose that the following responses are planned to be implemented in order to respond to the major risks, which will transfer these major risks to the moderate area, as shown in Figure 33-b: 


\begin{tabular}{|c|c|c|}
\hline ID & Risks & Planned response(s) \\
\hline 2 & $\begin{array}{l}\text { Safety incidents during the delivery and } \\
\text { locating process of new equipment and } \\
\text { decommissioning process of old } \\
\text { equipment }\end{array}$ & $\begin{array}{l}\text { - Insurance plans for the new equipment } \\
\text { - Training sessions before the process start }\end{array}$ \\
\hline 4 & $\begin{array}{l}\text { Lack of knowledge on how to repair the } \\
\text { new equipment, due to unlikeness }\end{array}$ & $\begin{array}{l}\text { - Training sessions for the repair staff } \\
\text { - Consulting agreements with the supplier } \\
\text { to get advice before and during the repair } \\
\text { period }\end{array}$ \\
\hline
\end{tabular}

Considering the costs of implementation of responses, the probability and impact of major risks were modified as a new scenario. As a result, $\mathrm{TRC}_{\varepsilon}$ and $\mathrm{TRC}_{\varepsilon}^{\prime}$ distributions show a lower range of costs (Figure 34), and the advantage would increase to $C \$ 76,589$.

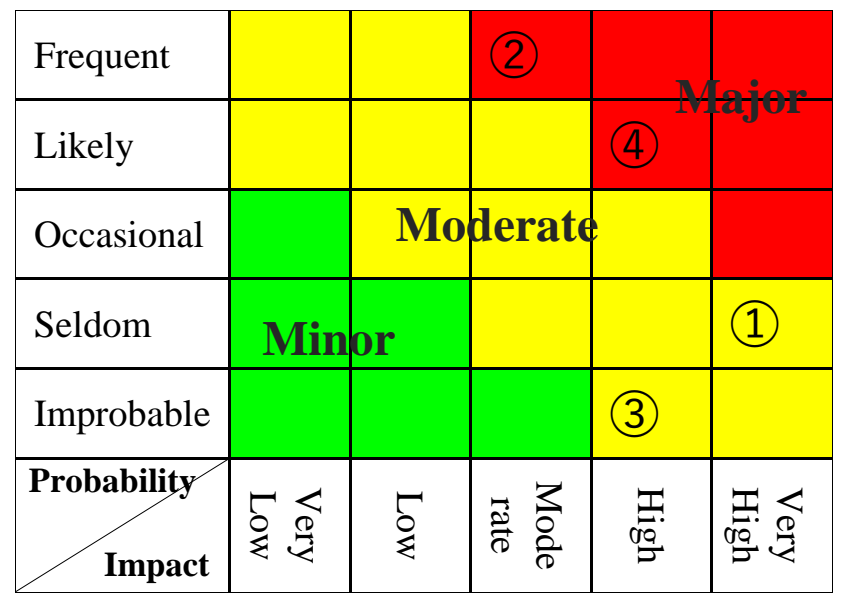

(a)

\begin{tabular}{|c|c|c|c|c|c|}
\hline Frequent & & & & & \\
\hline Likely & (4) & & & & \\
\hline Occasional & & (2) & Ioder & ate & \\
\hline Seldom & Mi & nor & & & (1) \\
\hline Improbable & & & & (3) & \\
\hline $\begin{array}{l}\text { Probability } \\
\text { Impact }\end{array}$ & & 5 & 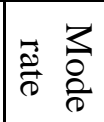 & 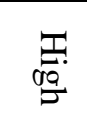 & 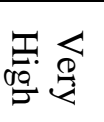 \\
\hline
\end{tabular}

(b)

Figure 33: Probability-Impact matrix before (a) and after (b) responses implementation 

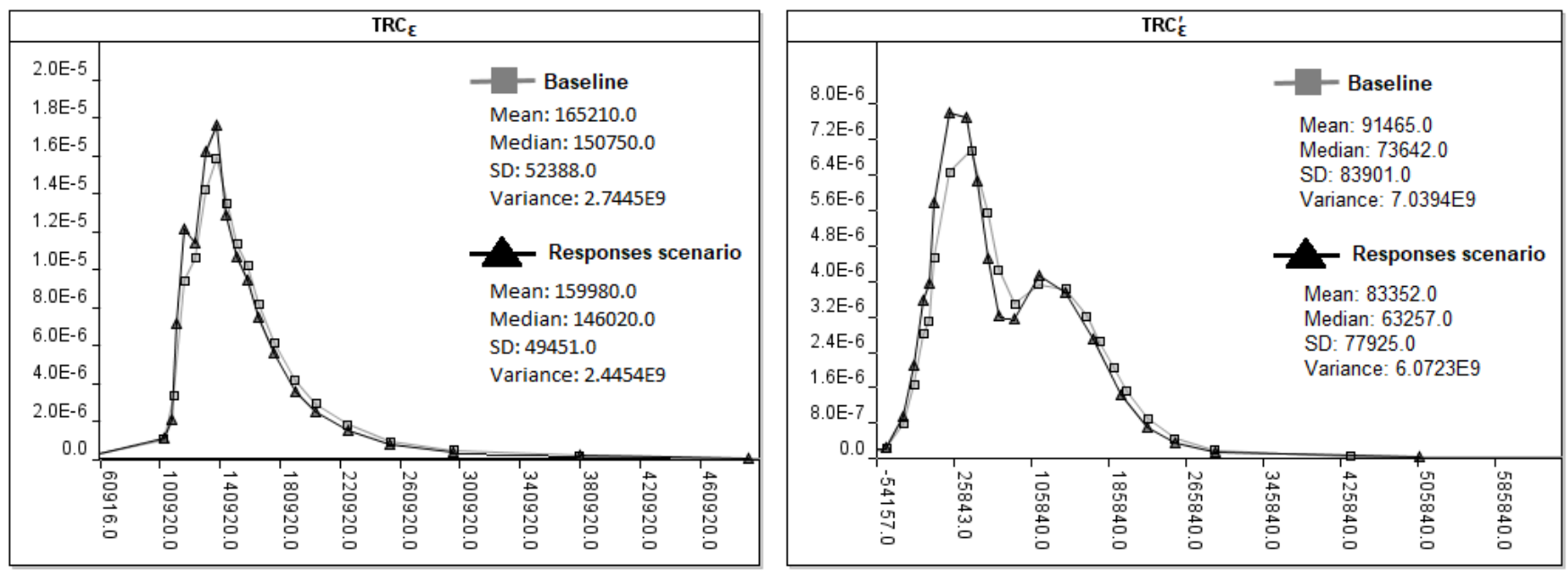

Figure 34: $\mathrm{TRC}_{\varepsilon}$ and $\mathrm{TRC}_{\varepsilon}^{\prime}$ distributions before and after responding to the high-level risks

Assuming the equipment owner does not pay for the cost of emissions associated with manufacturing, shipping, and decommissioning processes, the model was run without the related cost items. This scenario, as expected, would lead to a higher advantage in the replacement decision over repair decision (C\$88,583), as depicted in Fig. 16.
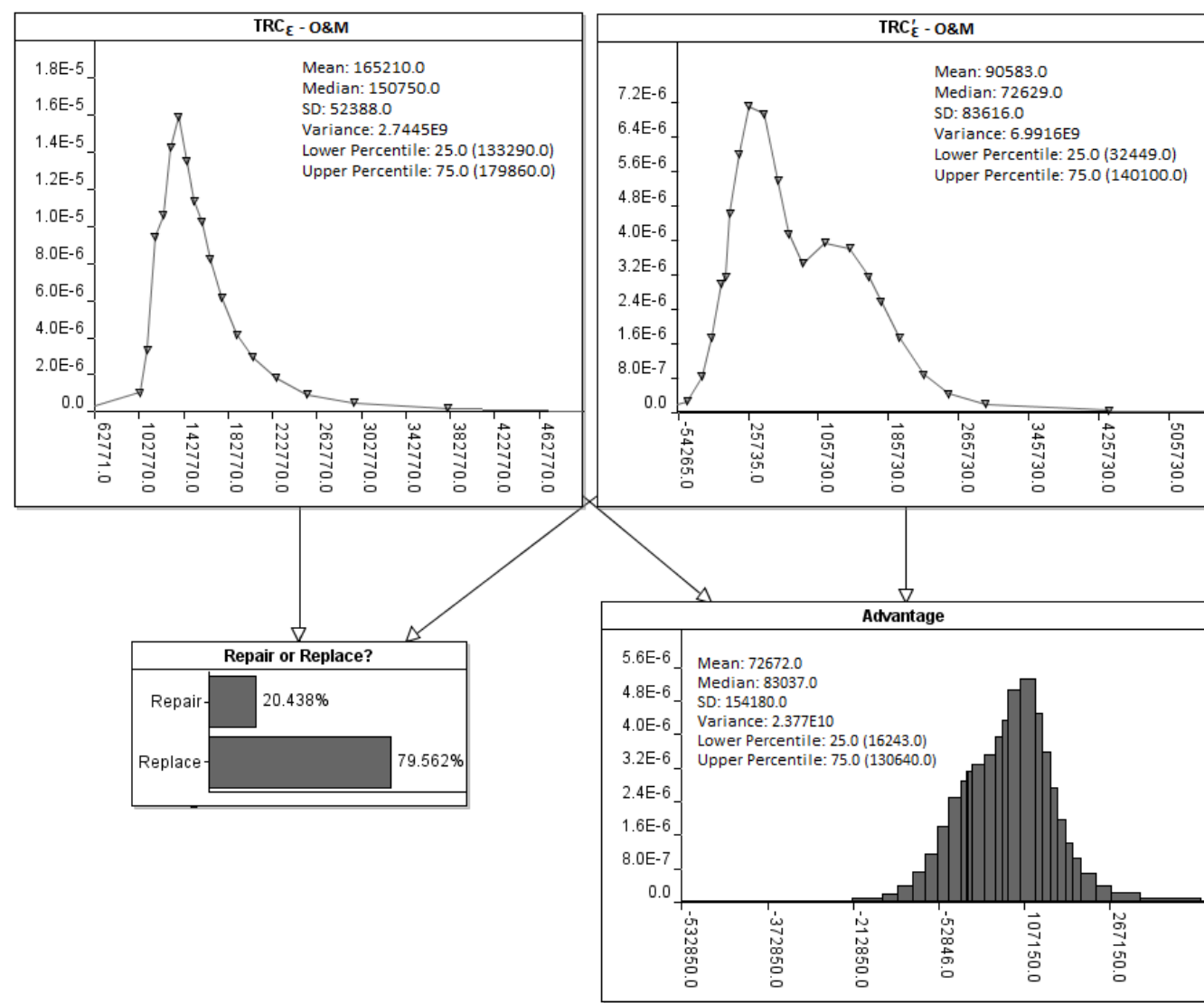

Figure 35: The PDF of combined total repair $\left(\mathrm{TRC}_{\varepsilon}\right)$ and replacement $\left(\mathrm{TRC}_{\varepsilon}^{\prime}\right)$ costs with only O\&M emissions 
Moreover, the proposed model is capable of propagating information backward (from effect to cause) to infer desired variables in order to meet a condition or to diagnose the root cause(s) of a favourable performance. For example, the management can set a target on the equipment reliability (through the distribution of failure time or number of failures), as well as maintainability (through TRD and repair tasks durations) to find the required level of PM quality, repair perfection, experience, and so forth. Likewise, observations on important cost items, such as $\operatorname{TRC}_{\varepsilon}, \operatorname{TRC}_{\varepsilon}^{\prime}$, during warranty costs, etc., can be entered into the model to diagnose the most probable causes. Similarly, a budget limit can be used to analyse the required level of performance in other variables or the maximum probability/impact of risks to meet that limit.

\subsection{Conclusion}

This paper proposes a repair/replacement decision model with both economic and environmental considerations. A deterministic model was first developed, considering a wide range of effectual variables on both repair and replacement sides. It was then mapped into a probabilistic Bayesian structure (called Bayesian R/R model), which allowed us to:

1. Capture the full uncertainty of input variables,

2. Model complex variables including the quality of preventive maintenance, repair perfection and staff experience, and the causality between them,

3. Incorporate risks and conduct a formal risk management process to further mitigate the lifecycle costs,

4. Infer the causality between the equipment failure behaviour and its operation's GHG emissions,

5. Learn the parameters and actual level of complex variables in the light of new evidence and therefore, improve the accuracy continuously.

Both economic and environmental costs of equipment are taken into consideration. Environmental burdens are modelled by capturing the GHG emissions of manufacturing new equipment, shipping them to the operation site, O\&M process, and decommissioning the retired equipment. The Bayesian R/R model was applied to a plastic shredder case study located in 
Canada. GHG emissions were converted into a monetary value using the expected carbon price in the WCI market.

This monetary value, however, may not reflect the exact cost of the equipment environmental impacts, in a global warming point of view. From the results of the case study, we found out that putting the reported price of carbon, that is $\mathrm{C} \$ 18.44$ per ton of $\mathrm{CO}_{2} \_$eq, cannot make a remarkable difference in the total costs, comparing to a mere economic decision model, whether it is a repair or a replacement decision. That is to say, it is unlikely that accounting for GHG emissions based on this carbon price would change the decision so that it can help mitigating carbon emissions. This would become even more discouraging if we exclude GHG emissions for which, the equipment owner does not yet pay in a carbon market (e.g. emissions from manufacturing new equipment or outsourced decommissioning projects). Much greater prices, with very small probabilities based on the historic records on the WCI market [158], might actually alter the decision variable and consequently reduce the total emissions.

As a future extension of this study, the Bayesian R/R model could be rebuilt using other impact assessment categories reported by EPA, such as Acidification Potential (moles of H+ eq), Ozone Depletion Potential (kg CFC-11 eq), and Fresh water use (kg).

\section{Acknowledgment}

This work was partially supported by Fiix Software and Ontario Centres of Excellence (OCE)'s Voucher for Innovation and Productivity (VIP) (No. 26114). The authors would like to acknowledge an initial version of the deterministic model from Fiix Software and constructive comments from Marc Castel and Katie Allen. 


\section{Carbon Price Forecasting in a Cap-and-Trade Market}

The present chapter is based on the following paper:

Abdi, A., Taghipour, S. (2018). Forecasting carbon price in the Western Climate Initiative market using Bayesian networks. Carbon Management. Accepted for publication.

Many studies have been conducted to forecast and analyse the price of carbon in an emission trading scheme (ETS), also known as cap-and-trade market. Exhaustive forecasting studies have been seldom (if not never) performed in the Western Climate Initiative (WCI)' market. Because of the distinctive market dynamics in WCI, the results of research on other markets may not be applicable to forecast the carbon price in this market. Moreover, modelling the causality between driving forces (including energy prices, economic growth, weather, etc.) and carbon price is a complex problem. The objective of this chapter is to forecast carbon price in the WCI market, by modelling the uncertainty of the driving forces and their causal relationship with carbon price. A probabilistic model is developed using Bayesian networks (BNs) to infer the possible ranges of each driving force that could have an escalation/depreciation effect on price as well as the magnitude of the impact. The model is developed based on retrospective and prospective information on the selected driving forces in all the jurisdictions of the WCI market, providing the most probable price(s) over the period 2018-2030.

Keywords: emission trading scheme (ETS); the Western Climate Initiative; Bayesian networks (BNs).

\subsection{Introduction and Background}

To fight climate change and mitigate greenhouse gas (GHG) emissions, governments have already implemented (or plan to implement) carbon pricing schemes such as a carbon tax and emission trading scheme (ETS), also known as cap-and-trade. According to Scholtens \& van der Goot [21], an ETS can influence the participating firms' value due to two circumstances. First, there is a direct complying cost which requires the firms to adjust their business processes 
towards low carbon technologies and/or purchase more emission allowances, thereby impacting their cash flows. Second, unlike carbon tax, ETS's price of carbon is uncertain in that it is changing and volatile.

Affected organizations in this market, therefore, need to be able to predict carbon price so that they can vigilantly adjust their business plans. Many studies have been conducted to forecast and analyse the price of carbon in, for example, European Union ETS (EUETS) [2130], China's ETSs [31,32], and Korea ETS [33]. However, similarly exhaustive forecasting studies have been seldom (if not never) performed in the Western Climate Initiative (WCI)' market. Sousa and Aguiar-Conraria [34] evaluated the dynamics of this market and the connection between energy and carbon prices. They reported contrasting market dynamics in WCI compared to EUETS. Hence, the results of research on other markets may not be applicable to forecast the carbon price in this market. Of course, regardless of the market, there is a continuous dispute over modelling the causality between driving forces (including energy prices, economic growth, weather, etc.) and carbon price.

The aim of this chapter is to capture the uncertainty of the carbon price in WCI market, by determining the causality between carbon price and its driving forces. A probabilistic model is developed using Bayesian networks (BNs) to infer the possible ranges of each driving force that could have an escalation/depreciation effect on price as well as the magnitude of the impact. The model is developed based on retrospective and prospective information on the selected driving factors in all the jurisdictions of the WCI market, providing the most probable price(s) over the next ten years.

Unlike classical estimators, Bayesian networks consider the parameters as random variables rather than unknown constants. Thus, there would be a probability density function for each parameter, which can be used for using any prior knowledge we might have about its value. Contrary to frequentist approaches in forecasting, such as traditional time series models, BNs allow us to factor in additional information, in the form of prior probabilities for the under-study parameters. These priors reflect our degree of belief about the parameters and can be updated in light of data, providing a sequential learning. This allows us to incorporate subjective beliefs in addition to objective information from historical records [139]. Moreover, the Bayesian 
inference is notably appropriate for forecasting, considering all effectual variables or even model uncertainty [159].

\subsubsection{Previous works}

It was not that long ago when forecasting carbon price in an ETS market became a field of research. In fact, the first and the largest market, EU ETS, began its test phase (in essence Phase I) in 2005. Many studies [28,160-166] revealed that carbon price is mainly affected by energy prices, due to the capacity of power generators to switch between possible fuel alternatives. Evaluating price drivers of EU ETS, Alberola et al. [28] reported that rare weather changes during colder events could also impact carbon price. The correlation between weather and carbon price is also supported by other studies [161,167,168]. Another driving factor of carbon price is economy, as an increase/decrease in economic activities can rise/decline the demand for emission allowances, thereby affecting carbon price $[161,169,170]$.

Focusing on the relationship between macroeconomic fundamentals and carbon price, Jiao et al. [171] proposed an economic state-dependent (SD) model to analyse carbon market Value at Risk (VaR). They applied their model to the EU ETS and concluded that the carbon returns are individually distributed in two different periods of the EU economy, i.e. expansion and recession periods. Applying EGARCH model and the crude oil volatility index (OVX), Dutta [172] evaluated the impact of oil market on carbon price. He reported that there is a strong correlation between oil market implied volatility and carbon prices. Moreover, extracting outliers from historical data and OVX improves the accuracy of carbon price volatility forecasts. Zhao et al. [173] developed a real-time method to predict weekly carbon price in the EU ETS. Applying MIDAS regression models, five weight-type schemes, as well as data on economic and energy indicators, they claimed that information on coal market can provide the best indicators for forecasting carbon price.

Zhao et al. [174] studied the effect of coal price, economy, and temperature on carbon price in six Chinees' ETS pilots. They concluded that coal price has the greatest influence on the carbon price, suggesting the existence of different weights for the carbon price driving forces. Studying the Korean ETS, Etiennea and Yu [175] evaluated the contributors of the ironic price correlation between carbon allowance credits and offset credits. After the Korean ETS began, 
offset credits were unexpectedly regularly traded at a much greater price, while an immediate liquidity happened soon.

Artificial intelligence (AI) techniques have been used to predict and analyse carbon price. For example, Atsalakis [176] developed and compared three AI-based models using fuzzy and artificial neural network techniques, to predict carbon price in the EU ETS. They claimed that their proposed hybrid neuro-fuzzy controller (also called PATSOS) outperforms other carbon price prediction methods. Various forecasting models including statistical and AI techniques proposed in the field of energy planning have been recently reviewed and evaluated in [177]. The models are compared based on their prediction accuracy, relevance to temporal and spatial forecasts, and appropriateness regarding the objectives and policies. Reviewing 483 models and considering the accuracy criterion, such techniques were identified as better methods than statistical techniques. In addition, they appear to be applicable for different forecasting horizons, whereas statistical methods are applied only to short and medium-term predictions. To improve the accuracy of carbon price forecasts, a multiscale nonlinear ensemble leaning paradigm is developed in [178] and [179] which is integrated with empirical mode decomposition and least square support vector machine. The authors of these studies claim that the proposed approach

yields better results with a greater robustness if the carbon price is considerably nonstationary, nonlinear, and irregular.

\subsection{Methodology}

This section explains our methodology including the techniques we have used to construct the proposed carbon price forecasting model. Figure 36 shows different stages of the model development. These stages are summarized as follows. First, driving forces of the carbon price in WCI market are identified. From the literature review, energy prices, weather, and economy are selected as the main categories of carbon price driving forces, which is supported by [34] as well. Natural gas, oil, coal, and electricity are considered as variables in energy prices category. Since the industries in the WCI market are energy intensive, gross domestic product (GDP) was selected to mirror economic activities. To model weather conditions, temperature is factored in. Second, retrospective (historical) data and prospective data (projections) on each driving force are collected over the market jurisdictions. Projections need to be collected based on the intended forecasting horizon. Third, the best-worst method (BWM) [180] is employed to 
generate a weight for the driving forces. Lastly, a Bayesian network (BN) model with an inference mechanism, as the focal point of the proposed approach, is built and run using the above information. Each of the above steps is described through the following subsections.

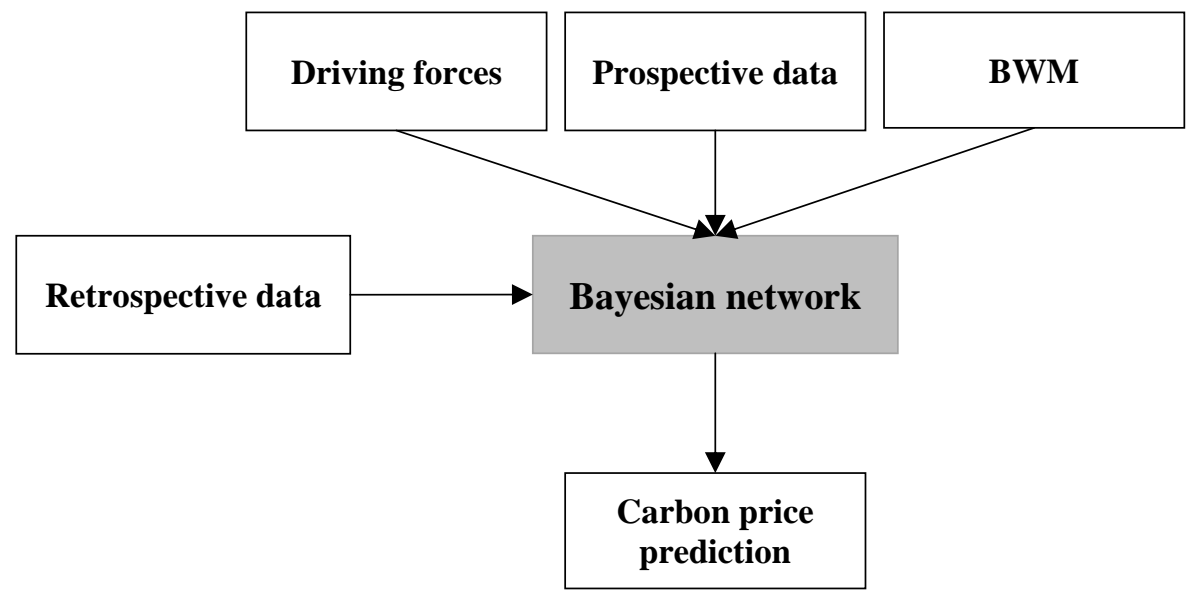

Figure 36: Model development stages

\subsection{Data collection}

For each driving force, projections over the period 2018-2030 were collected from reputable reports, for the participating jurisdictions, i.e. California, and Quebec ${ }^{5}$. They were then integrated into a single value for the whole market. To begin with, natural gas projections in Quebec were extracted from Deloitte's Price Forecast report [1002] ${ }^{6}$, and projections on natural gas price for California were extracted from California Gas Report [1003]. Average forecasts were then calculated over the two participating jurisdictions, in US\$/MMBtu. Oil, coal, and electricity price projections were collected from the EIA's Annual Energy Outlook [1004]; Canada National Energy Board's (NEB) Energy Future 2017: Projections to 2040 [1005]; California Energy Commission's Integrated Energy Policy Report [1006]; and Kanoema's Crude Oil Price Forecast [1007]. Likewise, the projections were converted into average, marketlevel predictions with the consistent units.

GDP projections of the province Quebec and the state of California were extracted from Desjardins's Economic Viewpoint [1008], and the California Country-Level Economic

\footnotetext{
${ }^{5}$ On January 1, 2017, Ontario's cap-and-trade program began, with the initial batch of carbon allowances auctioned off on March 22, 2017, and a linking agreement with WCI's ETS came into effect on January 1, 2018 [101]. However, recently the new provincial government cancelled the cap and trade regulations and prohibited trading emission allowances (effective July 3, 2018).

${ }^{6}[100 x]$ is a website reference
} 
Forecast 2016-2050 [1009], respectively. Average GDPs were then calculated in US\$ Trillion. Regarding the variable weather, average monthly records of temperature $\left({ }^{\circ} \mathrm{C}\right)$ from 2005 to 2018 were gathered from the Government of Canada website [1010], for Quebec, and from the Weather Company, LLC website [1011], for California.

\subsection{Best-Worst Method (BWM)}

Proposed by Rezaei in 2015 [180], BWM is a new multi criteria decision making (MCDM) model, which similar to Saaty's AHP [181] can be utilized by either one or a group of decision makers to prioritize a list of alternatives or to weight a set of criteria. BWM outperforms AHP in that it needs less comparison information, and generates more consistent comparisons and therefore more reliable rankings/weights $[180,182,183]$. Aiming to determine the weights of $n$ criteria, $w_{j}, j=1, \ldots, n$, one can perform BWM through the following steps:

(1) Decide the best (B) and worst (W) criteria (in essence, the most and the least important/desirable criteria). In the case of our forecasting study, B and W represent the most and least effectual carbon price driving force in the under-study market;

(2) Specify the preference of B over the rest of the criteria, based on a 9-point Likert scale from 1 to 9 . Number 1 and 9 indicate that the best criterion is equally and extremely more important than the related criterion, respectively. Thus, a best-to-others (BO) vector is created: $A_{B}=\left(a_{B 1}, a_{B 2}, \ldots, a_{B n}\right)$, where $a_{B j}$ is the preference of $\mathrm{B}$ over $\mathrm{j}$ and $a_{B B}=1$

(3) Specify the preference of other criteria over $\mathrm{W}$, based on a 9-point Likert scale from 1 to 9 . Number 1 and 9 indicate that the related criterion is equally and extremely more important than the worst criterion, respectively. Thus, an others-to-worst (OW) vector is created: $\mathrm{A}_{W}=\left(a_{1 W}, a_{2 W}, \ldots, a_{n W}\right)^{\mathrm{T}}$, where $a_{j W}$ is the preference of $\mathrm{j}$ over $\mathrm{W}$ and $a_{W W}=1$ 
(4) Calculate optimal weights, in a way that the maximum absolute differences $\left\{\mid w_{B}-\right.$ $\left.a_{B j} w_{j}|,| w_{j}-a_{j W} w_{W} \mid\right\}$ is minimised for all $\mathrm{j}$ :

$$
\begin{aligned}
& \underset{\mathrm{j}}{\operatorname{minmax}}\left\{\left|w_{B}-a_{B j} w_{j}\right|,\left|w_{j}-a_{j W} w_{W}\right|\right\} \\
& \text { s.t. } \\
& \qquad \sum_{\mathrm{j}} \mathrm{w}_{\mathrm{j}}=1 \\
& \mathrm{w}_{\mathrm{j}} \geq 0, \forall \mathrm{j}
\end{aligned}
$$

The above problem can be expressed as the following linear problem:

$$
\begin{aligned}
& \min \xi \\
& \text { s.t. } \\
& \left|w_{B}-a_{B j} w_{j}\right| \leq \xi, \quad \forall \mathrm{j} \\
& \left|w_{j}-a_{j W} w_{W}\right| \leq \xi, \quad \forall \mathrm{j} \\
& \sum_{\mathrm{j}} \mathrm{w}_{\mathrm{j}}=1 \\
& \mathrm{w}_{\mathrm{j}} \geq 0, \quad \forall \mathrm{j}
\end{aligned}
$$

The optimal weights, $w_{1}, \ldots, w_{n}$, as well as the optimal objective function, $\xi$, representing the consistency index, can be obtained by solving this linear model. Values of $\xi$ close to zero indicate a significant consistency associated with the expert pairwise comparisons.

\subsection{Proposed BN model}

We aim to model the cause and effect relationship between carbon price and its drivers. The general idea can be described using the simple BN in Figure 37. This model consists of two nodes: the price of carbon (or alternatively any trading price such as stock price, or the price of products and services) and a cause (C) that affects this price. Starting with a prior probability for the cause, $\mathrm{P}(\mathrm{C})$, the likelihood for carbon price conditional on the cause, $\mathrm{P}(\mathrm{P} \mid \mathrm{C})$, is calculated from a cause-to-effect inference or forward propagation:

$$
\mathrm{P}(\mathrm{P} / \mathrm{C})=\frac{\mathrm{P}(\mathrm{C} / \mathrm{P}) \mathrm{P}(\mathrm{P})}{\mathrm{P}(\mathrm{C})} .
$$




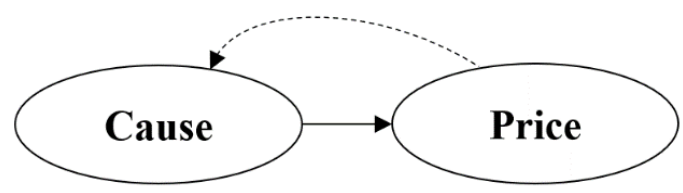

Figure 37: A naïve Bayesian network with two nodes: Carbon price (P) and its cause (C)

This rule provides an effect-to-cause or backward propagation, which allows the causation from carbon price to its cause to be captured (graphically represented by a dashed arrow in Figure 2). Thus, evidence on carbon price can be used to revise our prediction about the actual probability of its cause, that is $\mathrm{P}(\mathrm{C} \mid \mathrm{P})$, which can be calculated by multiplying the prior probability of the cause, $\mathrm{P}(\mathrm{C})$, by the likelihood $\mathrm{P}(\mathrm{P} \mid \mathrm{C})$, and normalizing the results by dividing by the constant $\mathrm{P}(\mathrm{P})$ :

$$
\mathrm{P}(\mathrm{C} / \mathrm{P})=\frac{\mathrm{P}(\mathrm{P} / \mathrm{C}) \mathrm{P}(\mathrm{C})}{\mathrm{P}(\mathrm{P})}
$$

Making an extreme assumption, let us suppose that oil price $(\mathrm{O})$ is the only cause for carbon price and that every oil price has always an escalating or depreciating impact on price. The degree to which oil price impacts carbon price can be incorporated to this simple BN, by adding the node I, as shown in Figure 38. The dependency connection between $\mathrm{O}, \mathrm{P}$, and I is $\mathrm{P}(\mathrm{O}, \mathrm{P}, \mathrm{I})=\mathrm{P}(\mathrm{P} \mid \mathrm{O}, \mathrm{I}) \mathrm{P}(\mathrm{O}) \mathrm{P}(\mathrm{I})$, which means an observation on oil price and/or its impact factor will influence carbon price. As long as nothing is known about $\mathrm{P}$, its parents, $\mathrm{O}$ and $\mathrm{I}$, are independent:

$$
P(I \mid O, P)=P(I \mid P)
$$

which means observing $\mathrm{O}$ does not influence $\mathrm{I}$, and vice versa. On the other hand, evidence on $\mathrm{P}$ makes the parent nodes $\mathrm{O}$ and I dependent:

$$
P(I \mid O, P)=P(I \mid P=p, 0)
$$

In other words, data (or new evidence) on both carbon and oil prices can be used to infer the impact factor. We have employed this simplified, conceptual BN to quantify the escalating and depreciating behaviours of carbon price in the WCI market depending on its driving factors. First, a node can be incorporated to determine the chance of a specific value of oil price, e.g. $O_{a}$, having an escalating/depreciating effect or otherwise having no effect on carbon price. 
Moreover, rather than only one impact node, two nodes should be created to estimate the size of both escalating and depreciating impacts, because we argue that an escalating effect due to an increasing change $\left(O_{a} \rightarrow O_{b}, O_{a}<O_{b}\right)$ in the oil price may not be equal to the depreciating effect due to the same decreasing change $\left(O_{b} \rightarrow O_{a}, O_{a}<O_{b}\right)$. This mechanism is demonstrated in the next section.

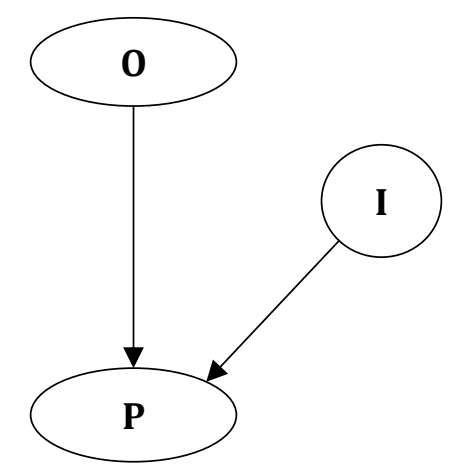

Figure 38: A BN to model the causality between oil price $(\mathrm{O})$, carbon price $(\mathrm{P})$ and the impact factor of oil price on carbon price (I)

We have developed a probabilistic BN model which captures the uncertainty of carbon price and its driving forces in the WCI market. Figure 39 presents the graphical structure of the model. As shown, a node is created for each driving force in the three corresponding categories. Using the projections of each driving force, a probabilistic distribution was calculated and assigned to their related nodes ${ }^{7}$. Distribution fitting for the node Temperature was performed for different months of a year and therefore the NPT of the node Temperature is conditional on the months. In this model. information propagates from a driving force to the others. For this reason, we did not call the driving forces as "independent" variables, as in the real world they may affect each other. Furthermore, new observations on the response and predictor variables can be used to calculate the posterior, updated distributions of the model's parameters, including the impact scales, the thresholds, and the impact factors.

\footnotetext{
${ }^{7}$ We used EasyFit Professional Version 5.6 to extract these distributions.
} 


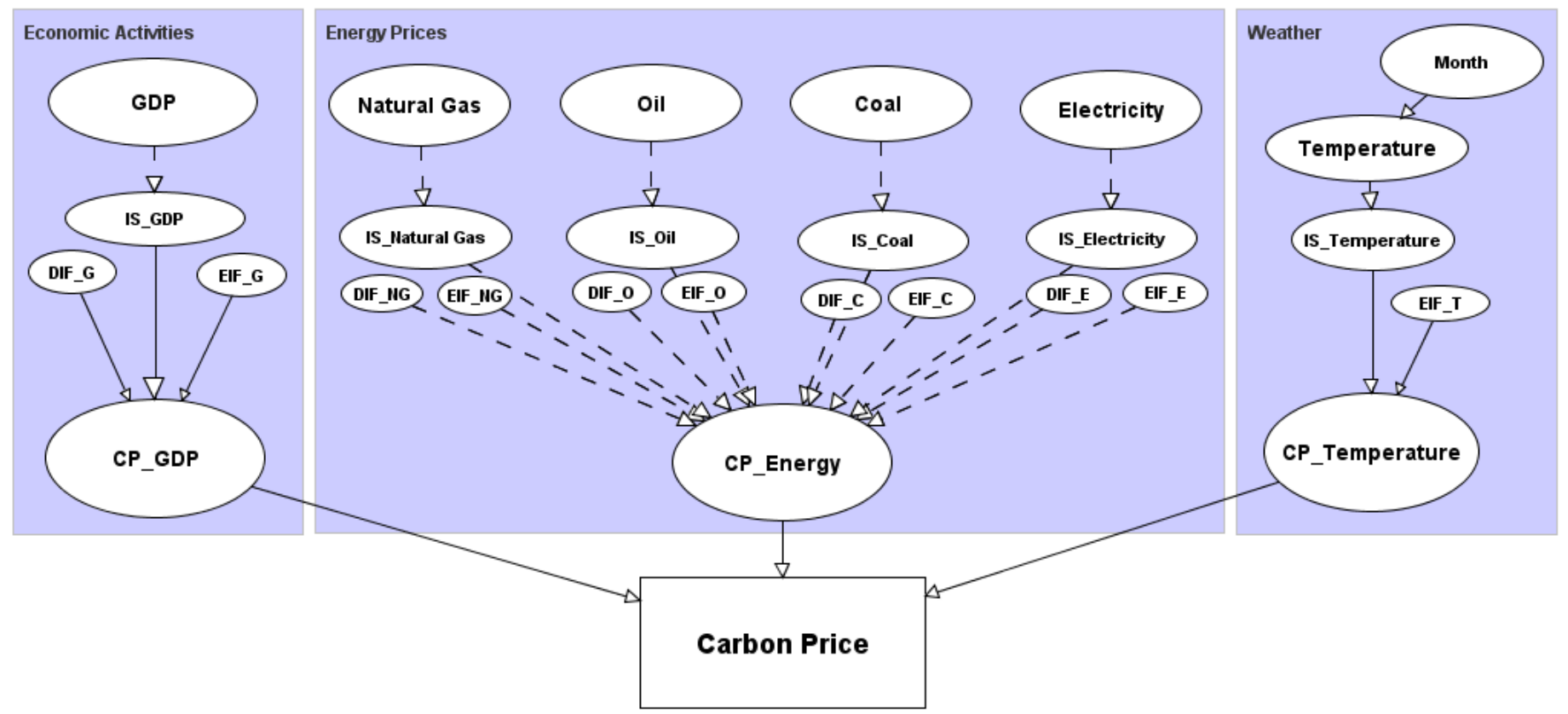

Figure 39: Graphical structure of the proposed BN model. The first layer indicates the nodes that are created to capture the uncertainty of driving forces. The second layer is the impact scale (IS) of the driving forces. The third layer of nodes shows the escalating and depreciating impact factors (EIF and DIF) (dashed lines are created because there are intermediate nodes in the model to facilitates NPT assignments and to lower the calculation volume).

Let's denote a driving variable as $\mathrm{X}$, with the two depreciating and escalating thresholds $x_{1}$ and $x_{2}$. An impact scale (IS) node is created for each X with the following NPT:

$$
\left\{\begin{array}{c}
P\left(\mathrm{IS}_{X}=\text { Normal }\right)=P\left(x_{1} \leq X \leq x_{2}\right) \\
P\left(\mathrm{IS}_{X}=\text { Escalating }\right)=P\left(X>x_{2}\right) \\
P\left(\mathrm{IS}_{X}=\text { Depreciating }\right)=P\left(X<x_{1}\right)
\end{array}\right.
$$

Historical data or expert elicitation can be used to estimate the thresholds $x_{1}$ and $x_{2}$. As illustrated in Figure 4, the purpose of defining IS is to calculate the probability of a driving force being in a normal, escalating, or depreciating status. 


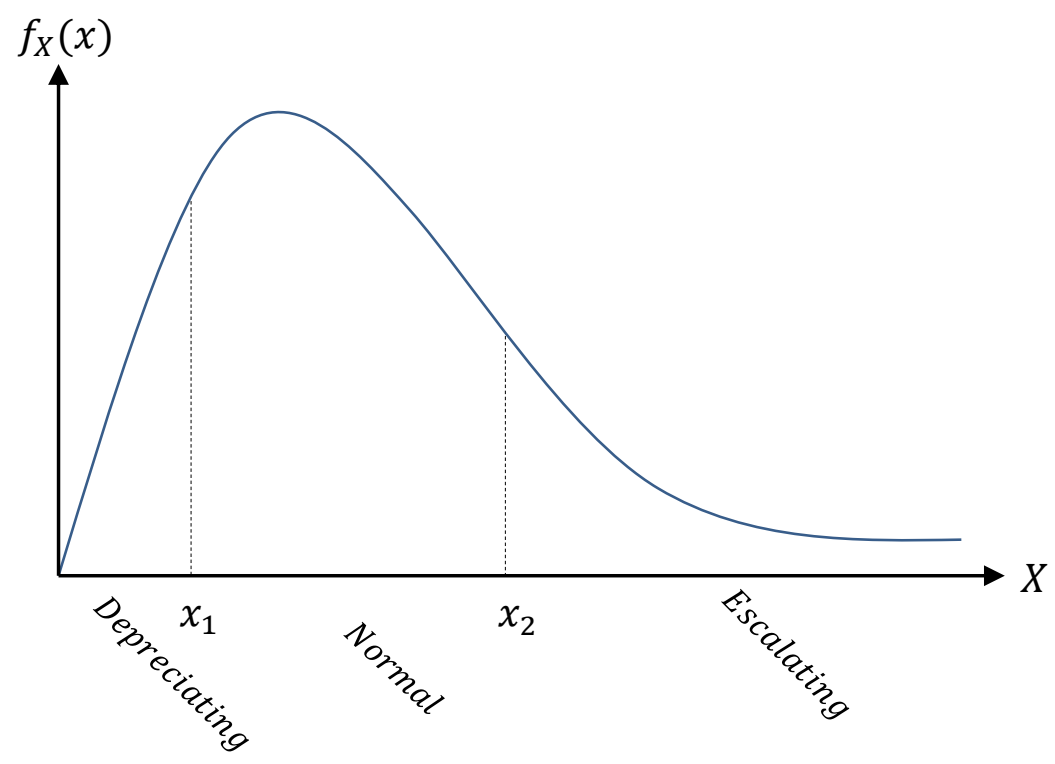

Figure 40: The probabilistic distribution of the driving force $X$ and its threshold parameters $x_{1}$ and $x_{2}$, to define normal, depreciating and escalating regions

The impact scale for temperature is defined a little differently. As extreme hot and cold weather both have an escalating impact on emission allowances demand, IS for Temperature comes with only two statuses, i.e. normal and escalating:

$$
\left\{\begin{array}{l}
P\left(\mathrm{IS}_{T}=\text { Normal }\right)=P\left(x_{1} \leq X \leq x_{2}\right) \\
P\left(\mathrm{IS}_{T}=\text { Escalating }\right)=P\left(X<x_{1} \text { or } X>x_{2}\right)
\end{array} .\right.
$$

In the next step, for each driving force, two depreciating and escalating impact factors (DIF and EIF, respectively) are incorporated into the model. These factors represent the significance of the depreciating/escalating effect of a driving force. The purpose of incorporating these factors is to modify a baseline carbon price (BCP). The $\mathrm{BCP}$ is an estimation of carbon price assuming all the driving forces are in their 'normal' status. If the impact scale of a driving force is depreciating (escalating), a depreciating (escalating) impact factor would be active to adjust the estimated baseline price. Otherwise, i.e. when the impact scale is normal, BCP does not alter. The motivation behind DIF and EIF is the fact that carbon price may not be affected by every driver equally.

Thus, carbon price derived by energy prices $\left(\mathrm{CP}_{\text {Energy }}\right)$, economic activities $\left(\mathrm{CP}_{\mathrm{GDP}}\right)$, and weather $\left(\mathrm{CP}_{\text {Temperature }}\right)$ are calculated as follows:

$$
\mathrm{CP}_{\text {Energy }}=\sum_{X}\left[\mathrm{P}\left(\mathrm{IS}_{\mathrm{XN}}\right) \cdot \mathrm{f}(\mathrm{BCP})+\mathrm{P}\left(\mathrm{IS}_{\mathrm{XE}}\right) \cdot \mathrm{f}(\mathrm{BCP}) \cdot \mathrm{f}\left(\mathrm{EIF}_{\mathrm{X}}\right)+\mathrm{P}\left(\mathrm{IS}_{\mathrm{XD}}\right) \cdot \mathrm{f}(\mathrm{BCP}) \cdot \mathrm{f}\left(\mathrm{DIF}_{-} \mathrm{X}\right)\right]
$$




$$
\begin{aligned}
& \mathrm{CP}_{\mathrm{GDP}}=\mathrm{P}\left(\mathrm{IS}_{\mathrm{GN}}\right) \cdot \mathrm{f}(\mathrm{BCP})+\mathrm{P}\left(\mathrm{IS}_{\mathrm{GE}}\right) \cdot \mathrm{f}(\mathrm{BCP}) \cdot \mathrm{f}\left(\mathrm{EIF}_{-} \mathrm{G}\right)+\mathrm{P}\left(\mathrm{IS}_{\mathrm{GD}}\right) \cdot \mathrm{f}(\mathrm{BCP}) \cdot \mathrm{f}\left(\mathrm{DIF}_{-} \mathrm{G}\right) \\
& \mathrm{CP}_{\mathrm{Temperature}}=\mathrm{P}\left(\mathrm{IS}_{\mathrm{TN}}\right) \cdot \mathrm{f}(\mathrm{BCP})+\mathrm{P}\left(\mathrm{IS}_{\mathrm{TE}}\right) \cdot \mathrm{f}(\mathrm{BCP}) \cdot \mathrm{f}\left(\mathrm{EIF}_{-} \mathrm{T}\right)
\end{aligned}
$$

where $I S_{\mathrm{XN}}$, IS $\mathrm{S}_{\mathrm{XN}}$, and IS $\mathrm{S}_{\mathrm{XN}}$ are the probability of the normal, escalating, and depreciating states in driving force $\mathrm{X}$, respectively. Considering the weights $\mathrm{w}_{\mathrm{e}}, \mathrm{w}_{\mathrm{g}}$, and $\mathrm{w}_{\mathrm{t}}$ associated with the categories energy prices, GDP, and temperature, forecasted carbon price (CP) is formulated as follows:

$$
\mathrm{CP}=\mathrm{w}_{\mathrm{e}} \cdot \mathrm{CP}_{\text {Energy }}+\mathrm{w}_{\mathrm{g}} \cdot \mathrm{CP}_{\mathrm{GDP}}+\mathrm{w}_{\mathrm{t}} \cdot \mathrm{CP}_{\mathrm{Temperature}}
$$

Like the thresholds $x_{1}$ and $x_{2}$, prior distribution of DIF, EIF, as well as BCP can be generated using historical records of the market or expert judgment. Whenever a new price is observed from the market, the proposed model would update the above parameters, by calculating their posterior distribution. In fact, even if the model begins with vague priors for the parameters, it learns these parameters by use of actual data and therefore the predictions would become more accurate.

\subsection{Results and analysis}

This section demonstrates the results of applying the proposed carbon price forecasting model to the WCI market. As discussed earlier, we assigned a probability distribution to the projections of energy prices and GDP over the period 2018-2030, for the two jurisdictions. For temperature, we used historical records of Quebec and California to extract its probabilistic distribution. We created a separate Bayesian inference network to estimate the thresholds $x_{1}$ and $x_{2}$, and the impact factors EIF and DIF of the driving variables. Using historical values of the driving forces and WCI carbon prices, the above parameters were learnt. To do so, we first assigned a uniform prior to the variables and parameters, and trained them by applying a K-fold cross-validation (CV) [184]. CV is a common technique to test the prediction power of a machine learning model. It allows the analyst to use part of limited data (called the training dataset) to measure the model performance from its accuracy on the rest of data which is not used in the training dataset (called test data). To run a $\mathrm{K}$-fold $\mathrm{CV}$, the entire dataset is split into $\mathrm{K}$ equal groups of samples; then the model will be trained using the samples of K-1 groups (that is the training dataset) and tested on one remaining group (which is the test or hold out dataset). The training and testing will be replicated on $\mathrm{K}$ different combinations of groups, to select the best prediction 
model.

We trained the model parameters and tested their performance in two processes of K-fold CVs:

1) After evaluating the posteriors on each test data, the parameters' priors were reset to the initial uniform distribution. We repeated this training/testing $\mathrm{K}$ times to obtain the most accurate posteriors for the model parameters.

2) We kept the calculated posteriors obtained in each of the $K$ tests and used them as the new priors for next test. Thus, we obtained $\mathrm{K}$ additional series of posteriors which needed to be compared to those in the first process (i.e. the overall number of comparisons was $2 \mathrm{~K}$ ). This second process of training allows to evaluate the learning capacity of the model.

In order to test the posteriors' prediction performance, the root mean squared error (RMSE) was used. The uniform priors for all the driving forces were defined as follows:

$$
\begin{array}{ll}
\mathrm{x}_{1} \sim \mathrm{U}(1 \%-\text { lower percentile, mean }) & \operatorname{DIF} \sim \mathrm{U}(0,1) \\
\mathrm{x}_{2} \sim \mathrm{U}(\text { mean, } 99 \%-\text { lower percentile }) & \mathrm{EIF} \sim \mathrm{U}(1,2)
\end{array}
$$

Using the last 64 historical weekly prices ${ }^{8}$ of the market from January, 2017 to March, 2018 [185] along with their corresponding driving forces, we created four groups of data (after shuffling them) to run two 4-fold CV processes, in which the groups had 16 samples. Having run the eight trainings, we compared their predictive accuracy, as plotted on Figure 41. As it can be seen, the second process of 4-fold CV generally generates more accurate posteriors. This is because we preserved the learnt posteriors obtained in the previous tests. This is evident especially in the significant improvement occurred in the second test, in which the priors come from the posteriors obtained in the first test.

\footnotetext{
${ }^{8}$ We considered the average value of the prices reported within a week.
} 


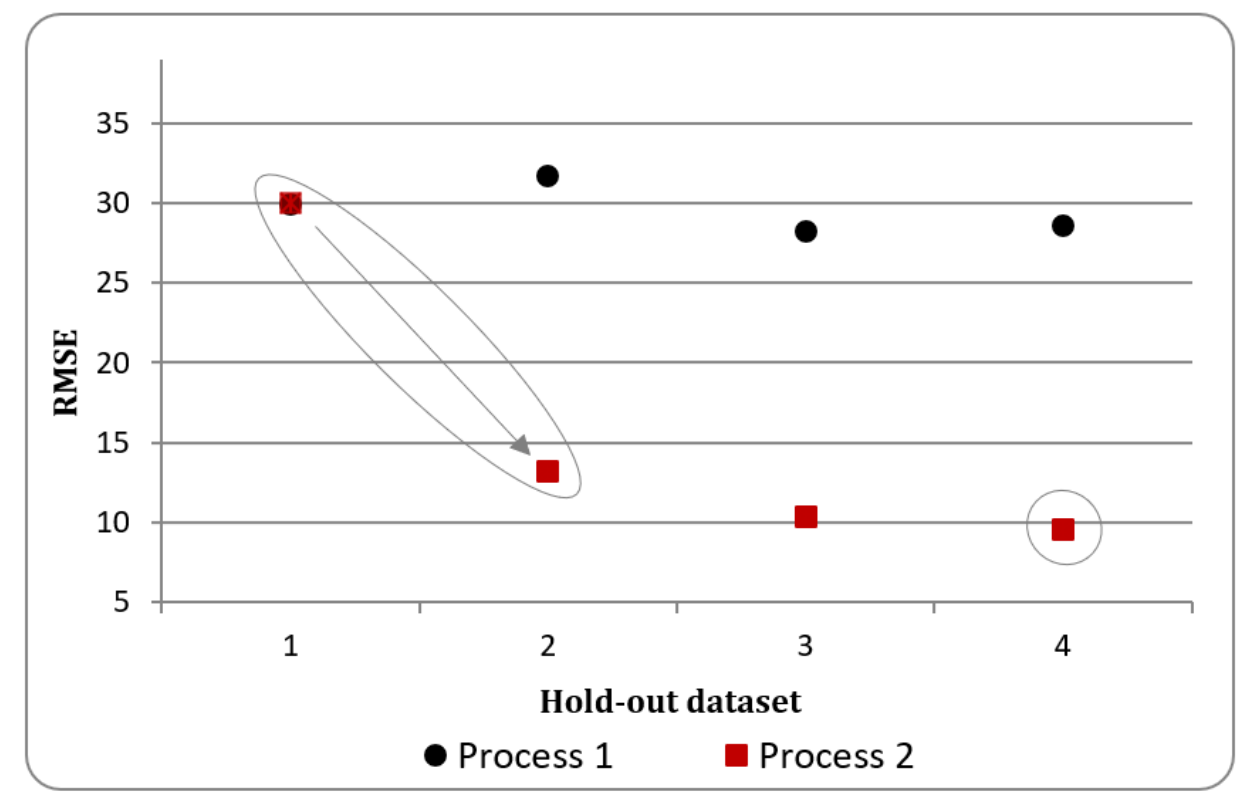

Figure 41: RMSE values associated with the eight tests conducted in two 4-fold cross-validations

Therefore, we selected the trained model with the least RMSE, obtained in the second process when it was tested using the fourth hold-out dataset. The posterior distributions of this model are presented in Table 1. The probability distribution functions (PDFs) extracted for the driving forces are also provided in this Tables. As mentioned earlier, we applied a software package to fit these PDFs to the average projections of the market. For example, the PDF best suited to oil prices is Logistic (72.26,5.77) US\$ per blue barrel (bbl). We modelled the baseline carbon price $(\mathrm{BCP})$ by a truncated normal distribution, using the mean value and variance of 500 recent prices of WCI market ( $\mathrm{C} \$ 17.32$ and $\mathrm{C} \$ 3.2$, respectively). The lower and upper bounds of the distribution were set as $\$ 10$ and \$67 respectively, as suggested by ICF's LongTerm Carbon Price Forecast Report (2017) [186]. Thus, BCP TNormal (17.21, 3.20, 10, 67). 
Table 23. Probability distribution functions (PDFs) and parameters of the proposed model for the WCI market.

\begin{tabular}{|c|c|c|c|c|c|}
\hline Variable & \multicolumn{2}{|l|}{ PDF } & $\left(\begin{array}{l}\mathbf{x}_{1} \\
\mathbf{x}_{2}\end{array}\right)$ & $\left(\begin{array}{l}\text { DIF } \\
\text { EIF }\end{array}\right)$ & $\begin{array}{c}\text { IS } \\
(\text { Esc., Norm., Dep.) }\end{array}$ \\
\hline \multirow{2}{*}{$\begin{array}{l}\text { Natural Gas } \\
\text { (US\$/MMBtu) }\end{array}$} & \multirow{2}{*}{\multicolumn{2}{|c|}{$\operatorname{Beta}(0.43,0.32,2.87,5.23)$}} & $\mathrm{U}(2.80,3.41)$ & $\mathrm{U}(0.68,0.82)$ & \multirow{2}{*}{$(26.81,66.49,7.69)$} \\
\hline & & & $\mathrm{U}(3.84,4.02)$ & $\mathrm{U}(1.15,1.37)$ & \\
\hline \multirow{2}{*}{$\begin{array}{l}\text { Oil } \\
(\mathrm{US} \$ / \mathrm{bbl})\end{array}$} & \multirow{2}{*}{\multicolumn{2}{|c|}{ Logistic $(72.26,5.77)$}} & $\mathrm{U}(51.17,63.29)$ & $\mathrm{U}(0.61,0.87)$ & \multirow{2}{*}{$(13.58,80.66,5.76)$} \\
\hline & & & $\mathrm{U}(76.11,82.91)$ & $\mathrm{U}(1.07,1.36)$ & \\
\hline \multirow{2}{*}{$\begin{array}{l}\text { Coal } \\
\text { (US\$/ton) }\end{array}$} & \multirow{2}{*}{\multicolumn{2}{|c|}{ Triangle $(34.14,35.34,36.79)$}} & $\mathrm{U}(34.19,34.45)$ & $U(0.67,0.93)$ & \multirow{2}{*}{$(7.10,83.37,9.53)$} \\
\hline & & & $\mathrm{U}(35.79,36.11)$ & $\mathrm{U}(1.09,1.50)$ & \\
\hline \multirow{2}{*}{$\begin{array}{l}\text { Electricity } \\
\text { (USC/kwh) }\end{array}$} & \multirow{2}{*}{\multicolumn{2}{|c|}{ Weibull $(73.81,10.59)$}} & $\mathrm{U}(9.40 .10 .08)$, & $U(0.58,0.96)$ & \multirow{2}{*}{$(2.51,85.31,12.18)$} \\
\hline & & & $\mathrm{U}(10.95,11.24)$ & $\mathrm{U}(1.15,1.45)$ & \\
\hline \multirow{2}{*}{$\begin{array}{l}\text { GDP } \\
\text { (Trillion USD) }\end{array}$} & \multirow{2}{*}{\multicolumn{2}{|c|}{ Beta $(0.65,0.75,1.3,1.78)$}} & $\mathrm{U}(1.16,1.40)$ & $\mathrm{U}(0.61,0.87)$ & \multirow{2}{*}{$(29.05,66.82,4.13)$} \\
\hline & & & $\mathrm{U}(1.37,1.68)$ & $\mathrm{U}(1.18,1.43)$ & \\
\hline Variable & Month & PDF & $\left(\begin{array}{l}\mathbf{x}_{1} \\
\mathbf{x}_{2}\end{array}\right)$ & EIF & $\begin{array}{c}\text { IS } \\
\text { (Esc., Norm.) }\end{array}$ \\
\hline \multirow{12}{*}{$\begin{array}{l}\text { Temperature } \\
\left({ }^{\circ} \mathrm{C}\right)\end{array}$} & Jan. & Beta $(0.59,0.69,-4,1)$ & \multirow{12}{*}{$\begin{array}{c}\mathrm{U}(-3.09,0.30) \\
\mathrm{U}(16.33,22.17)\end{array}$} & \multirow{12}{*}{$\mathrm{U}(1.14,1.36)$} & \multirow{12}{*}{$(16.41 ., 83.59)$} \\
\hline & Feb. & $\operatorname{Beta}(3,2,-1,4)$ & & & \\
\hline & Mar. & Beta $(3,2,4,8)$ & & & \\
\hline & Apr. & $\operatorname{Beta}(3,2,10,14)$ & & & \\
\hline & May & Beta $(3,2,15,20)$ & & & \\
\hline & Jun. & Beta $(3,2,20,24)$ & & & \\
\hline & Jul. & $\operatorname{Beta}(3,2,23,27)$ & & & \\
\hline & Aug. & $\operatorname{Beta}(3,2,22,26)$ & & & \\
\hline & Sep. & $\operatorname{Beta}(3,2,18,22)$ & & & \\
\hline & Oct. & Beta $(3,2,12,16)$ & & & \\
\hline & Nov. & Beta $(3,2,6,10)$ & & & \\
\hline & Dec. & $\operatorname{Beta}(3,2,2,8)$ & & & \\
\hline
\end{tabular}

Having constructed and run the $\mathrm{BN}$ model, the $\mathrm{PDF}$ of $\mathrm{CP}_{\text {Energy }}, \mathrm{CP}_{\mathrm{GDP}}, \mathrm{CP}_{\text {Temperature }}$ nodes are obtained as shown in Figures 42-44. As illustrated, energy prices, GDP and temperature generate different predictions for carbon price. Average price of carbon over the period 20182030 based on the correlation between carbon price and energy prices has a distribution close to Normal with the mean value of $\mathrm{C} \$ 17.293$ and variance of 1.67 . The distributions obtained from the dependency between carbon price and GDP and temperature are skewed toward right, with the mean values of $\mathrm{C} \$ 19.103$ and $\mathrm{C} \$ 18.278$, respectively. 


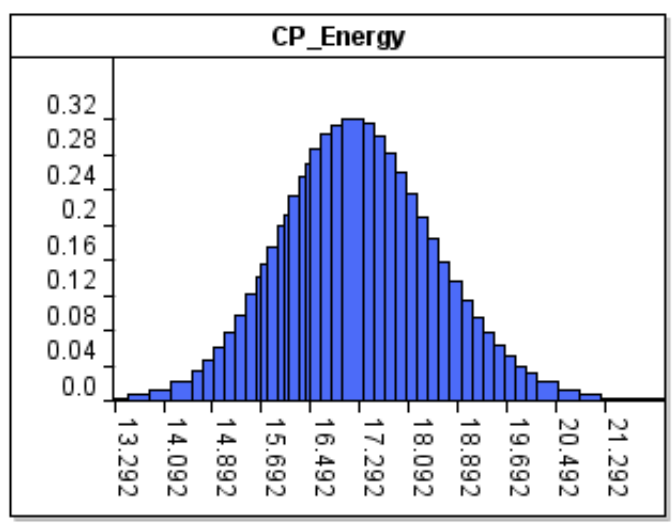

Mean: C $\$ 17.293$

Median: C $\$ 17.258$

SD: C\$ 1.2924

Variance: 1.6702

Lower Percentile: 25.0 (C\$16.377)

Upper Percentile: 75.0 (C\$18.077)

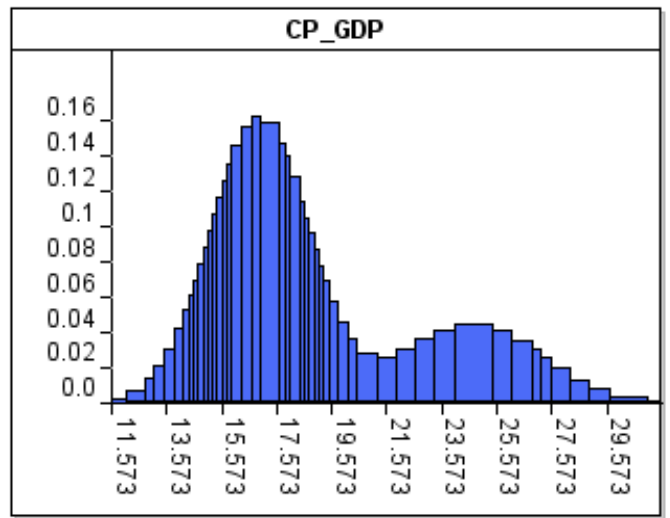

Mean: C\$19.103

Median: C $\$ 17.859$

SD: C\$ 3.9703

Variance: 15.764

Lower Percentile: 25.0 (C\$16.262)

Upper Percentile: 75.0 (C\$21.366)

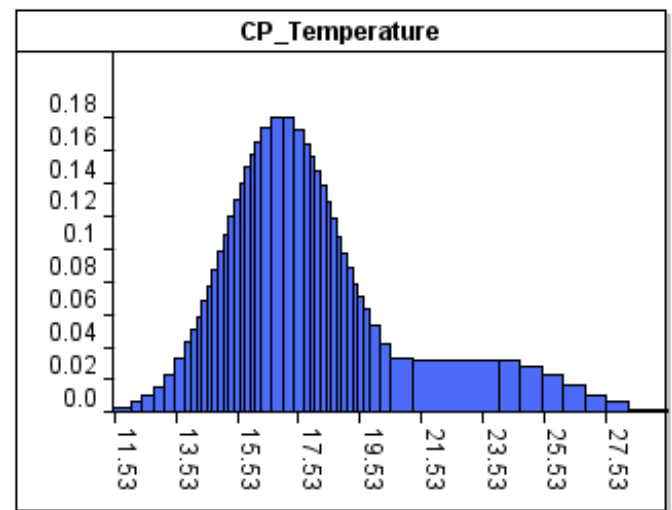

Mean: C $\$ 18.278$

Median: C $\$ 17.533$

SD: C\$ 3.2357

Variance: 10.47

Lower Percentile: 25.0 (C\$16.099)

Upper Percentile: 75.0 (C\$19.442)

Figure 42: Distribution of carbon price over the period 2018-2030 only dependent on a single category of driving forces, i.e. energy prices, GDP, and temperature

Assuming that the following weights corresponding weight of each driving category have been obtained using BWM method, $\mathrm{w}_{\mathrm{e}}=0.42 ; \mathrm{w}_{\mathrm{g}}=0.33$; and $\mathrm{w}_{\mathrm{t}}=0.25$, the overall distribution of carbon price (the node Carbon Price) was calculated as shown in Figure 43. This probabilistic distribution combines the effect of all the driving forces. As it can be seen from the graph, in average the price of carbon in the WCI market over the forecasting horizon is 
distributed mostly between $\mathrm{C} \$ 14$ and $\mathrm{C} \$ 25$, with a most likely price of $\mathrm{C} \$ 18.174$. The distribution is skewed toward right and its variance is around three. With a 90 percent confidence, the price would not be higher than C $\$ 20.58$.

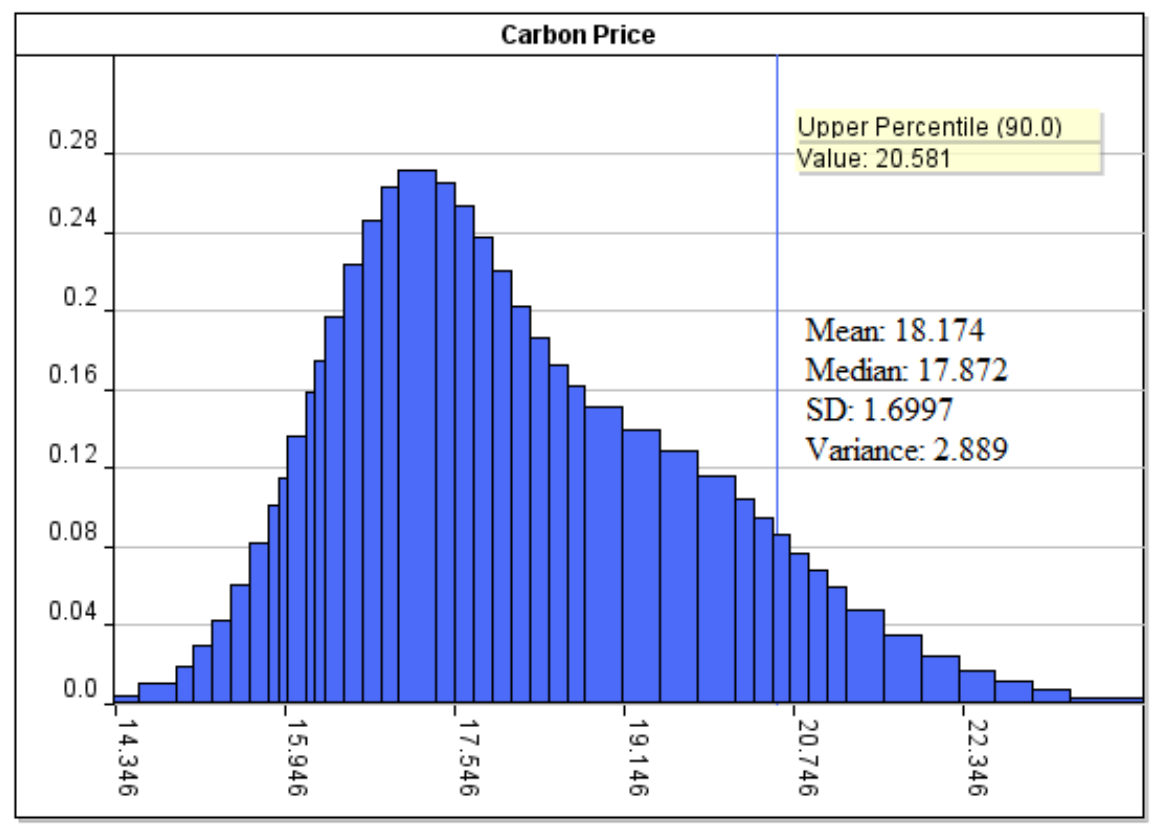

Figure 43: Probability distribution function of the predicted carbon price in the WCI market

The proposed model allows to predict the carbon price in different scenarios and perform various what-if analyses to update the prediction, when there is a new evidence on the driving forces, as well as the market's actual prices. For example, if we know that the average temperature will be $17^{\circ} \mathrm{C}$ (Scenario 1), the PDF of carbon price will be revised as presented in Figure 44, which compares the result of running the model under this scenario with the baseline scenario. As illustrated, the PDF of carbon price has slightly shifted toward left, decreasing the mean value of the distribution from $\mathrm{C} \$ 18.17$ to $\mathrm{C} \$ 17.04$. 


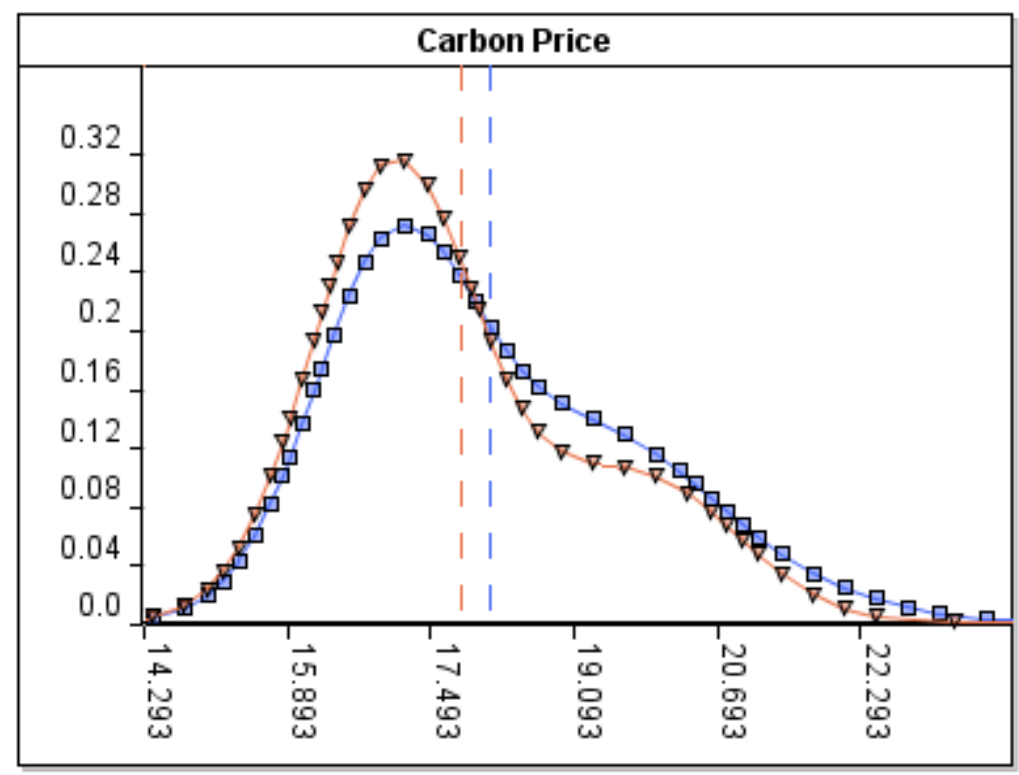

Baseline Scenario

Mean: 18.174

Median: 17.872

SD: 1.6997

Variance: 2.889

Scenario 1

Mean: 17.036

Median: 16.949

SD: 1.1274

Variance: 1.271

Figure 44: PDF of carbon price in Scenario 1 compared to the baseline PDF

In addition to the above long-term prediction, short term predictions including predictions for a specific period of time can be calculated by applying the projections of the driving forces, corresponding to that period. For instance, entering the projections for the years 2019, 2022, and 2027 into the model, we obtained carbon price forecasts specific to these years, as presented in Figure 45. The distributions of carbon price reveal a price of $\mathrm{C} \$ 17.22, \mathrm{C} \$ 18.65$, and $\mathrm{C} \$ 19.43$ for the years 2019, 2022, and 2027, respectively. This output provides a sense of midterm prediction of carbon price. The graph shows that as time goes on the distributions are skewed towards right, suggesting higher prices in the future of the WCI market. 


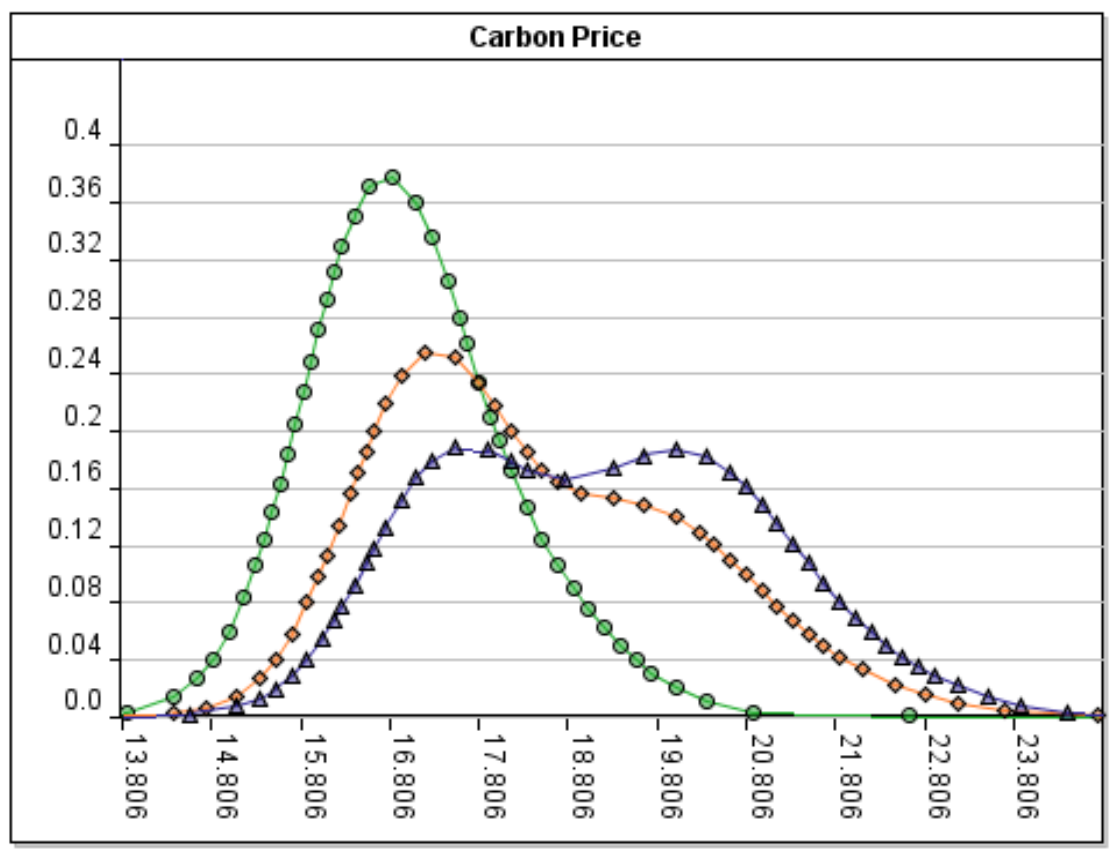

2019

Mean: 17.036

Median: 16.949

SD: 1.1274

Variance: 1.271

2022

Mean: 18.452

Median: 18.16

SD: 1.7341

Variance: 3.0073

2027

Mean: 19.175

Median: 19.141

SD: 1.8343

Variance: 3.3645

Figure 45: PDF of projected carbon price for the years 2019, 2022, and 2027

\subsection{Conclusion}

In this paper, a probabilistic approach to forecasting carbon price in an ETS was proposed, using Bayesian networks (BNs). Equipped with the inference mechanism of BNs, the proposed model is supported by based retrospective and prospective data on the driving forces of carbon price. This allows us to not only capture the historical correlations between carbon price and its drivers, and therefore estimate the future prices, but also update the correlations based on actual prices of the market. This mechanism can combine both historical data and expert knowledge.

We applied the proposed model to the Western Climate Initiative (WCI) market. The driving forces of carbon price were identified from the literature, including the studies conducted on the European Union ETS. For each driving force, a distribution was calculated using its projections in the participating jurisdictions, which reflects the uncertainty of the driving force in the whole market. We designed a cause-and-effect module which determines the chance of a driving force having an escalating/depreciating effect on carbon price. The parameters to perform this calculation analysis were first modeled using vague priors and then learnt through historical records of carbon prices. Likewise, the power of the driving forces to alter the carbon price was modeled using an impact factor specific to them. By integrating these variables and uncertainty 
of the driving forces, the probability density function of carbon price was simulated. The results showed that carbon prices over the future decade ranges between approximately $\mathrm{C} \$ 14$ and $\mathrm{C} \$ 26$, with the most likely prices around $\mathrm{C} \$ 18$. There is a 90 percent chance of the price being greater than $\mathrm{C} \$ 16.19$ or lower than $\mathrm{C} \$ 21.17$.

The model could be rebuilt if a new jurisdiction is joint to the WCI market. Had the Ontario's cap and trade regulations not been revoked by the new provincial government of Ontario, we would have included Ontario's projections of the driving factors in the proposed

forecasting model. Although joining a new participating jurisdiction increases the uncertainty of the market, the model first revises the prior estimations (using the revised market projections) and is capable of revising them continuously by calculating the posterior estimations as soon as an actual price is observed in the expanded market.

\section{Acknowledgment}

The author acknowledges financial support from the Natural Sciences and Engineering Research Council (NSERC) of Canada for this research. 


\section{Project GHG Performance Measurement}

The present chapter is based on the following paper:

Abdi, A., Taghipour, S., \& Khamooshi, H. (2018). A model to control environmental performance of project execution process based on greenhouse gas emissions using earned value management. International Journal of Project Management, 36(3), 397-413 [82]. Published online at: https://doi.org/10.1016/j.ijproman.2017.12.003

Abdi, A., Taghipour, S. (2018). Uncertainty Analysis of Project Emissions: A Bayesian Network Model to Estimate and Monitor Greenhous Gas Emissions. The 18th annual IEEE Canada Electrical Power and Energy Conference (EPEC 2018).

Projects do have a significant share in GHGs and therefore their environmental performance, like their schedule and cost performance, should be monitored and controlled. Although many large projects would pass an environmental assessment in the project evaluation phase, the issue of environmental performance monitoring during the project execution phase has not been addressed in project management methodologies. The objective of this chapter is to develop a model to estimate project GHG emissions, and to measure project GHG performance using the developed metrics, which can be used at any point in time over the life of a project. Two models are developed. First, a GHG performance measurement model is formulated based on the logic used in earned value management (EVM) methodology. A breakdown structure is proposed which supports managing all the project GHG accounts. This model is then implemented to a work package of a real construction project. The results present the project initial GHG plan and show that the model is able to calculate project GHG variance by the reporting date and predict project final GHG based on a project GHG performance index. Second, we propose a probabilistic model to quantify the uncertainty of project GHG emissions using Monte Carlo Simulation and BNs techniques. The model provides a quantitative risk analysis mechanism to estimate the total emissions of the project as well as prediction of final emissions during the implementation process. The proposed models are applied to a work package of a real construction project. 
Keywords: Greenhouse gas (GHG) emissions, Project control, Earned value management (EVM), Project quantitative risk analysis.

\subsection{Introduction and Background}

Projects, with a significant role in global economy as much as one third [15] have a serious contribution to global climate change and GHGs. This is the case specifically in construction projects which are the primary contributor of global GHG emissions [16]. Moreover, because of the growing competitive pressure and tendency to apply modern management techniques, organizations are being more and more projectized or project oriented [17]. Despite this fact, common practices in project performance measurement use project conventional triple constraints (i.e. quality, time and cost), neglecting its investment effectiveness and organizational benefits [18]. To integrate and incorporate the impact of GHGs emission in project execution and control, and to address national and international concern on the climate change, sustainability and reducing environmental impacts, GHGs emission can be considered as a cost for almost any types of project. Furthermore, carbon pricing using either a carbon tax or cap-and-trade program can motivate organizations to model project's environmental impacts in their estimations and performance measures. Therefore, it is essential for future project managers to have a monitoring system for their project environmental impact performance or GHG management, and hence it is not far-fetched to see a 'Project GHG Management' chapter in Project Management Institute's (PMI) standard "Project Management Body of Knowledge, PMBOK" [94].

The common practice for project performance measurement is earned value management (EVM) technique and its extensions. A comprehensive study by [187] shows that EVM-based models have been mostly developed for time or cost control. Many studies have been published to represent the basic concepts of EVM (e.g. $[94,188,189]$ and its more complicated, advanced extensions (e.g. $[187,190,191])$. It is believed that the traditional EVM technique is one of the most straightforward and widely used methods for monitoring and controlling project cost and schedule. For this reason, the EVM concepts have been used to propose a model to control environmental performance of a project during its execution process.

Recently, several studies have been conducted to estimate and report the total amount of GHG emissions contributed to construction phase of a project [16,192-196]. These studies are 
conducted with a focus on environmental review process within project evaluation phase and try to find the total emissions released from a project. This evaluation specifically addresses the environmental performance of project deliverables, without looking at the performance of project management during project delivery. As Kivilä et al. (2017) [197] pointed out, the sustainability of the delivery process, as well as that of deliverables themselves, are crucial as they could have considerable environmental and social impacts. Therefore, project management practices need to be modified to incorporate methods to assess the environmental impact of the project compared with the intended performance, during the execution phase. Previously, the issue of GHG emission control during project execution, however, has not been addressed in the literature. Kim et al. (2015) [198] developed a method to evaluate $\mathrm{CO}_{2}$, cost and schedule of building construction projects, using the cost and schedule performance indices (CPI and SPR). However, this method uses cost and schedule-based criteria to monitor project overall performance and fails to decouple the environmental performance from cost and schedule profiles. Therefore, this model does not reflect the project current environmental variance also its final $\mathrm{GHG}$ emission.

In current practices, environmental and social costs are only analysed during project inception and investment decision. The analysis normally includes some consideration of GHG emission reduction through changing and modification of methods, material, location, etc. After such planning and evaluation at the preparation phase, failure to monitor the project environmental impact generally and project GHG emissions specifically during the project delivery, can derail the intended plans. Therefore, there is a need for an all-encompassing approach to "sustainability-oriented project control" in projects [197]. In this regard, Martens and Carvalho (2017) [199] suggest that incorporating sustainability performance management into projects requires decision models/tools to be applied in various phases of the project including project selection, evaluation, production, and project processes.

\subsubsection{Previous studies}

Previous research makes it evident that a large amount of GHG emissions are being released from construction projects all around the world. For example, Hanson and Noland (2015) [4] reported 2671.5 metric tons of $\mathrm{CO}_{2}$ eq for a pavement rehabilitation project in the US, state of New Jersy. Fernández-Sánchez et al. (2015) [200] calculated 390 kilo tons of CO $_{2}$ eq for a 
highway project in Ciudad Real, Spain. About 273.5 kilo tons of $\mathrm{CO}_{2}$ eq was reported by Chou and Yek [194] for a wholesale building project in Taiwan. In China, after performing a comprehensive study on different types of highway project, Wang et al. (2015) [192] stated that there is an average $\mathrm{CO}_{2}$ eq of 5229,35547 , and $42302 \mathrm{~kg}$ per meter for road, bridge, and tunnel construction, respectively.

It is possible to identify the most effective reduction strategies by accounting for emissions. Not only can this lead to energy and material efficiency, but also the development of new products and services that reduce the GHG impacts of clients or suppliers. Consequently, limiting GHG emission reduces the cost of production and differentiates the company in the future environmentally responsive marketplace [79]. As an important driving force, energy consumption plays an essential role in economic development and social progress of the early twenty-first century. According to the 2013 BP World Energy Statistics [201], although the growth in consumption and production of most of fuels has slowed, compared to the past, they hit record levels. The consumption of fossil fuels is increasing fast, and this has the greatest impact on $\mathrm{CO}_{2}$ emissions [77]. The global demand for energy, as the life-blood of the modern world, has increased in recent years. Without a significant change in governments' policies, worldwide primary energy demand is predicted to rise from 12,271 to $18,048 \mathrm{Mtoe}^{9}$ between 2008 and 2035, which means an increase of $47 \%$ [202] while the global population mostly relies on traditional, polluting and unsustainable energy sources [203].

Review of the literature shows that in recent years many studies have been conducted to estimate Scope 1 GHGs, emitted from the equipment and or materials of construction projects. Cao et al. (2016) [204] made in-use emission measurements from 27 pieces of construction equipment, to accurately estimate emissions from non-road construction equipment. Using the life cycle assessment (LCA), Pöyry et al. (2015) [205], estimated the total GHG emissions associated with construction phase of a low-energy multi-story residential building in Finland. They reported that building frame and roofing, and HVAC and the electrical systems were the two main contributors to total emissions, with about 40 and 20 percent, respectively. Based on data from a road construction case in New Jersey, Hanson and Noland (2015) [4] analysed the amount of direct and indirect GHG emissions from materials, equipment, maintenance

${ }^{9}$ Million tons of oil equivalent 
activities, and transformation of resources to the project site. Ozcan-Deniz and Zhu (2017) [206] used a multi-objective optimization technique to analyse the correlation between time, cost, and environmental impact (as a new conflicting objective) of highway construction projects. Results of this study shows that correlation between time and cost, cost and GHG emissions, and time and GHG emissions are strongly positive, moderately positive, and weakly positive, respectively. Conversely, Cass et al. (2011) [207] had reported that there is a meaningful correlation between project GHGs and delays. Hong et al. (2016) [16] developed a multimethod-based framework for uncertainty analysis of construction GHG emissions and applied it to a residential complex project. Their model finally calculates the probabilistic distribution of total emissions related to construction activities. The Athena Sustainable Materials Institute (ASMI) (a Canadian science-based organization in life cycle assessment of the built environment) has developed a series of software which allows construction industry professionals to incorporate environmental considerations into building projects. Athena's Impact Estimator for Buildings is the most relevant tool in which users can model their own custom assembly and envelope configurations. The software then calculates the operating embodied, and a cradle-to-grave life cycle inventory profile for a whole building [1012]. In this tool, however, impacts associated with only construction material and transportation are calculated and therefore it does not incorporate Scope 2 emissions yet.

It can be observed that researchers are also paying attention to Scope 2 and Scope 3 (or indirect) GHGs. Sattary and Thorpe (2016) [208] investigated the level of GHG emissions reduction which can be obtained by use of bioclimatic principles in Australian buildings. Based on their results, bioclimatic principles can make up to 65 percent reduction in construction GHG emissions, for the whole building including floor, wall and roof. Using Monte Carlo simulation (MCS) tool, Chou and Yeh (2015) [194] estimated both Scope 1 and Scope $2 \mathrm{CO}_{2}$ emissions of a building during its life cycle (i.e. construction material manufacturing and transporting phase, occupation and renovation phase, and demolition phase). They also proposed a metric to convert $\mathrm{CO}_{2}$ emissions into environmental costs. Using data from four real highway construction projects, i.e. subgrade, pavement, bridge, and tunnel in China, Wang et al. (2015) [192] estimated the total $\mathrm{CO}_{2}$ emission of three construction phases: production of raw material, material transportation and construction. Both Scope 1 and Scope 2 emissions (from electricity consumption) have been considered in this study. Also, tunnel and bridge projects have 
generated more emission compared to pavement and subgrade projects. Du Can et al. (2015) [209] proposed a framework to estimate indirect $\mathrm{CO}_{2}$ emissions generated from electricity and heat production. Downie and Stubbs (2013) [210] evaluated Scope 3 emissions of Australian organizations by analysing the data and methods that they currently use. The authors found a considerable variation in the number of Scope 3 emission sources reported by their participants. Their suggestion was to utilize more comprehensive guidance on emission sources to improve the relevance and completeness of inventories based on WRI \& WBCSD's GHG Protocol.

Clearly, the focus in the previous studies has been directed on the life cycle of the project deliverable (such as a building). As Huemann and Silvius (2017) [211] argue, to appreciate sustainable development principles, project management should consider project development life cycle in addition to the life cycle of its deliverables. Moreover, there is a lack of decision support systems for measuring sustainability-oriented performance in project management practices, whereas the existing indicators are mostly focused on products to be developed.

\subsubsection{EVM, an overview}

Traditional EVM, introduced by the U.S. Department of Defense (DoD) primarily to measure cost performance and forecast project final cost, has three main quantities as shown in Figure 46. PV or planned value is budgeted cost of work scheduled, EV or earned value is planned cost of the work actually performed, and AC or actual cost is the observed cost of work actually performed. PV information can be extracted from the project baseline or contractor bid which has been initially submitted and accepted. AC curve indicates the accumulation of all the actual costs incurred. EV accounts for the sum of the planned costs of all the completed work. 


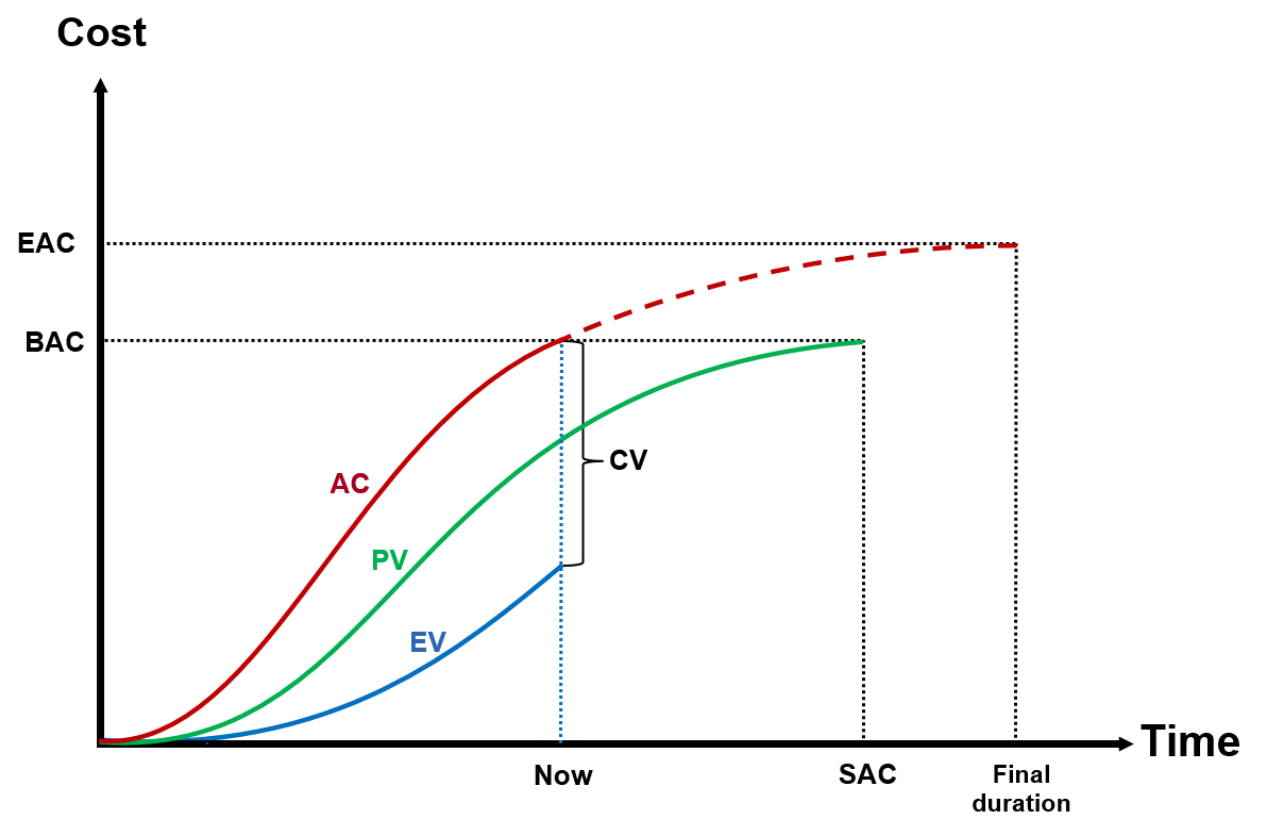

Figure 46: Basic EVM quantities

$\mathrm{EV}$ for in progress work packages can be measured by percent complete (PC) technique using the following formula:

$$
\mathrm{EV}=\mathrm{PV} \times \mathrm{PC}
$$

BAC or budget at completion is the estimated total cost approved as the baseline budget. At each reporting time, EVM uses a cost variance (CV) and cost performance index (CPI) to assess the performance of the project and to predict the project final cost or estimate at completion (EAC), as formulated in equations 84-86 [188]:

$$
\begin{aligned}
& \mathrm{CV}=\mathrm{EV}-\mathrm{AC}, \\
& \mathrm{CPI}=\frac{\mathrm{EV}}{\mathrm{AC}} \\
& \mathrm{EAC}=\mathrm{AC}+\frac{\mathrm{BAC}-\mathrm{EV}}{\mathrm{CPI}}=\frac{\mathrm{BAC}}{\mathrm{CPI}} .
\end{aligned}
$$

This control framework allows project managers to know the performance of their project at any time, and also gives new estimates about the project final cost. Traditional EVM was then extended to measure the performance of other attributes (such as time) and to consider real world conditions (such as uncertainty). Lipke et al. (2009) developed earned schedule (ES) metric to monitor project time performance and forecast its final duration. This method still uses cost-based measures as a proxy to measure project schedule performance. Therefore, 
Khamooshi \& Golafshani (2014) introduced their time-based earned duration management (EDM) technique in which time and cost dimensions have been decoupled. Dodson et al. (2015) introduced a new earned value-based model to monitor project quality, as the third element of EVM, and applied it to an agricultural project in Brazil. Using time and cost incentives and traditional EVM, Kerkhovea and Vanhoucke (2017) developed a new metric for project control. Instead of measuring time and cost performance based on the planned schedule, they evaluated incentives' variation.

Using the EVM approach, the present study develops a systematic model which provides project managers with measures to track the project GHG emissions during the execution phase and forecast its final emissions.

\subsection{Project GHG performance measurement model}

The conceptual framework of this study is represented in Figure 47. Briefly, the GHG Calculator is employed to measure emissions associated with an activity in a project. A project GHG breakdown is proposed and discussed using a case study to account for project emissions. The proposed mathematical model for GHG performance measurement is developed based on the EVM approach. This allows project managers to estimate total planned emission of the project before its commencement, quantify the emitting performance over project life cycle, compare the findings with the planned quantities and forecast final emissions. We first present quantities and metrics of the project GHG performance model at a micro level, i.e. for a single task and then we develop them at a macro level over multiple tasks within a work package. This hierarchical model could be used for the whole work breakdown structure of the project. 


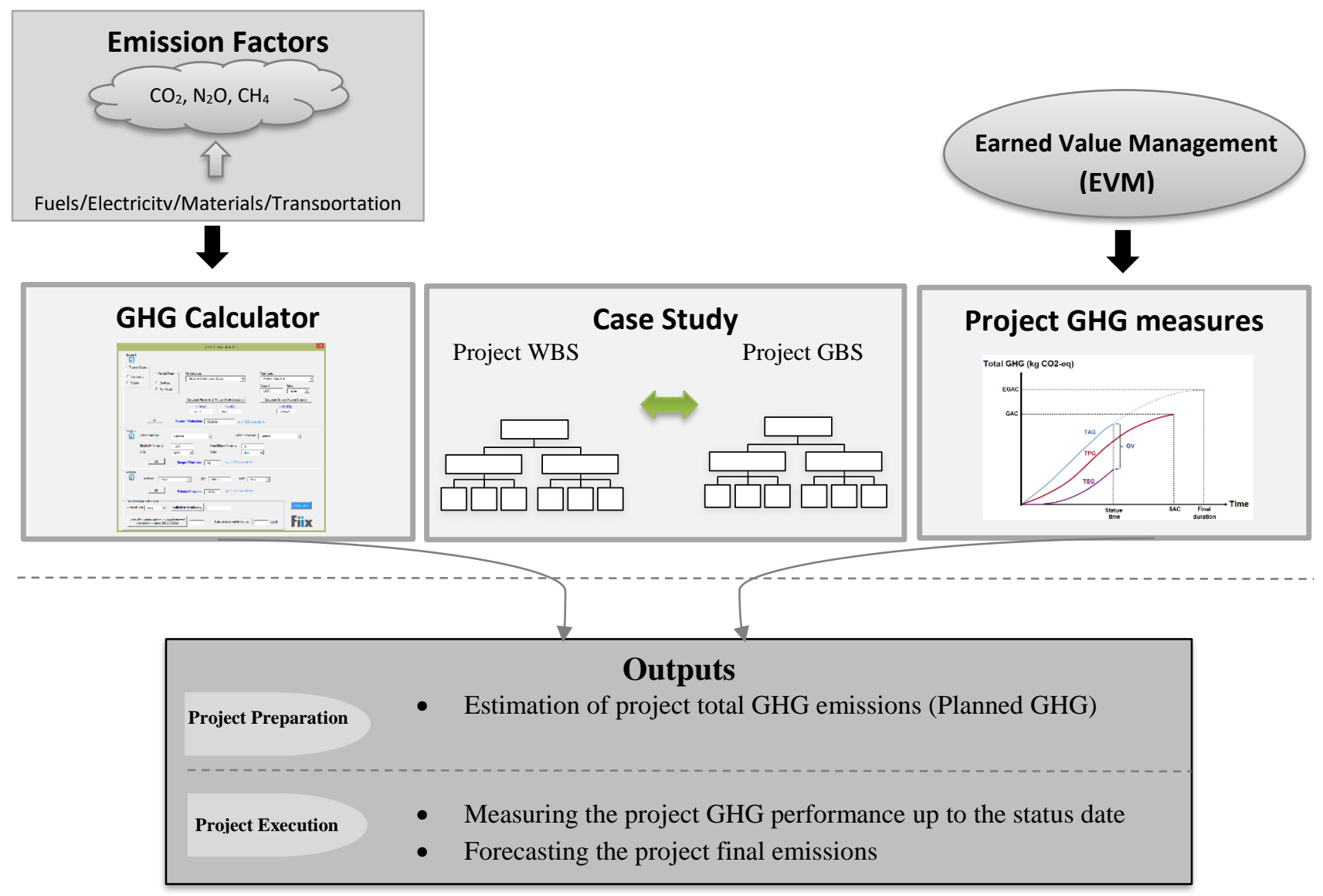

Figure 47: The research framework

\subsubsection{GHG measures of a single task}

We define the following variables to measure GHG emissions of an activity:

Planned GHG emissions of scheduled activity $i\left(P G_{i}\right)$ : is the amount of carbon dioxide equivalent emissions estimated for the scheduled work to be performed for activity $\mathrm{i}$. $\mathrm{PG}_{\mathrm{i}}$ quantity is the GHG emission counterpart to PV in the basic EVM model. Similar to the cost estimation classifications of AACE's International Recommended Practice [212], planned GHG could be developed using different levels of accuracy. The method presented in this paper is corresponding to the most accurate estimate (class I). To ease calculation, one may go with less accuracy. The level of accuracy is determined by and is correlated with the level of work breakdown structure used in the estimation process. The more layers of breakdown the more accuracy one can expect. 
Actual GHG emissions of scheduled activity $i\left(A G_{i}\right)$ : is the carbon dioxide equivalent emissions actually emitted and reported for work performed until the present time. This quantity is equivalent to actual cost in EVM.

Activity Progress, for activity $i\left(A P_{i}\right)$, is the progress of activity i at status time. Percent complete (PC) is one of the simplest techniques used for measuring progress if there is a linear relationship between activity progress and time. When such relationship does not exist, indicators for physical progress, such as material used, work hours, number of design documents, etc., can be used to estimate the progress [213]. Progress calculated by abovementioned techniques may not reflect the exact percentage of emitted GHGs. Therefore, in order to measure project environmental performance, we need to use an emission based method, similar to the activity progress index (API) defined by Khamooshi and Golafshani (2014) [190], which is duration based. We define $A P_{i}$ as follows:

$$
A P_{i}=\frac{A G_{i}}{A G_{i}+E G T C_{i}},
$$

where EGTC $_{\mathrm{i}}$ is the estimated GHG emission to complete scheduled activity i. This progress fraction is based on the actual GHG emission at status time and remaining GHG emission until the activity is complete. In fact, $A P_{i}$ will measure the activity's GHG progress, rather than its physical work or schedule progress. Starting from zero, $A P_{i}$ approaches one as the activity is becoming complete.

Earned $G H G$ of scheduled activity $i\left(E G_{i}\right)$ : is the amount of estimated $\mathrm{CO}_{2}$ eq that was expected or planned to be released from work performed. $\mathrm{EG}_{\mathrm{i}}$ can be regarded as the counterpart to EV of an activity in EVM. At first glance, it might seem unreasonable to call this variable "earned" GHG, as it not something positive to gain. However, if we can call the "budgeted cost of work performed' as "earned value", we can do the same for budgeted emissions of work performed, because both cost and greenhouse gas emissions are undesirable project objectives that should be minimized. In fact, project GHG should be considered as another cost element associated with any project. We can calculate $\mathrm{EG}_{\mathrm{i}}$ as follows:

$$
\mathrm{EG}_{\mathrm{i}}=\mathrm{PG}_{\mathrm{i}} \times \mathrm{AP}_{\mathrm{i}} .
$$

\subsubsection{GHG measures over multiple tasks}

The following variables are defined to measure GHG emissions at project level: 
Total Planned $G H G(T P G)$ : is the sum of $\mathrm{PG}_{\mathrm{i}}$ for completed or in-progress activities that are scheduled to occur up to the status date:

$$
\mathrm{TPG}=\sum_{\mathrm{i}} \mathrm{PG}_{\mathrm{i}} .
$$

Similar to EVM's BAC (budget at completion), total amount of carbon footprint of a project over its execution process, GHG at completion (GAC) is the last point on the TPG curve.

Total Actual $G H G(T A G)$ : is the sum of $\mathrm{AG}_{\mathrm{i}}$ for completed or in-progress activities up to the reporting time:

$$
\mathrm{TAG}=\sum_{\mathrm{i}} \mathrm{AG}_{\mathrm{i}} .
$$

Total Earned $G H G(T E G)$ : is the sum of $\mathrm{EG}_{\mathrm{i}}$ for completed or in-progress activities up to the reporting time, i.e. the total amount of GHG expected to be emitted from work performed:

$$
\mathrm{TEG}=\sum_{\mathrm{i}} \mathrm{EG}_{\mathrm{i}} .
$$

\subsubsection{Performance measurements and forecasting final emission}

Like any other control system, we want to measure the difference between the amount of emissions which were actually released and the amount of planned or earned emissions (EG). A GHG variance (GV) can be defined at both activity and project levels, as shown in Eq. 90 and 91, respectively. TGV in Eq. 91 stands for the total GHG variance. Negative variances make it evident that for the performed work, the project has emitted more GHGs than what was expected.

$$
\begin{aligned}
& \mathrm{GV}_{i}=\mathrm{EG}_{i}-\mathrm{AG}_{i} . \\
& \mathrm{TGV}=\mathrm{TEG}-\mathrm{TAG} .
\end{aligned}
$$

Using the same quantities, a GHG performance index (GPI) can be defined in activity and project levels, as indicated in Eq. 94 and 95:

$$
\begin{aligned}
& \mathrm{GPI}_{i}=\frac{\mathrm{EG}_{i}}{A G_{i}} . \\
& \mathrm{GPI}=\frac{\mathrm{TEG}}{T A G} .
\end{aligned}
$$

If the project is emitting as it was planned, the value of GPI would be one. If GPI is less than one, the project environmental performance is worse than what it was initially planned, and if GPI is greater than one, the project is environmentally performing better than expected. 
Using GPI as a project GHG performance, we can formulate estimated GHG at completion (EGAC), based on the assumption that project GHG performance will be similar to the past:

$$
\mathrm{EGAC}=\mathrm{TAG}+\frac{\mathrm{GAC}-\mathrm{TEG}}{\mathrm{GPI}}=\frac{\mathrm{GAC}}{\mathrm{GPI}} .
$$

A graphical representation of the proposed GHG performance model is portrayed in Figure 48.

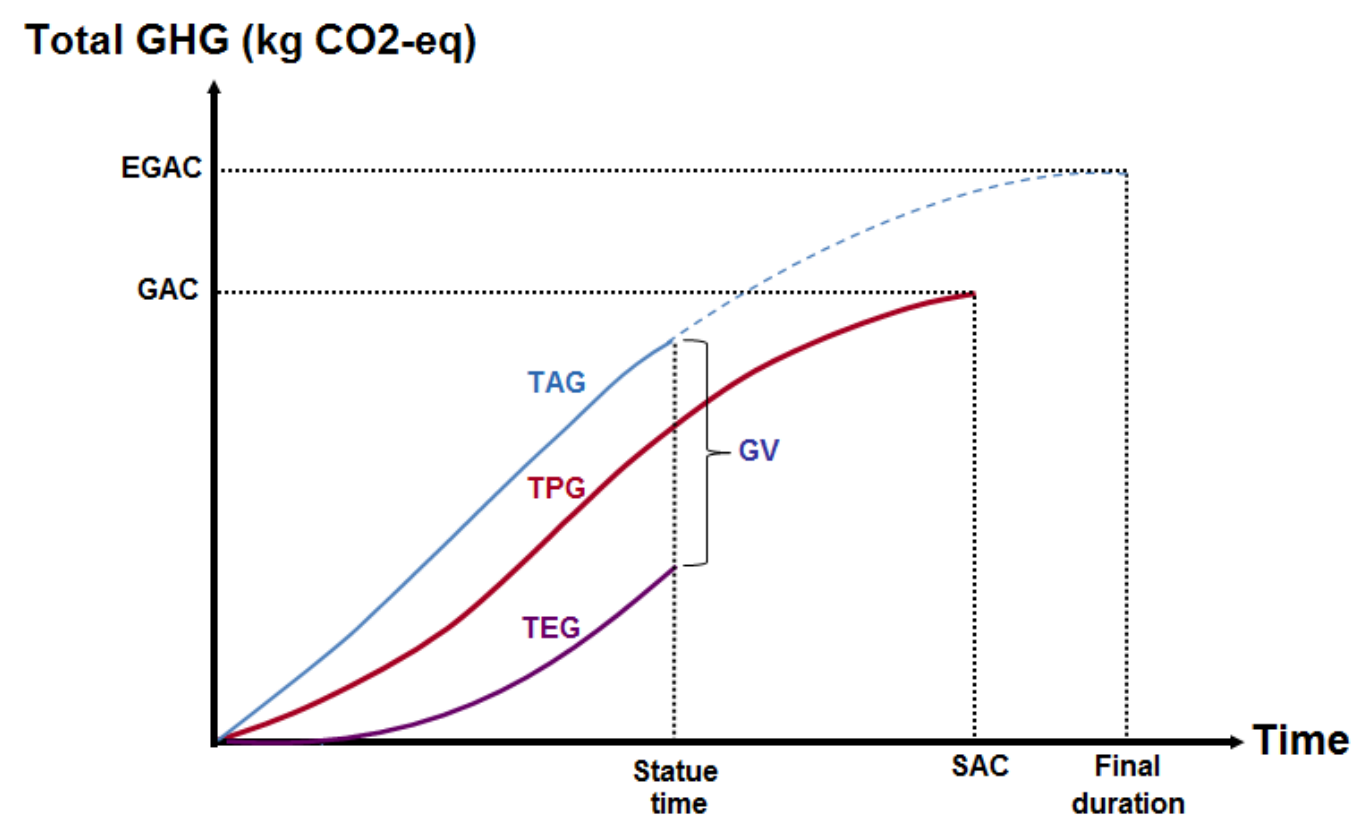

Figure 48: Project GHG performance measurement model

\subsubsection{Putting the model to work}

There are two applications for this model, estimation and control. Firstly, it could be used for estimation of total GHG for any construction or industrial project using the classic deliverable work breakdown structure (DWBS) approach, knowing that the level of detail/accuracy will be decided by the design of the DWBS. The second usage is monitoring and controlling the actual GHG emission. This data could be used for improving future estimates and accounting of the GHG emissions.

In this section, we demonstrate the applicability of GHG performance measurement model using an element within the DWBS of a construction project. The example used is a work package of a commercial complex construction project, consisting of five 3.5-story building totalling 36,289 square feet. The example refers to concrete foundation work package which 
consists of five activities: excavation, lean concrete, reinforcement, formwork, and concrete placement.

\subsubsection{Project GHGs breakdown structure}

In order to manage project GHG emissions, we propose a GHG breakdown structure (GBS) that can classify project total emissions into measurable GHG accounts. Using the intersection of GBS and work breakdown structure (WBS), project GHG accounts can be identified (see Figure 49).

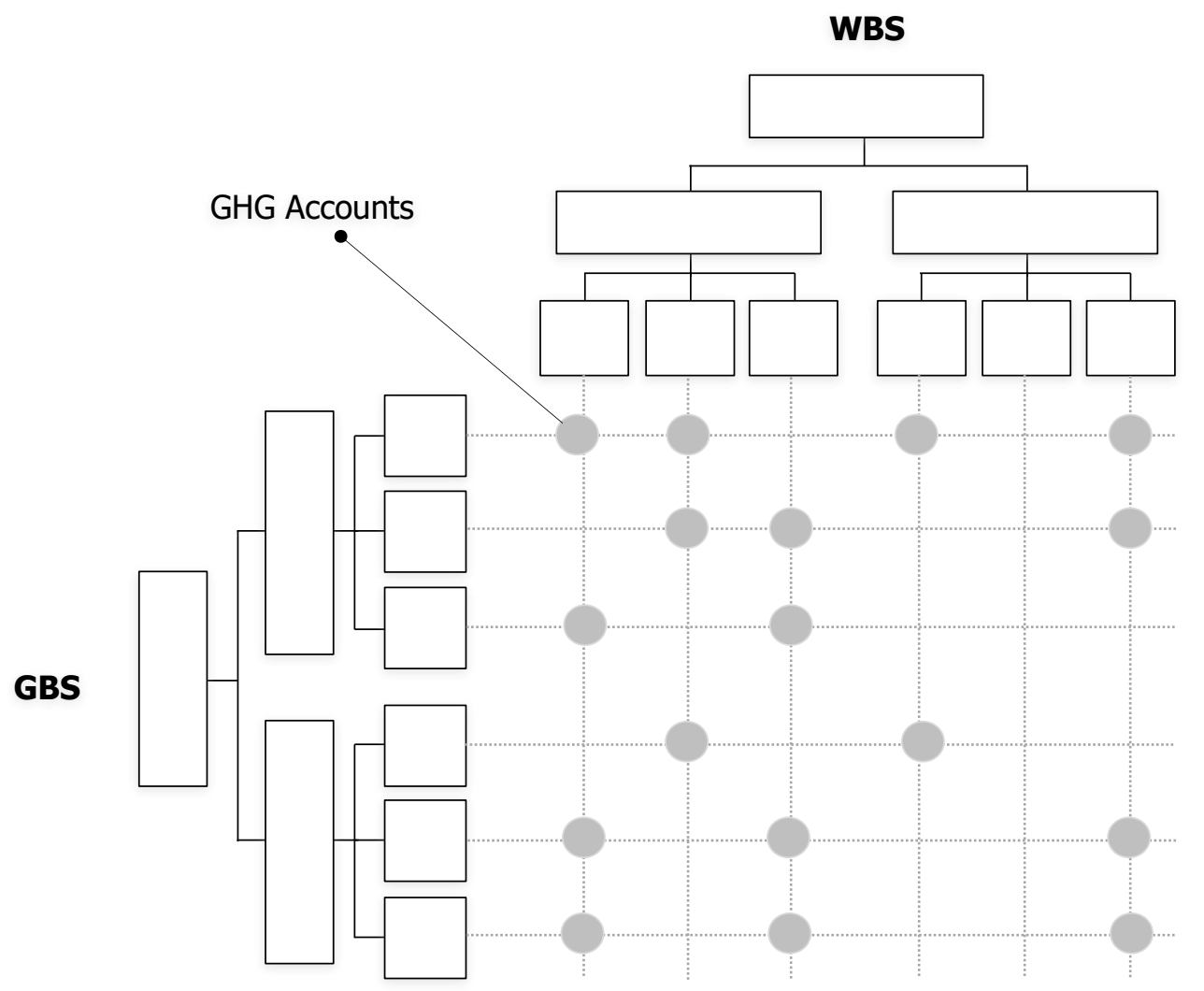

Figure 49: Intersection of project GHG breakdown structure (GBS) and work breakdown structure (WBS)

We used the breakdown structure depicted in Figure 50 as a possible GBS of the example project. In this decomposition, emissions associated with transportation are considered in mobile combustion package. On-site and out-site transportations are captured in non-road and on-road parts, respectively. 


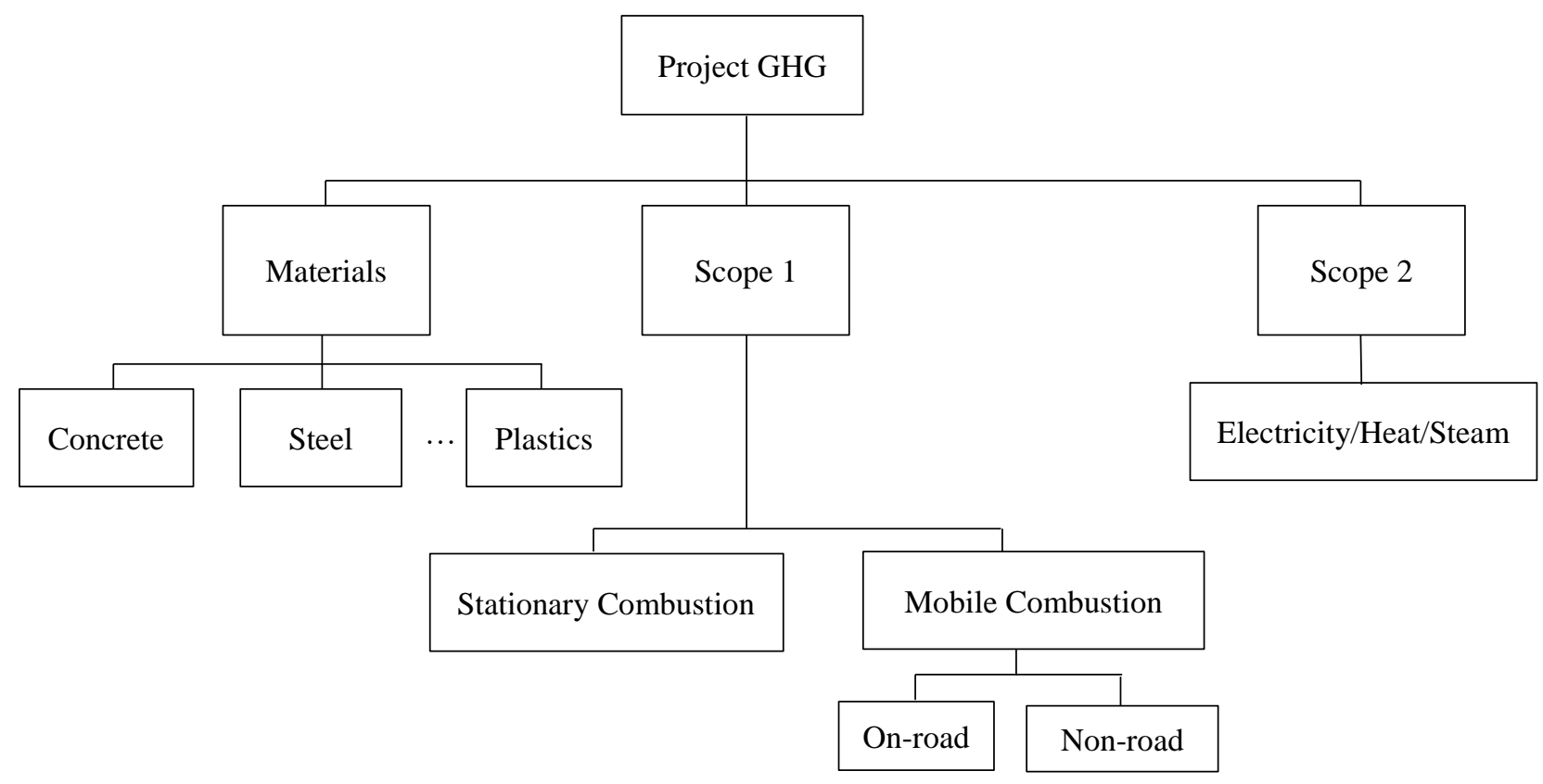

Figure 50: GBS of the example project

\subsubsection{Results}

By intersecting proposed GBS and Foundation activities, all GHG elements in the example project were identified. Table 24 represents each activity's GHG accounts including construction material, equipment and consumed fuels/energies, and their related category according to the GBS. Estimated activity data, emission factors for $\mathrm{CO}_{2}, \mathrm{CH}_{4}$ and $\mathrm{N}_{2} \mathrm{O}$, and $\mathrm{CO}_{2}$ eq of all GHG accounts are then calculated, as shown in Table 25. GWP factors associated with $\mathrm{CH}_{4}$ and $\mathrm{N}_{2} \mathrm{O}$ were also used to calculate the amount of $\mathrm{CO}_{2}$ eq released from each GHG account. For example, $\mathrm{CO}_{2}$ eq associated with gasoline combustion in wheeled excavator used for excavation activity can be calculated as follows:

$$
1000(2.2+0.00013 \times 28+0.000058 \times 265)=2,219.01 \mathrm{~kg}
$$

Table 24. Determination of GHG accounts of each activity and their related category in the GHG breakdown structure

\begin{tabular}{lll}
\hline \multirow{2}{*}{ Activity } & GHG account & Category in GBS \\
\hline Excavation & Gasoline-Wheeled Excavator & Scope 1-Mobile Combustion-NonRoad \\
\cline { 2 - 3 } & Gasoline-Truck (2005)* & Scope 1-Mobile Combustion-OnRoad \\
\hline \multirow{2}{*}{ Lean Concrete } & Concrete & Material \\
\cline { 2 - 3 } & Gasoline-Mixer & Scope 1-Stationary Combustion \\
\hline
\end{tabular}




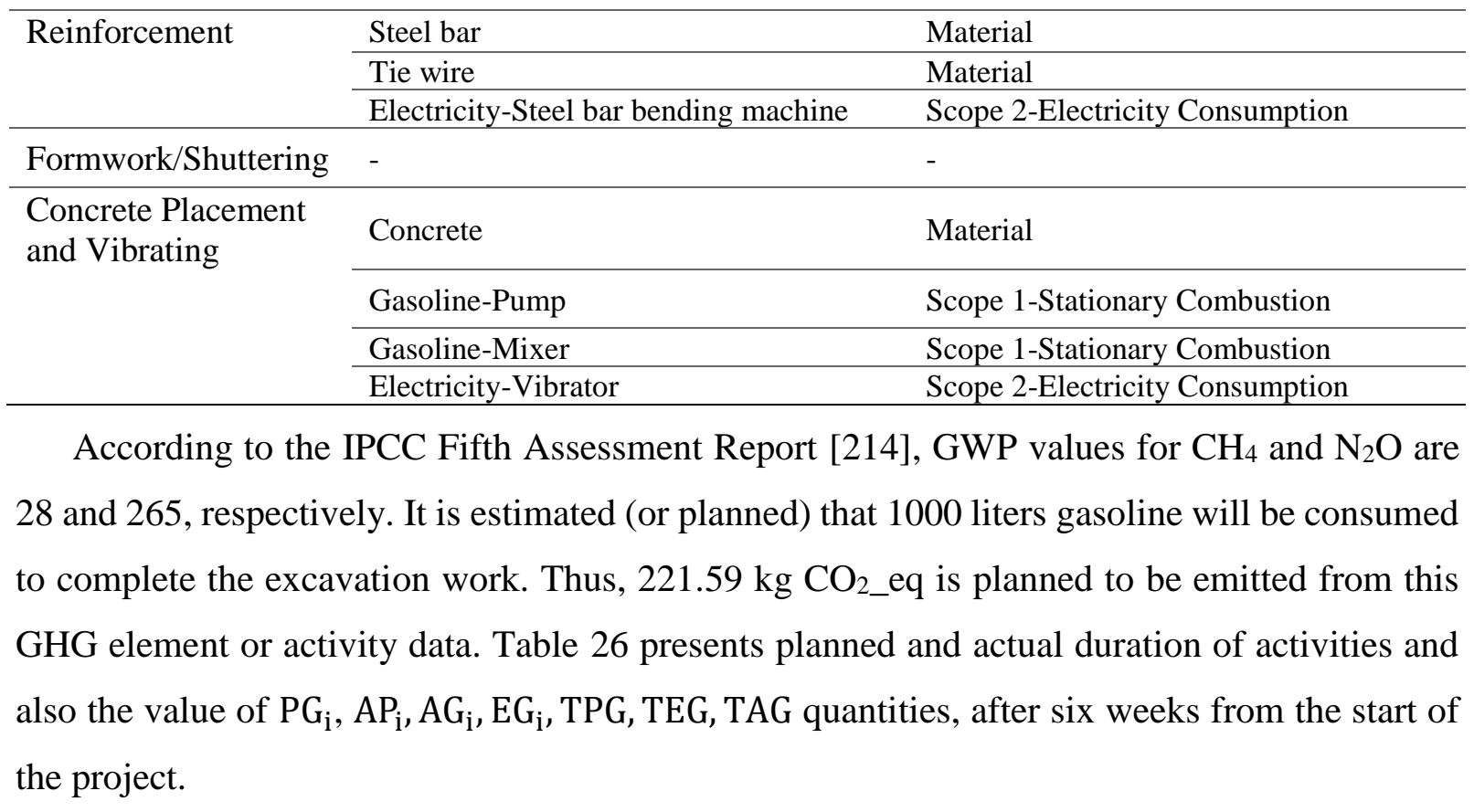

Table 25. Activity data, emission factors, and total $\mathrm{CO}_{2}$ eq associated with each $\mathrm{GHG}$ account

\begin{tabular}{|c|c|c|c|c|}
\hline Activity & GHG account & $\begin{array}{l}\text { Estimated } \\
\text { Activity Data }\end{array}$ & Emission Factor & $\mathrm{CO}_{2}$ eq $(\mathrm{Kg})$ \\
\hline \multirow{2}{*}{ Excavation } & $\begin{array}{l}\text { Gasoline-Wheeled } \\
\text { Excavator }\end{array}$ & 1000 (liters) & $\begin{array}{l}2.2\left(\mathrm{~kg} \mathrm{CO}_{2} / \text { liter }\right) \\
0.00013\left(\mathrm{~kg} \mathrm{CH}_{4} / \text { liter }\right) \\
0.000058\left(\mathrm{~kg} \mathrm{~N}_{2} \mathrm{O} / \mathrm{liter}\right)\end{array}$ & $2,219.01$ \\
\hline & Gasoline-Truck (2005)* & $\begin{array}{l}1550(\text { liters }) \\
500(\mathrm{~km})^{*}\end{array}$ & $\begin{array}{l}2.2\left(\mathrm{~kg} \mathrm{CO}_{2} / \text { liter }\right) \\
0.00029\left(\mathrm{~kg} \mathrm{CH}_{4} / \mathrm{km}\right) \\
0.00003\left(\mathrm{~kg} \mathrm{~N}_{2} \mathrm{O} / \mathrm{km}\right)\end{array}$ & $13,609.48$ \\
\hline \multirow{2}{*}{ Lean Concrete** } & Concrete & $1791\left(\mathrm{~m}^{3}\right)$ & $87\left(\mathrm{~kg} \mathrm{CO}_{2} \_\mathrm{eq} / \mathrm{m}^{3}\right)$ & 155,817 \\
\hline & Gasoline-Mixer & 500 (liters) & $\begin{array}{l}2.195\left(\mathrm{~kg} \mathrm{CO}_{2} / \text { liter }\right) \\
0.000095\left(\mathrm{~kg} \mathrm{CH}_{4} / \text { liter }\right) \\
0.000018\left(\mathrm{~kg} \mathrm{~N}_{2} \mathrm{O} / \mathrm{liter}\right)\end{array}$ & $1,101.215$ \\
\hline \multirow{3}{*}{ Reinforcement } & Steel bar & 446.5 (ton) & $1450\left(\mathrm{~kg} \mathrm{CO}{ }_{2}\right.$ eq $/$ ton $)$ & 647,425 \\
\hline & Tie wire & 0.19 (ton) & 1450 (kg CO $2 \_$eq /ton) & 275.5 \\
\hline & $\begin{array}{l}\text { Electricity-Steel bar } \\
\text { bending machine }\end{array}$ & 1000 (kwh) & $\begin{array}{l}0.040\left(\mathrm{~kg} \mathrm{CO}_{2} / \mathrm{kwh}\right) \\
0.00001\left(\mathrm{~kg} \mathrm{CH}_{4} / \mathrm{kwh}\right) \\
0.000001\left(\mathrm{~kg} \mathrm{~N}_{2} \mathrm{O} / \mathrm{kwh}\right)\end{array}$ & 40.545 \\
\hline Formwork/Shuttering & - & - & - & - \\
\hline \multirow{4}{*}{$\begin{array}{l}\text { Concrete Placement } \\
\text { and Vibrating }\end{array}$} & Concrete & $4480\left(\mathrm{~m}^{3}\right)$ & $261\left(\mathrm{~kg} \mathrm{CO}{ }_{2} \_\mathrm{eq} / \mathrm{m}^{3}\right)$ & $1,169,280$ \\
\hline & Gasoline-Pump & 500 (liters) & $\begin{array}{l}2.195\left(\mathrm{~kg} \mathrm{CO}_{2} / \text { liter }\right) \\
0.000095\left(\mathrm{~kg} \mathrm{CH}_{4} / \text { liter }\right) \\
0.000018\left(\mathrm{~kg} \mathrm{~N}_{2} \mathrm{O} / \text { liter }\right)\end{array}$ & 1540.224 \\
\hline & Gasoline-Mixer & 1000 (liters) & $\begin{array}{l}2.195\left(\mathrm{~kg} \mathrm{CO}_{2} / \text { liter }\right) \\
0.000095\left(\mathrm{~kg} \mathrm{CH}_{4} / \text { liter }\right) \\
0.000018\left(\mathrm{~kg} \mathrm{~N}_{2} \mathrm{O} / \text { liter }\right)\end{array}$ & 2200.32 \\
\hline & Electricity-Vibrator & 1200 (kwh) & $\begin{array}{l}0.040\left(\mathrm{~kg} \mathrm{CO}_{2} / \mathrm{kwh}\right) \\
0.00001\left(\mathrm{~kg} \mathrm{CH}_{4} / \mathrm{kwh}\right) \\
0.000001\left(\mathrm{~kg} \mathrm{~N}_{2} \mathrm{O} / \mathrm{kwh}\right)\end{array}$ & 48.654 \\
\hline
\end{tabular}


* For on-road vehicles, the $\mathrm{CO}_{2}$ eq of released emissions is dependent on the amount of combusted fuel, the traveled distance, and the age of the vehicle.

** The proportion of cement in the lean concrete used in this project was $1 / 3$ of that of the structure concrete.

Based on the planned duration (PD) of the project activities, schedule at completion (SAC) or project total duration is 16.9 days. Planned GHG (PG) of each activity is calculated by summing up its correspondent GHG elements, evaluated in Table 1. Using these values, the amount of GHG at completion (GAC) is $1,993,556 \mathrm{~kg}$. Actual percentage of completion (AP) of each activity and its related actual duration (AD) are presented in fourth and fifth columns. Activities earned GHGs (EG) for the amount of completed work are calculated using formulation of Eq. 86. Therefore, total earned GHG (TEG) is calculated as 269,907 kg. Actual GHGs are calculated based on the observed activity data and their emission factors. Using these values, total actual GHG (TAG) released by the time from the completed work is $323,530 \mathrm{~kg}$.

Table 26. Quantities of GHG control model for the case study

\begin{tabular}{lllllll}
\hline Activities & $\begin{array}{l}\text { PD } \\
(\mathbf{d a y})\end{array}$ & $\begin{array}{l}\text { PG } \\
(\mathbf{k g})\end{array}$ & $\begin{array}{l}\text { AD } \\
(\mathbf{d a y})\end{array}$ & $\begin{array}{l}\text { AP } \\
(\boldsymbol{\%})\end{array}$ & $\begin{array}{l}\text { EG } \\
(\mathbf{k g})\end{array}$ & $\begin{array}{l}\text { AG } \\
(\mathbf{k g})\end{array}$ \\
\hline Excavation & 21 & 15,828 & 24 & 100 & 15,828 & 19,230 \\
\hline Lean Concrete & 4 & 156,918 & 6 & 100 & 156,918 & 177,281 \\
\hline Reinforcement & 51 & 647,741 & 12 & 15 & 97,161 & 127,019 \\
\hline Formwork/Shuttering & 35 & 0 & - & 0 & 0 & - \\
\hline $\begin{array}{l}\text { Concrete Placement and } \\
\text { Vibrating }\end{array}$ & 7 & $1,173,069$ & - & 0 & 0 & - \\
\hline
\end{tabular}
SAC $=16.9$ day
GAC $=1,993,556 \mathrm{Kg}$
TEG $=269,907 \mathrm{~kg}$
TAG $=323,530 \mathrm{~kg}$

Based on Eq. 91 and 93, the total GHG variance and performance index of the project at the reporting time are calculated as follows:

$$
\begin{aligned}
& \mathrm{TGV}=\mathrm{TEG}-\mathrm{TAG}=269,907-323,530=-53,623 . \\
& \mathrm{GPI}=\frac{\mathrm{TEG}}{\text { TAG }}=\frac{269,907}{323,530}=0.83 .
\end{aligned}
$$

This is showing a GHG overrun. Using the GPI and Eq. 94, we can now calculate the project final GHG or estimated GHG at completion: 


$$
\mathrm{EGAC}=\mathrm{TAG}+\frac{\mathrm{GAC}-\mathrm{TEG}}{\mathrm{GPI}}=\frac{\mathrm{GAC}}{\mathrm{GPI}}=\frac{1,993,556}{0.83}=2,401,874.698 \mathrm{~kg} \mathrm{CO}_{2} \_\mathrm{eq},
$$

which is almost 408 tons greater than the initial estimate (i.e. GAC).

With the global warming point of view, this amount of emission overrun is quite significant in mega projects, as it equals to 20 percent of the initial estimated emissions. Considering the carbon price in Ontario's cap and trade program, the forecasted GHG overrun in this particular work package is economically equal to a C\$ 7,349 cost overrun.

\subsection{Uncertainty Analysis of Project Emissions}

As a key project management practice, quantitative risk analysis aims to capture the project uncertainty in terms of its cost or schedule. Similar to project schedule and cost, activities' carbon emissions are uncertain, and if not considered, the results of project emissions estimation may not be reliable. We propose a probabilistic model to quantify the uncertainty of project GHG emissions using Bayesian networks (BNs) and simulation techniques. The model provides a quantitative risk analysis to estimate the total emissions of the project, and a monitoring mechanism to predict the final emissions based on the completed activates.

Figure 51 illustrates different aspects of the modelling process. The basic inputs to estimate a project GHG emissions are the work breakdown structure (WBS) and GHG breakdown structure (GBS). These tools allow us to identify the GHG elements or activity data associated with each activity of the project. Examples of activity data are the amount of material (such as concrete and steel) that would be used in an activity, the amount of fuel or electricity that would be combusted or consumed, the distance that the equipment travel to complete the activity, etc.

Second step is to identify risks and other sources of uncertainty that act as a driving force to affect the volume of the above activity data. The uncertainty sources include risk events, such as test failures that would increase the amount of material in cases like concrete test. Test failures may also duplicate other activity data, i.e. electricity usage or transportation. For such risks, we assign a Bernoulli variable with the parameter $p$. Starting with the prior density for this parameter, $f(p)$ (corresponding to the probability $\mathrm{P}(\mathrm{Risk})=\mathrm{Yes}$ ), a posterior density, $f(p \mid x)$, will be obtained using evidence from the number of failures $(\mathrm{x})$ in each reporting time:

$$
f(p \mid x)=\frac{P(x \mid p) f(p) d p}{P(x)}=\frac{P(x \mid p) f(p) d p}{\int P(x \mid p) f(p) d p}
$$


The number of failures follows a Binomial variable: $\mathrm{x} \sim \operatorname{Bin}(\mathrm{n}, p)$, where $\mathrm{n}$ is the number of total tests performed in the related period. Therefore, it is possible to use actual evidences from the implementation phase of the project to revise the risks' probability of occurrence.

The second group of uncertainty sources are qualitative, complex variables, which could cause an increase/decrease in the volume of an activity data [119]. For example, project site's team quality and the maturity of the project management system are common causes that can impact the performance of the project. A ranked variable (with three states "Low", "Medium", and "High") is assigned to this group of effectual variables.

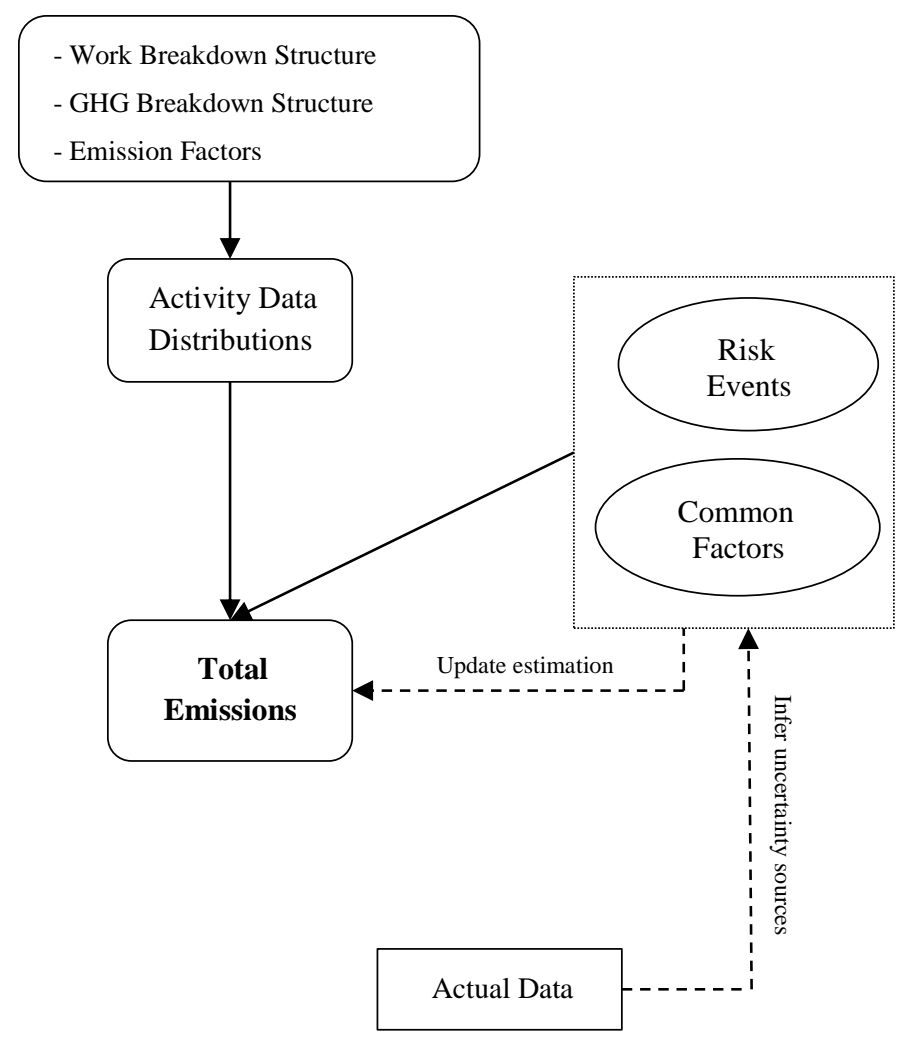

Figure 51: Components of the proposed model

Next step is to generate a probabilistic distribution for each activity data, to capture its uncertainty. The common practice in project quantitative risk analysis is to use Triangular, Beta, Lognormal distributions to calculate project cost and schedule risk analysis. Again, because of the simplicity of Triangular distribution, this distribution is used in this study to model the uncertainty of project activities data. To generate the distributions, the procedure is to elicit upper, lower, and most-likely values of each activity data, conditional on the states of its 
relevant risks or driving forces, and fit a Triangular distribution to these three values, using the upper and lower values to bound $90 \%$ of the probability to counteract known biases in elicitation.

A result variable is defined to integrate all the generated distributions to simulate the project total emission. This variable gives the project manager information about the level of emissions risk and the chance of failing to meet the targeted GHG emissions. After the project starts and activities are completed, the actual volume of activity data is used in the model to first infer the real level of risks and common factors and predict the final GHG emissions. In other words, the model uses the current performance of the project to forecast the final performance. This forecast is important, especially in the early stages of a project, as the managers would be able to take control actions to keep the project on track.

\subsubsection{Numerical example}

We apply the proposed model to the same work package in the previous case study. We exclude the formwork activity from the analysis, as no emission is released from performing this activity. We consider the risk of 'Test failures' and the common factor 'People experience' that can affect the identified GHG items. Unlike the variable "People experience' that affects all activities, the risk 'Test failure' only affects lean concrete and concrete placement activities. Hypothetical parameters for Triangular distribution of activity data of GHG items conditional on these variables are converted to $\mathrm{CO}_{2}$ eq value using the emission factors and GWP factors, as shown in Table 27. 
Table 27. The parameters for Triangular distribution of $\mathrm{CO}_{2}$ eq of values associated with $\mathrm{GHG}$ items, conditional on risks and common factors

\begin{tabular}{|c|c|c|c|c|c|c|c|c|c|c|}
\hline 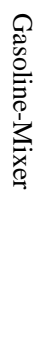 & 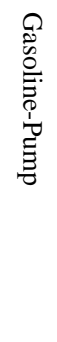 & $\begin{array}{l}\stackrel{Q}{0} \\
\stackrel{0}{0} \\
\frac{0}{0}\end{array}$ & 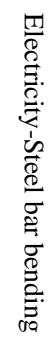 & 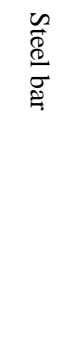 & 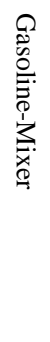 & 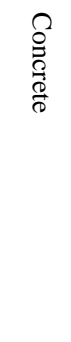 & 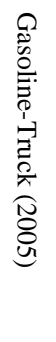 & 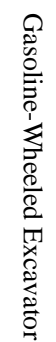 & 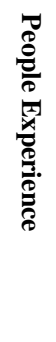 & 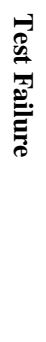 \\
\hline 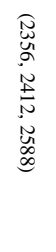 & 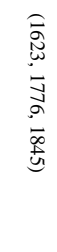 & 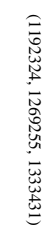 & & & 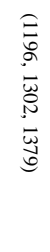 & 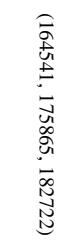 & & & 点 & $\vec{\Xi}$ \\
\hline 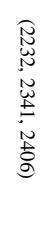 & 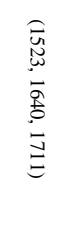 & 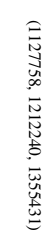 & & & 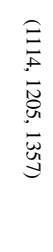 & 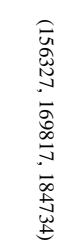 & & & $\begin{array}{l}3 \\
\text { : } \\
\stackrel{0}{0} \\
\text { : }\end{array}$ & \\
\hline 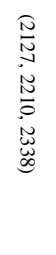 & 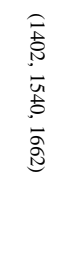 & 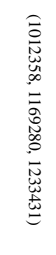 & & & 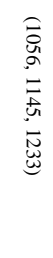 & 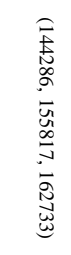 & & & 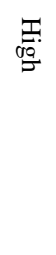 & \\
\hline 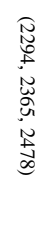 & 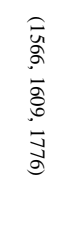 & 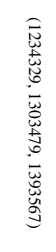 & $\begin{array}{l}\text { f } \\
\text { 苟 } \\
\text { t }\end{array}$ & 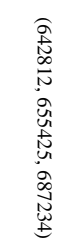 & 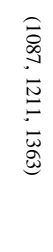 & 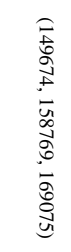 & 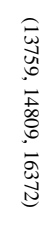 & 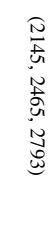 & 5 & 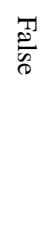 \\
\hline 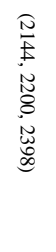 & 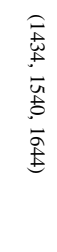 & 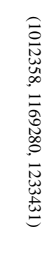 & 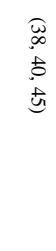 & 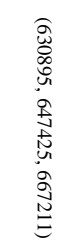 & 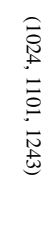 & 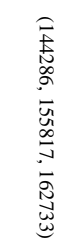 & 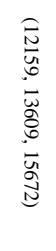 & 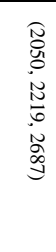 & $\begin{array}{l}\frac{3}{0} \\
\stackrel{0}{0} \\
\text { : }\end{array}$ & \\
\hline 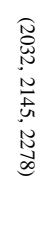 & 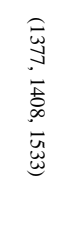 & 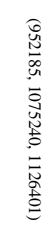 & 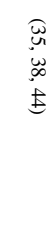 & 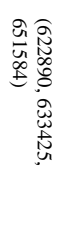 & 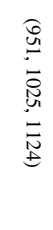 & 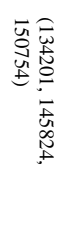 & 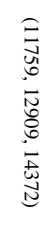 & 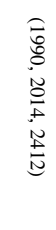 & 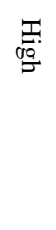 & \\
\hline
\end{tabular}


A uniform distribution was assigned as the prior probability of occurrence for the test failure risk:

$\mathrm{P}($ Test failure $=$ True $)=\mathrm{p} \sim \mathrm{U}(0.1,0.3)$

Prior probabilities for the variable people experience were estimated as follows:

$\left\{\begin{array}{c}\mathrm{P}(\text { People experience }=\text { Low })=0.18 \\ \mathrm{P}(\text { People experience }=\text { Medium })=0.43 \\ \mathrm{P}(\text { People experience }=\text { High })=0.39\end{array}\right.$

Using the above information, the BN model was constructed and run, as illustrated in Figure 52. The node $\mathrm{X}$ is the Binomial distribution associated with the expected number of test failures in 10 tests which is planned be conducted on the activities lean concrete and concrete placement. The model has calculated the statistical distribution of the total carbon emissions of the work package in the node 'GHG Emissions'. As indicated, possible values of total emission range from below $1.7 \mathrm{MtCO}_{2}$ eq to around $2.3 \mathrm{MtCO}_{2}$ eq. The most probable amount of GHG emissions (i.e. mean value) is $1.971 \mathrm{MtCO}_{2}$ eq.

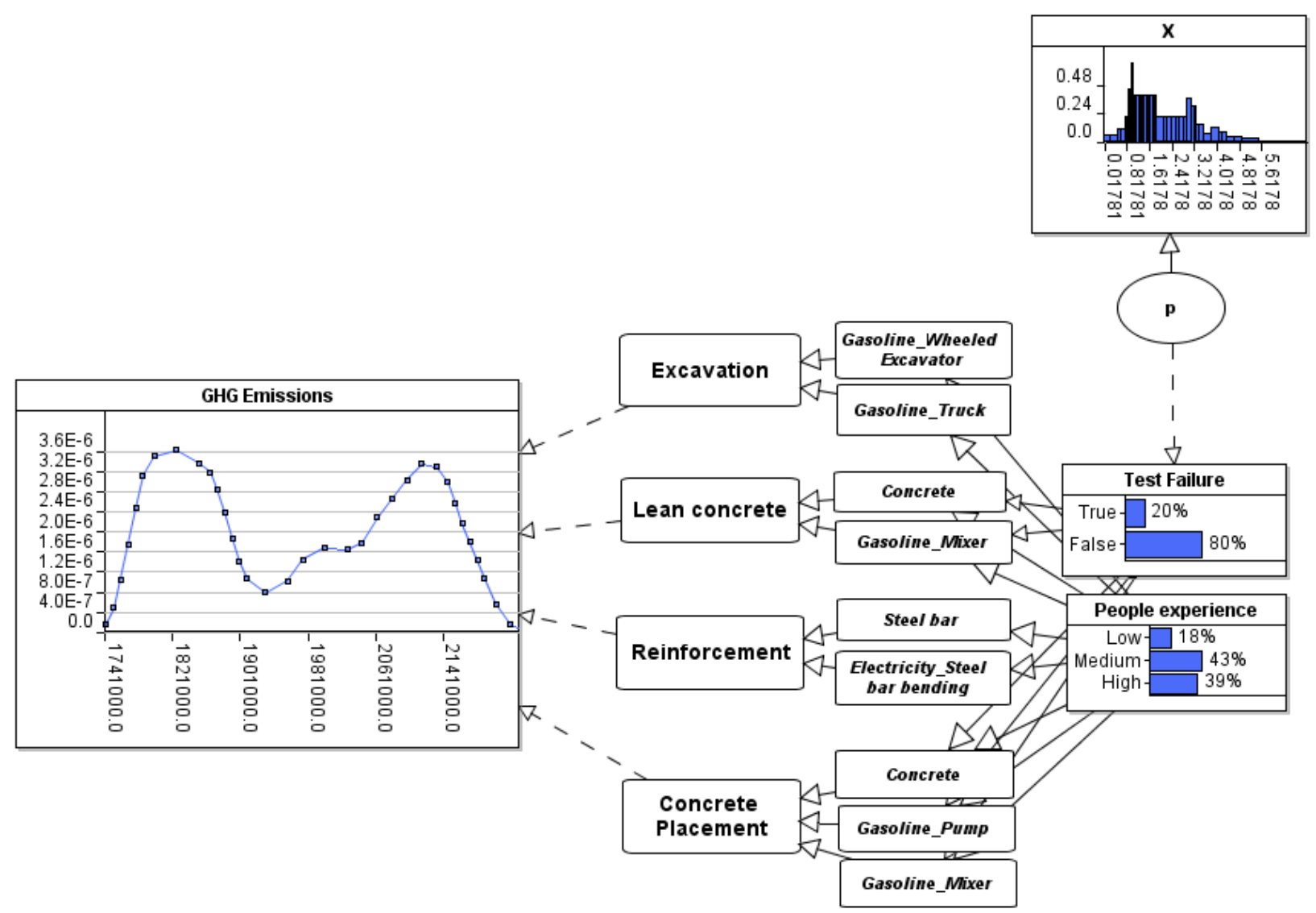


Figure 52: Baseline total GHG emissions of the example project (in $\mathrm{kg} \mathrm{CO}_{2}$ eq)

One could use the cumulative distribution function (CDF) of the result node, to calculate the probability of meeting a targeted emission limit or so-called cap on the work package. If, for example, this work package has an emission cap of $2.00 \mathrm{MtCO}_{2}$ eq, the probability of meeting this emission limit is only 54\% (Figure 53).

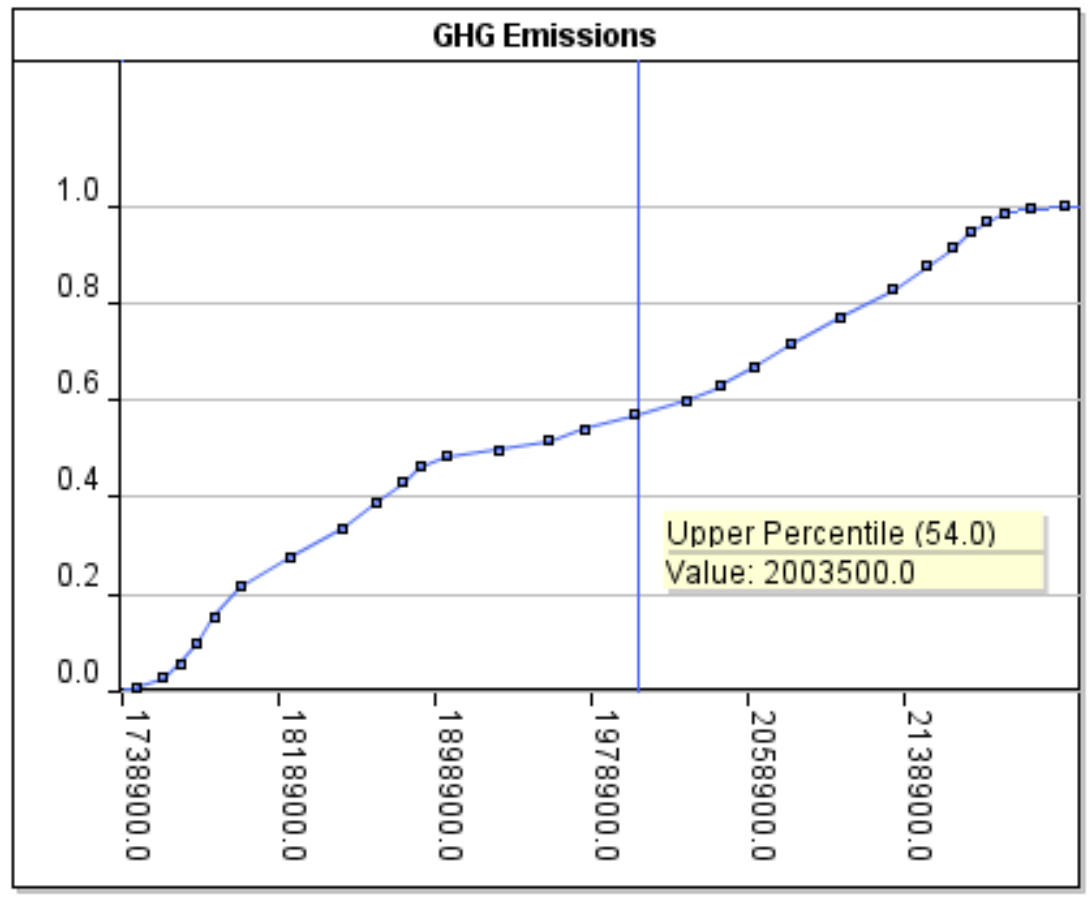

Figure 53: Cumulative distribution of total emissions

Now, we can present the inference-based approach to monitoring project performance. Suppose that the excavation and lean concrete activities are completed, with the following actual GHG emissions, and that four tests have been failed in lean concrete activity:

\begin{tabular}{llr}
\hline Excavation: & Gasoline-Wheeled Excavator & $2915 \mathrm{~kg} \mathrm{CO}_{2}$ eq \\
& Gasoline-Truck & $13000 \mathrm{~kg} \mathrm{CO}_{2}$ eq \\
Lean concrete: & Concrete & $168000 \mathrm{~kg} \mathrm{CO}_{2}$ eq \\
& Gasoline-Mixer & $1302 \mathrm{~kg} \mathrm{CO}_{2}$ eq \\
\hline
\end{tabular}

Having entered these observations into the $\mathrm{BN}$ model, the model first applies a backward propagation to infer the real level of the project risks/common factors (and in fact the real level of uncertainty sources). Thereby, it runs a forward propagation to update the estimation of the 
remaining activities, which are not started yet. Hence, the final emissions of the project will be recalculated, which is provided in Figure 54. As indicated, the range of the distribution gets smaller, showing a decrease in uncertainty of estimation, and the most likely final GHG emission is now predicted to be $2.07 \mathrm{Mt} \mathrm{CO}_{2}$ eq. This scenario will increase the probability of test failure to 0.22 and update our belief about the actual level of people experience, which appears to be low. Secondly, it will predict the emission of the remaining activities. This approach can be used, instead of heat maps, to identify a project's high-level risks.

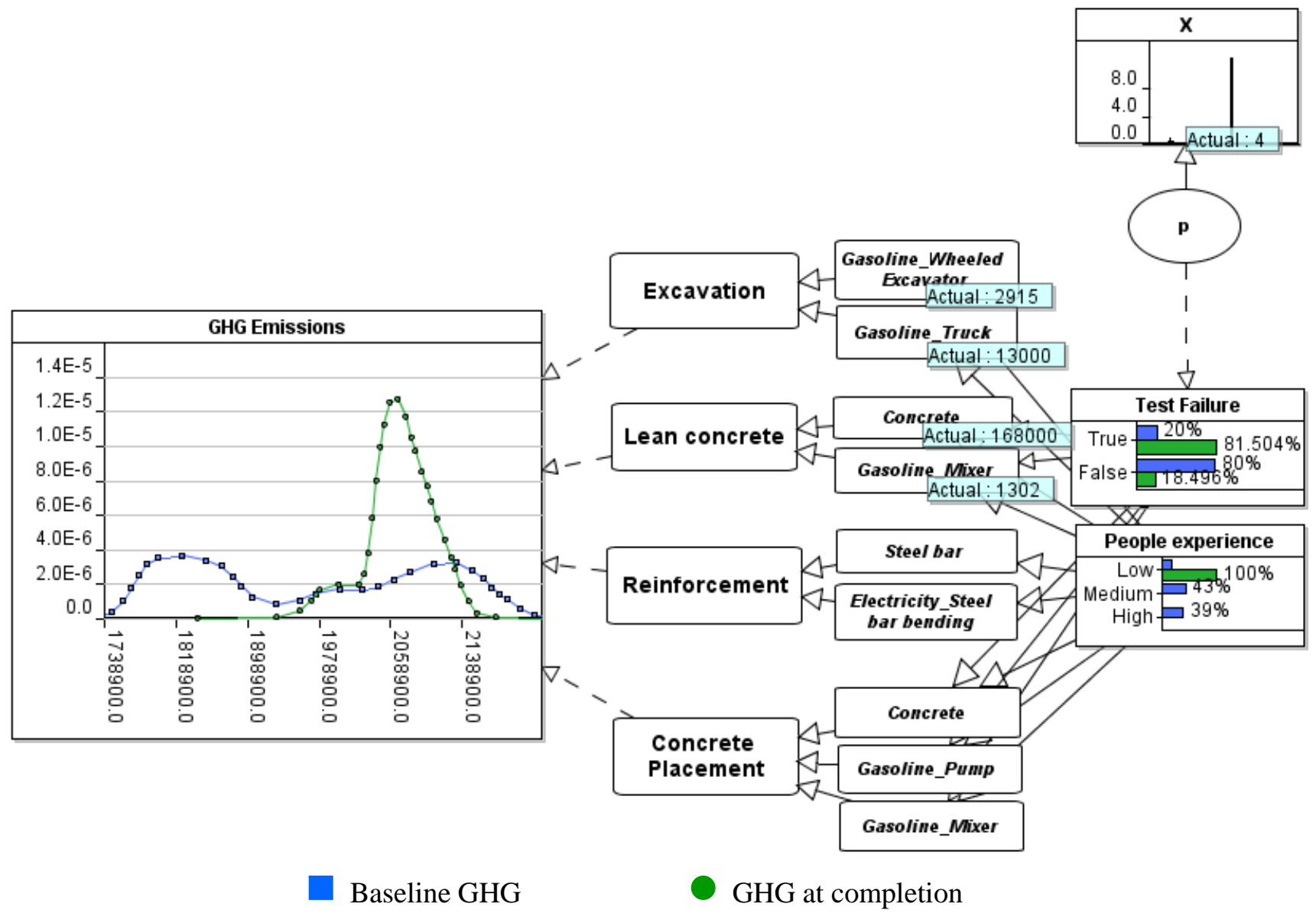

Figure 54: GHG emissions at completion

\subsection{Discussion}

As explained earlier, we used the price of carbon in an ETS to calculate the monetary value of the project GHG overrun in the deterministic GHG control model. This monetary value, however, may not reflect the exact impact of environmental burdens associated with the project GHG overrun, which is 408 tons of global warming potential (or carbon dioxide equivalent). In 
fact we cannot assign a dollar value to emission overruns and simply sum them, as the true cost of these GHG emissions is not yet understood [215]. We discussed the environmental performance of the project from the global warming potential perspective (with $\mathrm{kg} \mathrm{CO}_{2}$ eq unit), as the most common measure in environmental impact assessment and applied the proposed model to control this type of impact. The same calculation can be performed by considering other impact assessment categories, i.e. Fossil Fuel Consumption (MJ), Acidification Potential (moles of $\mathrm{H}+\mathrm{eq}$ ), Human Health-Particulate (kg PM10 eq), Human Health-Cancer (kg CTUcancer), Human Health-noncancer (kg CTUnoncancer), Eutrophication Potential (kg N eq), Ozone Depletion Potential (kg CFC-11 eq), Smog Potential (kg O3 eq), Eco toxicity (kg CTUe), Fresh water use (kg), as emphasized by EPA [151]. By replicating the model using such impact criteria, the GHG overrun may appear to be even more critical. Take, for example, concrete which is a major construction material and emits a large amount of substances with environmental impacts not only on global warming but also on acidification and eutrophication. Acidification and eutrophication are the main causes of air pollution, forest destruction, red tide phenomena, and deterioration of reinforced concrete structures [216].

While reducing GHG emission may not be pragmatic in the middle of a project, one can use the information to change the strategy for the future projects. This can be accomplished by several actions. According to Huisingh et al. (2015) [217] and Zhang et al. (2015) [218], the most effective action to reduce GHG emissions in constructions sector is to use low carbon materials and change the construction method. In fact, the benefits from implementing the proposed model include increased visibility and control to not necessarily promptly but proactively react to impacts overrun to meet the project environmental objective. The approach is more relevant to projectized organizations where multi-projects are run concurrently. In other words, the proposed approach can be applied more effectively by project-based companies such as contractors, with the objective of minimizing the environmental burden of their portfolio of projects, where organizational project management (OPM) plays a key role to harmonize the overall performance of an organizations' projects, resulting from performance of relatively disconnected projects/subcontractors/plans. Also, the obligations to follow international agreements to fight climate change, persuade and sometimes require investors as well as national governments to progressively reduce the negative impact of their portfolios on the environment, keeping financial returns. It is now well accepted that sustainable and low carbon 
businesses would benefit all the stakeholders. Hence when it comes to management practices, keeping projects on the right track, regarding their planned environmental impacts, is practically the role of project management as one expects the project managers to support and promote a low carbon economy.

Moreover, in public and especially mega projects, the societies, clients, governments and regulators could require formulation of strategies which evaluates the level of confidence in the contractor's capacity to keep the environmental impacts of project execution down. This could be achieved by using analytical tools developed in this paper. To this end, the introduced process of planning and controlling project GHGs could be one of the project management processes to monitor this capacity.

\subsection{Conclusion}

In this chapter, we have demonstrated how the GHG emissions from a work package and by the same token for the entirety of a project could be estimated. The calculated GHG allocation to each work package and thereby for the whole project could be regarded as a baseline GHG emissions plan or budget. Using the baseline GHG emissions plan, the performance of any project and specifically construction projects from GHG emissions point of view could be evaluated and costed to the project. Also, we presented a method for collecting all the required information for calculation of project GHG performance index and other related attributes such as EGAC. While monitoring and control of GHG emissions for small to medium size projects could be futuristic at present, applying the proposed GHG monitoring model in mega projects is well justified, as the cost of GHG emission could be a sizable share of the project budget. Not only monitoring and evaluation of GHG emission could lead to development of a GHG emissions estimation data base, it could also serve as an energy estimation platform. The size, complexity, duration and value of a project could dictate the duration of monitoring and control iterations cycles. For some projects, we may only develop quarterly reports. As such the ultimate objective for now, may not even be monetary values but to address climate change issue which relates to one of the three sustainability dimensions, i.e. environment, economic and society [219].

In this study, we also proposed a risk analysis model using Bayesian networks (BNs) for assessment of project greenhouse gas (GHG) emissions as a new objective of projects, in 
addition to the traditional objectives of schedule and cost. The model accounts for the risk events or qualitative driving forces that impact a project objective (in this study GHG emissions) and provides a full probabilistic estimation of the possible impacts of the project. This model can be used in the implementation phase as well, to monitor the environmental performance of the project and possibly take an action to return the project on track. It uses information on completed activities and also the number of observed risks to date, to modify the previous estimations on uncertainty sources, and update the final emissions of the project.

\section{Acknowledgment}

This work was partially supported by Ontario Centres of Excellence (OCE)'s Voucher for Innovation and Productivity (VIP) (No. 26114). The authors would also like to thank Mr. Ghasem Nasir for his assistance in the case study data collection and Prof. Jennifer McArthure and Arnold Yuan from Ryerson University for their guidance and comments. 


\section{Conclusions and Future Research}

\subsection{Main Results and Contributions}

In this dissertation, a number of management, analytical models, with the aim of improving sustainable asset and project management disciplines, were proposed. We have tried to incorporate the concept of sustainability into some of the traditional asset/project management practices, with a focus on environmental dimension of this concept. The dimension of society, therefore, is not considered in the present research. Among the environmental impact categories, the targeted impact of this research was limited to the category of global warming potential and the issue of greenhouse gas (GHG) emissions. So, we would rather call the topic of this dissertation as "green asset/project management".

The presented models and proposed approaches of this research contributed to the literature in two main lines:

1) Dealing with assets' and projects' carbon emissions in an emission trading scheme (ETS); and

2) Improving conventional, financial-based techniques in asset/project planning and control.

Starting with the first line, the main contributions are as follows:

1-a) Incorporating asset's emissions in fleet optimization-Chapter 2; we developed a mathematical fleet optimization model, which factors in the GHG emissions associated with different stages of an asset's lifecycle- that is manufacturing, shipping, operation and maintenance $(\mathrm{O} \& \mathrm{M})$, storage, and decommissioning.

1-b) Forecasting carbon price in an ETS-Chapter 5; we specifically studied the Western Climate Initiative (WCI) market, with the jurisdictions Quebec and California, and developed a probabilistic model using Bayesian networks (BNs) to predict the price of carbon for the next ten years. We used the price forecasts to put a dollar value on the emission related parameters of the proposed models. The driving forces of carbon price were identified by conducting a literature review on the existing ETSs. The proposed model employs projections of the driving forces and their historical records to capture the uncertainty of these variables and their causal relationship with the carbon price. 
1-c) The effect of equipment health on its O\&M emissions-Chapter 4; we proposed a Bayesian inference model to estimate the variability of equipment carbon emissions based on its reliability indicator, i.e. failure time/rate. The assumption behind this model is that there is a positive causation from equipment health to the amount of GHG emissions it releases during the operation phase.

1-d) Repair/Replacement (R/R) decision model with economic and GHG emission considerations-Chapter 4; we formulated a new model to decide whether to repair a failed equipment or replace it with a bran new equipment in the market. We also built an automatic tool (the R/R Calculator) that works with the mere economic model as well as the combined model with both economic and emission considerations.

1-e) Project GHG estimation and control- Chapter 6; two models were proposed to plan and monitor project carbon emissions during its implementation process. First, we used the mechanism of earned value management $(\mathrm{EVM})$, a common technique in project cost performance measurement, to plan the project emissions and track them in different reporting times during the execution phase. Second, we proposed a probabilistic method to estimate the uncertainty of project total emissions.

1-f) Emission footprinting; As a side contribution and a means of support for the above parts of the research, we conducted a comprehensive review to collect the latest emission factors in both Scope 1 (direct) and Scope 2 (indirect) categories of GHGs as well as emission factors of manufactured material, reported by well-known environmental organizations, such as Environmental Protection Agency (EPA), International Energy Agency (IEA), World Bank, Canada Environment, and different governments' energy related departments (Appendix A). Using the collected database, we developed a GHG calculator to calculate the direct and indirect carbon footprint of an activity, using Visual Basic for Applications (VBA) of Microsoft Excel (Appendix B). This calculator allows the users to enter detailed evidences about the activity data (such as location, type of vehicle, distance travelled, fuel, material, amount of electricity/heat/fuel, etc.), and provides the total carbon emissions and its cost in the corresponding carbon market, if in place.

Other contributions, covering technical and economic aspects of the proposed models are as follows: 
2-a) Fleet optimization with the possibility of storing equipment so that they would not age as an in-service equipment- Chapter 2; We designed a fleet optimization mathematical model that allows the assets to be kept in storage over any time period, in which such assets do not deteriorate as in-use assets do. The mathematical model optimizes the number of new, in-use, in-storage, and salvaged assets in each time period, so that the total economic costs and environmental impacts are minimized. To make a more realistic difference between assets, we consider asset capacity as well as its environmental impact. Therefore, the assets, which are purchased in the future, are considered more technologically improved, so they have a higher capacity and are more energy-efficient.

2-b) Uncertainty analysis of fleet availability, with respect to the effect of complex, organizational factors that affect equipment reliability, maintainability, or both simultaneouslyChapter 3; We have modeled variables that have dual effect on the two availability wings, i.e. failure rate and repair rate.

2-c) Incorporating extremely rare or previously unobserved events into fleet availability assessment- Chapter 3; We have combined a method to analyze the effect of rare risks (also known as emerging risks, with a low probability of occurrence and extreme impact) with our base Bayesian availability analysis model.

2-d) Maintenance quality and risks events in $\mathrm{R} / \mathrm{R}$ decision analysis- Chapter 4; We developed a probabilistic method for the repair/replacement problem, which factors in preventive maintenance (PM) quality and repair perfection. A probabilistic reasoning mechanism is designed to formulate the effect of PM quality (and/or any other driving force) on equipment health, and infer the effectiveness of maintenance. How perfect or imperfect the repair work is, is also modeled to more accurately predict the failure rate of the existing equipment during its remaining useful life. We, using Bayesian networks. Then, we also mapped a deterministic $\mathrm{R} / \mathrm{R}$ model into a fully probabilistic model and included supplementary variables to model the effect of common causal factors and risk events. Equipped with expert knowledge and data-driven inference, the proposed model provides asset managers with a smart, explanatory mechanism that not only makes more accurate R/R decisions, through capturing more real world uncertainties and causal factors, but also identifies risk and opportunities that should be focused on to further reduce lifecycle economic and environmental costs. 
2-e) Forecasting using BNs- Chapter 5; A new forecasting approach is introduced using the learning feature of BNs. We have formulated variables to capture the essence of a driving factor in terms of its depreciating or escalating impact on the targeted response variable (could be a trading price such as carbon price or stock price, or the price of products and services). For each driving force, we have defined a theoretical impact scale to determine the probable nature of causation- whether it is depreciating or escalating, and a depreciating/escalating impact factor to capture the significance of this causation. Regardless of how big or small the value of the driving force (also known as predictor or independent variable) is, multiple regression models assign a fixed coefficient to each driving factor. In our model, however, we have formulated probabilistic thresholds that decide whether or not a possible value of a driving force can hold a coefficient (what we called impact factor). The probability of possible impact scales and the distribution of their corresponding impact factor was extracted from the historical records of the response variable and its driving forces. The model also considers the causal relationship between the driving forces. Hence, it propagates information from a driving force to the others. For this reason, we did not call the driving forces as "independent" variables as in the real world they may affect each other. Furthermore, new observations on the response and predictor variables can be used to calculate posterior, and hence more accurate, distributions of the model parameters including the impact scales, the thresholds, and the impact factors.

2-f) Risk-based project performance measurement- Chapter 6; In general, the proposed approach suggests using project risks and uncertainty sources to monitor project performance. The concept model is: poor performance in project objectives (cost, GHG, time, quality, etc.) signifies high level of risk and knowing the real level of project risks updates our knowledge on how the remaining work will perform ${ }^{10}$. Unlike our EVM-based GHG model and the previous models introduced in the literature to measure project cost and schedule performance (such as EVM, ES, EDM, etc.), the risk-based model reflects the performance non-linearity and management interventions. It infers the actual level of uncertainty sources and thereby forecasts the project final performance. This mechanism also sheds light on the major uncertainties that should be focused on in order to return the project on track if we have observed a variance at the status time.

\footnotetext{
${ }^{10}$ Which implies "risk management is project management", the idea first heard from Lister \& Carr (1997),
} 
The main conclusions derived from the case studies of the present research are summarized as follows:

- Asset management decisions and strategies are not influenced by a price that a market like the WCI puts on carbon pollutions.

- The proposed BN approach to availability analysis has been found more accurate in forecasting the availability level of a fleet of assets. It provides an explanatory model for analyzing complex management causalities and rare risks.

- The expected price of carbon in the WCI market, that is $\mathrm{C} \$ 18.44$ per ton of $\mathrm{CO}_{2} \_$eq, cannot make a remarkable difference in the total cost of equipment and therefore the repair/replacement decision. That is to say, it is unlikely that accounting for GHG emissions based on this carbon price would change the decision so that it can help mitigating carbon emissions. This would become even more discouraging if we exclude GHG emissions for which, the equipment owner does not yet pay in a carbon market (e.g. emissions from manufacturing new equipment or outsourced decommissioning projects). Higher prices, small probabilities, might actually change the decision and consequently reduce the total emissions.

- The results of running the carbon price forecasting model showed that carbon prices over the future decade ranges between approximately $\mathrm{C} \$ 14$ and $\mathrm{C} \$ 26$, with the most likely prices around $\mathrm{C} \$ 18$. There is a 90 percent chance of the price being greater than $\mathrm{C} \$ 16.19$ or lower than $\mathrm{C} \$ 21.17$.

- Project GHG models has been found to applicable for evaluating the performance of any project from GHG emissions point of view. It provides a method for collecting all the required information for calculation of project GHG performance index and other related attributes such as EGAC. Although monitoring and control of GHG emissions for small to medium size projects could be futuristic at present, applying the proposed model to mega projects is well justified, as the cost of GHG emission could be a sizable share of the project budget.

\subsection{Weaknesses and Future Work}

There are weaknesses in the proposed models of this study, especially with regard to their applications from a practitioner's point of view. To begin with, because of the highly uncertain 
world of business and technology, relying on our optimization model which decides the combination of a fleet's assets in a decade seems far fetched. There are definitely known and unknown uncertainties that can impact the objective function of this model. Second, the impact of maintenance activities including preventative and corrective maintenance and also the management intervention are not considered in this model. Improving the quality of such interventions increases the cost of assets ownership (O\&M), but it may result in a greater benefit in terms of capacity, GHG emissions, etc.

As a future extension of this study, the uncertainty of parameters of the optimization model should be factored in, by mapping the model into a stochastic model. Further, parameters and decision variables should be included to consider the quality of preventive maintenance and the type of repairs-perfect, imperfect, or minimal. Hence, the more advanced model can decide on the optimum strategy for maintenance or repair type. Moreover, The replacement model could be remodeled into a multi objective function problem with separate objectives to minimize cost, carbon emissions, and other impact assessment categories stressed by the Environmental Protection Agency (EPA), such as Acidification Potential (moles of H+ eq), Ozone Depletion Potential (kg CFC-11 eq), Fresh water use (kg), etc. [220].

Regarding the fleet availability analysis model, the focus was primarily on external factors affecting reliability/maintainability of physical assets and it rather neglects the internal complex characteristics and configuration. We believe the model can be extended, mainly for improving its reliability side, to capture the risk of internal damages caused by components degradation, as well as the configuration of equipment components and common cause failures (CCFs), as investigated by O’Connor and Mosleh [221].

We integrated the model form Constantinou et al. [86] into our BN model to consider the effect of extremely rare or unobserved risks. The assumption behind their model is that the statistical outcomes of such rare events are already reflected in the historical data (or likewise in the expert judgments). This method, however, does not include extreme hidden, unknown risks which are surprising relative to the present knowledge and therefore have not been taken into consideration in data or expert belief. Such events were first introduced as black swans by Taleb [222] in his book: "The Black Swan- The Impact of the Highly Improbable". A black swan has three characteristics: 1) It is an outlier because it lies outside of the realm of regular 
expectations and nothing in the past can convincingly point to its possibility; 2) It carries an extreme impact; and 3) It is retrospectively predictable because despite its outlier status, human nature makes us concoct explanations for its occurrence after the fact, making it explainable and predictable.

When risks are rare or novel (like external risks), commonly used methods of risk assessment, such as risk register or data-driven approaches are inadequate because there is insufficient relevant data [139]. Although extreme events are not very frequent but these days they are actually more common than what people imagine, thanks to the climate change. A few studies show that these risks are on the rise [223-225]. By reviewing catastrophic events throughout the world during the recent years, even years ago Pells (2011) alarms that these events, especially natural disasters, are increasing: "If your program spans 2-3 years anywhere in the world, in my opinion, you will have one or more weather-related emergency to deal with" [224].

The proposed model can be extended to incorporate black swans. Our idea is to use a NoisyOR operator with a leak variable that allows to include the probability of hidden factors. The Noisy-OR operator (gate) is a member of the family of models referred to as independence of causal influences (ICI) [226]. The word 'noisy' reflects the fact that the interaction among the causes and the effect is not deterministic. Noisy-OR can be thought as a probabilistic extension of the deterministic binary OR. Mapping this operator into a BN will then allow for learning the leak parameter as new observations on the risk or its indicators are available.

The BN model developed for making R/R decision involves many nodes with continuous probabilistic distributions. The main shortcoming of this model is that in real size problems with several more common causes, the BN becomes too complex in terms of their speed of inference and running the model. This problem can be addressed using object oriented Bayesian networks (OOBNs) approach [227], by which complex models with many more variables can be constructed and run using inter-related objects. This not only facilitates the process of building the model but also can speed up the inference process [228].

Regarding the carbon price prediction model (Chapter 5), still the uncertainty of carbon price in the WCI market may have not been fully captured in our model. There is a possibility 
to extend the model for taking into account extremely rare or emerging events, such as financial crises, major green technological advances, natural disasters, etc. Moreover, political risks, such as new Government of Ontario which resulted in the cancellation of the linkage with The WCI market, should also be factored in.

We acknowledge the challenge of implementing the GHG performance model and collecting its required data. For instance, to calculate TAG at a given time, any consumed material, fuel or energy, and any vehicle movement on-site or off-site must be recorded. The same effort is needed to estimate total planned GHG (TPG), estimated GHG to complete (EGTC), etc. However, integrating the proposed mathematical model of this study and the GHG Calculator and the algorithm behind it to a project planning tool, will go a long way by entering the amount of work performed and resources spent, to automatically calculates the metrics for GHG related quantities. Furthermore, the EVM-based and BN-based models of project GHG can be extended to an integrated cost-schedule-GHG model to monitor and control the three objectives at the same time. Hence, the interrelationships among activities cost, durations, and emissions would be considered.

As mentioned earlier, we only included Scope 1 and Scope 2 categories of GHG emissions. As a future work, Scope 3 (or corporate value chain) emissions can be incorporated into the models presented in Chapters 2,4, and 6. Scope 3 emissions often represent a company's largest GHG impacts. According to road tester Kraft Foods, Scope 3 emissions comprise more than \%90 of their total GHGs. Therefore, a full consideration of Scope 1, 2 and 3 emissions enable organizations to account for their full value chain GHGs and to focus their efforts on the biggest emission reduction opportunities. This would also allow companies to engage their value chain partners including suppliers and contractors in GHG management.

Our GHG Calculator (Appendix A) can be improved by including the following items:

- Mix of energy: we decided to consider the average emission factor of electricity generation in a region. If the information about the mix of energy in the purchased electricity is available, a more accurate estimation of the GHG emissions can be calculated.

- Hydrofluorocarbon (HFC) and perfluorocarbon (PFC) emissions: we only included $\mathrm{CO}_{2}, \mathrm{~N}_{2} \mathrm{O}$, and $\mathrm{CH}_{4}$ gases. $\mathrm{HFC}$ and PFC emissions resulting from manufacturing, 
servicing, and disposal of refrigeration and air-conditioning equipment can be added specifically for this type of industrial units.

- Mode of transport (Road, Rail, etc.): although we have included almost every common type of vehicle in calculating emissions from mobile sources, they can be classified based on the mode of transport.

- Corporate Value Chain (Scope 3) emissions.

The next step towards a full sustainable asset/project management is to include other environmental objectives and also the society pillar of sustainability. Environmental objectives of sustainability merge primary objectives (e.g. environmental quality), secondary objectives (e.g. using less non-renewable resource), and objectives in terms of solutions (e.g. using public transport rather than personal vehicles). Due to the complexity of social factors, less study has been conducted on assessing this dimension of sustainability in the asset management literature. Social dimension of sustainability encompasses criteria such as social equity, community resilience, livability, health equity, community development, and social responsibility. To this aim, a sustainability breakdown structure (SBS) should be extracted from the standards and guidelines, including ISO 14000 (Environmental Management), ISO 37101 (Sustainable development in communities), ISO 26000 (Guidance on social responsibility), and the newly revised indicators for sustainable development of the UN Commission on Sustainable Development (CSD), containing 50 core indicators. Multi objective functions should be then considered in asset and project management models. Asset and project management success in the revised models goes beyond the mere economic considerations and requires benefit realization of all three sustainability dimensions and the requirements for circular economy (CE)- a new system of thinking for improving the efficiency of natural resources through reducing waste and pollution, keeping products and materials in use, and regenerating natural systems. 


\section{Appendices}

Appendix A. Global warming potentials and Scope 1 and Scope 2 emission factors

Appendix A-1. Global warming potentials (GWPs) by IPCC Fifth Assessment Report [214]

Industrial designation or common name
Chemical formula
Global Warming Potential (100 years)

\begin{tabular}{lll}
\hline CO2 & $\mathrm{CO}_{2}$ & 1 \\
Methane & $\mathrm{CH}_{4}$ & 28 \\
Nitrous oxide & $\mathrm{N}_{2} \mathrm{O}$ & 265 \\
\hline
\end{tabular}

Substances controlled by the Montreal Protocol

\begin{tabular}{|c|c|c|}
\hline CFC-11 & $\mathrm{CCl}_{3} \mathrm{~F}$ & 4660 \\
\hline CFC-12 & $\mathrm{CCl}_{2} \mathrm{~F}_{2}$ & 10200 \\
\hline CFC-13 & $\mathrm{CClF}_{3}$ & 13900 \\
\hline CFC-113 & $\mathrm{CCl}_{2} \mathrm{FCClF}_{2}$ & 5820 \\
\hline CFC-114 & $\mathrm{CClF}_{2} \mathrm{CClF}_{2}$ & 8590 \\
\hline CFC-115 & $\mathrm{CClF}_{2} \mathrm{CF}_{3}$ & 7670 \\
\hline Halon-1301 & $\mathrm{CBrF}_{3}$ & 6290 \\
\hline Halon-1211 & $\mathrm{CBrClF} 2$ & 1750 \\
\hline Halon-2402 & $\mathrm{CBrF} 2 \mathrm{CBrF} 2$ & 1470 \\
\hline Carbon tetrachloride & $\mathrm{CCl} 4$ & 1730 \\
\hline Methyl bromide & $\mathrm{CH} 3 \mathrm{Br}$ & 2 \\
\hline Methyl Chloroform & $\mathrm{CH} 3 \mathrm{CCl} 3$ & 160 \\
\hline HCFC-21 & $\mathrm{CHCl} 2 \mathrm{~F}$ & 148 \\
\hline HCFC-22 & CHCLF2 & 1760 \\
\hline HCFC-123 & $\mathrm{CHCl2CF3}$ & 79 \\
\hline HCFC-124 & $\mathrm{CHClFCF} 3$ & 527 \\
\hline HCFC-141b & $\mathrm{CH} 3 \mathrm{CCl} 2 \mathrm{~F}$ & 782 \\
\hline HCFC-142b & $\mathrm{CH} 3 \mathrm{CClF} 2$ & 1980 \\
\hline HCFC-225ca & $\mathrm{CHC12CF} 2 \mathrm{CF} 3$ & 127 \\
\hline HCFC-225cb & $\mathrm{CHClFCF} 2 \mathrm{CClF} 2$ & 525 \\
\hline \multicolumn{3}{|c|}{ Hydroflurocarbons (HFCs) } \\
\hline HFC-23 & CHF3 & 12400 \\
\hline HFC-32 & $\mathrm{CH} 2 \mathrm{~F} 2$ & 677 \\
\hline HFC-41 & $\mathrm{CH} 3 \mathrm{~F} 2$ & 116 \\
\hline HFC-125 & CHF2CF3 & 3170 \\
\hline HFC-134 & CHF2CHF2 & 1120 \\
\hline HFC-134a & CH2FCF3 & 1300 \\
\hline HFC-143 & CH2FCHF2 & 328 \\
\hline HFC-143a & $\mathrm{CH} 3 \mathrm{CF} 3$ & 4800 \\
\hline HFC-152 & $\mathrm{CH} 2 \mathrm{FCH} 2 \mathrm{~F}$ & 16 \\
\hline HFC-152a & $\mathrm{CH} 3 \mathrm{CHF} 2$ & 138 \\
\hline
\end{tabular}




\begin{tabular}{|c|c|c|}
\hline HFC-161 & $\mathrm{CH} 3 \mathrm{CH} 2 \mathrm{~F}$ & 4 \\
\hline HFC-227ea & CF3CHFCF3 & 3350 \\
\hline HFC-236cb & $\mathrm{CH} 2 \mathrm{FCF} 2 \mathrm{CF} 3$ & 1210 \\
\hline HFC-236еa & CHF2CHFCF3 & 1330 \\
\hline HFC-236fa & $\mathrm{CF} 3 \mathrm{CH} 2 \mathrm{CF} 3$ & 8060 \\
\hline HFC-245ca & CH2FCF2CHF2 & 716 \\
\hline HFC-245fa & CHF2CH2CF3 & 858 \\
\hline HFC-365mfc & $\mathrm{CH} 3 \mathrm{CF} 2 \mathrm{CH} 2 \mathrm{CF} 3$ & 804 \\
\hline HFC-43-10mee & CF3CHFCHFCF2CF3 & 1650 \\
\hline \multicolumn{3}{|c|}{ Perfluorinated compounds } \\
\hline Sulfur hexaflouride & SF6 & 23500 \\
\hline Nitrogen triflouride & NF3 & 16100 \\
\hline PFC-14 & CF4 & 6630 \\
\hline PFC-116 & $\mathrm{C} 2 \mathrm{~F} 6$ & 11100 \\
\hline PFC-218 & $\mathrm{C} 3 \mathrm{~F} 8$ & 8900 \\
\hline PFC-318 & c-C4F8 & 9540 \\
\hline PFC-31-10 & C4F10 & 9200 \\
\hline PFC-41-12 & $\mathrm{C} 5 \mathrm{~F} 2$ & 8550 \\
\hline PFC-51-14 & C6F14 & 7910 \\
\hline PFC-91-18 & $\mathrm{C} 10 \mathrm{~F} 18$ & 7190 \\
\hline $\begin{array}{l}\text { Trifluoromethyl sulfur } \\
\text { pentafluoride }\end{array}$ & SF5CF3 & 17400 \\
\hline Perflurocyclopropane & $\mathrm{c}-\mathrm{C} 3 \mathrm{~F} 6$ & 9200 \\
\hline \multicolumn{3}{|c|}{ Fluorinated ethers } \\
\hline HFE-125 & CH2OCF3 & 12400 \\
\hline HFE-134 & CHF2OCHF2 & 5560 \\
\hline HFE-143a & CH3OCF3 & 523 \\
\hline HFE-235da2 & CHF2OCHClCF3 & 491 \\
\hline HFE-245cb2 & CH3OCF2CF3 & 654 \\
\hline HFE-245fa2 & CHF2OCH2CF3 & 812 \\
\hline HFE-347mec3 & CH3OCF2CF2CF3 & 530 \\
\hline HFE-347pcf2 & $\mathrm{CHF} 2 \mathrm{CF} 2 \mathrm{OCH} 2 \mathrm{CF} 3$ & 889 \\
\hline HFE-356pcc3 & CH3OCF2CF2CHF2 & 413 \\
\hline HFE-449sl (HFE-7100) & C4F9OCH3 & 421 \\
\hline HFE-569sf2 (HFE-7200) & $\mathrm{C} 4 \mathrm{~F} 9 \mathrm{OC} 2 \mathrm{H} 5$ & 57 \\
\hline $\begin{array}{l}\text { HFE-43-10pecc124(H- Galden } \\
\text { 1040x) }\end{array}$ & CHF2OCF2OC2F4OCHF2 & 2820 \\
\hline HFE-236ca12 (HG-10) & CHF2OCF2OCHF2 & 5350 \\
\hline HFE-338pcc13 (HG-01) & CHF2OCF2CF2OCHF2 & 2,910 \\
\hline HFE-227ea & CF3CHFOCF3 & 6,450 \\
\hline HFE-236ea2 & CHF2OCHFCF3 & 1,790 \\
\hline HFE-236fa & CF3CH2OCF3 & 979 \\
\hline HFE-245fa 1 & $\mathrm{CHF} 2 \mathrm{CH} 2 \mathrm{OCF} 3$ & 828 \\
\hline HFE 263fb2 & CF3CH2OCH3 & 1 \\
\hline HFE-329mcc2 & CHF2CF2OCF2CF3 & 3,070 \\
\hline
\end{tabular}




\begin{tabular}{lll} 
HFE-338mcf2 & CF3CH2OCF2CF3 & 929 \\
HFE-347mcf2 & CHF2CH2OCF2CF3 & 854 \\
HFE-356mec3 & CH3OCF2CHFCF3 & 387 \\
HFE-356pcf2 & CHF2CH2OCF2CHF2 & 719 \\
HFE-356pcf3 & CHF2OCH2CF2CHF2 & 446 \\
HFE 365mcf3 & CF3CF2CH2OCH3 & $<1$ \\
HFE-374pc2 & CHF2CF2OCH2CH3 & 627 \\
\hline \multicolumn{2}{l}{ Perfluoropolyethers } \\
\hline PFPMIE & CF3OCF(CF3)CF2OCF2OCF3 \\
\hline \multicolumn{2}{|c}{ Hydrocarbons and other compounds - direct effects } \\
\hline Chloroform & CHCl3 & \\
Methylene chloride & CH2C12 & 16 \\
Methyl chloride & CH3Cl & 9 \\
Halon-1201 & CHBrF2 & 376
\end{tabular}

Appendix A-2. Scope 1 Emission Factors [229]

Table A-2-1. Stationary Combustion Emission Factors

\begin{tabular}{|c|c|c|c|c|}
\hline \multicolumn{2}{|l|}{ Fuel Type } & \multirow{2}{*}{$\begin{array}{l}\mathrm{CO}_{2} \text { Factor } \\
\mathrm{kg} \mathrm{CO} \text { per } \\
\text { short ton }\end{array}$} & \multirow{2}{*}{$\begin{array}{l}\mathrm{CH}_{4} \text { Factor } \\
\mathrm{g} \mathrm{CH}_{4} \text { per } \\
\text { short ton }\end{array}$} & \multirow{2}{*}{$\begin{array}{l}\mathrm{N}_{2} \mathrm{O} \text { Factor } \\
\mathrm{g} \mathrm{N}_{2} \mathrm{O} \text { per } \\
\text { short ton }\end{array}$} \\
\hline & & & & \\
\hline \multirow{9}{*}{ Coal and Coke } & Anthracite Coal & 2,602 & 276 & 40 \\
\hline & Bituminous Coal & 2,325 & 274 & 40 \\
\hline & Sub-bituminous Coal & 1,676 & 190 & 28 \\
\hline & Lignite Coal & 1,389 & 156 & 23 \\
\hline & Mixed (Commercial Sector) & 2,016 & 235 & 34 \\
\hline & Mixed (Electric Power Sector) & 1,885 & 217 & 32 \\
\hline & Mixed (Industrial Coking) & 2,468 & 289 & 42 \\
\hline & Mixed (Industrial Sector) & 2,116 & 246 & 36 \\
\hline & Coal Coke & 2,819 & 273 & 40 \\
\hline \multirow{4}{*}{$\begin{array}{l}\text { Fossil Fuel- } \\
\text { derived Fuels } \\
\text { (Solid) }\end{array}$} & Municipal Solid Waste & 902 & 318 & 42 \\
\hline & Petroleum Coke (Solid) & 3,072 & 960 & 126 \\
\hline & Plastics & 2,850 & 1,216 & 160 \\
\hline & Tires & 2,407 & 896 & 118 \\
\hline \multirow{4}{*}{$\begin{array}{l}\text { Biomass Fuels } \\
\text { (Solid) }\end{array}$} & Agricultural Byproducts & 975 & 264 & 35 \\
\hline & Peat & 895 & 256 & 34 \\
\hline & Solid Byproducts & 1,096 & 332 & 44 \\
\hline & Wood and Wood Residuals & 1,640 & 126 & 63 \\
\hline \multirow{3}{*}{ Natural Gas } & & $\begin{array}{l}\text { kg CO2 per } \\
\text { scf }\end{array}$ & $\mathrm{g} \mathrm{CH}_{4}$ per scf & $\begin{array}{l}\mathrm{g} \mathrm{N}_{2} \mathrm{O} \text { per } \\
\text { scf }\end{array}$ \\
\hline & Natural Gas & 0.05444 & 0.00103 & 0.00010 \\
\hline & Blast Furnace Gas & 0.02524 & 0.000002 & 0.000009 \\
\hline
\end{tabular}




\begin{tabular}{|c|c|c|c|c|}
\hline Fossil-derived & Coke Oven Gas & 0.02806 & 0.000288 & 0.000060 \\
\hline Fuels & Fuel Gas & 0.08189 & 0.004164 & 0.000833 \\
\hline (Gaseous) & Propane Gas & 0.15463 & 0.000055 & 0.000252 \\
\hline \multirow{18}{*}{$\begin{array}{l}\text { Biomass Fuels } \\
\text { (Gaseous) }\end{array}$} & Landfill Gas & 0.025254 & 0.001552 & 0.000306 \\
\hline & Other Biomass Gases & 0.034106 & 0.002096 & 0.000413 \\
\hline & & $\begin{array}{l}\mathrm{kg} \mathrm{CO}_{2} \text { per } \\
\text { gallon }\end{array}$ & $\begin{array}{l}\mathrm{g} \mathrm{CH}_{4} \text { per } \\
\text { gallon }\end{array}$ & $\begin{array}{l}\mathrm{g} \mathrm{N}_{2} \mathrm{O} \text { per } \\
\text { gallon }\end{array}$ \\
\hline & Asphalt and Road Oil & 11.91 & 0.47 & 0.09 \\
\hline & Aviation Gasoline & 8.31 & 0.36 & 0.07 \\
\hline & Butane & 6.67 & 0.31 & 0.06 \\
\hline & Butylene & 7.22 & 0.32 & 0.06 \\
\hline & Crude Oil & 10.29 & 0.41 & 0.08 \\
\hline & Distillate Fuel Oil No. 1 & 10.18 & 0.42 & 0.08 \\
\hline & Distillate Fuel Oil No. 2 & 10.21 & 0.41 & 0.08 \\
\hline & Distillate Fuel Oil No. 4 & 10.96 & 0.44 & 0.09 \\
\hline & Ethane & 4.05 & 0.20 & 0.04 \\
\hline & Ethylene & 3.83 & 0.17 & 0.03 \\
\hline & Heavy Gas Oils & 11.09 & 0.44 & 0.09 \\
\hline & Isobutane & 6.43 & 0.30 & 0.06 \\
\hline & Isobutylene & 7.09 & 0.31 & 0.06 \\
\hline & Kerosene & 10.15 & 0.41 & 0.08 \\
\hline & Kerosene-Type Jet Fuel & 9.75 & 0.41 & 0.08 \\
\hline \multirow{18}{*}{$\begin{array}{l}\text { Petroleum } \\
\text { Products }\end{array}$} & $\begin{array}{l}\text { Liquefied Petroleum Gases } \\
\text { (LPG) }\end{array}$ & 5.68 & 0.28 & 0.06 \\
\hline & Lubricants & 10.69 & 0.43 & 0.09 \\
\hline & Motor Gasoline & 8.78 & 0.38 & 0.08 \\
\hline & Naphtha (<401 deg F) & 8.50 & 0.38 & 0.08 \\
\hline & Natural Gasoline & 7.36 & 0.33 & 0.07 \\
\hline & Other Oil (>401 deg F) & 10.59 & 0.42 & 0.08 \\
\hline & Pentanes Plus & 7.70 & 0.33 & 0.07 \\
\hline & Petrochemical Feedstocks & 8.88 & 0.38 & 0.08 \\
\hline & Petroleum Coke & 14.64 & 0.43 & 0.09 \\
\hline & Propane & 5.72 & 0.27 & 0.05 \\
\hline & Propylene & 6.00 & 0.27 & 0.05 \\
\hline & Residual Fuel Oil No. 5 & 10.21 & 0.42 & 0.08 \\
\hline & Residual Fuel Oil No. 6 & 11.27 & 0.45 & 0.09 \\
\hline & Special Naphtha & 9.04 & 0.38 & 0.08 \\
\hline & Still Gas & 9.54 & 0.43 & 0.09 \\
\hline & Unfinished Oils & 10.36 & 0.42 & 0.08 \\
\hline & Used Oil & 10.21 & 0.41 & 0.08 \\
\hline & Biodiesel (100\%) & 9.45 & 0.14 & 0.01 \\
\hline \multirow{4}{*}{$\begin{array}{l}\text { Biomass Fuels } \\
\text { (Liquid) }\end{array}$} & Ethanol $(100 \%)$ & 5.75 & 0.09 & 0.01 \\
\hline & Rendered Animal Fat & 8.88 & 0.14 & 0.01 \\
\hline & Vegetable Oil & 9.79 & 0.13 & 0.01 \\
\hline & & $\begin{array}{l}\mathrm{kg} \mathrm{CO}_{2} \text { per } \\
\text { mmBtu }\end{array}$ & $\begin{array}{l}\mathrm{g} \mathrm{CH}_{4} \text { per } \\
\text { mmBtu }\end{array}$ & $\begin{array}{l}\mathrm{g} \mathrm{N}_{2} \mathrm{O} \text { per } \\
\text { mmBtu }\end{array}$ \\
\hline
\end{tabular}




\begin{tabular}{lllll}
\hline Biomass Fuels & North American Softwood & 94.4 & 1.9 & 0.42 \\
(Kraft Pulping & North American Hardwood & 93.7 & 1.9 & 0.42 \\
Liquor, by & Bagasse & 95.5 & 1.9 & 0.42 \\
Wood Furnish) & Bamboo & 93.7 & 1.9 & 0.42 \\
& Straw & 95.1 & 1.9 & 0.42 \\
\hline
\end{tabular}

Table A-2-2. Mobile Combustion $\mathrm{CO}_{2}$ Emission Factors

\begin{tabular}{lll}
\hline Fuel Type & kg CO2 per unit & Unit \\
\hline Aviation Gasoline & 8.31 & gallon \\
Biodiesel (100\%) & 9.45 & gallon \\
Compressed Natural Gas (CNG) & 0.05444 & scf \\
Diesel Fuel & 10.21 & gallon \\
Ethanol (100\%) & 5.75 & gallon \\
Kerosene-Type Jet Fuel & 9.75 & gallon \\
Liquefied Natural Gas (LNG) & 4.46 & gallon \\
Liquefied Petroleum Gases (LPG) & 5.68 & gallon \\
Motor Gasoline & 8.78 & gallon \\
Residual Fuel Oil & 11.27 & gallon \\
\hline
\end{tabular}

Table A-2-3. Mobile Combustion $\mathrm{CH}_{4}$ and $\mathrm{N}_{2} \mathrm{O}$ Emission Factors for On-Road Gasoline Vehicles

\begin{tabular}{llll}
\hline Vehicle Type & Year & $\begin{array}{l}\mathbf{C H}_{4} \text { Factor } \\
(\mathbf{g} / \text { mile })\end{array}$ & $\begin{array}{l}\mathbf{N}_{2} \mathbf{O} \text { Factor } \\
(\mathbf{g} / \text { mile })\end{array}$ \\
\hline & $1973-74$ & 0.1696 & 0.0197 \\
1975 & 0.1423 & 0.0443 \\
$1976-77$ & 0.1406 & 0.0458 \\
$1978-79$ & 0.1389 & 0.0473 \\
1980 & 0.1326 & 0.0499 \\
1981 & 0.0802 & 0.0626 \\
1982 & 0.0795 & 0.0627 \\
Gasoline Passenger Cars & 1983 & 0.0782 & 0.0630 \\
& $1984-93$ & 0.0704 & 0.0647 \\
& 1994 & 0.0531 & 0.0560 \\
& 1995 & 0.0358 & 0.0473 \\
& 1996 & 0.0272 & 0.0426 \\
1997 & 0.0268 & 0.0422 \\
& 1998 & 0.0249 & 0.0393 \\
& 1999 & 0.0216 & 0.0337 \\
2000 & 0.0178 & 0.0273 \\
& 2001 & 0.0110 & 0.0158 \\
& 2002 & 0.0107 & 0.0153 \\
& 2003 & 0.0114 & 0.0135 \\
& 2004 & 0.0145 & 0.0083 \\
& 2005 & 0.0147 & 0.0079 \\
2006 & 0.0161 & 0.0057 \\
\hline
\end{tabular}




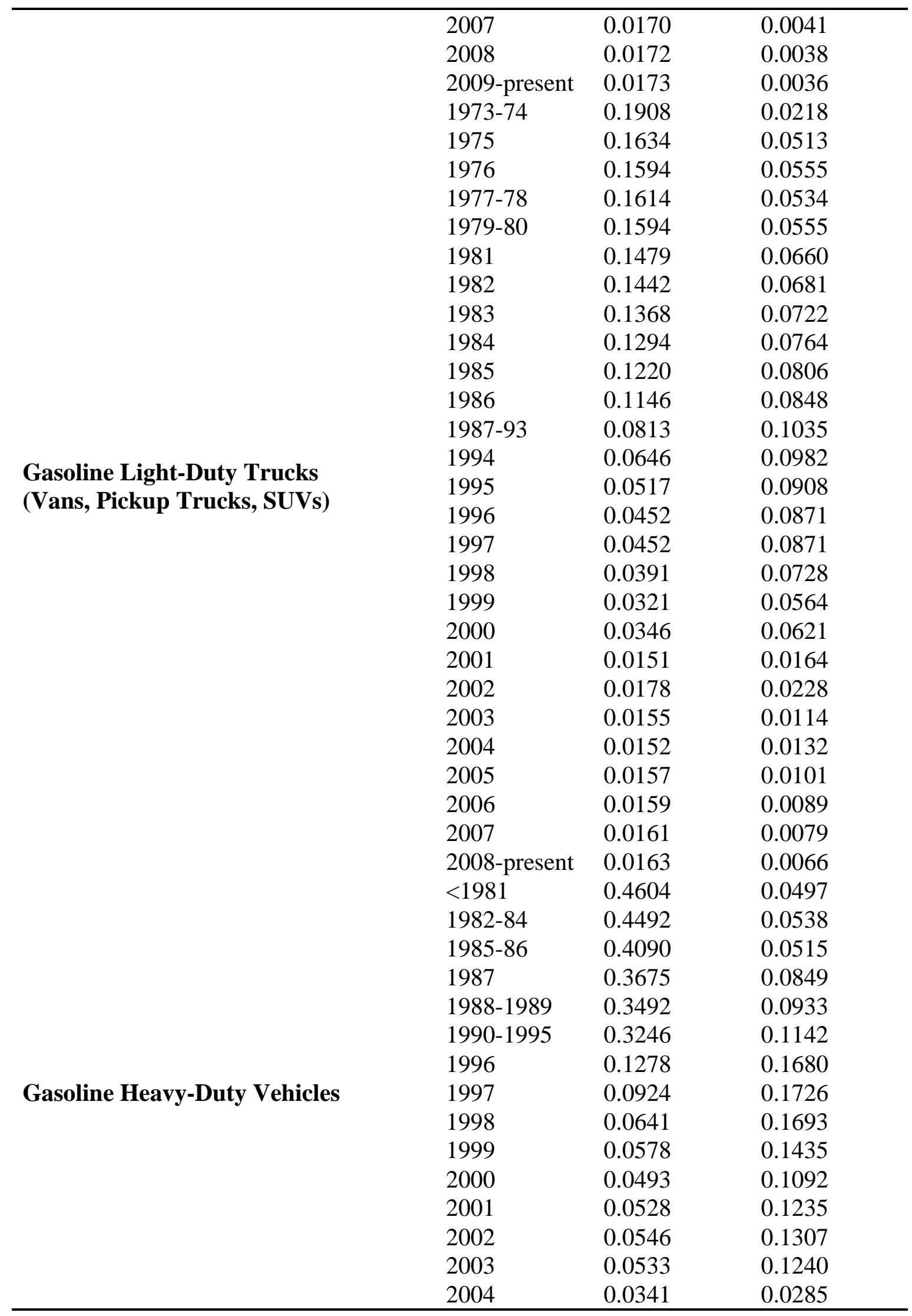




\begin{tabular}{llll}
\hline & 2005 & 0.0326 & 0.0177 \\
& 2006 & 0.0327 & 0.0171 \\
& 2007 & 0.0330 & 0.0153 \\
\multirow{2}{*}{ Gasoline Motorcycles } & 2008 -present & 0.0333 & 0.0134 \\
& $1960-1995$ & 0.0899 & 0.0087 \\
\hline
\end{tabular}

Table A-2-4. Mobile Combustion $\mathrm{CH}_{4}$ and $\mathrm{N}_{2} \mathrm{O}$ Emission Factors for On-Road Diesel and Alternative Fuel Vehicles

\begin{tabular}{llll}
\hline Vehicle Type & Vehicle Year & $\begin{array}{l}\text { CH4 Factor } \\
\text { (g/ mile) }\end{array}$ & $\begin{array}{l}\text { N2O Factor } \\
\text { (g / mile) }\end{array}$ \\
\hline & $1960-1982$ & 0.0006 & 0.0012 \\
Diesel Passenger Cars & $1983-1995$ & 0.0005 & 0.0010 \\
& $1996-$ present & 0.0005 & 0.0010 \\
Diesel Light-Duty Trucks & $1960-1982$ & 0.0011 & 0.0017 \\
& $1983-1995$ & 0.0009 & 0.0014 \\
Diesel Medium- and Heavy-Duty Vehicles & $1996-$ present & 0.0010 & 0.0015 \\
CNG Light-Duty Vehicles & & 0.0051 & 0.0048 \\
CNG Medium- and Heavy-Duty Vehicles & & 0.737 & 0.050 \\
CNG Buses & & 1.966 & 0.175 \\
LPG Light-Duty Vehicles & & 0.037 & 0.175 \\
LPG Medium- and Heavy-Duty Vehicles & & 0.066 & 0.067 \\
LNG Medium- and Heavy-Duty Vehicles & & 1.966 & 0.175 \\
Ethanol Light-Duty Vehicles & 0.055 & 0.175 \\
Ethanol Medium- and Heavy-Duty & & 0.197 & 0.067 \\
Vehicles & & 0.197 & 0.175 \\
Ethanol Buses & 0.0005 & 0.175 \\
Biodiesel Light-Duty Vehicles & & 0.001 \\
Biodiesel Medium- and Heavy-Duty & 0.005 & 0.005 \\
Vehicles & & 0.005 & 0.005 \\
Biodiesel Buses & & \\
\hline
\end{tabular}

Table A-2-6. Mobile Combustion $\mathrm{CH}_{4}$ and $\mathrm{N}_{2} \mathrm{O}$ Emission Factors for Non-Road Vehicles

\begin{tabular}{lll}
\hline Vehicle Type & $\begin{array}{l}\text { CH4 Factor } \\
\text { (g / gallon) }\end{array}$ & $\begin{array}{l}\mathbf{N}_{2} \text { O Factor } \\
\text { (g/ gallon) }\end{array}$ \\
\hline Residual Fuel Oil Ships and Boats & 0.11 & 0.57 \\
Gasoline Ships and Boats & 0.64 & 0.22 \\
Diesel Ships and Boats & 0.06 & 0.45 \\
Diesel Locomotives & 0.80 & 0.26 \\
Gasoline Agricultural Equip. & 1.26 & 0.22 \\
Diesel Agricultural Equip. & 1.44 & 0.26 \\
Gasoline Construction Equip. & 0.50 & 0.22 \\
Diesel Construction Equip. & 0.57 & 0.26 \\
Jet Fuel Aircraft & 0.00 & 0.30 \\
\hline
\end{tabular}




\begin{tabular}{lll}
\hline Aviation Gasoline Aircraft & 7.06 & 0.11 \\
Other Gasoline Non-Road Vehicles & 0.50 & 0.22 \\
Other Diesel Non-Road Vehicles & 0.57 & 0.26 \\
LPG Non-Road Vehicles & 0.50 & 0.22 \\
Biodiesel Non-Road Vehicles & 0.57 & 0.26 \\
\hline
\end{tabular}

\section{Appendix A-3. Scope 2 Emission Factors}

Table A-3-1. Location-based electricity generation GHG emission factors: Sample of Canada [230]

\begin{tabular}{llll}
\hline Province & $\begin{array}{l}\text { CO2 intensity } \\
(\mathbf{g ~ C O 2} / \mathbf{k W h})\end{array}$ & $\begin{array}{l}\text { CH4 intensity } \\
(\mathbf{g} \text { CH4 / kWh })\end{array}$ & $\begin{array}{l}\text { N2O intensity } \\
(\mathbf{g ~ N 2 O} / \mathbf{~ k W h})\end{array}$ \\
\hline Newfoundland and Labrador & 30 & 0.0004 & 0.001 \\
Prince Edward Island & 8 & 0.0002 & 0.0002 \\
Nova Scotia & 690 & 0.03 & 0.01 \\
New Brunswick & 290 & 0.02 & 0.004 \\
Quebec & 2.1 & 0.0002 & 0.0001 \\
Ontario & 40 & 0.01 & 0.001 \\
Manitoba & 3.4 & 0.0003 & 0.0001 \\
Saskatchewan & 780 & 0.05 & 0.02 \\
Alberta & 790 & 0.04 & 0.02 \\
British Columbia & 14.3 & 0.003 & 0.0009 \\
Yukon & 38 & 0.002 & 0.01 \\
the Northwest Territories and Nunavut & 400 & 0.02 & 0.06 \\
\hline
\end{tabular}

Table A-3-2. Heat and Steam generation emission factors [231]

\begin{tabular}{lll}
\hline Kg Co2 per mmBtu & g CH4 per mmBtu & g N2O per mmBtu \\
\hline 66.33 & 0.00125 & 0.000125 \\
\hline
\end{tabular}

Appendix A-4. CO2_eq Emission Factors for manufactured materials [16,192]

\begin{tabular}{lll}
\hline Material & Factor & Unit \\
\hline Concrete & 261 & $\mathrm{Kg} \mathrm{CO}_{2} / \mathrm{m}^{3}$ \\
Talcum Powder & 1.25 & $\mathrm{Kg} \mathrm{CO}_{2} / \mathrm{Kg}$ \\
Steel & 1.45 & $\mathrm{Kg} \mathrm{CO}_{2} / \mathrm{Kg}$ \\
U.F. foamed plastic & 2.91 & $\mathrm{Kg} \mathrm{CO}_{2} / \mathrm{Kg}$ \\
Polyamides safety net & 9.27 & $\mathrm{Kg} \mathrm{CO}_{2} / \mathrm{Kg}$ \\
Cement & 0.759 & $\mathrm{Kg} \mathrm{CO}_{2} / \mathrm{Kg}$ \\
Aluminum & 5.9 & $\mathrm{Kg} \mathrm{CO}_{2} / \mathrm{Kg}$ \\
Stainless steel product & 1.45 & $\mathrm{Kg} \mathrm{CO}_{2} / \mathrm{Kg}$ \\
Glass & 1.09 & $\mathrm{Kg} \mathrm{CO}_{2} / \mathrm{Kg}$ \\
Slag & 0.433 & $\mathrm{Kg} \mathrm{CO}_{2} / \mathrm{Kg}$ \\
\hline
\end{tabular}




\begin{tabular}{lll}
\hline Clay hydite & 0.327 & $\mathrm{Kg} \mathrm{CO}_{2} / \mathrm{Kg}$ \\
Welding rode & 20.5 & $\mathrm{Kg} \mathrm{CO}_{2} / \mathrm{Kg}$ \\
Polyurethane & 4.31 & $\mathrm{Kg} \mathrm{CO}_{2} / \mathrm{Kg}$ \\
Perlite & 0.995 & $\mathrm{Kg} \mathrm{CO}_{2} / \mathrm{Kg}$ \\
Timber plates & 583 & $\mathrm{Kg} \mathrm{CO}_{2} / \mathrm{m}^{3}$ \\
Asphalt & 248 & $\mathrm{Kg} \mathrm{CO}_{2} /$ ton \\
Emulsified asphalt & 160 & $\mathrm{Kg} \mathrm{CO}_{2} /$ ton \\
Pebbles & 3.11 & $\mathrm{Kg} \mathrm{CO}_{2} / \mathrm{m}^{3}$ \\
Gravel & 3.9 & $\mathrm{Kg} \mathrm{CO}_{2} / \mathrm{m}^{3}$ \\
\hline
\end{tabular}




\section{Appendix B. The GHG Calculator}

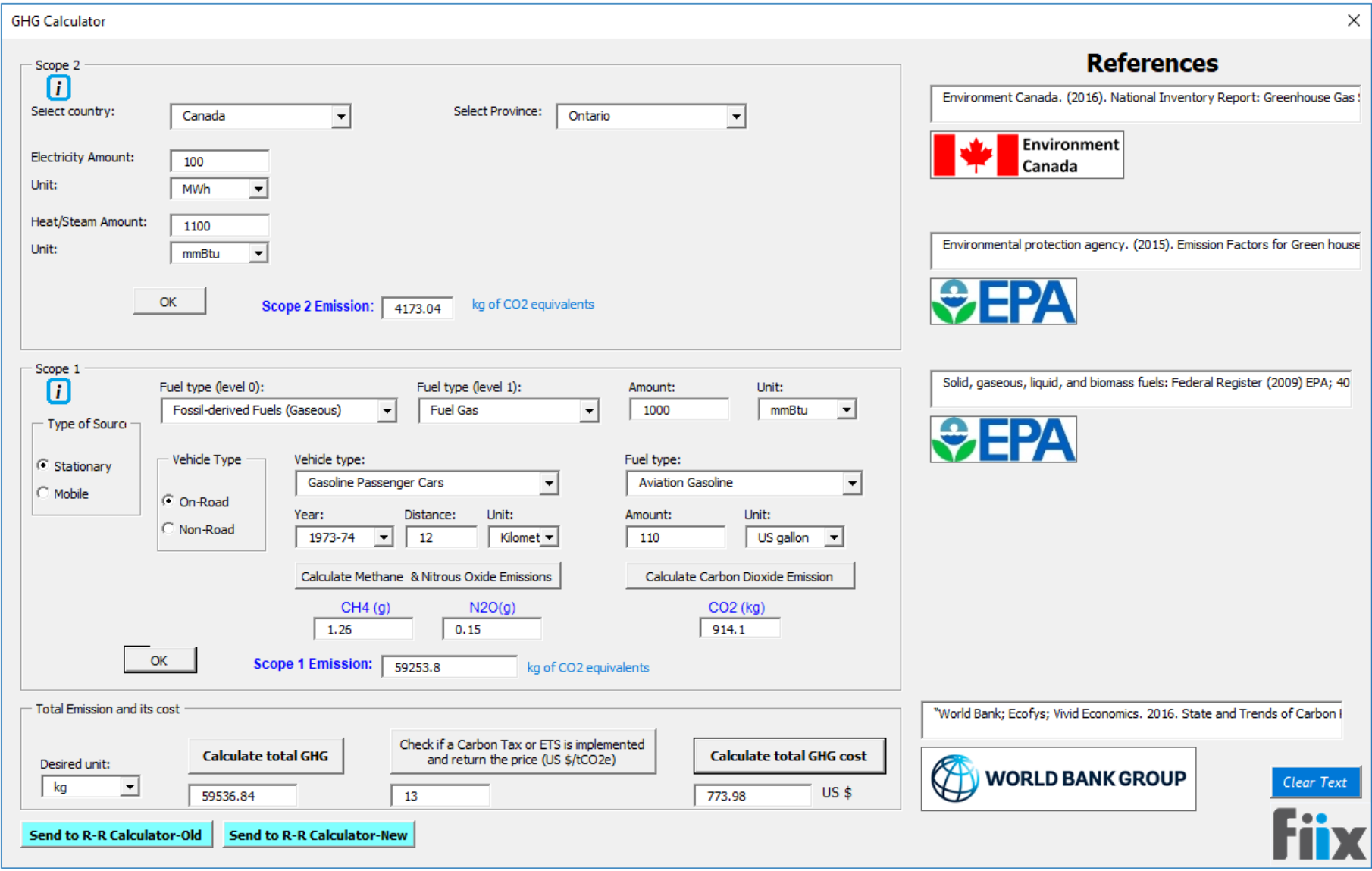

Figure B-1. The GHG calculator (Fiix ${ }^{\circledR}$ is a registered trademark of Maintenance Assistant Inc., that supported this part of the study)

\section{Appendix C. A method to estimate prior probabilities of common causes [123].}

Assume that the node $\mathrm{N}$, with no parents, has n states $\mathrm{S}_{1}, \mathrm{~S}_{2}, \ldots, \mathrm{S}_{\mathrm{n}}$, and $\mathrm{P}\left(\mathrm{S}_{\mathrm{i}}\right)$, i.e. the probability of the state $S_{i}$, is needed to be generated. Traditional method is to directly assign a value to $\mathrm{P}\left(\mathrm{S}_{\mathrm{i}}\right)$ by the expert(s), which may involve significant biases when as the number of states increases. A more reliable method would be performing pair-wise comparisons among different states to specify the probabilities. Obviously, providing expert values for only two states at a time by pair-wise comparisons would be considerably easier, rather than directly providing $\mathrm{n}$ state probabilities. The states' prior probability can be specified by a pair-wise comparison matrix, as follows:

$\begin{array}{lccccc} & \mathbf{S}_{1} & \mathbf{S}_{2} & \ldots & \mathbf{S}_{\mathbf{n}} & \boldsymbol{\omega} \\ \mathbf{S}_{1} & \mathrm{a}_{11} & \mathrm{a}_{12} & \ldots & \mathrm{a}_{1 \mathrm{n}} & \omega_{1} \\ \mathbf{S}_{2} & \mathrm{a}_{21} & \mathrm{a}_{22} & \ldots & \mathrm{a}_{2 \mathrm{n}} & \omega_{2}\end{array}$




\begin{tabular}{cccccc}
$\ldots$ & $\ldots$ & $\ldots$ & $\ldots$ & $\ldots$ & $\ldots$ \\
$\boldsymbol{S}_{\mathbf{n}}$ & $\mathrm{a}_{\mathrm{n} 1}$ & $\mathrm{a}_{\mathrm{n} 2}$ & $\ldots$ & $\mathrm{a}_{\mathrm{nn}}$ & $\omega_{\mathrm{n}}$ \\
$\boldsymbol{\lambda}_{\mathbf{m a x}}=$ & & $\mathrm{CI}=$ & & $\mathrm{CR}=$ & \\
\hline
\end{tabular}

To determine $\mathrm{a}_{\mathrm{ij}}(\mathrm{i}=1,2, \ldots, \mathrm{n} ; \mathrm{j}=1,2, \ldots, \mathrm{n})$ questions like "comparing the state $S_{i}$ with $S_{j}$ : which one is more likely to occur and how much more likely?" can be used. In fact, $\mathrm{a}_{\mathrm{ij}}$ reflects the multiplication of the likelihood of the presence of $S_{i}$ by that of $S_{j}$. This is to say $a_{j i}=1 / a_{i j}$ and $a_{i i}=1$, and hence there are $n(n-1)$ different comparisons in the pair-wise comparison matrix. Although having more comparisons is helpful to check consistency, it would be more satisfactory to provide $(n-1)$ inter-related comparisons than all the $n(n-1)$ comparisons.

Like Saaty's AHP, the maximum eigenvector $\omega=\left(\omega_{1}, \ldots, \omega_{n}\right)^{\mathrm{T}}$ of the matrix $S_{i}$ can be applied to calculate the relative priorities of $\mathrm{S}_{\mathrm{i}}$. Consistency of the pair-comparison matrix can be confirmed by a consistency ratio $\mathrm{CR}=\mathrm{CI} / \mathrm{RI}$, where $\mathrm{CI}$ represents consistency index, defined as $\left(\lambda_{\max }-n\right) /(n-1)\left(\lambda_{\max }\right.$ shows the maximum eigenvalue corresponding to $\left.\omega\right)$, and RI is a random index related to $\mathrm{n}$, as provided in Table $\mathrm{C}$-1. Pair-wise comparison matrixes with $\mathrm{CR}$ values less than 0.10 are consistent. It would be adequate to consider $\omega_{\mathrm{i}}$ as the prior probability of stat $\mathrm{S}_{\mathrm{i}}$, as the sum of all the elements in $\omega$ is 1 , and the $i$ th element $\omega_{\mathrm{i}}$ shows the relative importance of the state $S_{i}$ among all the states. Thus:

$$
\mathrm{P}\left(\mathrm{S}_{\mathrm{i}}\right)=\omega_{\mathrm{i}}
$$

Table C-1. Random consistency index.

\begin{tabular}{cccccccccc}
\hline $\mathbf{n}$ & $\mathbf{1}$ & $\mathbf{2}$ & $\mathbf{3}$ & $\mathbf{4}$ & $\mathbf{5}$ & $\mathbf{6}$ & $\mathbf{7}$ & $\mathbf{8}$ & $\mathbf{9}$ \\
\hline $\mathbf{R I}$ & 0 & 0 & 0.58 & 0.90 & 1.12 & 1.24 & 1.32 & 1.41 & 1.45 \\
\hline
\end{tabular}




\section{References}

1. Jeurissen R. Book Reviews. J. Bus. Ethics. (2000).

2. Pagell M, Wu ZH. Building a more complete theory of sustainable supply chain management using case studies of 10 exemplars. J. Supply Chain Manag. (2009).

3. Svensson G, Wood G, Callaghan M. A corporate model of sustainable business practices: An ethical perspective. J. World Bus. (2010).

4. Hanson CS, Noland RB. Greenhouse gas emissions from road construction: An assessment of alternative staging approaches. Transp. Res. Part D Transp. Environ. (2015).

5. Searcy C. Defining Tru Sustainability. MIT Sloan Manag. Rev. [Internet]. (2018). Available from: https://sloanreview.mit.edu/article/defining-true-sustainability/.

6. Searcy C. Measuring enterprise sustainability. Bus. Strateg. Environ. 25(2), 120-133 (2016).

7. IPCC. Climate Change 2014: Mitigation of Climate Change. .

8. Hastings NAJ. Physical asset management. .

9. Niekamp S, Bharadwaj UR, Sadhukhan J, Chryssanthopoulos MK. A multi-criteria decision support framework for sustainable asset management and challenges in its application. J. Ind. Prod. Eng. [Internet]. 32(1), 44-57 (2015). Available from: http://dx.doi.org/10.1080/21681015.2014.1000401.

10. de Vries HJ, Bayramoglu DK, van der Wiele T. Business and environmental impact of ISO 14001. Int. J. Qual. Reliab. Manag. (2012).

11. Jardine AKS, Tsang AHC. Maintenance, replacement, and reliability: theory and applications. CRC press.

12. Feldman RM, Valdez-Flores C. Applied probability and stochastic processes. Springer Science \& Business Media.

13. Environment and Climate Change Canada. Canadian Environmental Sustainability Indicators: Progress Towards Canada's Greenhouse Gas Emissions Reduction Target. Consulted on Month day, year. .

14. Maltzman R, Shirley D. Green project management. CRC Press.

15. Turner JR. Handbook of project-based management. McGraw-hill New York, NY.

16. Hong J, Shen GQ, Peng Y, Feng Y, Mao C. Uncertainty analysis for measuring greenhouse gas emissions in the building construction phase: A case study in China. $J$. Clean. Prod. 129, 183-195 (2016).

17. Hazir Ö. A review of analytical models, approaches and decision support tools in 
project monitoring and control. Int. J. Proj. Manag. (2015).

18. Zwikael O, Smyrk J. A General Framework for Gauging the Performance of Initiatives to Enhance Organizational Value. Br. J. Manag. (2012).

19. UNFCCC. Conference of the Parties (COP). Paris Climate Change ConferenceNovember 2015, COP 21. .

20. Wang S, Wan L, Li T, Luo B, Wang C. Exploring the effect of cap-and-trade mechanism on firm's production planning and emission reduction strategy. J. Clean. Prod. (2018).

21. Scholtens B, Van Der Goot F. Carbon prices and firms' financial performance: An industry perspective. Carbon Manag. 5(5-6), 491-505 (2014).

22. Chevallier J. Carbon price drivers: an updated literature review. Available SSRN 1811963 [Internet]. 33(April), 1-9 (2011). Available from: http://papers.ssrn.com/sol3/papers.cfm?abstract_id=1811963.

23. Hong KH, Jung H, Park M. Predicting European carbon emission price movements. Carbon Manag. 8(1), 33-44 (2017).

24. Zhu B, Wang P, Chevallier J, Wei Y. Carbon Price Analysis Using Empirical Mode Decomposition. Comput. Econ. 45(2), 195-206 (2013).

25. Creti A, Jouvet PA, Mignon V. Carbon price drivers: Phase I versus Phase II equilibrium? Energy Econ. [Internet]. 34(1), 327-334 (2012). Available from: http://dx.doi.org/10.1016/j.eneco.2011.11.001.

26. Balcilar M, Demirer R, Hammoudeh S, Nguyen DK. Risk spillovers across the energy and carbon markets and hedging strategies for carbon risk. Energy Econ. 54, 159-172 (2016).

27. Deeney P, Cummins M, Dowling M, Smeaton AF. Influences from the European parliament on EU emissions prices. Energy Policy [Internet]. 88, 561-572 (2016). Available from: http://dx.doi.org/10.1016/j.enpol.2015.06.026.

28. Alberola E, Chevallier J, Chèze B. Price drivers and structural breaks in European carbon prices 2005-2007. Energy Policy. 36(2), 787-797 (2008).

29. Segnon M, Lux T, Gupta R. Modeling and forecasting the volatility of carbon dioxide emission allowance prices: A review and comparison of modern volatility models. Renew. Sustain. Energy Rev. [Internet]. 69(August 2016), 692-704 (2017). Available from: http://dx.doi.org/10.1016/j.rser.2016.11.060.

30. Enrique W, Chimayco H. submitted to the Faculty of the Graduate School of Arts and Sciences of Georgetown University in partial fulfillment of the requirements for the degree of Master of Public Policy in Public Policy By. (2011).

31. Chang K, Pei P, Zhang C, Wu X. Exploring the price dynamics of CO2emissions 
allowances in China's emissions trading scheme pilots. Energy Econ. [Internet]. 67, 213-223 (2017). Available from: http://dx.doi.org/10.1016/j.eneco.2017.07.006.

32. Fan JH, Todorova N. Dynamics of China's carbon prices in the pilot trading phase. Appl. Energy [Internet]. 208(September), 1452-1467 (2017). Available from: http://dx.doi.org/10.1016/j.apenergy.2017.09.007.

33. Kim W, Yu J. The effect of the penalty system on market prices in the Korea ETS. Carbon Manag. [Internet]. 9(2), 145-154 (2018). Available from: https://doi.org/10.1080/17583004.2018.1440852.

34. Sousa R, Aguiar-Conraria L. Energy and carbon prices: A comparison of interactions in the European Union emissions trading scheme and the Western climate initiative market. Carbon Manag. 6(3-4), 129-140 (2015).

35. Dos Santos Silva FJ, Garcia Viana HR, Aquino Queiroz AN. Availability forecast of mining equipment. J. Qual. Maint. Eng. (2016).

36. Neil M, Marquez D. Availability modelling of repairable systems using Bayesian networks. Eng. Appl. Artif. Intell. (2012).

37. Dugan JB, Sullivan KJ, Coppit D. Developing a low-cost high-quality software tool for dynamic fault-tree analysis. IEEE Trans. Reliab. (2000).

38. Kutyłowska M. Neural network approach for failure rate prediction. Eng. Fail. Anal. (2015).

39. Marquez D, Neil M, Fenton N. Improved reliability modeling using Bayesian networks and dynamic discretization. Reliab. Eng. Syst. Saf. (2010).

40. Billinton R, Chen H, Ghajar R. A sequential simulation technique for adequacy evaluation of generating systems including wind energy. IEEE Trans. Energy Convers. (1996).

41. Khalafi Z, Dehghani M, Goel L, Li W. Observability reliability evaluation in power systems considering data uncertainty. In: PowerTech, 2015 IEEE Eindhoven. IEEE, 15 (2015).

42. Weckman GR, Shell RL, Marvel JH. Modeling the reliability of repairable systems in the aviation industry. Comput. Ind. Eng. (2001).

43. Soro IW, Nourelfath M, Aït-Kadi D. Performance evaluation of multi-state degraded systems with minimal repairs and imperfect preventive maintenance. Reliab. Eng. Syst. Saf. (2010).

44. Jia J, Wu S. A replacement policy for a repairable system with its repairman having multiple vacations. Comput. Ind. Eng. (2009).

45. Vose D. Risk Anaysis - A quantitative guide. .

46. Kadane JB, Wolfson LJ. Experiences in elicitation. J. R. Stat. Soc. Ser. D Stat. (1998). 
47. ISO ISO. 15686-5: Buildings and Constructed Assets-Service-Life Planning-Part 5: Life-Cycle Costing. Geneva, Switz. Int. Organ. Stand. (2008).

48. Yatsenko Y, Hritonenko N. Two-cycle optimization in replacement models with nonexponential technological improvement. IMA J. Manag. Math. 28(3), 359-372 (2015).

49. Zheng S, Chen S. Fleet replacement decisions under demand and fuel price uncertainties. Transp. Res. Part D Transp. Environ. (2018).

50. Merrick JR, Soyer R. Semiparametric Bayesian optimal replacement policies: application to railroad tracks. Appl. Stoch. Model. Bus. Ind. (2017).

51. Fouladirad M, Paroissin C, Grall A. Sensitivity of optimal replacement policies to lifetime parameter estimates. Eur. J. Oper. Res. (2018).

52. Ansaripoor AH, Oliveira FS, Liret A. A risk management system for sustainable fleet replacement. Eur. J. Oper. Res. 237(2), 701-712 (2014).

53. Ahani P, Arantes A, Melo S. A portfolio approach for optimal fleet replacement toward sustainable urban freight transportation. Transp. Res. Part D Transp. Environ. (2016).

54. Afrinaldi F, Taufik, Tasman AM, Zhang HC, Hasan A. Minimizing economic and environmental impacts through an optimal preventive replacement schedule: Model and application. J. Clean. Prod. (2017).

55. Peralta S, Sasmito AP, Kumral M. Reliability effect on energy consumption and greenhouse gas emissions of mining hauling fleet towards sustainable mining. $J$. Sustain. Min. (2016).

56. Abdi A, Taghipour S. Optimal replacement of a fleet of assets with economic and environmental considerations. In: Proceedings of the Annual Reliability and Maintainability Symposium (RAMS®) 2018. (2018).

57. Abdi A, Taghipour S. An optimization model for fleet management with economic and environmental considerations, under a cap-and-trade market. J. Clean. Prod. 204, 130 143 (2018).

58. Terborgh GW. Dynamic equipment policy. (1949).

59. Hatoyama Y. On Markov maintenance problems. IEEE Trans. Reliab. 33(4), 280-283 (1984).

60. Derman C. Optimal Replacement and Maintenance under Markovian Deterioration with Probability Bounds on Failure. Manage. Sci. (1963).

61. Vander Veen DJ, Jordan WC. Analyzing Trade-Offs Between Machine Investment and Utilization. Manage. Sci. (1989).

62. Hartman JC, Ban J. The series-parallel replacement problem. Robot. Comput. Integr. Manuf. 18(3-4), 215-221 (2002). 
63. Regnier E, Sharp G, Tovey C. Replacement under ongoing technological progress. IIE Trans. (Institute Ind. Eng. (2004).

64. Yatsenko Y, Hritonenko N. Two-cycle optimization in replacement models with nonexponential technological improvement. In: IMA Journal of Management Mathematics. (2017).

65. Ouda BK, Mohamed ASA, Saleh NSK. A simple quantitative model for replacement of medical equipment proposed to developing countries. In: 2010 th Cairo International Biomedical Engineering Conference, CIBEC 2010. (2010).

66. Ben Abdallah S, Lasserre P. Asset retirement with infinitely repeated alternative replacements: Harvest age and species choice in forestry. J. Econ. Dyn. Control. (2016).

67. Büyüktahtakın İE, Hartman JC. A mixed-integer programming approach to the parallel replacement problem under technological change. Int. J. Prod. Res. (2015).

68. He H, Fan J, Li Y, Li J. When to switch to a hybrid electric vehicle: A replacement optimisation decision. J. Clean. Prod. (2017).

69. Wang K-J, Nguyen PH. Capacity planning with technology replacement by stochastic dynamic programming. Eur. J. Oper. Res. (2017).

70. Nguyen KTP, Yeung T, Castanier B. Acquisition of new technology information for maintenance and replacement policies. Int. J. Prod. Res. (2017).

71. Adams CA. The ethical, social and environmental reporting-performance portrayal gap. Accounting, Audit. Account. J. (2004).

72. Sloan TW. Green renewal: Incorporating environmental factors in equipment replacement decisions under technological change. J. Clean. Prod. (2011).

73. NAIR SK. MODELING STRATEGIC INVESTMENT DECISIONS UNDER SEQUENTIAL TECHNOLOGICAL-CHANGE. Manage. Sci. (1995).

74. Matthews JC, Piratla K, Koo DD. Sustainability Evaluation of Pipe Asset Management Strategies. In: Procedia Engineering. (2016).

75. Stasko TH, Oliver Gao H. Developing green fleet management strategies: Repair/retrofit/replacement decisions under environmental regulation. Transp. Res. Part A Policy Pract. (2012).

76. Feng W, Figliozzi M. An economic and technological analysis of the key factors affecting the competitiveness of electric commercial vehicles: A case study from the USA market. Transp. Res. Part C Emerg. Technol. (2013).

77. Sun $\mathrm{W}, \mathrm{Xu} \mathrm{Y}$. Using a back propagation neural network based on improved particle swarm optimization to study the influential factors of carbon dioxide emissions in Hebei Province, China. J. Clean. Prod. (2016). 
78. UNFCCC. Kyoto Protocol Reference Manual on accounting of emissions and assigned amount. In: United Nations Framework Convention on Climate Change. (2008).

79. World Business Council for Sustainable Development (WBCSD), World Resources Institute (WRI). A Corporate Accounting and Reporting Standard. Greenh. Gas Protoc. (2016).

80. Zhang Z, Wang B. Research on the life-cycle CO2emission of China's construction sector. Energy Build. (2016).

81. Houghton JT, Meira Filho LG, Lim B, Treanton K, Mamaty I. Revised 1996 IPCC guidelines for national greenhouse gas inventories. v. 1: Greenhouse gas inventory reporting instructions.-v. 2: Greenhouse gas inventory workbook.-v. 3: Greenhouse gas inventory reference manual. (1997).

82. Abdi A, Taghipour S, Khamooshi H. A model to control environmental performance of project execution process based on greenhouse gas emissions using earned value management. Int. J. Proj. Manag. 36(3) (2018).

83. Pratt D. Fundamentals of construction estimating. Cengage Learning.

84. ILOG I. CPLEX optimizer [Internet]. (2012). Available from: available: http://www01.ibm. com/software/commerce/optimization/cplex-optimizer. 2012 Apr.

85. Kabir S, Papadopoulos Y. Applications of Bayesian networks and Petri nets in safety, reliability, and risk assessments: A review. Saf. Sci. 115, 154-175 (2019).

86. Constantinou AC, Fenton N, Neil M. Integrating expert knowledge with data in Bayesian networks: Preserving data-driven expectations when the expert variables remain unobserved. Expert Syst. Appl. (2016).

87. Avižienis A, Laprie JC, Randell B, Landwehr C. Basic concepts and taxonomy of dependable and secure computing. IEEE Trans. Dependable Secur. Comput. (2004).

88. Juran JM, Godfrey a B, Hoogstoel RE, Schilling EG. Juran' S Quality Handbook. Train. Qual. (1999).

89. Aven T. Foundations of risk analysis. John Wiley \& Sons.

90. Leemis LM. Reliability: probabilistic models and statistical methods. Prentice Hall New Jersey.

91. Maleque MA, Salit M. Mechanical failure of materials. Mater. Sel. Des. (2013).

92. Yang Q, Zhang N, Hong Y. Reliability analysis of repairable systems with dependent component failures under partially perfect repair. IEEE Trans. Reliab. (2013).

93. Jian X, Cai S, Chen Q. A study on the evaluation of product maintainability based on the life cycle theory. J. Clean. Prod. (2017).

94. Project Management Institute. A guide to the project management body of knowledge 
(PMBOK $®$ guide). .

95. Hajdu M, Bokor O. Sensitivity analysis in PERT networks: Does activity duration distribution matter? Autom. Constr. (2016).

96. Yamín RA, Harmelink DJ. Comparison of Linear Scheduling Model (LSM) and Critical Path Method (CPM). J. Constr. Eng. Manag. (2001).

97. Billinton R, Allan RN. Reliability Evaluation of Engineering Systems. .

98. Ireson WG, Coombs CF, Moss RY. Handbook of reliability engineering and management. McGraw-Hill Professional.

99. Stapelberg RF. Handbook of reliability, availability, maintainability and safety in engineering design. Springer Science \& Business Media.

100. Rausand M, Hoyland A. System Reliability Theory: Models, Statistical Methods, and Applications (2nd Edition). .

101. Sriramdas V, Chaturvedi SK, Gargama H. Fuzzy arithmetic based reliability allocation approach during early design and development. Expert Syst. Appl. (2014).

102. Alam A, Pant V, Das B. Switch and recloser placement in distribution system considering uncertainties in loads, failure rates and repair rates. Electr. Power Syst. Res. (2016).

103. Brissaud F. Using field feedback to estimate failure rates of safety-related systems. Reliab. Eng. Syst. Saf. (2017).

104. Levitin G, Xing L, Dai Y. Optimal backup frequency in system with random repair time. Reliab. Eng. Syst. Saf. (2015).

105. Kumar L, Rath SK. Hybrid functional link artificial neural network approach for predicting maintainability of object-oriented software. J. Syst. Softw. (2016).

106. Barabadi A, Barabady J, Markeset T. Maintainability analysis considering timedependent and time-independent covariates. In: Reliability Engineering and System Safety. (2011).

107. Angus JE. On Computing MTBF for a k-out-of-n:G Repairable System. IEEE Trans. Reliab. (1988).

108. Amiri M, Ghassemi-Tari F, Shahi MRM, Sadaghiani JS, Mahtasshami A. A methodology for analyzing the transient availability and survivability of a system with every combination of components by using fault tree. J. Appl. Sci. (2009).

109. Penttinen JP, Niemi A, Gutleber J, Koskinen KT, Coatanéa E, Laitinen J. An open modelling approach for availability and reliability of systems. Reliab. Eng. Syst. Saf. (2019).

110. Smit R, van de Loo J, van den Boomen M, Khakzad N, van Heck GJ, Wolfert ARMR. 
Long-term availability modelling of water treatment plants. J. Water Process Eng. 28, 203-213 (2019).

111. Uusitalo L. Advantages and challenges of Bayesian networks in environmental modelling. Ecol. Modell. (2007).

112. Dezfuli H, Kelly D, Smith C, Vedros K, Galyean W. Bayesian Inference for NASA Probabilistic Risk and Reliability Analysis. .

113. Malagrino LS, Roman NT, Monteiro AM. Forecasting stock market index daily direction: A Bayesian Network approach. Expert Syst. Appl. (2018).

114. Ticknor JL. A Bayesian regularized artificial neural network for stock market forecasting. Expert Syst. Appl. (2013).

115. Zuo Y, Kita E. Stock price forecast using Bayesian network. Expert Syst. Appl. (2012).

116. Roos J, Gavin G, Bonnevay S. A dynamic Bayesian network approach to forecast short-term urban rail passenger flows with incomplete data. In: Transportation Research Procedia. (2017).

117. Mazorra Aguiar L, Pereira B, David M, Díaz F, Lauret P. Use of satellite data to improve solar radiation forecasting with Bayesian Artificial Neural Networks. Sol. Energy. (2015).

118. Bassamzadeh N, Ghanem R. Multiscale stochastic prediction of electricity demand in smart grids using Bayesian networks. Appl. Energy. (2017).

119. Khodakarami V, Abdi A. Project cost risk analysis: A Bayesian networks approach for modeling dependencies between cost items. Int. J. Proj. Manag. (2014).

120. Jensen F V. An Introduction to Bayesian Networks. .

121. Agena. Bayesian Network and Simulation Software for Risk Analysis and Decision Support. [Internet]. (2018). Available from: http://www.agenarisk.com.

122. Pérez-Miñana E. Improving ecosystem services modelling: Insights from a Bayesian network tools review. Environ. Model. Softw. (2016).

123. Chin KS, Tang DW, Yang JB, Wong SY, Wang HW. Assessing new product development project risk by Bayesian network with a systematic probability generation methodology. Expert Syst. Appl. (2009).

124. Law AM, Kelton WD. Simulation Modeling and Analysis. .

125. Yang IT. Stochastic time-cost tradeoff analysis: A distribution-free approach with focus on correlation and stochastic dominance. Autom. Constr. (2011).

126. O’Hagan A, Buck CE, Daneshkhah A, et al. Uncertain judgements: Eliciting experts' probabilities. . 
127. Arena M V, Younossi O, Galway LA, Fox B, Graser JC. Impossible certainty: cost risk analysis for Air Force systems. Rand Corporation.

128. Goodpasture JC. Quantitative methods in project management. J. Ross Publishing.

129. Galway LA. Subjective Probability Distribution Elicitation in Cost Risk Analysis- A Review. .

130. Keefer DL, Verdini W a. Better Estimation of PERT Activity Time Parameters. Manage. Sci. (1993).

131. Nocedal J, Wright SJ. Limited-memory quasi-Newton methods: Numerical optimization. (2000).

132. Naseri M, Baraldi P, Compare M, Zio E. Availability assessment of oil and gas processing plants operating under dynamic Arctic weather conditions. Reliab. Eng. Syst. Saf. (2016).

133. Shaw JA. Distributed control systems: cause or cure of operator errors. Reliab. Eng. Syst. Saf. (1993).

134. Hollnagel E. Reliability analysis and operator modelling. Reliab. Eng. Syst. Saf. (1996).

135. Antonovsky A, Pollock C, Straker L. System reliability as perceived by maintenance personnel on petroleum production facilities. Reliab. Eng. Syst. Saf. (2016).

136. Tuyl F, Gerlach R, Mengersen K. A comparison of bayes-laplace, jeffreys, and other priors: the case of zero events. Am. Stat. (2008).

137. Guikema SD. Formulating informative, data-based priors for failure probability estimation in reliability analysis. Reliab. Eng. Syst. Saf. (2007).

138. CBC. The great North America blackout. August 14, 2003. Retrieved November 18, 2017. (2003).

139. Fenton N, Neil M. Risk assessment and decision analysis with Bayesian networks. .

140. de Faria EL, Albuquerque MP, Gonzalez JL, Cavalcante JTP, Albuquerque MP. Predicting the Brazilian stock market through neural networks and adaptive exponential smoothing methods. Expert Syst. Appl. (2009).

141. Athanasiou M, Clark JY. A Bayesian network model for the diagnosis of the caring procedure for wheelchair users with spinal injury. Comput. Methods Programs Biomed. (2009).

142. Yeh L. A note on the optimal replacement problem. Adv. Appl. Probab. 20(2), 479-482 (1988).

143. Zhang YL. A bivariate optimal replacement policy for a repairable system. J. Appl. Probab. 31(4), 1123-1127 (1994). 
144. Reindorp MJ, Fu MC. Capital renewal as a real option. Eur. J. Oper. Res. (2011).

145. Stutzman S, Weiland B, Preckel P, Wetzstein M. Optimal replacement policies for an uncertain rejuvenated asset. Int. J. Prod. Econ. (2017).

146. Wang GJ, Zhang YL. Optimal repair-replacement policies for a system with two types of failures. Eur. J. Oper. Res. (2013).

147. The International Standards Organisation. Environmental management - Life cycle assessment — Principles and framework. Iso 14040. (2006).

148. Alba-Rodríguez MD, Martínez-Rocamora A, González-Vallejo P, Ferreira-Sánchez A, Marrero M. Building rehabilitation versus demolition and new construction: Economic and environmental assessment. Environ. Impact Assess. Rev. (2017).

149. Giordano A, Fischbeck P, Matthews HS. Environmental and economic comparison of diesel and battery electric delivery vans to inform city logistics fleet replacement strategies. Transp. Res. Part D Transp. Environ. (2017).

150. Ajukumar VN, Gandhi OP. Evaluation of green maintenance initiatives in design and development of mechanical systems using an integrated approach. J. Clean. Prod. (2013).

151. Bare J, Young D, Qam S, Hopton M, Chief S. Tool for the Reduction and Assessment of Chemical and other Environmental Impacts (TRACI). Washington, DC US Environ. Prot. Agency. (2012).

152. Nakagawa T. Optimum policies when preventive maintenance is imperfect. IEEE Trans. Reliab. (1979).

153. Pham H, Wang H. Imperfect maintenance. Eur. J. Oper. Res. (1996).

154. Al-Saleh JA, Agarwal SK. Finite mixture of gamma distributions: A conjugate prior. Comput. Stat. Data Anal. (2007).

155. Edition T, Gelman. Bayesian data analysis. .

156. Chapman C, Ward S. Project risk management: processes, techniques, and insights. Wiley.

157. Aven T. On the new ISO guide on risk management terminology. Reliab. Eng. Syst. Saf. (2011).

158. Climate Policy Initiative. California Carbon Dashboard [Internet]. (2018). Available from: http://calcarbondash.org/.

159. Tsay R. Bayesian time series analysis. A Course Time Ser. Anal. (2001).

160. Oberndorfer U. EU Emission Allowances and the stock market: Evidence from the electricity industry. Ecol. Econ. (2009). 
161. Hintermann B. Allowance price drivers in the first phase of the EU ETS. J. Environ. Econ. Manage. (2010).

162. Mansanet-Bataller M, Chevallier J, Hervé-Mignucci M, Alberola E. EUA and sCER phase II price drivers: Unveiling the reasons for the existence of the EUA-sCER spread. Energy Policy. (2011).

163. Mansanet-Bataller M, Pardo A, Valor E. CO2 prices, energy and weather. Energy J. (2007).

164. Kanen JLM. Carbon trading and pricing. Environmental Finance Publications; 1 edition (15 June 2006).

165. Fezzi C, Bunn DW. Structural interactions of European carbon trading and energy markets. J. Energy Mark. (2009).

166. Convery FJ, Redmond L. Market and Price Developments in the European Union Emissions Trading Scheme. Rev. Environ. Econ. Policy. (2007).

167. Daskalakis G, Psychoyios D, Markellos RN. Modeling CO2emission allowance prices and derivatives: Evidence from the European trading scheme. J. Bank. Financ. [Internet]. 33(7), 1230-1241 (2009). Available from: http://dx.doi.org/10.1016/j.jbankfin.2009.01.001.

168. Benz E, Trück S. Modeling the price dynamics of CO2emission allowances. Energy Econ. [Internet]. 31(1), 4-15 (2009). Available from: http://dx.doi.org/10.1016/j.eneco.2008.07.003.

169. Chevallier J. Carbon futures and macroeconomic risk factors: A view from the EU ETS. Energy Econ. (2009).

170. Seifert J, Uhrig-Homburg M, Wagner M. Dynamic behavior of $\mathrm{CO}<\mathrm{inf}>2</ \mathrm{inf}>$ spot prices. J. Environ. Econ. Manage. (2008).

171. Jiao L, Liao Y, Zhou Q. Predicting carbon market risk using information from macroeconomic fundamentals. ,\#pagerange\# (2018). Available from: https://doi.org/10.1016/j.eneco.2018.05.008.

172. Dutta A. Modeling and forecasting the volatility of carbon emission market: The role of outliers, time-varying jumps and oil price risk. J. Clean. Prod. [Internet]. 172, 27732781 (2016). Available from: https://doi.org/10.1016/j.jclepro.2017.11.135.

173. Zhao X, Han M, Ding L, Kang W. Usefulness of economic and energy data at different frequencies for carbon price forecasting in the EU ETS. Appl. Energy [Internet]. 216(October 2017), 132-141 (2018). Available from: https://doi.org/10.1016/j.apenergy.2018.02.003.

174. Zhao X, Zou Y, Yin J, Fan X. Cointegration relationship between carbon price and its factors: Evidence from structural breaks analysis. Energy Procedia [Internet]. 142, 2503-2510 (2017). Available from: https://doi.org/10.1016/j.egypro.2017.12.190. 
175. Etienne XL, Yu J. Inverse price spread and illiquid trading in Korea-ETS. Carbon Manag. [Internet]. 8(3), 225-235 (2017). Available from: https://doi.org/10.1080/17583004.2017.1309205.

176. Atsalakis GS. Using computational intelligence to forecast carbon prices. Appl. Soft Comput. J. [Internet]. 43, 107-116 (2016). Available from: http://dx.doi.org/10.1016/j.asoc.2016.02.029.

177. Debnath KB, Mourshed M. Forecasting methods in energy planning models. Renew. Sustain. Energy Rev. [Internet]. 88(August 2016), 297-325 (2018). Available from: https://doi.org/10.1016/j.rser.2018.02.002.

178. Zhu B, Ye S, Wang P, He K, Zhang T, Wei YM. A novel multiscale nonlinear ensemble leaning paradigm for carbon price forecasting. Energy Econ. [Internet]. 70, 143-157 (2018). Available from: https://doi.org/10.1016/j.eneco.2017.12.030.

179. Zhu B, Han D, Wang P, Wu Z, Zhang T, Wei YM. Forecasting carbon price using empirical mode decomposition and evolutionary least squares support vector regression. Appl. Energy [Internet]. 191, 521-530 (2017). Available from: http://dx.doi.org/10.1016/j.apenergy.2017.01.076.

180. Rezaei J. Best-worst multi-criteria decision-making method. Omega (United Kingdom). (2015).

181. Saaty TL. How to make a decision: The analytic hierarchy process. Eur. J. Oper. Res. (1990).

182. Rezaei J. Best-worst multi-criteria decision-making method: Some properties and a linear model. Omega (United Kingdom) [Internet]. 64, 126-130 (2016). Available from: http://dx.doi.org/10.1016/j.omega.2015.12.001.

183. Guo S, Zhao H. Fuzzy best-worst multi-criteria decision-making method and its applications. Knowledge-Based Syst. [Internet]. 121, 23-31 (2017). Available from: http://dx.doi.org/10.1016/j.knosys.2017.01.010.

184. Peña JM, Björkegren J, Tegnér J. Learning and validating Bayesian network models of gene networks. Stud. Fuzziness Soft Comput. (2007).

185. Climate Policy Initiative. No Title [Internet]. Calif. Carbon Dashboard,. (2018). Available from: http://calcarbondash.org/.

186. ICF International I. Long-Term Carbon Price Forecast Report. Submitted to: Ontario Energy Board, Submitted by: ICF Consulting Canada, Inc. .

187. Willems LL, Vanhoucke M. Classification of articles and journals on project control and earned value management. Int. J. Proj. Manag. (2015).

188. Anbari FT. Earned value project management method and extensions. Proj. Manag. J. (2003). 
189. Quentin W fleming, Joel MK. Earned Value Project Management, Fourth Edition. $J$. Internet Bank. Commer. (2011).

190. Khamooshi H, Golafshani H. EDM: Earned Duration Management, a new approach to schedule performance management and measurement. Int. J. Proj. Manag. (2014).

191. Kerkhove LP, Vanhoucke M. Extensions of earned value management: Using the earned incentive metric to improve signal quality. Int. J. Proj. Manag. (2017).

192. Wang X, Duan Z, Wu L, Yang D. Estimation of carbon dioxide emission in highway construction: A case study in southwest region of China. J. Clean. Prod. (2015).

193. Hong J, Shen GQ, Feng Y, Lau WS, Mao C. Greenhouse gas emissions during the construction phase of a building: a case study in China. J. Clean. Prod. (2015).

194. Chou J-S, Yeh K-C. Life cycle carbon dioxide emissions simulation and environmental cost analysis for building construction. J. Clean. Prod. (2015).

195. Sandanayake M, Zhang G, Setunge S. Environmental emissions at foundation construction stage of buildings - Two case studies. Build. Environ. (2016).

196. Yeo Z, Ng R, Song B. Technique for quantification of embodied carbon footprint of construction projects using probabilistic emission factor estimators. J. Clean. Prod. (2016).

197. Kivilä J, Martinsuo M, Vuorinen L. Sustainable project management through project control in infrastructure projects. Int. J. Proj. Manag. (2017).

198. Kim J, Koo C, Kim C-J, Hong T, Park HS. Integrated CO2, cost, and schedule management system for building construction projects using the earned value management theory. J. Clean. Prod. (2014).

199. Martens ML, Carvalho MM. Key factors of sustainability in project management context: A survey exploring the project managers' perspective. Int. J. Proj. Manag. (2017).

200. Fernández-Sánchez G, Berzosa Á, Barandica JM, Cornejo E, Serrano JM. Opportunities for GHG emissions reduction in road projects: A comparative evaluation of emissions scenarios using $\mathrm{CO}<\mathrm{inf}>2<$ inf $>$ NSTRUCT. J. Clean. Prod. (2015).

201. BP Statistical Review of World Energy 2013. [Internet]. (2013). Available from: http//www.bp.com/zh_cn/china/reports-and-publications/bp_2013.html.

202. International Energy Agency. World Energy Outlook 2016. .

203. IAEA. IAEA_climate change and nuclear 2015. J. Chem. Inf. Model. (2015).

204. Cao T, Durbin TD, Russell RL, et al. Evaluations of in-use emission factors from offroad construction equipment. Atmos. Environ. (2016).

205. Pöyry A, Säynäjoki A, Heinonen J, Junnonen J-M, Junnila S. Embodied and 
Construction Phase Greenhouse Gas Emissions of a Low-energy Residential building. Procedia Econ. Financ. (2015).

206. Ozcan-Deniz G, Zhu Y. Multi-objective optimization of greenhouse gas emissions in highway construction projects. Sustain. Cities Soc. (2017).

207. Cass D, Tang P, Mukherjee A. Managing construction operations to minimize greenhouse gas emissions. In: The 2 nd International Conference on Transportation Construction Management, February. , 7-10 (2011).

208. Sattary S, Thorpe D. Potential carbon emission reductions in australian construction systems through bioclimatic principles. Sustain. Cities Soc. (2016).

209. de la Rue du Can S, Price L, Zwickel T. Understanding the full climate change impact of energy consumption and mitigation at the end-use level: A proposed methodology for allocating indirect carbon dioxide emissions. Appl. Energy. (2015).

210. Downie J, Stubbs W. Evaluation of Australian companies' scope 3 greenhouse gas emissions assessments. J. Clean. Prod. (2013).

211. Huemann M, Silvius G. Projects to create the future: Managing projects meets sustainable development. Int. J. Proj. Manag. (2017).

212. Christensen P, Dysert LR. Cost Estimate Classification System - As Applied in Engineering, Procurement, and Construction for the Process Industries. .

213. Project Management Institute. Practice Standard for Earned Value Management, 2nd Edition. .

214. Myhre G, Shindell D, Bréon F-M, et al. Anthropogenic and Natural Radiative Forcing. Clim. Chang. 2013 Phys. Sci. Basis. Contrib. Work. Gr. I to Fifth Assess. Rep. Intergov. Panel Clim. Chang. (2013).

215. Grande DE. Asset replacement considering environmental and economic objectives. ProQuest Diss. Theses. (2004).

216. Kim TH, Chae CU. Environmental impact analysis of acidification and eutrophication due to emissions from the production of concrete. Sustain. (2016).

217. Huisingh D, Zhang Z, Moore JC, Qiao Q, Li Q. Recent advances in carbon emissions reduction: Policies, technologies, monitoring, assessment and modeling. J. Clean. Prod. (2015).

218. Zhang S, Pang B, Zhang Z. Carbon footprint analysis of two different types of hydropower schemes: Comparing earth-rockfill dams and concrete gravity dams using hybrid life cycle assessment. J. Clean. Prod. (2015).

219. Carvalho MM, Rabechini R. Can project sustainability management impact project success? An empirical study applying a contingent approach. Int. J. Proj. Manag. (2017). 
220. Bare J. TRACI 2.0: The tool for the reduction and assessment of chemical and other environmental impacts 2.0. Clean Technol. Environ. Policy. (2011).

221. O’Connor A, Mosleh A. A general cause based methodology for analysis of common cause and dependent failures in system risk and reliability assessments. Reliab. Eng. Syst. Saf. (2016).

222. Taleb NN. The Black Swan - The Impact of the Highly Improbable. getAbstract Compress. knowlegde. (2007).

223. Kovacs P, Kunreuther H. Managing catastrophic risk: lessons from Canada. Institute for Catastrophic Loss Reduction.

224. Pells DL. Project Management in the Ring of Fire! Force Majeure Revisited - Extreme Weather and Natural Disasters are neither Acts of God nor Black Swans. PM World Today-April 2011 (Vol. XIII, Issue IV). (2011).

225. Kunreuther HC, Linnerooth-Bayer J. The financial management of catastrophic flood risks in emerging-economy countries. Risk Anal. (2003).

226. Henrion M. Some Practical Issues in Constructing Belief Networks. In: Uncertainty in Artificial Intelligence 3. (1987).

227. Koller D, Pfeffer A. Object-Oriented Bayesian Networks. In: 13th Conference on Uncertainty in Artificial Intelligence. (1997).

228. Pitchforth J, Mengersen K. A proposed validation framework for expert elicited Bayesian Networks. Expert Syst. Appl. (2013).

229. EPA Center for Corporate Climate Leadership. GHG Inventory Guidance [Internet]. Available from: https://www.epa.gov/climateleadership/center-corporate-climateleadership-ghg-emission-factors-hub.

230. Environment Canada. National Inventory Report: Greenhouse Gas Sources and Sinks in Canada 1990-2015. Environment. (2017).

231. Defra. Greenhouse Gas Reporting Emission Factors [Internet]. Defra. (2016). Available from:

https://www.gov.uk/government/uploads/system/uploads/attachment_data/file/553488/ 2016_methodology_paper_Final_V01-00.pdf.

232. Elkington J. Towards the Sustainable Corporation: Win-Win-Win Business Strategies for Sustainable Development. Calif. Manage. Rev. (1994).

233. Walia DS, Huria J, Cordero I. Equipment maintenance and repair. Community eye Heal. 23(73), 26 (2010).

234. Lister T, Carr MJ. Risk management is project management for adults. IEEE Softw. (1997). 


\section{Websites:}

1001. Government of Ontario, Cap and Trade. https://www.ontario.ca/page/cap-and-trade. Retrieved on January 11, 2018.

1002. Deloitte. (2017). Price forecast September 30, 2017; Resource Evaluation \& Advisory.https://www2.deloitte.com/content/dam/Deloitte/ca/Documents/REA/ca-enrea-price-forecast-oct-2017-AODA.PDF

1003. CALIFORNIA GAS REPORT (2016), PREPARED BY THE CALIFORNIA GAS AND ELECTRIC UTILITIES. Southern California Gas Company; Pacific Gas and Electric Company; San Diego Gas \& Electric Company; Southwest Gas Corporation City of Long Beach Gas; and Oil Department Southern California Edison Company. https://www.socalgas.com/regulatory/documents/cgr/2016-cgr.pdf

1004. Energy Information Administration (EIA). (2017). Annual Energy Outlook 2017, https://www.eia.gov/analysis/projection-data.php\#annualproj

1005. The National Energy Board's (NEB). 2017. Canada's Energy Future 2017: Energy Supply and Demand Projections to 2040, An Energy Market Assessment. https://www.neb-one.gc.ca/nrg/ntgrtd/ftr/2017/2017nrgftr-eng.pdf

1006. California Energy Commission. (2017). 2017 Integrated Energy Policy Report (IEPR), www.energy.ca.gov/2017_energypolicy/

1007. Kanoema. (2017). Crude Oil Price Forecast: 2017, 2018 and Long Term to 2030, https://knoema.com/infographics/yxptpab/crude-oil-price-forecast-2017-2018-andlong-term-to-2030. Retrieved on December 15, 2017.

1008. Desjardins. (2014). Economic Viewpoint, December 16, 2014. https://www.desjardins.com/ressources/pdf/pv141216-e.pdf

1009. The California Economic Forecast. (2016). The California Country-Level Economic Forecast 2016-2050. http://www.dot.ca.gov/hq/tpp/offices/eab/index_files/2016/FullReport2016.pdf

1010. Government of Canada. (2017). Environment and natural resources, Monthly Climate Summaries, http://climate.weather.gc.ca/prods_servs/cdn_climate_summary_e.html

1011. The Weather Company, LLC (2018). Monthly Weather History, https://www.wunderground.com/history/airport/KLAX/2005/1/28/MonthlyHistory.html ?req_city $=\& r e q \_s t a t e=\& r e q \_s t a t e n a m e=\& r e q d b . z i p=\&$ reqdb.magic $=\&$ reqdb. $w m o=$

1012. ASMI, 2017, [web page], http://www.athenasmi.org/, Athena Sustainable Materials Institute, Ottawa, Canada, Accessed: Jun 2017. 